\title{
DEVELOPMENT AND FORMATIVE IMPLEMENTATION OF A NUTRITION ASSESSMENT AND PEER EDUCATION PROGRAM BASED ON DIETARY ANALYSIS AT A CALIFORNIA STATE UNIVERSITY
}

\author{
A Project \\ Presented to \\ The Faculty of California Polytechnic State University, \\ San Luis Obispo
}

In Partial Fulfillment

Of the Requirements for the Degree of

Master of Science in Kinesiology

by

Janay Jelso

September 2009 
(C) 2009

Janay Jelso

ALL RIGHTS RESERVED 


\section{COMMITTEE MEMBERSHIP}

Title: Development and Formative Implementation of a Nutrition Assessment And Peer Education Program Based on Dietary Analysis at a California State University

Author: Janay Jelso

Date Submitted: September 2009

COMMITEE CHAIR: $\quad$ Steven C. Davis, Ph.D., R.C.E.P

COMMITTEE MEMBER: $\quad$ Lisa M. Nicholson, Ph.D., R.D

COMMITTE MEMBER: $\quad$ Camille O’Bryant, Ph.D. 


\begin{abstract}
Development and Formative Implementation of a Nutrition Assessment and Peer Education Program Based on Dietary Analysis at a California State University Janay Jelso
\end{abstract}

September 2009

A healthy diet has been established as a key component contributing to an individual's quality of life. Statistics show that the diet of Americans needs improvement (Guenther et al., 2007) indicating possible lack knowledge of what healthy eating behaviors are. There is an abundance of nutrition misinformation available to the consumer (American Dietetic Association, 2002a). Dietary interventions that provide credible education based on readiness to change behaviors and goal setting have been successful in increasing awareness of what healthy eating behaviors are and changing existing behaviors over time (Ammerman et al., 2002; Evans \& Sawyer-Morse, 2002; Gambera et al., 1995; Hebert et al., 1999; Oenema \& Brug, 2003; Proper, et al., 2003). In an effort to provide a college community with credible nutrition education based on dietary analysis and stage of change, a nutrition assessment and consultation program was developed and implemented at a college campus during the fall 2003 quarter. It was integrated into the existing fitness testing and prescription program, polyFIT. Seven students, referred to as fitness consultants, majoring in Nutrition or Kinesiology were recruited and trained to distribute appropriate education based on individual clients' dietary analysis, a stage of change assessment and personal goals. Intervention materials were constructed using a variety of resources focusing on areas of nutrition. Thirty clients participated during the fall 2003 quarter; all were freshman and 
sophomores enrolled in a Healthy Living course. Separate survey questionnaires were designed for the consultants and the clients to gather their perceptions of the program components. PolyFIT continued to offer the program, modifying it over time, for at least 4 years after the initial implementation. 


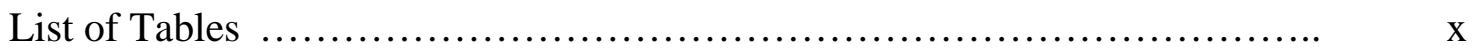

List of Figures ...................................................... xi

Chapter

1 Introduction.......................................................... 1

Background of the Study...................................... 1

Statement of the Problem.............................................. 3

Statement of the Purpose........................................... 3

Delimitations ................................................ 3

Assumptions .............................................. 4

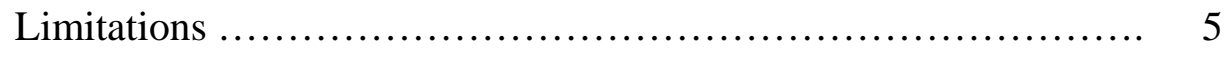

Project Objectives ............................................. 5

Definition of Terms ........................................ 6

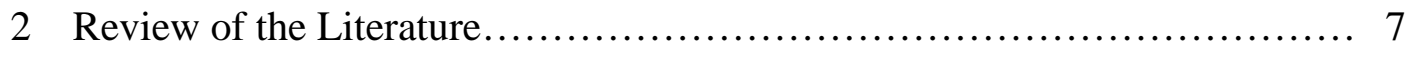

Nutrition Knowledge of Americans .............................. 10

Nutrition and Prevention of Disease............................. 14

Nutrition and Existing Conditions................................ 14

Nutrition and Athletic Performance................................ 15

Dietary Interventions....................................... 16

Stages of Change.............................................. 16

Dietary Assessment Tools....................................... 20

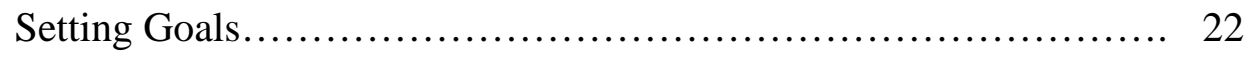


Provision of Nutrition Knowledge................................ 23

Nutrition Counseling........................................... 24

Who Does or Does Not Seek Counseling......................... 25

Effectiveness of Dietary Interventions.......................... 26

Best Practices............................................... 29

Health Educators $. . \ldots \ldots \ldots \ldots \ldots \ldots \ldots \ldots \ldots \ldots \ldots \ldots \ldots \ldots \ldots \ldots \ldots, 31$

Conclusion..................................................... 32

3 Methods and Procedures............................................. 35

Restatement of the Purpose...................................... 35

Design................................................... 35

Participants................................................ 35

Materials......................................................... 36

Client Assessment Questionnaire........................ 36

Goal Sheet........................................... 37

Stages of Change Assessment......................... 37

Food Frequency Checklist................................ .38

Twenty-Four Hour Recall/Usual Diet Form................. 39

Diet Analysis Software.............................. 40

Education Materials.................................... 40

Nutrition File........................................ 42

Transtheoretical Framework..................................... 44

Implementation.............................................. 45 
Recruitment of Fitness Consultants.......................... 45

Training of Fitness Consultants........................ 46

Client Consultations...................................... 47

Survey................................................... 48

Continuation of the Program.....................................49

Data Analysis........................................... 49

4 Results and Discussion............................................ 50

Results....................................................... 50

Fitness Consultants.................................. 50

Clients................................................. 51

Survey Questionnaire Distribution....................... 51

Client Survey Results................................ 54

Fitness Consultant Survey Results......................... 54

Education Materials..................................... 58

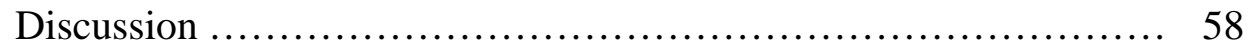

5 Summary, Conclusions and Recommendations........................ 65

Summary................................................... 64

Conclusions............................................. 67

Recommendations.......................................... 68

6 Epilogue....................................................... 71

References..................................................... 73 
Appendices

A Client Health Screening and Guide................................... 80

B Goal Sheet and Guide............................................ 89

C Stage of Change Assessment Ruler and Guide............................ 92

D Education Materials................................................. 95

E Food Frequency Checklist....................................... 231

F Twenty-four Hour Recall.......................................... 233

G Protocol for Dietary Interview................................... 235

H Decision Tree...................................................... 237

I Detailed Methods of Training...................................... 241

J Informed Consent................................................. 247

K Order of Operations - Client Session Protocol......................... 251

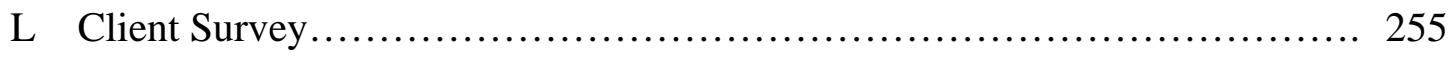

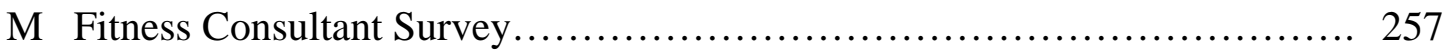




\section{List of Tables}

Table

1. Training Protocol............................................. 47

2. Demographics of Consultants ................................ 50

3. Results of Client Survey........................................ 52

4. Results of Fitness Consultant Survey........................... 53 


\section{List of Figures}

Figure

Page

1. Decision Tree Excerpt............................................... 43 


\section{Chapter 1}

Introduction

\section{Background of the Study}

A healthy diet has been established as a key component contributing to an individual's quality of life (United States Department of Health and Human Services [DHHS], 2005). Awareness of what comprises a healthy diet is essential in optimizing nutrition. Although the concern for health may be a strong influence on behavior (Nitzke et al., 1999), the link between a good diet and wellness may not be as obvious.

The Dietary Guidelines for Americans provide authoritative advice about the way to eat healthfully in order to reduce risk of disease and promote healthy eating habits. Developed by the United States Department of Health and Human Services (DHHS) and the United States Department of Agriculture (USDA), these guidelines, along with MyPyramid, provide simple guides for Americans to follow for purposes of planning a healthy diet (2005). However, there is a gap between what is recommended and what the population actually eats. According to the Healthy Eating Index - 2005 (Guenther et al., 2007b), between the years 1994-96, and 2001-02, the diet quality of Americans needed improvement, specifically in the areas of fruits, vegetables, whole grains, and fat-free or low-fat milk products. Foods high in solid fats and saturated fats, sodium and added sugars were consumed in excess according to HEI-2005 scores (Guenther et al., 2007a). This may be a reason to assume that the population lacks awareness of what healthy eating may be. There is an abundance of health information available to the population through many different vehicles. Discerning what dietary information is credible may be difficult. Some messages may be better understood and more widely accepted than 
others, such as the dangers in eating excess fat versus the benefits of eating more whole grains, fruits and vegetables (Nitzke et al., 1999). This may have important consequences in the prevention of chronic disease, management of existing conditions, and optimization of athletic performance.

Behavioral choices, such as poor eating habits and lack of physical activity, have been implicated as primary contributors to the morbidity and mortality of the nation. A poor or inadequate diet contributes to four of the ten leading causes of death in America which include heart disease, cancer, stroke, and diabetes (National Center for Health Statistics [NCHS], 2005). They also have been linked to health conditions such as hypertension, cancer, and overweight or obesity (National Center for Chronic Disease Prevention and Health Promotion [NCCDPHP], 2008). Therefore, the influence of nutrition on good health and well-being is significant in the prevention of chronic disease.

Athletic performance is also dependent on proper nutrition. Optimal physical performance will result when good nutrition and hydration are put into practice. Adequate energy intake and a variety of foods will increase the likelihood that nutrient needs are met before, during, and after exercise. It may also contribute to positive outcomes relative to athletic sport or physical activity (American Dietetic Association [ADA], Dieticians of Canada, American College of Sports Medicine [ACSM], 2000). Statistics, as stated previously, indicate that the diet of America needs improvement. Dietary interventions that focus on the dissemination of education specific to the individual have proven to be effective in increasing dietary awareness and facilitating behavior change (Ammerman et al., 2002). Behavior change is accelerated when interventions are tailored to the individual's readiness to change, thus improving 
the overall health and well-being of the individual (Greene et al., 1994). Dietary assessment and information that are credible and available from an institution with which the individual is affiliated may increase the likelihood that that individual would seek nutrition consulting. This would provide the opportunity to raise part of the population's awareness of the importance of a healthy diet.

\section{Statement of the Problem}

The Kinesiology Department at California Polytechnic State University, San Luis Obispo, offers a comprehensive program of fitness testing and exercise prescription for the Cal Poly community. This program is called polyFIT. Kinesiology majors are trained to conduct individualized fitness tests and provide exercise prescriptions that fit the personal goals of clients. However, currently, polyFIT lacks a dietary assessment and consultation program.

\section{Statement of the Purpose}

The purpose of the project was to develop a nutrition assessment and consultation program to complement the existing polyFIT fitness testing program available at California Polytechnic State University, San Luis Obispo.

\section{Delimitations}

This project had the following delimitations.

1. Seven fitness consultants, majoring in Kinesiology or Nutrition and thirty clients, freshmen and sophomores, participated in the program.

2. Fitness consultants were trained in conducting dietary interviews and assessment, stage of change assessment and goal setting. 
3. Dietary assessment included food frequency checklists, 24-hour recalls and computerized diet analysis.

4. Education materials were provided based on dietary assessment, stage of change, and goals.

5. Educational materials were compiled by the program developer from secondary resources, such as textbooks, review articles, websites, and online publications

6. The program was implemented during the Fall quarter of 2003.

7. The program was implemented at California Polytechnic State University, San Luis Obispo.

\section{$\underline{\text { Assumptions }}$}

This project was based on the following assumptions.

1. Participants were honest when reporting demographic information, past eating patterns and behaviors, and readiness to change.

2. Participants were honest when answering questionnaires.

3. The computer program chosen, Diet Analysis Plus, Version 6.0 from Elizabeth Stuart Hands and Associates (ESHA) Research, was accurate in analyzing intake and in calculating individual needs.

4. Participants were able to correctly interpret the information provided.

5. Participants' awareness of healthy eating behaviors and individual dietary status increased by providing dietary assessment results and appropriate education. 


\section{$\underline{\text { Limitations }}$}

This study was limited by the following factors.

1. Participants self-selected themselves to be part of the program.

2. Twenty-four hour recalls and food frequency questionnaires were selfreported.

3. Twenty-four hour recalls and food frequency questionnaires were retrospective.

4. The dietary analysis program had a limited food database.

5. Some clients failed to complete and return the survey questionnaire.

6. Some nutrition coaches failed to complete and return the survey questionnaire.

\section{$\underline{\text { Project Objectives }}$}

The project had the following primary objectives.

1. Develop and implement a program to assess dietary status at California Polytechnic State University, San Luis Obispo.

2. Provide nutrition education based on dietary assessment, stage of change and individual goals.

3. Train and prepare consultants to assess dietary status and stage of change and disseminate appropriate education based on results of assessment.

4. Develop a session plan that was logical and effective in gathering necessary information.

5. Develop systematic and easy-to-use tools to assist in determining what education was appropriate per individual client needs. 
6. Gather consultants' perceptions of the adequacy of training and preparation and the usefulness and completeness of tools.

7. Gather clients' perceptions of consultants' rapport and knowledge and the clarity and usefulness of education.

Definition of Terms

Dietary intervention. Any effort to raise dietary awareness and/or change dietary behavior.

Food frequency questionnaire. A dietary assessment method based on how often foods are consumed.

polyFit. A fitness testing and exercise prescription program offered through the Department of Kinesiology at California Polytechnic State University, San Luis Obispo, CA.

Twenty -four hour recall. A dietary assessment method in which an individual is requested to recall what was eaten in the previous 24 hours. 


\section{Chapter 2}

Review of the Literature

The purpose of the project was to develop a nutrition assessment program to complement the existing fitness testing program available at California Polytechnic State University, San Luis Obispo. It was designed to provide education and nutrition recommendations relative to individual goals and/or status and stage of change that were credible and available from an institution with which the individual was affiliated. This might increase participants’ awareness of healthy eating behaviors and nutritional status.

The development of the nutrition assessment and consultation program was based on a variety of resources. A search for previous interventions that have been published and reviewed was conducted using Medline, ERIC, PubMed, and Expanded Academic Index. Accredited organizations, government websites, and research articles were searched for ideas and best practices relative to nutrition interventions. Previous nutrition education and nutrition counseling and intervention experience provided the program coordinator direction for the design of client consultations. Secondary resources, such as textbooks, review articles, websites, and online publications were reviewed and portions were used for the development of the nutrition file to be used as a resource/guide for the student volunteers.

A healthy diet has been established as a key component contributing to an individual's quality of life (U.S. DHHS, 2005). Awareness of what comprises a healthy diet is important for optimizing nutrition and health. The Dietary Guidelines for Americans, developed by the United States Department of Health and Human Services (DHHS) and the United States Department of Agriculture (USDA), provide authoritative 
advice on the way to eat healthfully in order to reduce risk of disease and promote healthy eating habits. Because overall health is linked to a balanced diet, the purpose of these guidelines is to take information about specific nutrients and food components and translate it into recommendations for an overall eating pattern that Americans can understand. These guidelines are useful in developing educational material and messages for the public. In order for the public to more easily implement the guidelines, the USDA's Food Guide provides a simple guide for Americans to follow for purposes of planning a healthy diet (2005). The original Food Guide Pyramid was developed in 1992 and has since been revised and updated. The USDA's MyPyramid Food Guidance system is the most current version. It has made the 2005 Dietary Guidelines more personal for the consumer by providing a variety of levels of dietary recommendations so that change in behavior might occur more easily (Hentges, 2006). However, there is a gap between what is recommended and what the population actually eats.

The Healthy Eating Index (HEI) was developed by the USDA's Center for Nutrition Policy and Promotion (CNPP) to assess and monitor the dietary status of Americans. Originally, the HEI was created in 1995 by the USDA based on the Dietary Guidelines for Americans and the Food Guide Pyramid. Nutritional data were collected and evaluated for the years 1989-1990, 1994-1996, and 1999-2000 using the HEI. Because of the release of the most current version of Dietary Guidelines for Americans in 2005 along with the USDA's Food Guide, MyPyramid, the original HEI needed to be revised. The new version, HEI-2005, uses 12 components that relate to those groups displayed on MyPyramid to measure overall diet quality and specific aspects of the diet which are emphasized in the Dietary Guidelines of 2005 (Guenther et al., 2007b). 
These components are Total Fruit; Whole Fruit; Total Vegetables; Dark Green and Orange Vegetables and Legumes; Total Grains; Whole Grains; Milk; Meat and Beans; Oils; Saturated Fat; Sodium; Calories from Solid Fats, Alcoholic beverages and Added Sugars. Higher intakes for most of the components result in higher scores except for Saturated Fat, Sodium, and Calories from Solid Fats, Alcoholic beverages and Added Sugars (SoFAAS). Lower intake levels of these components result in higher scores as it is better for one’s health to consume less. Nutritional data from years 1994-96 and 200102 were collected and used to calculate the HEI-2005 scores. HEI-2005 scores were well below maximum for all components except Total Grains and Meat and Beans. The lowest scores were given to Whole Grains, Dark Green and Orange Vegetables and Legumes, Sodium, and Calories from SoFAAS. Also, well below maximum were the scores for Total Fruit, Whole Fruit, Total Vegetables, Milk, Oils, and Saturated Fat. The HEI-2005 scores also indicated that there was little change in diet quality between 199496 and 2001-02. Researchers concluded that the diet quality of Americans needed to be improved specifically in the areas of fruits, vegetables, whole grains, and fat-free or lowfat milk products. Americans also will benefit from choosing more nutrient dense foods that are lower in sodium and saturated fats (Guenther et al., 2007a). Previous measures of diet quality using the original Healthy Eating index indicated that scores did improve with a higher level of education (Basiotis et al., 2002).

Clearly the status of the American diet is in trouble, and therefore, so is the health of the nation. The USDA states that food consumption is influenced by consumer incomes; prices of foods and other goods; consumers' knowledge of nutrition and health; and tastes and preferences. In order to change the way Americans eat one of the above 
must change (Variyam et al., 1998). Nutrition information is given to individuals by way of an abundance of different sources, such as peers, teachers, physicians, dieticians, personal trainers, books, and the media. Although there appears to be a wealth of assumed knowledge among the American population with such an extensive variety of resources, discerning what dietary information is credible may be difficult. In addition, some messages may be better understood and more widely accepted than others, such as

the dangers in eating excess fat versus the benefits of eating more whole grains, fruits and vegetables (Nitzke et al., 1999).

\section{Nutrition Knowledge of Americans}

Correct knowledge of proper nutrition can predict healthy eating behaviors. Research indicates that nutrition knowledge and proper information positively impact the choices that Americans, in general, make relative to diet (Kopp \& Young, 2003; Nitske et al., 1999; Wilta et al., 1995). Those with more nutrition information have a higher quality-diet and are able to link health information to better food choices. This indicates that efforts towards nutrition education can lead to healthy eating behaviors (Variyam et al., 1998). However, misconceptions about nutrition commonly advertised by the media lead to eating behaviors that are unhealthy and are associated with the knowledge they currently have (Main \& Wise, 2002). As determined by questionnaires, this indicates incorrect information is assumed to be true by those individuals who may not be properly educated about healthy eating behaviors.

In general, college students, those involved in sport and those who are not, have a less than average understanding of basic nutrition information as well as nutrition information related to performance (Kopp \& Young, 2003; Rosenbloom et al., 2002; 
Dunn et al., 2007; Rash et al., 2008; Wilta et al., 1995). Kopp \& Young (2003) found college students at a Midwestern state university demonstrated a below average level of basic nutrition knowledge during a Fitness for Living course. With pre and post test scores being $40 \%$ and $52 \%$ respectively, the nutrition portion of the course made some positive impact on the knowledge of the college students. However, results indicated that more nutrition education is needed at the college level and an increased awareness of the consequences of poor choices

In several studies, researchers have assessed the nutrition knowledge of college athletes across the country using a variety of questionnaires. Although athletes believed that consuming healthy foods will improve performance (Rash et al., 2008), they seemed to lack awareness of how to do that. Some athletes demonstrated an awareness of the dietary guidelines, fat content of specific foods, and the link between fat and heart disease (Dunn et al., 2007). Some also knew that fluids should be replaced before, during and after exercise, that dehydration can adversely affect performance and that thirst is not an indicator of fluid needs (Rosenbloom et al., 2002). However, there seemed to be confusion about the role of carbohydrates and fat as sources of energy for activity and whether carbohydrates will make athletes fat (Dunn et al., 2007; Rosenbloom et al., 2002). Many athletes believed protein is the main source of energy for the muscle and that a protein supplement is needed if consuming a vegetarian diet (Rash et al., 2008.) Vitamins and minerals were also believed by many athletes to increase energy or as being a source of energy (Rosenbloom et al., 2002; Rash et al., 2008). Some did not know that they should not consume a high-fat meal 2-3 hours before competition, nor did they believe that consuming simple sugars before competition might positively affect 
performance (Rosenbloom et al., 2002). This information can guide dietitians or health educators toward athletes' need for nutrition education about basic nutrition principles and specifics relative to their individual sport in order to maintain a healthy body and remain competitive.

Better food choices might come with greater nutrition knowledge. This was confirmed by Wilta et al., (1995) after assessing nutrition knowledge and attitudes along with dietary behavior of high school and college athletes. They found that college athletes had more knowledge than high school athletes relative to basic and sport nutrition, and therefore made healthier food choices. Knowledge, however, was not the only influence in dietary behavior. Coaches and others were said to be sources of information and helpful in shaping attitudes. This contrasts findings by Rash et al. There was no correlation between knowledge nor attitude with dietary intake of track athletes indicating that there are other influences other than knowledge and attitude affecting what athletes eat.

Although there seems to be a discrepancy in the research to date as to whether there is a relationship between nutrition knowledge and healthy eating habits, research indicates that misconceptions about proper nutrition for performance and lack of basic nutrition knowledge are prevalent among college athletes. This misinformation could have negative consequences for performance.

The concern for health is a strong influence on the knowledge acquired and behavior among adults, both high-risk and healthy. Nitske et al. (1999) defined high risk as having one or more of these conditions: heart disease, hypercholesterolemia, hypertension, colorectal cancer or polyps, or breast cancer. Dietitians and high-risk 
adults were found to realize the impact of fat and fiber on specific health outcomes when compared to healthy adults. This might be expected as dietitians are nutrition professionals and adults that have health issues might have acquired nutrition education to better manage their health. This information, however, can contribute to the types of messages delivered to the public to increase awareness of nutrition and its role in health as a motivational tool for changing behavior (Nitske et al., 1999). Including healthy adults in a population to be educated about basic nutrition principles could prevent future health issues, which in turn might contribute to less mortality.

This lack of knowledge and awareness seems indicative of eating behaviors of Americans. Efforts to increase awareness of Americans are numerous as there is a wealth of information at the population's disposal. However, the information provided by food organizations, community interventions, food labels and packages, and the media, may be the source of confusion among much of the population. The internet offers numerous sites that give nutrition and health advice, but distinguishing which is from reputable sources providing accurate and safe information is difficult for the average individual.

Many health promotion organizations have created campaigns based on extensive research and planning, such as the USDA’s MyPyramid, Dietary Guidelines for Americans, National Cholesterol Education Program, and Fruits and Veggies More Matters, to enhance the health of America. These, however, are a mere fraction of the seemingly booming industry of diet information that may or may not be backed by legitimate investigation. The typical consumer seeking nutrition information might be more likely to be misinformed by the abundance of nutrition misbeliefs, health fraud and quackery (American Dietetic Association, 2002a). This might be a factor contributing to 
the population's lack of awareness about how certain dietary behaviors can affect the prevention of chronic disease, the management of existing conditions and optimization of athletic performance.

\section{Nutrition and Prevention of Disease}

The DHHS released Healthy People 2010, the national health promotion and disease prevention initiative. It provides national objectives relative to the most significant and preventable health conditions of the nation in order to reduce the threat of disease. The primary goal the initiative attempts to achieve is to increase the quality and number of years of healthy life and to eliminate health disparities (U.S. DHHS, 2000a).

Behavioral choices, such as poor eating habits and physical inactivity, have been implicated as primary contributors to the morbidity and mortality of the nation. A poor or inadequate diet contributes to 4 of the 10 leading causes of death in America, which include heart disease, cancer, stroke, and diabetes. It also has been linked to health conditions such as hypertension, cancer, and overweight or obesity (NCCDPHP, 2008). Therefore, the influence nutrition has on good health and well-being has been determined to be significant in the prevention of chronic disease.

\section{Nutrition and Existing Conditions}

Existing conditions such as digestive problems, food intolerances, and heartburn may be controlled by knowing what foods to consume and being aware of how certain foods affect the body. The digestive tract is what food and drink moves through in order for nutrients to be extracted and used by the body. Digestion is a complex process completed by several different organs and muscles along with digestive juices, regulatory hormones and nerves that complete the absorption and transportation of nutrients to the 
parts of the body that need them. Awareness of why some diseases or intolerances occur and what foods trigger adverse reactions as well as those that relieve symptoms is very important in maintaining quality of life and preventing the progression into something serious.

Nutrition and Athletic Performance

Athletes are bombarded with nutrition information from numerous sources. Coaches, parents, friends, teammates, trainers, the media etc., all have some knowledge to contribute with regard to the optimal nutrition for optimal performance. As indicated previously, the knowledge of college students, both athletes and recreational exercisers, could be better relative to general nutrition and sports nutrition. Although one might assume that better nutrition knowledge always leads to healthier eating habits, this relationship is not always supported in the research.

The American Dietetic Association (ADA), Dieticians of Canada and The American College of Sports Medicine (ACSM) all take the position that optimal nutrition enhances physical activity, sports performance and recovery from exercise. The selection of appropriate foods and fluids, and proper timing of consumption will contribute to the overall performance of exercise of athletes as well as recreational exercisers as part of a healthy lifestyle. More specifically, exercisers should know what energy intake is appropriate, the weight that is most beneficial for sport, the appropriate amount of macro and micro nutrients for an activity level and the importance of adequate hydration before, during and after activity (2000). Acquiring this knowledge through proper education for college athletes along with coaches and trainers to whom athletes often go for nutritional advice, will enhance both performance as well as general health. 


\section{Dietary Interventions}

Health promotion is accomplished in several ways. One of these ways is by programs that are based on education and skill-building, community action or environmental support. Programs targeting dietary behavior change, which can also be referred to as dietary interventions, have certain components to increase the chance of healthy eating among participants.

The foundation of any type of behavior change is arguably increased awareness. If the individual is not aware of the consequences of an unhealthful diet, motivation to change may be non-existent (Sigman-Grant, 1996). Once awareness is established, the provision of education and feedback about eating behaviors is a mainstay in many dietary interventions (Evans \& Sawyer-Morse, 2002; Gambera, Schneeman, \& Davis, 1995; Hebert et al., 1999; Oenema \& Brug, 2003; Proper, Hildebrandt, Van der Beek, Twisk, \& Mechelen, 2003). Assessment of an individual's readiness to change allows interventions to be targeted more specifically to their needs and motivation level (Sigman-Grant, 1996). The use of dietary assessment tools such as food frequency questionnaires and 24-hour recalls provides information about current eating behaviors as well as guidance for the direction of education for the individual. Goal setting has proven to be promising in modifying dietary behavior if goals are clearly defined, specific, measurable and timely (Rosal et al., 2001; Ammerman, Lindquist, Lohr, \& Hersey, 2002).

\section{Stages of Change}

Health behavior change has often been approached at an individual level incorporating counseling and education interventions (ADA, 2002b). Researchers support the notion of using theory to better explain how behaviors change and to tailor 
interventions to the individual. Although the most effective theoretical framework has not yet been determined (Ammerman et al., 2002), the Stages of Change model proposed by Prochaska (1994) has been shown to be effective in dietary behavior change. The stages of change, a key construct of the Transtheoretical Model of behavior change, describe behavior as it progresses through a succession of stages. These stages include precontemplation, contemplation, preparation, action, and maintenance.

Precontemplation is the time when change is not being considered because the individual is unaware of any health consequences or problem with current behavior. Contemplation describes a time when the individual is aware that there is a problem and is considering taking action to resolve the problem. This stage typically lasts about 6 months. Preparation is the time when the individual is getting ready to take action, usually within 30 days, and some behavior modification, although small, may be taking place. Action designates the time when noticeable changes are happening. Maintenance refers to attempts made by the individual to maintain the adopted behavior for at least six months.

As indicated, these stages occur over a period of time. Particular to dietary change, researchers can use these stages to measure what people think about their eating habits and the interest they have in actually changing them. In order for the framework to be effective, interventions must be tailored to an individual's readiness to change in order to actually facilitate dietary change and promote long-term adherence (Kristal, Glanz, Curry, \& Patterson, 1999; Rosal et al., 2001; Sigman-Grant, 1996, Glanz et al., 1994).

Researchers have validated the Stages of Change Model relative to certain dietary behaviors. Greene et al. (1994), attempted to determine a methodology to define stages of change using the action goal of fat intake less than or equal to $30 \%$ of energy. 
An algorithm was developed relative to stage of change for the determination of dietary fat intake less than $30 \%$, and was then validated. Questionnaires were sent to noninstitutionalized, non-smoking adults who comprised sample 1 and sample 2 respectively. The study was university based and comprised of graduate students and staff. Returned questionnaires totaled 614 for sample one and 130 for sample two. Three algorithms were initially developed focusing on specific questions and were called the Avoid algorithm, Limit algorithm and the Low-fat algorithm. Subjects were classified in categories relative to the 5 stages of change depending on responses. It was found that there were no significant differences in the proportions of people in each stage for the Avoid or Limit algorithm and so individuals were combined. The individuals assigned to the Low-fat algorithm were eliminated due to the inability to understand what low-fat meant. To determine behavioral criteria, food frequency questionnaires were administered to each sample and specific questions about fat reduction behaviors were selected to determine the best five markers that would serve as action criteria, meaning individuals must meet these criteria to be categorized as in the action or maintenance stage. The specificity (93\% and $87 \%$ ) and predictive value (64\% and 58\%) of the Behavioral algorithm were good, however the sensitivity was low (44\% and 27\%). The investigators concluded the Behavioral algorithm can determine the stage of change for reducing fat intake to less than $30 \%$ and be used tailor to interventions to individuals based on their readiness to change. However, some misclassification can occur.

Ling \& Horwath (2000) designed two algorithms to predict stage of change for consuming the recommended servings of grains, fruits and vegetables. They were assessed in an attempt to overcome this misclassification by applying the stage of change 
model to easily understood and specific food-based goals. Food frequency questionnaires provided the objective measure of behavior and diet recalls were used for reference and validation of the algorithms. It was found that individuals in the action and maintenance stages had significantly higher intakes of grains than those in precontemplation/contemplation and higher intakes than those in preparation. Those in action maintenance had significantly higher intakes of fruits and vegetables than those in preparation and in precontemplation/contemplation . It was suggested that accurate assessments of actual intakes should be made before designing interventions and acknowledgement made of past successful changes even though goals may not have been reached.

Vallis et al. (2003) identified characteristics of individuals with diabetes at different stages of readiness to change to low-fat, healthy eating, and used existing algorithms to assess Type 1 and Type 2 diabetics. Among the dependant variables were eating related factors, specifically BMI, percent daily calories from fat, and intake of fruits and vegetables. For Type $1 \&$ Type 2 diabetics, both insulin-requiring and oral anti-hyperglycemic medication patients, individuals in the action/maintenance stages had the lowest percent of calories from fat and the highest intake of vegetables. Fruit intake increased across stages for Type 2 diabetics on oral anti-hyperglycemic medication. Vallis et al. concluded that the stages of change algorithm was supported relative to eating behaviors and that the stage actually matched the eating behavior. Researchers did find the stages of change model inconsistent with regard to BMI as those in maintenance had the lowest BMI which was consistent with the model's predictions; however, precontemplators also had a low BMI when compared to individuals in contemplation, 
preparation and action. This may be due to possible heterogeneity of precontemplators and difficulty in measuring intention.

The studies mentioned give support to the stages of change model when assessing readiness to change relative to dietary behavior. Although defining the stages of change concerning dietary behavior may be difficult and some discrepancy between perceived intake and actual intake may occur (Kristal et al., 1999; Ling \& Horwath, 2000), the model is still effective and robust when applied to healthful eating patterns. Because of this success in the predictive nature of the model, many professionals in the dietetic field have used this model in counseling and implementation of programs.

\section{Dietary Assessment Tools}

Dietary assessment is an important element in a complete nutrition assessment of an individual. There are a variety of tools used by dietitians, physicians, fitness professionals, and nutritionists for purposes of assessing the diet. These tools include, but are not limited to, food frequency checklists and 24-hour diet recalls. There are positives and negatives about each tool, but each has its own characteristics and purpose for acquiring information about one’s eating habits.

The food frequency checklist has often been used to assess the role the diet plays in chronic disease. It is a method based on how often items from food groups are consumed on a daily, weekly, monthly, or yearly basis which allows a picture to be presented of the overall diet. It does not, however, allow for any dietary pattern to be established and it assumes that individuals are knowledgeable about portion sizes.

The twenty-four hour recall or usual diet has been frequently used to estimate mean intakes of the population. It leads individuals through a series of questions that 
describe the typical foods that are eaten in a day. A trained interviewer asks and probes the individual to reveal exactly what, how much, and sometimes how foods were prepared along with drink within a twenty-four hour period. The 24-hour recall does not require literacy on the client's part nor does it take much time to complete, however it is retrospective in nature, requiring the client to remember what was eaten. Although this tool is very useful if the client's intake is similar each day, if eating patterns vary, more than one recall would be necessary to create a better representation of the diet.

Computerized nutrient analysis programs are an integral part of a nutrition assessment program. Many computer programs exist; however some are more accurate in calculating nutrients and contain a more extensive database. In a comparison of four commercially available databases that are frequently used in nutrition research, researchers calculated the nutrient content of 36 daily menus. The programs chosen for evaluation were ESHA Food Processor, Minnesota Nutrition Data System, Moore’s Extended Nutrient Database, and Nutritionist IV database. Researchers were interested in database accuracy which is affected by factors such as source of nutrient information, number of foods and nutrients in the database, completeness of the database, method of handling missing values and frequency of database updates. All four programs proved to be comparable in accuracy and precision when analyzed against chemical composition data (McCullough et al., 1999). ESHA Food Processor manufactures a program called Diet Analysis Plus, based on ESHA research that is specifically for students and aids in the input of food records and recalls. 


\section{Setting goals}

Goal setting seems to have a considerable effect in modifying dietary behavior according to a review of existing literature. Interventions of all types that met study criteria and that reported fruit and vegetable intake and/or dietary fat intake were chosen for review by Ammerman et al (2002). Intervention components included, but were not limited to, theoretical framework, individual counseling, dietary modifications, individual tailoring, delivery mode, goal setting, and duration. Types of analyses included metaanalysis, difference in deltas, and summary of significant findings for total fat, saturated fat, and/or fruit and vegetable intake. Overall, the studies reviewed were all similarly successful in reducing total fat and saturated fat intake, and increasing fruit and vegetable intake. When analyzing intervention characteristics separately, goal setting and small groups had a positive significant effect in most analyses conducted, however, the other components analyzed were positively associated in at least 2 of the analyses conducted and should not be ignored

Setting goals takes a change in behavior that might be multifaceted and breaks it down into manageable and achievable steps. Some important elements are necessary to consider when setting goals and being successful. Goals should be specific, that is they should be able to be measured and observed and have well-defined outcomes. Stating when, where and how often when developing the goal will make it easy for the client to measure how well he is doing. Goals should be realistic and reasonable enough to be considered achievable by the client. Goals must be stated in a positive manner. The client must be in control of the goal, meaning his/her actions alone are what ultimately 
will lead to success. The outcome should not be dependent upon another person (Bauer and Sokolik, 2002).

\section{Provision of nutrition knowledge}

The ability to make healthy choices relative to diet is partly dependent upon how much knowledge one has. Without a strong knowledge base built on sound nutrition principles, the population cannot make informed decisions about what behaviors to choose. An important, critical element included in dietary interventions is the provision of nutrition education.

The importance of accurate information is critical when it relates to the health of the population (ADA, 2002a). Professionals in nutrition or health educators trained to deliver nutrition education must be able to select appropriate nutrition sources that are both accurate and easy to understand. Their knowledge must be extensive and they must be able to discern fact from fiction among the abundance of nutrition information available to the general population. There is a profusion of nutrition misinformation misleading the consumer such as the media misinterpreting scientific findings, the internet, cultural and food beliefs, product literature and marketing, testimonials from respected individuals, and other sources. Therefore, the nutrition educator must learn to deliver effective messages that are focused on the consumer and their healthful lifestyle. Nutrition educators must be confident in the knowledge and skills they have to be able to influence behavior change in people in a variety of venues (ADA, 2002a; Friesen \& Hoerr, 1990).

Nutrition education can be delivered in a variety of ways. Dietitians, physicians, or health educators can provide education one on one to clients during counseling 
sessions or consultations, or in small groups during group presentations (Hebert et al., 1999; Evans and Sawyer-Morse, 2002, Gambera et al., 1995). Food models and measuring tools are used to identify portion size (Gambera et al., 1995). Other modes of education can include brochures, information tables at school, the workplace, or in the community, nutrition columns in a school newspaper, or point-of purchase information in frequented places (Evans and Sawyer-Morse, 2002).

Nutrition counseling

Nutrition counseling is one way in which awareness of dietary behaviors is targeted. It is often the key in successful dietary interventions because of the way the components mentioned above, such as stages of change, dietary assessment, goal setting, and education, may be incorporated. Research on eating behavior change has often used nutrition counseling as an individual approach to guide clients toward healthy lifestyle choices.

Nutrition counseling attempts to achieve three goals, according to Bauer and Sokolik in Basic Nutrition Counseling (2002). These goals are to facilitate lifestyle awareness; encourage healthful lifestyle decision-making; teach the client how to take appropriate action to engage and continue a healthful lifestyle; and become selfsufficient. These goals can be applied to a variety of people of different age, gender, and culture with various conditions, purposes, and individual goals.

The enhancement of dietary adherence has occurred through patient-centered counseling. By assessing the stage of change an individual is in and then tailoring the intervention to the stage and individual goals along with specific needs or challenges, behavior change takes place. The model is suggested to be used by nutritionists in order 
to provide more specific educational and skill-building information relative to the individual's needs. The objectives that patient-centered counseling attempts to meet are 1) increase awareness of diet-related risks; 2) provide the individual with nutrition education; 3) increase confidence that change can be made by the individual; and 4) enhance the skills necessary to promote adherence. The 4-step process includes a thorough assessment of current stage of change, advice and assistance relative to the need to change eating behaviors, and follow-up to monitor progress. Goal setting, reassessment of self-efficacy, behavioral contracts, and prevention of relapse are also important aspects of the Patient-Centered Model (Rosal et al., 2001). Although this model is suggested to be used by nutritionists with education in behavioral strategies and counseling techniques relative to dietary change, aspects of the model may be applied to nutrition programs that endeavor to target dietary interventions to individuals seeking assistance.

Who does or does not seek counseling?

Individuals with chronic disease related to diet and fitness clearly can benefit from nutrition counseling, but they may assume that their primary physician is providing all of the information necessary for improvement of health. Although primary physicians believe that nutrition counseling is their responsibility (Kushner,1995), research suggests that the prevalence of nutrition counseling provided by practitioners is less than $25 \%$ when seeing patients with chronic and acute conditions and the amount of time spent with individual patients is very short (Eaton, Goodwin, \& Stange, 2002). This may indicate that more in-depth counseling is needed when chronic conditions already exist, as well as in prevention of disease. This can be provided by dietitians, nutritionists, and/or health 
educators. However, many individuals may not be aware of the need for further nutrition counseling outside of the doctor's office. Those who do not seek nutritional counseling may not be aware that change is necessary, may lack motivation, may lack interest, may have logistical problems, or have low referral rates from physicians (Hebert et al., 1999) Among college students who sought nutrition counseling on a university campus, Welch et al., (1992) found out of 106 students, almost three-quarters lived off campus, two-thirds were classified as overweight or obese as indicated by BMI, and half had dieted at some time in their life. When assessing body image perception, almost $40 \%$ of women overestimated body size when compared to their BMI Effectiveness of Dietary Interventions

Nutrition interventions can be delivered in a variety of ways and be successful in facilitating dietary behavior change.

A study by Hebert et al. (1999) was designed to determine the effectiveness of dietitian- based nutrition counseling and education programs for patients with hyperlipidemia. It examined the changes in dietary fat and serum lipid concentrations relative to a nutrition program delivered by dietitians and referred by physicians. This was part of the Worchester Area Trial for Counseling in Hyperlipidemia (WATCH). The dietitian-based program followed the Patient-Centered Counseling Model. Physicians referred patients if LDL-C was in the $90^{\text {th }}$ percentile of the population from which WATCH participants were recruited. Those in the remaining upper quartile received physician- based nutrition counseling unless LDL-C rose above the established criteria designated by the National Cholesterol Education Program. Results indicated that significant reductions were found in total and saturated fat intakes, serum cholesterol, 
LDL-C, and body weight $(\mathrm{p}<.05)$ for patients referred to the dietitian-based program. Patients who attended a majority or more of the sessions had greater changes in the mentioned variables than those who attended fewer sessions. This change was attributed to the increased time spent with the dietician, which was mentioned to have been found in previous studies. Weight loss was significantly greater in patients attending 3 or 4 sessions. The authors concluded that nutrition education and counseling, especially when delivered by dietitians, plays an important role in the modification of dietary habits of patients with hyperlipidemia.

Another intervention targeting college students from a small, minority college in Texas delivered nutrition education using a variety of media through the use of trained student peer educators (Evans \& Sawyer-Morse, 2002). The program was designed to increase students’ awareness and participation in the program, increase students' nutrition knowledge and change their attitudes toward healthy eating as well as their eating behaviors. Using the Social Cognitive Theory as the framework and formative data collection from focus groups, the intervention included small group presentations, information tables, brochures, point-of-purchase information in the cafeteria and vending machines and nutrition columns in the newsletter. Much of the educational information offered was specific to topics of interest revealed during focus groups. One hundred and ninety-four students completed a self-report questionnaire that contained sections and scales measuring demographics, program awareness and participation, behavioral knowledge, expectations and dietary intake. This provided baseline data. One year later, another 189 students completed the same questionnaire for the collection of interim data. Demographics of the two separate groups did not vary significantly. After one year, there 
were significant differences between groups. Students in group two had increased nutrition knowledge, fruit, fruit juice, and vegetable consumption, as well as a significant decrease in fat intake. This study did not show a significant difference in student outcome expectations or attitude relative to healthful eating. This was attributed to a possible ceiling effect as students initially had a very positive attitude about healthful eating before implementation.

Gambera et al. (1995) attempted to discover whether a diet which followed both the Dietary Guidelines for Americans and the Food Guide Pyramid in conjunction with an exercise program would result in significant reductions in cardiovascular risk when compared to just exercise alone. Thirty-two McClellan Air Force personnel were entered into a 90-day fitness program which entailed exercising 3 times per week. Activities included walking, jogging, cycling and step aerobics. Half of these subjects received nutrition counseling using the Food Guide Pyramid as a primary tool for education. Weekly counseling sessions with a registered dietitian emphasized a diet of fruits, vegetables and whole grains as well as balancing choices. Other areas covered were portion sizes, leaner methods of cooking, and choosing foods lower in fat. Whole foods were encouraged as good sources of dietary fiber. The Food Guide Pyramid was used as a guide for dietary changes and to communicate the Dietary Guidelines. Food records were used to enhance tracking and food models and measuring tools were used to enhance education. Food Guide Pyramid posters were displayed in the dining hall providing nutrition education exposure to both groups. Results showed positive significant changes in weight, BMI, total fat intake, saturated fat intake, total energy intake, dietary cholesterol and dietary fiber intakes for the treatment group (exercise plus 
diet). This group also made marked improvements in food choices. In the exercise-only group, no changes in total cholesterol or LDL-C were observed but significant reductions occurred in the treatment group. Neither group experienced an increase in HDL-C nor a reduction in triglyceride concentrations. Researchers attributed this lack of significant effect to several things, such as a level of exercise below a threshold for change, relatively short study period, small sample size, or a relatively large increase in carbohydrate intake from baseline. Researchers concluded that the Food Guide Pyramid and the Dietary Guidelines are both useful tools for educating subjects about a nutritious diet that is also protective against cardiovascular disease. These educational tools, in conjunction with individualized dietary counseling and exercise, proved to be effective in changing dietary behavior as well as plasma lipoprotein concentrations, fitness levels and cardiovascular risk.

\section{Best practices}

Interventions that have been successful often had common components that might be considered best practices in the industry. As previously mentioned, dietary interventions that have proven successful on many levels are those that are theory-based. Studies have shown that Procheska’s Transtheoretical Model, which describes a progression of changes an individual goes through when considering a behavior change, is successful (Ammerman et al., 2002; Kristal et al., 1999; Rosal et al., 2001; SigmanGrant, 1996). Assessment of an individual's readiness to change a behavior, whether specific or non-specific, has been suggested as being a best practice according to research in order to tailor any type of intervention. Tailoring the intervention to the individual's lifestyle has also proven to be successful according to dieticians around the nation 
(Brown, Pope, Hunt, \& Tolman, 1998; Proper et al., 2003) and is suggested as part of the Patient-Centered Counseling Model so many experts use in the field (Rosal et al., 2001). Goal setting and small groups are also associated with intervention efficacy relative to modifying dietary behavior change (Ammerman et al., 2002).

Other successful intervention components are frequency of visits (Hebert et al., 1999), the amount of time spent with a professional, and the particular profession (Eaton et al., 2002). These have all been shown to also influence behavior which leads to changes in health-related variables.

The amount of time spent with a counselor has been shown to affect the overall effectiveness of nutrition counseling provided by a dietician trained in patient-centered counseling. In the same study by Hebert et al. (1999), mentioned previously, after attendance at $3-4$ sessions with the dietician, weight loss was greater in patients with hyperlipidemia in a study designed to assess the effectiveness of a dietician- based nutrition counseling and education program. Those attending 3-4 sessions also experienced greater reductions in total cholesterol and LDL, even after adjusting for cholesterol lowering medications, than those patients who attended fewer than 3 sessions. From these results, it was concluded that a greater amount of education specific to the needs of the patient and accountability to a dietitian may produce more favorable results, such as reduction in weight and cholesterol (Hebert et al., 1999).

Regardless of the setting, whether it be at group or individual level, in a community or clinical environment, many nutrition interventions focus on building the knowledge and skill base to adopt and maintain healthful eating behaviors (SigmanGrant, 1996). The importance of nutrition education as part of health promotion efforts 
has been well established in the research mentioned previously, as well as the influence of dieticians trained in the Patient Centered Counseling Model. Unfortunately, many individuals who may need direction from an expert in nutrition have to settle for the limited knowledge from their family physicians or other specialists. Although family care physicians may consider nutrition counseling their responsibility, more often than not they are failing to provide this service. Eaton et al. (2002), conducted an observational study of a family care community to assess the frequency, time spent, and factors associated with nutrition counseling which was defined as the provision of any specific advice about food or nutrient intake. Overall, nutrition counseling was delivered by physicians in $24 \%$ of all patient visits, $17 \%$ of acute visits, $30 \%$ of chronic illness, and $41 \%$ of well-care visits. The average time spent on nutrition counseling was 1 minute of the total average visit time which was 10.5 minutes. Nutrition counseling occurred during less than $50 \%$ of all patient visits for patients diagnosed with diabetes, myocardial infarction, hypertension, obesity, and during prenatal visits. All of these conditions are either directly, or indirectly, related to nutrition (Eaton et al., 2002).

\section{Health Educators}

Registered dietitians have proven their influence on dietary change in the research, and are the most knowledgeable and experienced in the field of nutrition. Not to dispute this, but there is also evidence that peer educators who have limited nutrition education in the classroom, but training in the principles and behaviors associated with nutrition and dietary knowledge and change have been effective in changing behaviors of their peers. 
The lack of nutrition knowledge and unhealthful dietary habits of college students at a Texas University were modified by the same intervention program mentioned previously (Evans and Sawyer-Morse, 2002). This program was developed and implemented primarily by students who were enrolled in the nutrition curriculum or had taken at least one nutrition course. All of the volunteer peer educators underwent extensive training before implementation and continuing for the duration of the program, initially by the program director, also the coordinator of the Nutrition Department, and followed thereafter by the graduate research assistant. The peer educators were responsible for group presentations, staffing information tables, analyzing students' diets, writing a weekly column, giving tours of the cafeteria, and creating an ongoing poster campaign. As indicated before there were significant changes in dietary knowledge and specific behaviors. Researchers indicated that the volunteers recruited for this intervention who became peer educators were a critical part of the program. Researchers hypothesized because students were leading activities they were able to recruit other students to become peer educators as well. A responsibility of a peer educator was to be a role model for healthful eating behaviors. New recruits were to adopt healthy eating behaviors if they hadn’t already.

\section{Conclusion}

According to the ADA, the public is beginning to recognize the link between long-term health and nutrition and is beginning to take a more active role in self-care (2002). However, this has also created great opportunity for food and nutrition misinformation to abound. Among many health consequences that can occur due to misinformation are indirect consequences on the health and economic status of 
consumers when the media reports incorrect information or information that might be correct though incomplete. Although consumer interest in health and nutrition information is high, that which is reported can be confusing due to volume and variety. The ability to decipher sound, science-based nutrition principles from those that are not is challenging. Without help from professionally-trained individuals, nutrition misinformation can be discouraging and even harmful to the consumer.

The ADA states that qualified dietetic professionals are the best qualified to communicate accurate nutrition information that is backed by scientific principles and is balanced and qualitative. They also support the role of health professionals as support for dietetic professionals in educating the consumer. With the use of the ADA as well as other nutrition information resources such as the American Heart Association, American Diabetic Association, The American Council on Science and Health and others, along with web navigators such as Nutrition.gov, individuals in the health field can deliver messages to the consumer that are backed by science and can guide the consumer to these information sources for use.

Although dietitians have great influence on behavior change, students educating other students, peer educators, have been shown to be effective as well. It is possible that with proper training and resources, health educators who are not dietitians could influence the behaviors of individuals in their environment. With some background in health, particularly fitness and/or nutrition, and proper training in some or all of the principles of patient-centered counseling and the Stages of Change Model, students might be able to increase nutrition knowledge and provide useful information about the dietary status of their peers and/or adults. Though resources, such as nutrition training and time 
available for frequent consultations, might be limited, students implementing best practices of dietary intervention following guidance from the American Dietetic Association might prove effective in educating a particular population. 


\section{Chapter 3}

Methods and Procedures

\section{Restatement of the Purpose}

The purpose of the project was to develop a nutrition assessment program to complement the existing fitness testing program available at California Polytechnic State University, San Luis Obispo. In addition, a goal of the project was to provide education and nutrition recommendations relative to individual goals and/or status and stage of change that were credible and involved resources available from the university. This might increase participants’ awareness of healthy eating behaviors and nutritional status. Design

The design of the program was based on a variety of resources. A search for previous interventions that have been published and reviewed was conducted using Medline, ERIC, PubMed, and Expanded Academic Index. Accredited organizations, government websites, and research articles were searched for ideas and best practices

relative to nutrition interventions. Previous nutrition education and nutrition counseling and intervention experience and secondary resources provided the program coordinator direction for the design of client consultations and training of the consultants. Secondary resources, such as textbooks, review articles, websites, and online publications were reviewed and portions were used for the development of the nutrition education file to be used as a resource/guide for the student volunteers.

\section{Participants}

The polyFIT program was offered exclusively to students, faculty, staff, retirees and alumni affiliated with California Polytechnic State University, San Luis Obispo. 
Thirty students, all freshmen and sophomores enrolled in Kinesiology 250, a Healthy Living course for undergraduates, actually participated in the project as clients. Seven students participated as fitness consultants. Five were Kinesiology undergraduates; one sophomore, two juniors, two seniors. Two were Nutrition undergraduates, both seniors. Materials

The materials used for the project were as follows:

- Client Assessment Questionnaire (see Appendix A)

- Goal Sheet (see Appendix B)

- $\quad$ Stage of Change Assessment (see Appendix C)

- Food Frequency Checklist (see Appendix E)

- Twenty-Four Hour Recall/Usual Diet Form (see Appendix F)

- $\quad$ Diet Analysis Plus Version 6.0

- $\quad$ Education Materials (see Appendix D)

- Nutrition File

\section{Client Assessment Questionnaire}

A client assessment questionnaire was designed using two references. The existing polyFIT Health Screening form provided the template. Sections pertaining to medical history, family history, stress and smoking were deleted. A section pertaining to exercise was shortened and one that pertained to nutrition was extended to provide more information relative to dietary habits and expectations of the individual. Additional questions were provided by the Lifestyle Management Form 4.1 found in Bauer \& Sokolik’s Basic Nutrition Counseling Skill Development (2002; p. 254 - 255). The purpose of the form was to provide the fitness consultant, who conducted dietary 
interviews and provided nutrition education, with demographic information, medical conditions that may have nutritional impact, past familial conditions for which the client may be at risk that have nutritional relevance, prescription and OTC drug intake to determine any possible nutrient interactions, food pattern data and an area for additional education to assist with goal setting, and socioeconomic history to determine the client's support system. The client assessment questionnaire and a guide identifying particular questions to which consultants were to be especially attentive relative to the health screening are provided in Appendix A.

\section{Goal Sheet}

A goal sheet was completed by the client with the help of the fitness consultant. At the end of the first session, after review of the client assessment questionnaire, determining the client's reason(s) for seeking nutrition assessment, and the dietary interview, two goals were established. These goals could be long term or short term. They were to be stated positively with a specific and measurable outcome to be achieved in a certain time frame. The goal sheet provided spaces for both general and specific goals. A guide describing how to structure a written goal was provided for reference. The completed goal sheet was given to the client after the first session. The goal sheet and guide are in Appendix B.

\section{Stages of Change Assessment}

The stages of change assessment was conducted using a readiness-to-change ruler as suggested by Snetselaar (2001). The assessment ruler and guide are provided in Appendix C. The ruler was numbered from 1 at the bottom signifying "not at all” ready to change to 12 at the top, signifying "very" ready to change. A range of numbers was 
provided corresponding to a particular stage of change. For ease of use, the stages were condensed into three groups: Stage 1- not ready to change (score of 1-4); Stage 2- unsure about change, considering meeting goals (score of 5-8); Stage 3- ready to change (score of 9-12) (Snetselaar, 2001). After each client chose a number on the ruler, polyFIT consultants would use the stages to choose education materials. Education materials (Appendix D) were labeled with a 1, 2, or 3, corresponding to the stages and targeted some of the educational goals of each stage.

\section{Food Frequency Checklist}

The food frequency checklist chosen was comprehensive in nature to provide a broad picture of what was frequently eaten (Bauer \& Sokolik, 2002). It was a simple, self-administered questionnaire with 5 columns. Column 1 made reference to serving sizes, giving examples of servings of common foods. Column 2 listed food groups with examples of foods that would fall into that particular group. For example, for refined grains, white bread, pasta, and cereal were listed. The last 3 columns were titled servings per day, servings per week and never or rarely. In order to overcome the barrier of portion size recognition, a guide to portion sizes was made available to the client when completing the food frequency checklist during the first session and was used by the fitness consultant for clarification when reviewing the checklist with the client. Along with the guide to portion sizes, the fitness consultant used plastic food replicas, ordered from Nasco Nutrition, which assisted in achieving more accurate representation of the client's actual food intake. The food frequency checklist is provided in Appendix E. 


\section{Twenty-Four Hour Recall/Usual Diet Form}

The 24-hour-recall/usual diet form was used to record the client's food intake over a 24-hour period (Bauer \& Sokolik, 2002). It is provided in Appendix F. The form was divided into 2 subheadings: 1) food and drink consumed and 2) number of servings from each group. Under the first subheading, time, name and type, and amount relative to the consumption of food were listed. The second subheading included 6 columns corresponding to the tiers on the food guide pyramid with the recommended servings for reference. For example, the milk group was listed in the first column under number of servings from each group, and 2-3 indicated the recommended servings, which are standard for adults. The plastic food replicas used with the food frequency checklist were also used during the 24-hour-recall/usual diet interview. The 24-hour-recall/usual diet interviews were conducted by the fitness consultants.

Instructions for conducting the dietary interview were distributed by the program coordinator to each fitness consultant, as part of their training packet, during initial training (Appendix G). There was also a master copy of instructions in the consultation area for reference during interviews. A revised version of the interview protocol provided by Tapsell et al. (2000) was to be followed when diet interviews were conducted. Dietary assessment, particularly the 24-hour recall/usual diet, was to be facilitated like a conversation, using the narrative approach meaning the clients were allowed to finish their "story” before they are asked any questions. This type of interviewing has been shown to have consistency in accurate reporting of eating behaviors (Tapsell, Brenninger, \& Barnard, 2000). 
Although the above tools for dietary assessment have significant limitations, including both being retrospective in nature, assuming the client is knowledgeable about portion sizes, and their inability to establish patterns of eating exclusively, the strength of the two forms matched closest to the program resources and goals.

\section{Diet Analysis Software}

Diet Analysis Plus, Version 6.0 (2003) from Elizabeth Stuart Hands and Associates (ESHA) Research was used for diet analysis because access to the program was available through the Food Science and Nutrition Department at the university and the program was simple to use. Instructions for use were provided by the instruction manual and tutorials written into the program. Specific printouts, such as the Food Guide Pyramid showing the client's distribution of food intake relative to the guide's recommended intake corresponding to the five food groups, and a nutrition summary displaying nutrients in a bar graph comparing actual intake with Daily Reference Intakes, were used.

\section{Education Materials}

Education materials were gathered from a variety of resources specializing in areas of nutrition that pertained to the possible issues of interest of the target population. These sources included:

- American Cancer Society

- American Diabetes Association

- American Dietetic Association

- American Heart Association

- Calgary Health Region 
- Department of Health and Human Services

- Food and Drug Administration and Center for Food Safety and Applied Nutrition

- Harvard School of Public Health

- Mayo Foundation for Education and Research

- National Eating Disorders Association

- National Heart, Blood, and Lung Institute

- National Heartburn Alliance

- National Institute of Diabetes and Digestive and Kidney Diseases (NIDDK)

- National Institutes of Health

- National Resource Center for Osteoporosis and Bone Related Diseases

- Office of the Surgeon General

- Produce for Better Health Foundation's 5-a-day The Color Way Campaigns

- Stanford University

- The Gatorade Sports Science Institute

- U.S. Department of Agriculture

- University of Illinois, McKinley Health Center

Areas covered were:

- specific chronic diseases,

- specific nutrition-related problems/intolerances, 
- performance altering elements relative to athletes and general physical activity,

- miscellaneous nutrition-related topics.

Education was based upon the Dietary Guidelines for Americans developed in 2000 by the U. S. Department of Health and Human Services (U. S. DHHS) and the United States Department of Agriculture (USDA) because they provide authoritative advice about the way to eat healthfully in order to reduce risk of disease and to promote healthy eating habits. The guidelines, along with the Food Guide Pyramid, provide a simple guide for Americans to follow for purposes of planning a healthy diet.

Nutrition information was reviewed, selected, and/or adapted to be included in original documents compiled by the program developer. The basis for selection of information was how closely the information followed the Dietary Guidelines and the Food Guide Pyramid, the simplicity and completeness of the messages, how the information related to the different stages of change, and the nutrition knowledge of the program developer. Most materials were designed using the Microsoft Office Publisher program. Some were ordered from the American Dietetic Association and/or downloaded and printed from the Gatorade Sports Science Institute web site.

\section{Nutrition File}

The nutrition file was a reference guide for fitness consultants. Education materials gathered from the previously listed sources were divided into topics that were color coded for easy navigation and access. Information relative to chronic disease, digestive disorders, athletics/exercise, nutrients/food groups, and miscellaneous topics were placed in red, yellow, blue, purple, and brown colored files, respectively. The file 
consisted of original copies of information that would be photocopied and disseminated to the clients relative to the topic pertaining to specific goals or needs (see Appendix D). A decision tree was created for further ease of navigation and is provided in Appendix $\mathrm{H}$. This was color coded as well, corresponding to the topic files. Depending upon the general goal(s) of the client and/or nutrition needs, fitness consultants were instructed to begin at the left of the tree and work across using the information gathered from the health screening questionnaire and session one. For example, if a client's general goal was related to exercise, specifically if and what to eat before and/or after activity to increase performance, the consultant found the corresponding general topic/goal on the left labeled “Athletic/Exercise Related” (blue) and moved their way to the right. The consultant came to a section labeled "Fuel" and moved further right to find education meeting the specific need of the client. The consultant pulled materials "Fuel- Before \& After" and "First Class Fuel" to give to the client at the second session. An example is provided in Figure 1.

\begin{tabular}{|c|c|c|}
\hline Athletic/Exercise & & \\
\hline Related & $\begin{array}{l}\text { General } \\
\text { Sports } \\
\text { Nutrition }\end{array}$ & Nutrition 101 For Athletes $(1,2,3)$ \\
\hline & Hydration & $\begin{array}{l}\text { Hydration - Critical To Athletic Performance }(1,2) \\
\text { Optimizing Hydration (3) }\end{array}$ \\
\hline & Fuel & $\begin{array}{l}\text { Nutrition } 101 \text { For Athletes }(1,2,3) \\
\text { First Class Fuels }(1,2) \\
\text { Fuel - Before \& After }(1,2,3) \\
\text { Energy for Tournaments }(1,2,3)\end{array}$ \\
\hline & Protein & $\begin{array}{l}\text { Nutrition } 101 \text { For Athletes } \\
\text { Power Play - Protein's Role AS A Team Player }\end{array}$ \\
\hline & $\begin{array}{l}\text { Carbohydrate } \\
\text { Loading }\end{array}$ & Carbohydrate Loading $(1,2,3)$ \\
\hline
\end{tabular}

Figure 1. Decision Tree Excerpt (developed by Janay Jelso) 
The information provided in the education materials was labeled with a 1, 2, or 3. These numbers corresponded to the stage of readiness to which the information was targeted. For example, information that raised awareness of a health problem or diet option, and/or the effects on one's health or performance was labeled with a 1 for clients scoring a 1-4 on the assessment ruler, which corresponds to the stage of precontemplation, as explained below. Individuals in this stage are not ready to change behavior.

\section{Transtheoretical Framework}

The Transtheoretical Model (TTM) provided the framework for this program. The TTM approaches change as being a process. A person systematically progresses through stages relative to their readiness to change a behavior. Many dietary interventions have used this behavioral model to facilitate adherence to a particular dietary behavior identification of an individual's stage of change (Ammerman et al., 2002; Berg-Smith et al., 1999; Kristal et al., 1999; Prochaska et al., 1994; Sigman-Grant, 1996; Vallis et al., 2003). The intervention is then matched to that particular stage. The stages of change are as follows: precontemplation, contemplation, preparation, action and maintenance. Precontemplation is the time when change is not being considered because the individual is unaware of any health consequences or problem with current behavior. Contemplation describes a time when the individual is aware that there is a problem and is considering taking action to resolve the problem. This stage typically lasts about 6 months. Preparation is the time when the individual is getting ready to take action, usually within 30 days, and some behavior modification, although small, may be taking place. Action designates the time when noticeable changes are happening. Maintenance 
refers to attempts made by the individual to maintain the adopted behavior for at least six months (Prochaska et al., 1994).

This program was implemented to provide dietary assessment in hopes of enhancing individuals' awareness of dietary practices. It also provided appropriate education specific to individual goals and readiness to change. The primary goal was to provide information that might increase overall awareness of what healthy dietary behaviors are and the steps to adopting such behaviors.

\section{Implementation}

The nutrition program was implemented in the fall of 2003 as a supplement to the existing polyFIT program, which is offered during Fall, Winter, and Spring quarters of the academic year. Survey of the program was completed at the end of the Fall 2003 quarter. Student volunteers enrolled as Kinesiology majors or involved in the Nutrition Club at California Polytechnic State University were recruited to conduct nutrition assessments. The process of recruitment is explained in the next section.

\section{Recruitment of Fitness Consultants}

During the first week of the fall quarter, a meeting for potential fitness consultants was held to introduce the polyFIT program. Students were recruited from the Kinesiology Department and the Nutrition Department. The project coordinator for the nutrition component of the existing fitness testing program briefly explained the purpose of the program and what would be expected of the volunteers if they chose to participate in the nutrition component. Along with the weekly time commitment of 2.5 hours for training of the volunteers and conducting appointments, an additional estimated 2 hours per week were needed to complete homework assignments during the training period and 
to conduct diet analyses and gather and prepare relevant education materials for clients after the first session. Students who showed interest and agreed to commit to a common weekly meeting time for the remainder of the quarter for purposes of training and conducting appointments were offered a volunteer position as a fitness consultant.

\section{Training of Fitness Consultants}

Fitness consultants were trained by the project coordinator, whose qualifications included a Bachelor of Science Degree in Nutrition from California Polytechnic State University and nearing completion of a Master of Science Degree in Kinesiology.

Training lasted two weeks. Students attended two 2-hour training sessions the first week and one 2-hour training session the second week for a total of 6 hours. This last session was used for volunteers to ask questions, review previous session topics, and practice client consultations. The project coordinator was also available at another time during the second week for consultants to drop in as needed for review. During this "free session," the client consultation was the most reviewed topic. Each training session followed a schedule to properly prepare the consultants for implementation. The training protocol is provided in Table 1. A more extensive explanation of what was covered within each topic is provided in Appendix I. Students were assigned a task to complete on their own time before the next training meeting. Fitness consultants were encouraged to contact the project coordinator via email or telephone during the quarter if necessary for reasons specified during training, including questions about the health questionnaire, diet interview process or education gathering process, advice or direction about a client, and problems with the computer program. 
Table 1

Training Protocol

\begin{tabular}{ll}
\hline \multicolumn{1}{c}{ Session } & Topic \\
\hline One & Purpose of the program \\
2003 & Importance of language \\
& Introduce client session protocol \\
& Navigation of nutrition file- "Nutri-file”, \\
& Computer program- Diet Analysis Plus \\
& Standard forms introduction: Health Screening - Nutrition \\
& Assessment \\
& Homework assignment \\
& Review of the previous session \\
& Review of homework \\
October 2, 2003 & Review client session protocol \\
& Standard forms continued: Food Frequency Checklist, \\
& 24-hour- recall/usual diet form, Assessment Rule \\
& Conducting a 24-hour recall \\
& Homework assignment \\
\hline Three & Review of the previous session \\
October 7, 2003 & Review of homework \\
& Practice consultations \\
\hline
\end{tabular}

Client Consultations

Individuals who participated in the Nutrition program by having their nutritional status assessed and receiving educational materials were called "clients." The clients during the 2003 Fall quarter were students, specifically freshmen and sophomores, enrolled in Kinesiology 250. They were informed about the Nutrition program by their professor who offered extra credit if they participated.

Clients completed a polyFIT nutrition information packet consisting of a client assessment questionnaire and informed consent form (see Appendix J). After completion, clients dropped the packet in a locked box located in the James Webb Human Performance Lab, room 250 of building 43A on the Cal Poly campus. The polyFIT coordinator picked up the packet and called the client to schedule the first and second appointments during the hours available. Clients were asked for the specific 
reason for wanting a nutrition consultation. This latter question was to allow the fitness consultant to prepare adequately for the appointment. Clients were informed that each session would take approximately 1 hour to complete.

A motivational nutrition counseling algorithm developed by Berg-Smith et al. (1999) was used as a guide in developing the order of the client sessions. Motivational interviewing is based on the notion that motivation is the basis for behavior change and that everyone varies in their readiness to change behavior. The protocol was modified for purposes of the program. The client session protocol was referred to as the "Order of Operations" and is presented in Appendix K. It gives the order of steps in which the sessions were conducted.

Materials relative to goals established, expectations of the participant, and dietary assessment were provided. Review of the materials by both the consultant and the client allowed for better understanding and might have increased the likelihood that the information would be used in the future.

Survey

During the last week of the fall quarter, a questionnaire, developed by the program coordinator, was emailed to clients with five questions pertaining to the delivery and provision of information and its perceived usefulness. There was space provided for additional comments (see Appendix L). Three weeks later, at the beginning of winter quarter, the questionnaire was emailed again to those clients who had not responded to the previous attempt.

A questionnaire, developed by the program coordinator, was emailed to the fitness consultants the last week of the fall quarter. The purpose was to survey the 
consultants' perceptions regarding the adequacy of the training, if the assessment/consultation process was logical and effective, and the usefulness of the resources/tools. See Appendix $\mathrm{M}$ for a copy of the questionnaire.

\section{Continuation of the Program}

The program was expected to continue for the remainder of the academic year. Each new quarter, training of the fitness consultants was conducted by an experienced volunteer who participated in the program the previous quarter. These potential student "trainers" would ideally be completing a major or minor in nutrition. If there was not a student completing a major or minor in nutrition that was willing to conduct training, a willing, experienced volunteer majoring in Kinesiology was to be recruited.

\section{Data Analysis}

Responses to survey questions were analyzed by tallying responses and calculating percentages of positive and negative responses. Any additional comments from the clients and consultants were observed as to how they described aspects of the program and/or how they might contribute to improvements in the program. 


\section{Chapter 4}

\section{Results and Discussion}

\section{Results}

\section{Fitness Consultants}

Seven Cal Poly students were recruited to be fitness consultants of the polyFIT Nutrition program. Five were Kinesiology undergraduates; one sophomore, two juniors, two seniors. Two were Nutrition undergraduates, both seniors. There were 5 women and 2 men. Table 2 presents demographics of the consultants. All students participated in the nutrition training as well as fitness testing training for the polyFIT program. One student volunteer was able to attend only two of the three nutrition training sessions. She received separate instruction from the coordinator on the material she missed and was assisted by her fellow consultants who had completed three sessions.

Table 2

Demographics of Consultants

\begin{tabular}{lccccccc}
\hline & Consultant & Consultant & Consultant & Consultant & Consultant & Consultant & Consultant \\
& A & B & C & D & E & F & G \\
\hline Gender & Female & Male & Female & Male & Female & Female & Female \\
Year & Senior & Junior & Junior & Senior & Sophomore & Senior & Senior \\
Major & Kinesiology & Kinesiology & Kinesiology & Kinesiology & Kinesiology & Nutrition & Nutrition \\
\hline
\end{tabular}

There were five polyFIT teams assembled at the beginning of the quarter, with 2 to 4 people on each team. Teams were assembled based on their availability during the week. Some volunteers were trained in conducting fitness assessments only. The seven volunteers who were part of the polyFIT Nutrition program were trained to conduct both fitness and nutrition assessments. Each team met for 2.5 hours scheduled during a common block of time, on its respective day, Monday, Tuesday, Wednesday, Thursday, 
or Friday. At least one volunteer on each of the five teams had been trained to conduct nutrition assessments and consultations.

\section{Clients}

Over the course of the 10 week fall 2003 quarter, the student volunteers interviewed 30 clients. All of the clients were students enrolled in Kinesiology 250, a Healthy Living course for undergraduates, primarily freshmen and sophomores. This was the result of extra credit that was offered to the students by the professor at the beginning of the quarter. The interest in nutrition assessment and consultation by these students filled the available nutrition appointments for the entire quarter. This was not the only opportunity for students to receive extra credit in this course.

First session appointments lasted 30 minutes to an hour. Second session appointments lasted 15 minutes if the client was able or chose to return the following week to pick up the education materials. There were 2 out of 30 instances of clients failing to return to pick up the materials, which remained in their file folder. Some clients were not able to take the time to review the material with the fitness consultant but did take the materials. The specific number of clients is not available.

\section{Survey Questionnaire Distribution}

Survey questionnaires were emailed the week of finals to the thirty clients for purposes of gathering feedback on the feasibility of the program. In three weeks, only 2 (7\%) clients responded. During the first week of the winter quarter, after winter break, survey questionnaires were emailed again to those who had not responded. Four additional clients completed the survey totaling 6 completed surveys out of thirty, a 20\% response rate. Table 3 presents the results of the client surveys. 
A survey questionnaire was also emailed to the seven fitness consultants during

winter quarter, 2004. Four of the seven responded (57\% response rate). Table 4 presents

the results of the fitness consultant surveys.

Table 3

Results of Client Survey

\begin{tabular}{|c|c|c|c|c|}
\hline Question & $\begin{array}{l}\text { Number of } \\
\text { yes } \\
\text { responses }\end{array}$ & $\begin{array}{c}\text { Number } \\
\text { of no } \\
\text { responses }\end{array}$ & Unanswered & $\begin{array}{c}\text { Optional } \\
\text { additional } \\
\text { comments }\end{array}$ \\
\hline
\end{tabular}

1. Did you feel comfortable during session 1 -discussion of the health screening questionnaire, dietary analysis, and goal setting?

2. Did you feel comfortable during session 2- presentation of dietary analysis results and education materials?

3. Did you feel as if the fitness specialist knew what they were doing?

4. Did you understand the materials presented to you?

5. Did you find the materials useful?
6

0

0

5

0

1

5

0

1

5

0

1

5

0

0

1 "comfortable the whole time,” "informative, pleasant, friendly, thoughtful, inquisitive"

“surprised at my results...how much healthier I need to eat"

"Knowledgeable, qualified,” “a bit unorganized”

“questions were answered thoughtfully and complete"

“now, when I eat, I make sure am choosing the right foods," "especially the nutrition requirement printout based on activity level, body type, and body measurements" 
Table 4

\begin{tabular}{|c|c|c|c|c|}
\hline \multirow[t]{2}{*}{ Question } & \multicolumn{4}{|c|}{ Responses } \\
\hline & $\underline{\text { Consultant A }}$ & $\underline{\text { Consultant B }}$ & $\underline{\text { Consultant C }}$ & $\underline{\text { Consultant D }}$ \\
\hline $\begin{array}{l}\text { 1. Did you feel as if the } \\
2 \text { week-training } \\
\text { adequately prepared you } \\
\text { for client sessions? }\end{array}$ & Yes & Yes & Yes & $\begin{array}{l}\text { Yes, one on one practice } \\
\text { was most effective }\end{array}$ \\
\hline $\begin{array}{l}\text { 2. Did you feel as if the } \\
\text { order in which sessions } \\
\text { were conducted was } \\
\text { logical in acquiring } \\
\text { information from } \\
\text { clients? Effective? }\end{array}$ & $\begin{array}{l}\text { Yes, we had } \\
\text { plenty of time to } \\
\text { gather info and } \\
\text { give thoughtful } \\
\text { feedback }\end{array}$ & $\begin{array}{c}\text { Yes, the order was } \\
\text { logical and } \\
\text { effective }\end{array}$ & Yes & $\begin{array}{l}\text { Yes, it was good for } \\
\text { someone who was } \\
\text { genuinely interested in } \\
\text { assessment. Having } 2 \\
\text { sessions for KINE } \\
\text { students seemed a waste } \\
\text { of our time. }\end{array}$ \\
\hline $\begin{array}{l}\text { 3. Did you feel as if the } \\
\text { time allotted for client } \\
\text { sessions was adequate? }\end{array}$ & Yes & $\begin{array}{l}\text { Yes, the time } \\
\text { allotted was more } \\
\text { than enough }\end{array}$ & $\begin{array}{c}\text { Yes, we were able to } \\
\text { do them faster than } \\
\text { we thought }\end{array}$ & Yes \\
\hline 4. How would you rate & Rating: 4 & Rating: 5 & Rating: 4 & Rating: 8 \\
\hline $\begin{array}{l}\text { the Diet Analysis } \\
\text { Program based on ease } \\
\text { of use and why? (Scale } \\
\text { of } 1-10,1 \text { being } \\
\text { Impossible and } 10 \text { being } \\
\text { Very easy). }\end{array}$ & $\begin{array}{l}\text { It would not } \\
\text { allow you to } \\
\text { enter simple } \\
\text { foods, such as a } \\
\text { banana or apple, } \\
\text { too complicated, } \\
\text { got frustrated }\end{array}$ & $\begin{array}{l}\text { You have to enter } \\
\text { every food item } \\
\text { instead of being } \\
\text { able to select } \\
\text { common food } \\
\text { items }\end{array}$ & $\begin{array}{c}\text { The selections are } \\
\text { limited }\end{array}$ & $\begin{array}{l}\text { Nice program, fairly } \\
\text { easy to use, but basic } \\
\text { food items were not on } \\
\text { the foodlist or were very } \\
\text { hard to find or substitute }\end{array}$ \\
\hline $\begin{array}{l}\text { 5. Did the Decision Tree } \\
\text { assist you in finding } \\
\text { proper education based } \\
\text { on your clients needs? }\end{array}$ & $\begin{array}{l}\text { No, a good idea } \\
\text { on paper, but a } \\
\text { waste of time }\end{array}$ & $\begin{array}{l}\text { Yes, it was clear } \\
\text { and easy to follow }\end{array}$ & Yes, definitely & Yes, very handy \\
\hline $\begin{array}{l}\text { 6. Did the Nutrition file } \\
\text { contain the } \\
\text { education/information } \\
\text { that clients requested or } \\
\text { needed? }\end{array}$ & $\begin{array}{c}\text { Yes, great } \\
\text { information, } \\
\text { very thorough }\end{array}$ & Yes & Yes, definitely & $\begin{array}{l}\text { Yes, for KINE students, } \\
\text { yes, but could see some } \\
\text { clients requiring a bit } \\
\text { more research }\end{array}$ \\
\hline $\begin{array}{l}\text { 7. Were clients } \\
\text { receptive to returning } \\
\text { for the } 2 \text { nd session to } \\
\text { receive their } \\
\text { handouts/diet analysis? } \\
\text { If not, why? }\end{array}$ & $\begin{array}{l}\text { Yes, the ones } \\
\text { who were } \\
\text { actually } \\
\text { interested }\end{array}$ & Yes & $\begin{array}{c}\text { Yes, though mostly } \\
\text { for extra credit in } \\
\text { class }\end{array}$ & $\begin{array}{l}\text { No, as my clients just } \\
\text { wanted their handouts to } \\
\text { get extra credit. They } \\
\text { seemed uninterested in } \\
\text { the second session. }\end{array}$ \\
\hline $\begin{array}{l}\text { 8. If clients did pick up } \\
\text { their } \\
\text { handouts/education, did } \\
\text { they stay long enough to } \\
\text { have you briefly review } \\
\text { the information } \\
\text { (required for session 2)? }\end{array}$ & Yes & $\begin{array}{l}\text { Yes, they } \\
\text { generally stayed } \\
\text { long enough to } \\
\text { review the } \\
\text { information }\end{array}$ & Yes, for the most part & Yes, I made them stay \\
\hline $\begin{array}{l}\text { 9. Name } 2 \text { things that } \\
\text { would have made this } \\
\text { program better. }\end{array}$ & $\begin{array}{l}\text { A better diet } \\
\text { analysis } \\
\text { program, less } \\
\text { busywork (goal } \\
\text { sheet, decision } \\
\text { tree) }\end{array}$ & $\begin{array}{l}\text { Diet analysis } \\
\text { software that } \\
\text { contains common } \\
\text { food items, more } \\
\text { clients to practice } \\
\text { assessment skills }\end{array}$ & $\begin{array}{l}\text { Targeting nutrition } \\
\text { students so that more } \\
\text { nutrition assessments } \\
\text { could be done }\end{array}$ & $\begin{array}{l}\text { No extra credit, better } \\
\text { computer program }\end{array}$ \\
\hline
\end{tabular}




\section{Client Survey Results}

Five of the six clients (83\%) who responded to the survey answered yes (positively) to all five questions. One student answered yes to the first question but did not complete the remaining four questions, claiming that she could not respond to those pertaining to materials because she was never scheduled to review dietary results and education. Of the five students who completed the survey, three of them completed open ended responses. Two students stated that the fitness consultants they worked with were "knowledgeable” and "qualified,”; one stated that although the fitness consultant knew what he was doing, the student could tell the program was new because "they were kind of unorganized” (in response to question \#3). In response to questions relative to comfort (questions \#1 and \#2), one student said "he was comfortable the whole time” and another said the fitness consultant was “informative, pleasant, friendly, thoughtful, inquisitive.” One student, responding to question \#4, in addition to understanding the materials given, said questions were answered "thoughtfully and complete." In response to the usefulness of materials (question \#5), one student mentioned he was surprised at the results of the dietary analysis, how much healthier he needed to eat and that he was

"choosing the right foods" at the time of survey. Another student found the "nutrition requirements printout based on activity level, body type, and body measurements” especially useful.

\section{Fitness Consultant Survey Results}

Four of the seven (57\%) fitness consultants responded to the survey questionnaire the project coordinator sent via email. All who responded were Kinesiology majors. 
Table 4

\begin{tabular}{|c|c|c|c|c|}
\hline \multirow[t]{2}{*}{ Question } & \multicolumn{4}{|c|}{ Responses } \\
\hline & $\underline{\text { Consultant A }}$ & $\underline{\text { Consultant B }}$ & $\underline{\text { Consultant C }}$ & $\underline{\text { Consultant D }}$ \\
\hline $\begin{array}{l}\text { 1. Did you feel as if the } \\
2 \text { week-training } \\
\text { adequately prepared you } \\
\text { for client sessions? }\end{array}$ & Yes & Yes & Yes & $\begin{array}{l}\text { Yes, one on one practice } \\
\text { was most effective }\end{array}$ \\
\hline $\begin{array}{l}\text { 2. Did you feel as if the } \\
\text { order in which sessions } \\
\text { were conducted was } \\
\text { logical in acquiring } \\
\text { information from } \\
\text { clients? Effective? }\end{array}$ & $\begin{array}{l}\text { Yes, we had } \\
\text { plenty of time to } \\
\text { gather info and } \\
\text { give thoughtful } \\
\text { feedback }\end{array}$ & $\begin{array}{c}\text { Yes, the order was } \\
\text { logical and } \\
\text { effective }\end{array}$ & Yes & $\begin{array}{l}\text { Yes, it was good for } \\
\text { someone who was } \\
\text { genuinely interested in } \\
\text { assessment. Having } 2 \\
\text { sessions for KINE } \\
\text { students seemed a waste } \\
\text { of our time. }\end{array}$ \\
\hline $\begin{array}{l}\text { 3. Did you feel as if the } \\
\text { time allotted for client } \\
\text { sessions was adequate? }\end{array}$ & Yes & $\begin{array}{l}\text { Yes, the time } \\
\text { allotted was more } \\
\text { than enough }\end{array}$ & $\begin{array}{c}\text { Yes, we were able to } \\
\text { do them faster than } \\
\text { we thought }\end{array}$ & Yes \\
\hline 4. How would you rate & Rating: 4 & Rating: 5 & Rating: 4 & Rating: 8 \\
\hline $\begin{array}{l}\text { the Diet Analysis } \\
\text { Program based on ease } \\
\text { of use and why? (Scale } \\
\text { of } 1-10,1 \text { being } \\
\text { Impossible and } 10 \text { being } \\
\text { Very easy). }\end{array}$ & $\begin{array}{l}\text { It would not } \\
\text { allow you to } \\
\text { enter simple } \\
\text { foods, such as a } \\
\text { banana or apple, } \\
\text { too complicated, } \\
\text { got frustrated }\end{array}$ & $\begin{array}{l}\text { You have to enter } \\
\text { every food item } \\
\text { instead of being } \\
\text { able to select } \\
\text { common food } \\
\text { items }\end{array}$ & $\begin{array}{c}\text { The selections are } \\
\text { limited }\end{array}$ & $\begin{array}{l}\text { Nice program, fairly } \\
\text { easy to use, but basic } \\
\text { food items were not on } \\
\text { the foodlist or were very } \\
\text { hard to find or substitute }\end{array}$ \\
\hline $\begin{array}{l}\text { 5. Did the Decision Tree } \\
\text { assist you in finding } \\
\text { proper education based } \\
\text { on your clients needs? }\end{array}$ & $\begin{array}{l}\text { No, a good idea } \\
\text { on paper, but a } \\
\text { waste of time }\end{array}$ & $\begin{array}{l}\text { Yes, it was clear } \\
\text { and easy to follow }\end{array}$ & Yes, definitely & Yes, very handy \\
\hline $\begin{array}{l}\text { 6. Did the Nutrition file } \\
\text { contain the } \\
\text { education/information } \\
\text { that clients requested or } \\
\text { needed? }\end{array}$ & $\begin{array}{c}\text { Yes, great } \\
\text { information, } \\
\text { very thorough }\end{array}$ & Yes & Yes, definitely & $\begin{array}{l}\text { Yes, for KINE students, } \\
\text { yes, but could see some } \\
\text { clients requiring a bit } \\
\text { more research }\end{array}$ \\
\hline $\begin{array}{l}\text { 7. Were clients } \\
\text { receptive to returning } \\
\text { for the } 2 \text { nd session to } \\
\text { receive their } \\
\text { handouts/diet analysis? } \\
\text { If not, why? }\end{array}$ & $\begin{array}{l}\text { Yes, the ones } \\
\text { who were } \\
\text { actually } \\
\text { interested }\end{array}$ & Yes & $\begin{array}{c}\text { Yes, though mostly } \\
\text { for extra credit in } \\
\text { class }\end{array}$ & $\begin{array}{l}\text { No, as my clients just } \\
\text { wanted their handouts to } \\
\text { get extra credit. They } \\
\text { seemed uninterested in } \\
\text { the second session. }\end{array}$ \\
\hline $\begin{array}{l}\text { 8. If clients did pick up } \\
\text { their } \\
\text { handouts/education, did } \\
\text { they stay long enough to } \\
\text { have you briefly review } \\
\text { the information } \\
\text { (required for session 2)? }\end{array}$ & Yes & $\begin{array}{l}\text { Yes, they } \\
\text { generally stayed } \\
\text { long enough to } \\
\text { review the } \\
\text { information }\end{array}$ & Yes, for the most part & Yes, I made them stay \\
\hline $\begin{array}{l}\text { 9. Name } 2 \text { things that } \\
\text { would have made this } \\
\text { program better. }\end{array}$ & $\begin{array}{l}\text { A better diet } \\
\text { analysis } \\
\text { program, less } \\
\text { busywork (goal } \\
\text { sheet, decision } \\
\text { tree) }\end{array}$ & $\begin{array}{l}\text { Diet analysis } \\
\text { software that } \\
\text { contains common } \\
\text { food items, more } \\
\text { clients to practice } \\
\text { assessment skills }\end{array}$ & $\begin{array}{l}\text { Targeting nutrition } \\
\text { students so that more } \\
\text { nutrition assessments } \\
\text { could be done }\end{array}$ & $\begin{array}{l}\text { No extra credit, better } \\
\text { computer program }\end{array}$ \\
\hline
\end{tabular}


The consultants felt the training sessions, in both length and content, adequately prepared them for the nutrition consultations. The practice/mock dietary assessments were specifically mentioned as that which prepared the consultants most. They were able to conduct and complete consultations, both sessions, in less time than was expected by the coordinator. However, Consultant D believed that because of the lack of interest in the actual results by the clients, the second session was somewhat of a "waste of time." The order in which the sessions were conducted was mutually accepted as being logical and effective in gathering information necessary for a complete consultation. Consultant A suggested some of the materials used, such as the goal sheet and decision tree were a lot of "busywork" and that the clients didn't respond well. There is question, however, about how this consultant, who attended only two training sessions, used these particular tools and if they were actually used properly. Overall, consultants thought the decision tree and the nutrition file were helpful, as both guides and resources, in targeting the needs of clients. Consultant D mentioned that although the information provided in the nutrition file was adequate for kinesiology students, in the future, it would need to include more research/education for other clients that were not in KINE 250. No suggestions as to what type of information or specific topics needed were provided by this consultant.

The average rating for the Diet Analysis Program, on a scale of 1-10, with a score of 1 being "impossible” and 10 being "very easy,” was 6.5. Three of the four fitness consultants (75\%) gave the program a score of 5 or lower, with only one giving it a score above average. They unanimously agreed that the program was not easy to use, specifically when searching for foods in the food list database. It was stated that the 
primary problem was that the program's food list did not list basic foods, such as "banana or apple” as one mentioned, which proved difficult when selecting common food items. When searching for a food using the Diet Analysis Plus program, an apple for example, the word "apple" is typed in the space provided and an alphabetical list of 98 items is displayed. It might be assumed that "apple" would be at the top of the list. However, the program distinguishes similar items by size, such as " 8 inch Apple Pie - Commercial Prep”; brand name, such as “Dannon Apple Cinn Yogurt Fruit/Bttom”; or restaurant chain, such as "Burger King Dutch Apple Pie.” Therefore, you find the first option for "apple” as simply a piece of fruit under the name "Large Apple w/Peel - 3 1/4" diameter.” Because not all foods or food products are the same, which affects the nutritional components of the food, the program lists items in detail. To find the most appropriate and representative item, it requires time to search carefully through the listed items.

Consultants observed that if they attended the second appointment, clients were generally uninterested in the actual content of the educational materials provided after dietary assessment. These materials provided the results of the diet analysis and information pertaining to the client's needs and/or goal(s) set at the first appointment. Some clients did not return for the second session, although an actual count is not available because the project coordinator was not informed by the consultants as to how many, despite efforts to retrieve information.

Upon asking fitness consultants how the program could be improved, 3 of the 4 consultants answered changing the computerized diet analysis program. Following this was to disallow the offer of extra credit to students in KINE 250. Consultant C 
mentioned that more trained fitness consultants would allow for more clients to be seen and therefore more consultations conducted which another mentioned would be helpful to practice their newly learned skills. Less busywork was stated as something that would improve the program; however, what was considered busywork was not specified.

Throughout the fall 2003 quarter, the coordinator had received feedback from the volunteer fitness consultants, both verbally and via email. Some consultants who did not complete and return the survey provided comments about the program during the quarter. With regard to the whole process, one consultant said that it was "fun and interesting to do.” The program materials and session protocol were described as "being organized and easy to understand." One consultant made the suggestion that both client sessions be scheduled at the same time. This same consultant suggested that the client be informed about the 24-hour recall ahead of time so that they might be better prepared.

\section{Education Materials}

The materials distributed to four of the thirty clients (13\%) are known. A total of eleven handouts were presented to the four clients. Of the education presented, three handouts were on snacking, two on fruits and vegetables, two on weight loss, one on fad diets, one on lactose intolerance, one on shopping solutions for healthier eating and one on secrets for shopping smarter.

\section{Discussion}

The polyFIT Nutrition program was designed as a nutrition assessment program that provided education and nutrition recommendations relative to individual goals and/or status and stage of change that was credible and available from an institution with which 
the individual was affiliated. This might increase participants' awareness of healthy eating behaviors and nutritional status.

By developing this nutrition assessment and consultation program and implementing it in conjunction with polyFIT, the Cal Poly community could find out what aspects of their health, specifically physical and dietary behavior, are good and what could be better. Before implementation, polyFIT included assessment of fitness level and provided exercise plans tailored to clients' needs and goals. Because both eating and exercise behaviors play a major role in the prevention of chronic disease and obesity (NCHS, 2005; NCCDPHP, 2008) and optimizing sports performance (ADA, Dieticians of Canada, ACSM, 2000), with the addition of the nutrition program, polyFIT could now assess both behaviors and provide education that might increase awareness about their health and ways to change it for the better.

The intention of this project was to develop a nutrition program to complement the existing fitness testing program already in existence and distribute materials relative to healthy eating behaviors and dietary status of clients. That being the ultimate goal, it was achieved. Fitness consultants, who had some or did not have any formal nutrition education, were successfully trained, completed 30 dietary interviews and provided education materials to most clients. Clients reported that they were comfortable during interviews, understood the intervention materials and were using them to make better food choices.

The two fields, nutrition and kinesiology, experienced some crossover due to the health aspect in both majors and the everyday application of principles from both in day to day living. Students' exposure to both fields might better equip them in consulting 
with clients participating in the program, or outside individuals, about how to live healthier lives.

One weakness in the design was the lack of written data on each client by the consultant. Before the training period was completed by the consultants, the program coordinator distributed an email to all the fitness consultants listing the information that the coordinator needed documented after each client consultation. This list included the name and email address of the client, and the education/information that was given. Although it was not an objective of this project to assess what education was most commonly needed and/or requested, the program coordinator thought the information would be useful for further development of the nutrition file to better fit the needs of the clients. It was assumed by the coordinator that this email, as well as verbally repeating the list at the final training session and attaching a hard copy to the nutrition file, would be adequate. However, the coordinator did not receive all the necessary information on any one client. For future quarters, providing a client log book in the polyFIT area for the consultants to record clients' information and education provided at the time of the appointment might prove effective. Knowing which materials are being provided and the frequency with which they are provided would prove useful for program improvements and possible future research of the target population.

The practice dietary interviews during training were the most helpful for the fitness consultants in preparation for actual client consultations. Although they reported feeling prepared after training, more practice might have better prepared them for the first client, making them feel more comfortable with the process. Listening to one another conduct interviews would increase one's exposure to the appropriate language, the order 
of the process, clients' possible responses, individual styles in communicating, etc. This would give the consultants more examples of how an interview should be conducted, but also how much variability might occur.

According to the consultants, the decision tree and the nutrition file were helpful tools in assisting the consultants with finding the best educational materials for meeting the clients' needs and requests. It should be noted that these tools were created by the program developer for the use of the student volunteers in conjunction with the information gathered during the client interview and to find the appropriate resources for the client. A very thorough interview that provides detailed information might not require the extra help that the Decision Tree was designed to provide. The nutrition file provides information about a wide variety of health topics, but it by no means is exhaustive. Although the file served the clients well this particular quarter, it may not in subsequent quarters when there is greater diversity in clients' needs. Therefore, updating and providing new information in the file on a regular basis is necessary for the program to continue meeting the needs of clients.

The goal sheet was included because it has been proven effective in modifying behavior (Ammerman et al., 2002) and is part of the Patient Centered Model of facilitating dietary change (Rosal et al., 2001). It has been suggested that goal setting is best when done after review of what needs to change in the diet (Rosal et al., 2001). However, during implementation of the program, goals were set after 24-hour recalls and food frequency checklists were completed in session one. The client most likely was not aware of the aspects of his/her diet that needed improvement because the results of the analysis had not yet been presented. It was assumed that clients sought nutrition 
assessment for a reason and that reason could be used to focus the efforts of the fitness consultants. That reason or motive was used to create a goal(s) or target behavior which then guided the fitness consultant when reviewing the results of the dietary assessment. Because there could have been many aspects of the diet that needed modification, the project coordinator did not believe it was within the scope of the fitness consultants' ability to consult clients on all aspects nor to determine which were the most important to discuss. Determining the personal goal based on the motives of the client helped decipher which aspects of the diet should be discussed. A suggestion for future quarters is to review the dietary results with the client and then set goals based on what needs to change in the diet and the motives of the client. The consultant can then gather education based on these goals.

Although the computerized nutrient analysis program delivered the necessary printouts and consultants were able to input foods for analysis, the food database provided by Diet Analysis Plus made it difficult for the volunteers to find basic or common items. This could mean that some diet analysis results were not accurate. It was unfortunate that the program was not as user-friendly as expected considering that it was a student version. However, it was made available at no cost to polyFIT and because it was the first quarter and trial of the nutrition program as part of polyFIT, Diet Analysis Plus was used. In the future, installing a more comprehensive analysis program might be easier for the consultants to use and provide more accurate results.

All of the clients assessed during fall quarter were enrolled in Kinesiology 250, a Healthy Living course in which the professor offered extra credit to students who completed the nutrition assessment, received the education materials, and submitted them 
for credit. The professor offered extra credit to the students to provide the new program with clients for which the volunteers could practice consultations. It was unexpected that these students would fill the appointment book and unknown to the coordinators of both the nutrition and fitness programs of polyFIT that extra credit would be offered. The program developer assumed that because extra credit was offered, students who might not have sought nutrition consulting for benefit of health did schedule appointments to receive extra credit. All of the available times for nutrition consulting were taken by these students. In the future, a greater number of volunteers trained in nutrition consultations will allow for more clients to be seen. As well, by not offering extra credit in future quarters, this would free even more time for appointments with a greater diversity of clients. The program is designed to provide education to a variety of people with different needs. Being that all of the students were freshman and sophomores this particular quarter, they represented only a portion of the target population for which the nutrition program was designed.

There seemed to be a lack of client interest in session two. This was believed to be because of many clients' initial motive for participating in the program. Clients may have been interested in receiving extra credit rather than being educated about their eating habits. Therefore, consultants found it difficult to properly review the results of the dietary analysis and the educational materials. Some students did not stay for any review and just picked up their materials, two students did not pick up any materials, and others had little time to spare. The fitness consultants, in accommodating these latter clients, rushed through session two. 
Scheduling of the second sessions became a challenge, if they had not been previously scheduled along with the first session, due to already filled time slots. In the future, scheduling both sessions at the same time might prove to be successful in completing consultations. Another option would be to complete consultations in one session in which assessment, analysis, and results could be completed and presented. This had been a possibility during the development of the program, however, research has indicated that the more time spent with a health educator, the greater compliance with behavior change (Hebert et al., 1999). This was one reason behind conducting 2 sessions. With some of the consultants being new to diet analysis and the computer program, two sessions were also thought to be necessary for adequate time to complete analysis and gather education. The time between sessions 1 and 2 allowed for that.

There is some speculation as to why so many clients failed to respond to the survey questionnaire. One reason might be that because they were all participating in the program because of extra credit and some were uninterested in the actual outcome of their results, it is unlikely that they were interested in a survey of the program and they deleted the questionnaire. The lack of response might be attributed to an unfamiliar email address. Many email users have separate email inboxes to which unfamiliar mail is automatically forwarded. These inboxes might not be viewed by the owner and the emails are ultimately deleted. 


\author{
Chapter 5 \\ Summary, Conclusions and Recommendations
}

\title{
Summary
}

Research indicates that Americans’ diet needs improvement (Guenther et al., 2007a). A healthy diet can aid in the prevention of chronic disease and obesity, manage existing digestive and other conditions, and optimize sport performance (ADA, Dieticians of Canada, and ACSM, 2000; NCCDPHP, 2008). However, people of all ages and stages of life are unaware of what healthy eating behaviors are (Dunn et al., 2007; Kopp \& Young, 2003; Main \&Wise, 2002; Nitske et al.,1999; Rosenbloom et al., 2002; Variyam et al., 1998). There is an abundance of nutrition information available to the consumer, but what information is reliable and what is not can be hard for the average person to decipher (American Dietetic Association, 2002; Main \& Wise, 2002). If people are not aware of how to eat properly, changing eating behaviors can be difficult.

Dietary interventions that provide education to increase awareness of healthy eating behaviors have proven successful in changing behaviors over time (Evans \& Sawyer-Morse, 2002; Gambera et al., 1995; Hebert et al., 1999; Oenema \& Brug, 2003; Proper, et al., 2003). Tailoring the intervention to the individual by assessing his/her readiness to change eating behaviors and setting personal goals have been components of successful dietary interventions (Ammerman et al., 2002; Rosal et al., 2001; SigmanGrant, 1996).

The polyFIT Nutrition program is a nutrition assessment and consultation program at Cal Poly State University, San Luis Obispo. The purpose of this project was to develop a program to accompany the existing fitness testing and prescription program 
already known as polyFIT and was implemented for the first time in the fall quarter of 2003. It was designed to provide credible education and nutrition recommendations relative to individual goals and/or status and stage of change. This might increase participants' awareness of healthy eating behaviors and nutritional status.

Student volunteers, called fitness consultants, were trained in conducting dietary interviews and diet analysis and distributing individually-tailored education to clients requesting nutrition assessment. They followed a client session plan that was agreed to be adequate and logical in acquiring the necessary information to complete intervention. Overall tools chosen or designed to assist consultants were useful and complete. The computerized diet analysis program scored a 6.5 out of 10 for ease of use, however, most consultants did not find the food database easy to use. Despite this, consultants were able to interview thirty clients during the fall quarter, assess their diet, and gather education specific to their goals and dietary status. Although the target population for the program was any person currently or formerly affiliated with the university, all thirty clients were freshman and sophomores in a Healthy Living course.

Student staff in polyFIT continued to offer nutrition assessment and consultations to the Cal Poly community for at least 3 years after the program was first implemented. Over time, changes were made to the program. Currently, polyFIT is not offering the nutrition program due to a problem with the current computerized diet analysis program. There are plans to continue offering the program when the problem can be addressed. 


\section{Conclusions}

There were several objectives that were hoped to be reached in the development of the nutrition program. The following are the conclusions to those objectives. Conclusion \#1:

A nutrition assessment and consultation program was developed and implemented at California Polytechnic State University, San Luis Obispo. Conclusion \#2:

Nutrition education was provided using the goals established by the clients, clients’ readiness to change eating behaviors, and results of clients' diet analysis. Conclusion \#3:

Over the course of 2 weeks, the fitness consultants were trained in all aspects of the program to prepare and enable them to conduct dietary assessment and determine clients' stage of change so that they could distribute appropriate materials based on these results.

Conclusion \#4:

Fitness consultants agreed that the order in which session content was presented was effective and logical in acquiring the necessary information.

\section{Conclusion \#5:}

A decision tree for gathering educational materials was designed for the fitness consultants for reference. A nutrition file contained education that was adequate for the clientele. 


\section{Conclusion \#6:}

Consultants perceived the training as adequate in preparing them to conduct dietary interviews and distribute education. Consultants perceived most tools as very useful and complete as well as easy to use.

Conclusion \#7:

Clients felt comfortable and perceived the knowledge of the consultants to be good. Clients perceived the education materials as easy to understand and useful.

\section{Recommendations}

1. Recommendations for polyFIT

This paper describes the first quarter that the nutrition assessment and consultation program was developed and implemented. Following are recommendations relative to the first quarter but keeping in mind the known changes that had been made to the program in the 2 years that followed.

To better prepare the consultants to conduct dietary interviews, more training is advised. An extra training session that focuses on practicing dietary interviews might help the consultants feel more confident in their learned skills. The consultants might benefit from each one conducting an interview while being observed by the program director. This will allow for constructive feedback.

In order that the diet analysis results provided by the computer program are as accurate as possible, two things could be done. The first thing is to continue to provide a current, updated version of a computerized diet analysis program with an extensive database that is easy to use. The other is to advise the consultants to familiarize 
themselves with the program's database by requiring them to complete a number of diet analyses before seeing clients.

The development of the polyFIT nutrition assessment and consultation program provides numerous opportunities for future research. Ultimately the goal is to change dietary behaviors but the first step to that is increasing awareness. For this program, it was assumed that clients' awareness would increase, however research to validate that assumption is recommended in order to measure the effectiveness of the program. Determining if, after intervention, the target population's dietary and fitness behaviors change over time and by how much will provide useful information on the program’s effectiveness as well as the target population. In addition, if assessment of one's readiness to change is included again as part of the program, clients' readiness to change and whether it relates to eating behaviors and/or body measurements can be studied.

\section{Recommendations for Initiating a Dietary Analysis and Consulting Program}

When initiating a dietary analysis and consulting program, consult the research and accredited organizations, such as the American Dietetic Association, for the most current practices that are recommended in successful dietary interventions. Design the program so that the dietary interview, analysis, assessments, and intervention can be completed in one session. Recruit participants that have a background in nutrition and that have some experience in conducting dietary interviews. Train consultants thoroughly in all materials and protocols, monitor progress, and provide adequate time to practice dietary interviews. Inform consultants of their boundaries (language, diet prescription, etc.) due to lack of credentials and the importance of the clients' privacy. Provide user-friendly tools and resources that will enable them to accurately assess 
dietary status and easily determine appropriate education materials. Include food models and food guides for clients to refer to when completing dietary interviews. Provide a way to record client information and education materials so that future research can be done on the target population and the program's effectiveness, and materials can be updated to provide the most current and credible information.

\section{Recommendation for Future Research}

With the establishment of the nutrition program, future research can be done. Information such as the population's eating habits and nutritional status, nutrition trends, education most sought after, and education most needed can be gathered and assessed. The effectiveness of the program should be determined, also. By assessing the nutrition knowledge before and after participating in the program and/or tracking changes in dietary behaviors, the program can continue to evolve to better fit the needs of the target population and have an effect on nutrition knowledge and dietary behaviors. 


\section{Epilogue}

After the trial quarter fall 2003, the program continued in existence. The following quarter the developer of the program continued her role as coordinator and continued to oversee the program. During this time, session 1 and 2 were scheduled at the same time. Two students from the fall quarter continued participating in the program as fitness consultants and 8 new students volunteered, for a total of 10 fitness consultants for the winter 2004 quarter. In subsequent quarters, students who were previous fitness consultants took on the role as program coordinator. Some were Nutrition majors and some were Kinesiology majors. As time went on, the program grew from a total of 7 volunteers, 2 of them majoring in nutrition to as many as 15 volunteers majoring in nutrition in 2005. The inflation of nutrition students participating in the program supplies greater knowledge and brings experience specific to nutrition education and analysis.

The polyFIT nutrition program has initiated crossover between the Nutrition and Kinesiology departments. Select faculty within the Nutrition department have successfully marketed the program to their students as a way to gain practical experience in their field. Students majoring in nutrition are now using equipment and resources within the Kinesiology department to complete senior projects and graduate theses/projects. Due to this crossover of departments, some faculty are discussing the development of a new major consisting of elements of both fields, Nutrition and Kinesiology.

As time has gone on, the program has changed and evolved relative to the way in which consultations are conducted. Instead of meeting for 2 sessions, the client comes in only once and the student volunteer completes both the diet analysis and consultation in 
one session. After the initial introductions and dietary assessment, the client then goes through fitness testing while his diet is computer analyzed and education is gathered, after which results are presented along with results of fitness tests.

In 2005, the 24-hour recall and the goal sheet were still being used for assessment and the nutrition file was still used for intervention materials.

Sometime after the program had been implemented, a faculty member from the Nutrition Department at Cal Poly provided the computerized dietary analysis program ESHA Food Processor. This program is considered user-friendly and has a more extensive food database than Diet Analysis Plus, which makes the search for basic food items faster and successful. This allows for a more accurate analysis and better results for the client. However, polyFIT students stopped using the computerized diet analysis program due to some problems with the software. Plans for repairing the software or installing new software are in place. 


\section{References}

American Dietetic Association. (2000). Position of the American Dietetic Association, Dieticians of Canada, and the American College of Sports Medicine: Nutrition and athletic performance. Journal of the American Dietetic Association, 100(12), 1543-1556

American Dietetic Association. (2002a). Food and nutrition misinformation. The Journal of the American Dietetic Association, 102, 260-266.

American Dietetic Association. (2002b). Position of the American Dietetic Association: The role of dietetics professionals in health promotion and disease prevention. Journal of the American Dietetic Association, 102(11), 1680-1687.

Ammerman, A. S., Lindquist, C. H., Lohr, K. N., \& Hersey, J. (2002). The efficacy of behavioral interventions to modify dietary fat and fruit and vegetable intake: A review of the evidence. Preventive Medicine, 35, 25-41.

Basiotis, P., P., Carlson, A., Gerrior, S., A., Juan, W. Y., \& Lina, M. (2002). The Healthy Eating Index: 1999-2000. U. S. Department of Agriculture, Center for Nutrition Policy and Promotion. CNPP-12.

Bauer, K. \& Sokolik, C. (2002). Basic Nutrition Counseling Skill Development: A Guideline for Lifestyle Management. Wadsworth Group: Stamford Connecticut Berg-Smith, S. M., Stevens, K. M., Van Horn, N., Gernhofer N., Peters, E., Snetslelaar, L., Aherns, L., \& Smith, K. (1999). A brief motivational intervention to improve dietary adherence in adolescents. Health Education Research, 14(3), 399-410.

Brown, S. L., Pope, J. F., Hunt, A. E., \& Tolman, N. M. (1998). Motivational strategies 
used by dieticians to counsel individuals with diabetes. The Diabetes Educator; 24(3), 313-318.

Dunn, D., Turner, L.A., \& D., George. (2007). Nutrition knowledge and attitudes of college athletes. The Sport Journal, 10(4). Retrieved from http://www.thesportjournal.org/article/nutrition-knowledge-and-attitudes-collegeathletes.

Eaton, C. B., Goodwin, M., \& Stange, K. C. (2002). Direct observation of nutrition counseling in a community family practice. American Journal of Preventive Medicine, 23(3), 174-179.

Evans, A.E. \& Sawyer-Morse, M.K. (2002). The right bite program: A theory-based nutrition intervention at a minority college campus. Journal of the American Dietetic Association, 102(3), S89-93.

Friesen, C. A., \& Hoerr, S. L. (1990). Nutrition education strategies for work-site wellness: Evaluation of a graduate course targeted to work-site wellness majors. Journal of the American Dietetic Association, 90(6), 854-856.

Gambera, P.J., Schneeman, B.O., \& Davis, P.A. (1995). Use of the food guide pyramid and U.S. dietary guidelines to improve dietary intake and reduce cardiovascular risk in active-duty air force members. Journal of the American Dietetic Association, 95(11), 1268-1273.

Glanz, K., Patterson, R. E., Kristal, A. R., DiClemente, C. C., Heimendinger, J., Linnan, L., \& McLerran, D. F. (1994). Stages of change in adopting healthy diets: Fat, fiber, and correlate of nutrient intake. Health Education Quarterly, 21(4), 499519. 
Greene, G. W., Rossi, S., Reed, G. R., Willey, C., \& Prochaska, J. O. (1994). Stages of change for reducing dietary fat to $30 \%$ of energy or less. Journal of the American Dietetic Association, 94, 1105-1110.

Guenther, P.M., Juan, W., Reedy, J., Britten, P., Lino, M., Carlson, A., et al. (2007a). Diet quality of Americans in 1994-96 and 2001-02 as measured by the healthy eating index, Nutrition insight. (Center for Nutrition Policy and Promotion, U.S. Department of Agriculture). Retrieved from http://www.cnpp.usda.gov/Publications/NutritionInsights/Insight37.pdf

Guenther, P.M., Reedy, J., Krebs-Smith, S.M., Reeve, B.B., \& Basiotis, P.P. (2007b). Development and evaluation of the healthy eating index-2005: Technical report. Center for Nutrition Policy and Promotion, U.S. Department of Agriculture. Retrieved from http://www.cnpp.usda.gov/HealthyEatingIndex.htm.

Hebert, J. R., Ebbeling, C. B., Ockene, I. S., Ma, Y., Rider, L., Merriam, P.A., et al. (1999). A dietician-delivered group nutrition program leads to reduction in dietary fat, serum cholesterol, and body weight: The worchester area trial for counseling in hyperlipidemia. Journal of the American Dietetic Association, 99(5), 544-552.

Hentges, E. (2006). Foreword. In Development of MyPyramid. J Nutr Educ Behav, 38: S77. Retrieved from http://www.cnpp.usda.gov/Publications/MyPyramid/DevelopmentMaterials/JNEB supplement/JNEBForeword.pdf

Kopp, S. D. \& Young, J. C. (2003). Abstract: College students’ knowledge of basic nutrition information. Research Quarterly of Exercise Science, Supplement, March; a-17. 
Kristal, A. R., Glanz, K., Curry, S., \& Patterson, R. E. (1999). How can stages of change be best used in dietary interventions? Journal of the American Dietetic Association, 99(6), 679-684.

Kushner, R. F. (1995). Barriers to providing nutritional counseling by physicians: A survey of family care practitioners. Preventative Medicine, 20,197-212.

Ling, A. \& Horwath, C. (2000). Defining and measuring stages of change for dietary behaviors: Readiness to meet fruit, vegetable, and grain guidelines among Chinese Singaporeans. Journal of the American Dietetic Association, 100, 898904.

Main, F. \& Wise, A. (2002). Relationship between knowledge and claimed compliance with genuine and false nutrition messages. Journal of Human Nutrition and Dietetics, 15, 349-353.

McCullough, M. L., Karanja, N. M., Lin, P., Obarzanek, E., Phillips, K. M., Laws, R. L., et al. (1999). Comparison of 4 nutrient databases with chemical composition data from the Dietary Approaches to Stop Hypertension trial. Journal of the American Dietetic Association, 99(8), S45-S53.

National Center for Chronic Disease Prevention and Health Promotion. (2008). Preventing obesity and chronic diseases through good nutrition and physical activity. (U.S. Department of Health and Human Services). Retrieved on October $1^{\text {st }}, 2008$ at http://www.cdc.gov/nccdphp/publications/factsheets/prevention/obesity.htm National Center for Health Statistics (2005). Fast stats- death and 
mortality. (CDC Publication for Deaths: Final Data 2005). Retrieved November 24, 2008 from http://www.cdc.gov/nchs/fastats/deaths.htm.

Nitzke, S., Auld, G., McNulty, J., Bock, M., Bruhn, C., Gabel, K., et al. (1999). Stages of change for reducing fat and increasing fiber among dieticians and adults with a diet-related chronic disease. Journal of the American Dietetic Association, 99(6), 728-730.

Oenema, A. \& Brug, J. (2003). Feedback strategies to raise awareness of personal dietary intake: Results of a randomized controlled trial. Preventative Medicine, 36, 429-439.

Prochaska, J. O., Velicer, W. F., Rossi, J. S, Goldstein, M. G., Marcus, B. H., Rakowski W., et al. (1994). Stages of change and decisional balance for 12 problem behaviors. Health Psychology, 13(1), 39-46.

Proper, K. I., Hildebrandt, V. H., Van der Beek, A. J., Twisk, J., \& W. R., Mechelen, W.V. (2003). Effect of individual counseling on physical activity, fitness and health. American Journal of Preventive Medicine, 24(3), 218-226.

Rash, C. L., Malinauskas, B. M., Duffrin, M. W., Barber-Heidal, K., Overton, R. (2008). Nutrition - related knowledge, attitude, and dietary intake of college track athletes. The Sport Journal, 11(1). Retrieved from http://www.thesportjournal.org/article/nutrition-related-knowledge-attitude-anddietary-intake-college-track-athletes

Rosal, M. C., Ebbeling, C. B., Lofgren, I., Ockene, J.K.,Ockene, I. S., \& Hebert, J. R. (2001). Facilitating dietary change: The patient-centered counseling model. The Journal of the American Dietetic Association, 101(3), 332-340. 
Rosenbloom, C. A., Jonnalagadda, S. S., \& Skinner, R. (2002). Nutrition knowledge of collegiate athletes in a division one national athletic association institution. The Journal of the American Dietetic Association, 102(3), 418-420.

Sigman-Grant, M. (1996). Stages of change: A framework for nutrition interventions. Nutrition Today, 31(4), 162-170.

Snetselaar, L. (2001). Counseling for Change. In: L. K. Mahan \& S. Escott-Stump (Eds.), Food, nutrition, \& diet therapy (pp. 452-462). Philadelphia, PA: W. B. Saunders Company.

Tapsell, L., Brenninger, V., Barnard, J. (2000). Applying conversation analysis to foster accurate reporting in the diet history interview. Journal of the American Dietetic Association, 100(7), 818-824.

U.S. Department of Health and Human Services and U.S. Department of Agriculture. (2005). Background and Purpose of the Dietary Guidelines for Americans. In Dietary Guidelines for Americans, 2005 (Chapter 1). 6th Edition, Washington, DC: U.S. Government Printing Office. Retrieved from http://www.health.gov/dietaryguidelines/dga2005/document/html/chapter1.htm

U.S. Department of Health and Human Services. (2000). Healthy People 2010: The Cornerstone for Prevention. Retrieved from http://www.healthypeople.gov/Publications/Cornerstone.pdf

U. S. Department of Health and Human Services and U. S. Department of Agriculture. (2000). Nutrition and Your Health: Dietary Guidelines for Americans, fifth edition. Home and Garden Bulletin, No. 232. Retrieved from 
http://www.cnpp.usda.gov/Publications/DietaryGuidelines/2000/2000DGProfessi onalBooklet.pdf

Vallis, M., Ruggiero, L., Greene, G., Jones, H., Zinman, B., Rossel, S., et al. (2003). Stages of change for healthy eating in diabetes. Diabetes Care, 26(5); 1468-1474.

Variyam, J. N., Blaylock, J., Smallwood, D., Basiotis, P. P. (1998). USDA’s Healthy Eating Index and Nutrition Information. Technical Bulletin No. 1866.

Vallis, M., Ruggiero, L., Greene, G., Jones, H., Zinman, B., Rossel, S., et al. (2003). Stages of change for healthy eating in diabetes. Diabetes Care, 26(5); 1468-1474.

Welch, T., Nidiffer, M., Zager, K., \& Lyerla, R. (1992). Attributes and perceived body image of students seeking nutrition counseling at a university wellness program. Journal of the American Dietetic Association, 92(5),609-611.

Wilta, B., Stombaugh, I., \& Buch, J. (1995). Nutrition knowledge and eating practices of young female athletes. Journal of Physical Education, Recreation and Dance, 66(3), 36-41. 
Appendix A: Client Assessment Health Screening 
- All of the information provided in this questionnaire is confidential, and will not be released in any way that might identify you without your prior consent.

- Your participation may be limited due to your responses to items on this questionnaire.

- You are free to withdraw consent and stop participation at any time without penalty.

\section{Personal / Emergency Information}

Last Name

First Name

Middle Initial

Date of Birth

Age

Sex $(M / F)$

Mailing Address

City

State

Zip

Email Address

(

Home Phone

$\left(\frac{1}{W 0 r k}\right)$

Work Phone

Name of Emergency Contact

Relationship

Phone Number

Family Physician

)

Phone Number

\section{Medical History}

1. Do you know the date of your last medical examination?

Yes No

2. If you answered Yes, when was it? (month/year)

3. Have you had any surgeries, diseases, or injuries that could limit your physical activity?

Yes No

If you answered Yes, please describe each, including its date. 


\section{Present Medical Status}

1. Do you experience shortness of breath during light exertion?

Yes No

2. Do you experience any lasting pain or discomfort in your chest?

Yes No

3. Do you experience sudden tingling, numbness, or loss of feeling?

Yes No

If you answered Yes, please indicate the site(s).

a. Hands Arms Feet Legs Face Other

4. Do you know what your cholesterol and/or triglyceride concentrations are? Yes No If you answered Yes, please provide the information below.

a. Total Cholesterol $\mathrm{mg} / \mathrm{dL} \quad \mathrm{HDL}$ $\mathrm{mg} / \mathrm{dL} \quad \mathrm{LDL}$ $\mathrm{mg} / \mathrm{dL}$

b. Triglycerides $\mathrm{mg} / \mathrm{dL}$

How long ago did you have your cholesterol tested?

(Note: The Cal Poly Health Center provides cholesterol testing at minimal cost.)

5. Do you know what your fasting blood glucose concentration is?

Yes No

If you answered Yes, what is it? $\mathrm{mg} / \mathrm{dL}$

6. Do you have diabetes?

If you answered Yes, which form? (Circle one.) Type 1 Type 2

If you answered Yes, how are you controlling it? (Circle all that apply.)

a. Diet Exercise Oral Medication Insulin Other

Uncontrolled

7. If you are female, are you currently pregnant?

Yes No

If you answered Yes, when is your due date? (mm/yy)

8. Are there any other medical concerns you may have at the present time?

9. Please list any allergies you have, including food allergies or food intolerances. 
10. Please describe any prescription and/or over-the-counter medications (Tylenol, Advil, Nyquil, etc.), herbal, vitamin/mineral supplements, or other you are currently taking.
a. Name/Type
Dosage
Reason for Taking

\section{Family History}

1. Has anyone in your immediate family (mother, father, son, daughter, brother, sister) suffered any of the following?

Myocardial Infarction

Yes No

Sudden death

Yes No

Coronary bypass

Yes No

If you answered Yes to any of the items above, please describe each incident, including the individual's age at the time of the incident.

2. Indicate whether you have had any blood relatives with any of the following problems.

Check all that apply (for nutrition clients only).
- Cancer
口 Diabetes
- Heart disease
a High cholesterol
- High blood pressure
a Osteoporosis

3. Do you have any complaints about any of the following? Check all that apply (for nutrition clients only).
appetite
a Chewing/
- Sudden
- Constipation/
swallowing weight
change
Diarrhea
口 Indigestion 
Fitness Testing \& Prescription

Nutrition Assessment \& Consultation

\section{Lifestyle Considerations}

\section{Exercise habits}

1. Do you exercise on a regular basis?

Yes No

If you answered Yes, please describe your activities.

On average, how many minutes are your exercise sessions?

minutes

On average, how many sessions a week do you participate in? sessions

2. Does your occupation usually require you to be physically active?

Yes No

If you answered Yes, please rate the activity? (Circle one.) Light Moderate Heavy

3. Do you participate in recreational activities that require you to be physically active?

Yes No

If you answered Yes, please describe your activities.

\section{Stress}

1. How would you characterize the stress in your daily life? (Circle one.)

Low Moderate Heavy

2. How would you characterize your ability to deal with stress? (Circle one

Excellent Good Moderate Poor

\section{Smoking}

1. Have you ever smoked cigarettes?

Yes No

If you answered Yes, please answer the following questions.

Do you currently smoke?

Yes No 
Fitness Testing \& Prescription Nutrition Assessment \& Consultation

If you answered Yes,

how many years have you smoked?

how many cigarettes do you smoke on an average day?

If you answered No, when did you quit? (month/year)

\section{Nutritional habits}

1. Do you eat at regular times during the day?

Yes No

If you answered Yes, please circle all of the following that you usually eat during a typical day.

Breakfast

Midmorning snack

Lunch

Mid-afternoon snack

Dinner

After-dinner snack

2. Do you consider your eating habits to be generally healthy?

Yes No Briefly explain why you chose your answer.

3. Do you regularly consume caffeine or other stimulants?

Yes No

4. Have you consumed any caffeine or stimulants within the last $2 \mathrm{hr}$ ?

Yes No

5. Do you consume alcoholic beverages?

Yes No

If you answered Yes, how many alcoholic drinks do you consume in a typical week? drinks in a typical week

Note: The following questions need only to be answered by nutrition clients.

6. Do you follow a special dietary plan, such as low cholesterol, low sodium, vegetarian?

7. Are there certain foods you do not eat?

Yes No

If you answered yes, what are they? 
8. List foods you particularly like.

9. Who does the grocery shopping in your household?

10. Do you eat convenience foods daily?

Yes No

11. How often do you eat out? Where?

12. What changes would you like to make? Circle all that apply.

a. Improve my eating habits

b. Learn to manage my weight

c. Learn how much water to consume when exercising

d. Improve my cholesterol levels

e. Learn how to grocery shop

f. Have more energy

g. Feel better

h. Other

13. Have you made any food changes in your life you feel good about?

14. Who could support and encourage you to make these changes?

15. Please add any additional information you feel may be relevant to understanding your eating habits or nutritional health. 
16. Education interests (Check all that apply):
- Grocery shopping
a Food labels
- Eating out the healthy way
- Meal planning
- Ways to get fiber
- Snack foods
a Eating less fat
a Portion size
a Healthy recipes
口 Weight management
Other

Is there any health issue or behavior that has not been addressed on this questionnaire that might affect your ability to engage in exercise?

YES NO

If you answered Yes, please describe the issue or behavior.

The information I have provided is true and complete. I understand that my responses are confidential. My participation may be limited by my responses. I am free to withdraw my consent and stop participation at any time without penalty.

Client Name
Client Signature

Date
Fitness Specialist Name Fitness Specialist Signature
Date

FOR OFFICE USE ONLY

\begin{tabular}{|ll|}
\hline Height & in \\
Weight & $\mathrm{lb}$ \\
$\mathrm{BMI}$ & $\mathrm{kg}$ \\
$\mathrm{BP}$ & $\mathrm{kg}$ \\
$\mathrm{BP}$ & $\mathrm{mm} \mathrm{Hg}$ \\
\hline
\end{tabular}




\section{Guide for Fitness Consultants Conducting Nutrition Assessment}

Upon receiving the health screening questionnaire particular to Nutrition Assessment, please carefully observe each page paying close attention to the following questions:

\section{Health Screening/Nutrition Assessment Guide}

\begin{tabular}{|c|c|c|c|}
\hline Section & Questions & Special Notes & Help? \\
\hline \multirow{5}{*}{$\begin{array}{l}\text { Present Medical } \\
\text { Status }\end{array}$} & & & \\
\hline & $4 \& 5$ & Do they qualify as risk factors? & $\begin{array}{l}\text { ACSM } \\
\text { Guidelines }\end{array}$ \\
\hline & 6 & Have they seen a doctor? & \\
\hline & 8 & $\begin{array}{l}\text { Have they seen a doctor? } \\
\text { Are any nutrition related? }\end{array}$ & \\
\hline & 9 & $\begin{array}{l}\text { Have they seen a doctor/dietician? } \\
\text { Do they know what foods to avoid, etc? }\end{array}$ & \\
\hline \multirow[t]{3}{*}{ Health History } & & & \\
\hline & 2 & Who in their family? & \\
\hline & 3 & $\begin{array}{l}\text { Have they seen a doctor/dietician? } \\
\text { Foods that trigger? }\end{array}$ & \\
\hline \multirow{7}{*}{$\begin{array}{l}\text { Lifestyle } \\
\text { considerations } \\
\quad \text { Exercise habits }\end{array}$} & & & \\
\hline & $1 \& 2$ & $\begin{array}{l}\text { Determine their activity level - careful to } \\
\text { not overestimate }\end{array}$ & \\
\hline & 1 & $\begin{array}{l}\text { Are they missing meals? Enough that it } \\
\text { may be a red flag? }\end{array}$ & \\
\hline & 6 & Reason why? & \\
\hline & 7 & Reasons why? & \\
\hline & 12 & To better target information & \\
\hline & 15 & Anything interesting? & \\
\hline
\end{tabular}


Appendix B: Goal Sheet and Guide 


\section{Setting Goals} Contract with Yourself

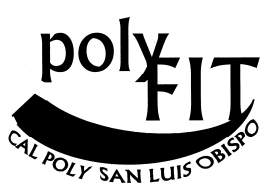

Name

Date

My first general goal is to

I am going to accomplish this goal by specifically

My second general goal is to

I am going to accomplish this goal by specifically

('Remember - what are you going to do, by how much, and by when)

Your signature

Date 


\section{Goal Setting}

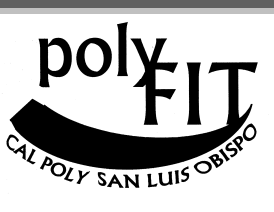

Specific. Be precise. Write down exactly what you expect to achieve.

Measurable. Include amounts, times, days, and other milestones for gauging success.

Achievable. Set your sights on an attainable goal, yet one that causes you to stretch, to go beyond what you're doing today.

Relevant. Although it's nice for your spouse, kids, boss, parents, and friends to want you to be successful, your goal should matter to you, first and foremost.

Trackable. Behavior change doesn't happen in a fell swoop - it takes time.

Record your progress over days or weeks to see how much you've achieved.

Some examples of SMART goals:

"Beginning Monday, June 11, I will pack my lunch each night before work."

"I will register for a 4-week healthy cooking class at our local community college 
Appendix C: Stage of Change Assessment Ruler and Guide 


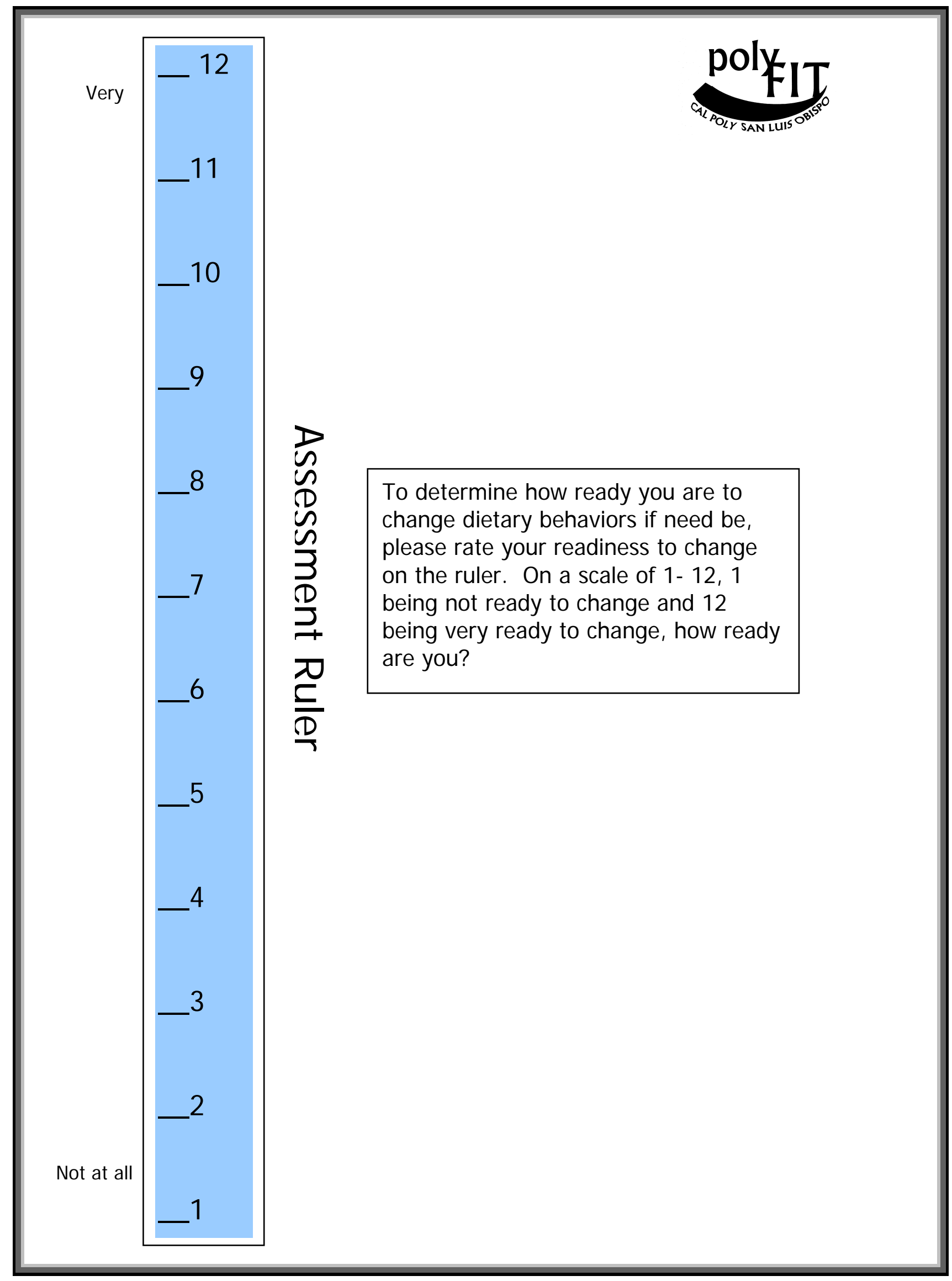




\section{Stages of Change Model for Behavior Change}

\section{poly/TIT}

This model attempts to explain behavior change as it passes through different stages of motivation. An individual can begin at any one of the motivational levels, which defines how ready they are to change a particular behavior. The stages of change model has been used to design and evaluate successful dietary change intervention.

Stages

* Level 1

o Ruler $=1-4$

o Not motivated or ready for change

- Educational goals:

- Raise awareness about the negative aspects of the unhealthy dietary behavior(s)

- Raise awareness of the impact healthy eating can have

- Raise awareness about the tools available to make eating healthy simple

- Generate healthy thinking

* Level 2

o Ruler $=5-8$

o Unsure about change, low confidence

- Educational goals:

- Personalize benefits of eating healthier

- Reduce confusion, provide straightforward and correct information

- Generate positive thinking and imagination

- Give knowledge

* Level 3

o Ruler $=9-12$

o Motivated, confident, ready to change

- Educational goals:

- Continue to personalize benefits

- Continue giving knowledge

- Skill building

- Goal setting

- Accountability 


\section{Guide to Healthy Eating}

Nutrition

Assessment \&

Consultation

Exercise Testing \&

Prescription

Special points of interest:

- D ietary Guidelines For A mericans

- The Food Guide Pyramid and suggested Food Patterns

- W hat is a Serving?

- W hat Does a Serving Look Like?

- Variety From the Food Groups

- Wh Choose...

- What is on a Food Label?

\section{Dietary Guidelines For Americans}

Eating should be one of life's great pleasures. A healthy diet can be enjoyable if you are aware of the many food choices that are out there and the ways to build a healthy lifestyle.

The following guidelines are for you to use to take action and promote your health and reduce your risk for chronic disease.

Check out the A, B, C's of nutrition for good health!

\section{Aim for fitness...}

Aim for a healthy weight

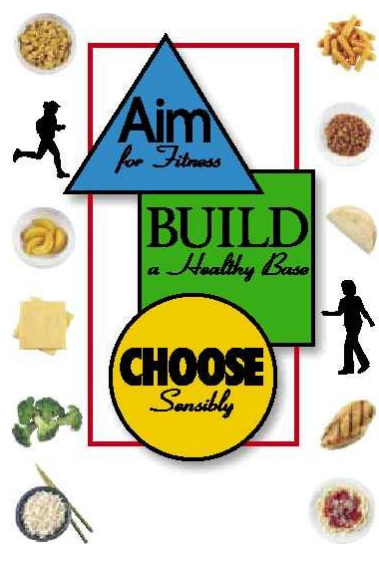

Balance the calories you eat with physical activity.

Be physically active each day

G et moving! Do 30 minutes or more of moderate physical activity on most days or every day. Make physical activity part of your daily routine.

\section{BUILD A HEALTHY BASE...}

Let the Pyramid guide your food choices.

Choose a variety of grains daily, especially whole grains.

Choose a variety of fruits and vegetables daily.

Keep food safe eat.

\section{CHOose SEnSibly...}

Choose a diet that is low is saturated fat and cholesterol and moderate in total fat

Choose beverages and foods to moderate your intake of sugars.

Choose and prepare foods with less salt

If you drink alcoholic beverages, do so in moderation

Adapted from the D epartment of Health and Human Service and Untied States D epartment of Agriculture, $\mathrm{N}$ utrition and Y our $\mathrm{H}$ ealth: D ietary G uidelines for A mericans found at http:/ / www.health.gov/ dietary guidelines/ 


\section{The Food Guide Pyramid}

A nutritious diet has these five characteristics.

Adequacy: the foods provide enough of each essential nutrient, fiber, and energy.

Balance: the choices do not overemphasize on nutrient or food type at the expanse of another.

Calorie control: the foods provide the amount of energy you need to maintain appropriate weight- not more, not less.

Moderation: the foods do not provide excess fat, salt, sugar or other unwanted constituents.

Variety: the foods chosen differ from one day to the next

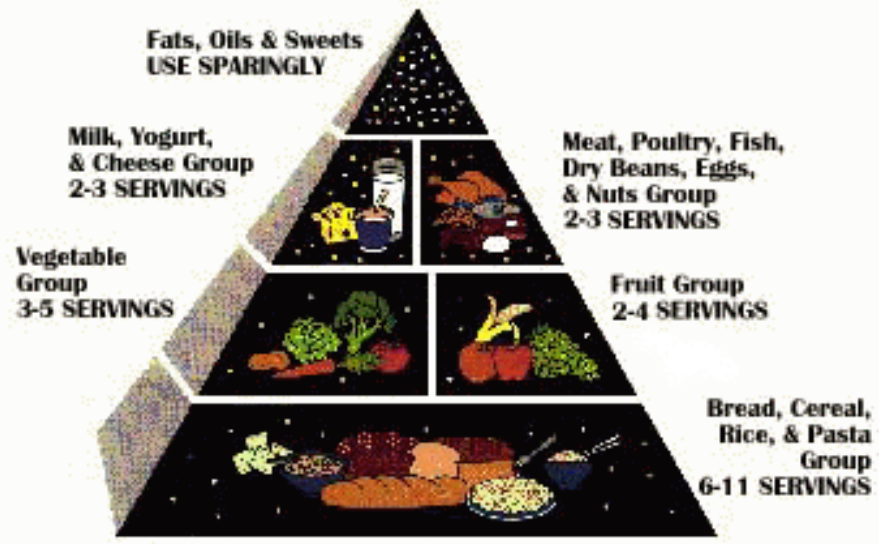

\section{Sample Food Patterns}

\begin{tabular}{|c|c|c|c|c|c|c|c|}
\hline \multicolumn{8}{|c|}{ Number of calories } \\
\hline & 1,600 & 1,800 & 2,000 & 2,220 & 2,400 & 2,600 & 2,800 \\
\hline $\begin{array}{l}\text { Bread } \\
\text { Group } \\
\text { Servings }\end{array}$ & 6 & 7 & $7-8$ & 9 & $9-10$ & 10 & 11 \\
\hline $\begin{array}{l}\text { Fruit Group } \\
\text { Serving }\end{array}$ & 2 & $2-3$ & $2-3$ & 3 & $3-4$ & $3-4$ & 4 \\
\hline $\begin{array}{l}\text { Vegetable } \\
\text { Group } \\
\text { Serving }\end{array}$ & 3 & $3-4$ & $3-4$ & 4 & $4-5$ & $4-5$ & 5 \\
\hline $\begin{array}{l}\text { Meat } \\
\text { Group } \\
\text { Serving }\end{array}$ & 5 ounces & 5 ounces & 5-6 ounces & 6 ounces & 6 ounces & 6-7 ounces & 7 ounces \\
\hline $\begin{array}{l}\text { Milk Group } \\
\text { Serving * }\end{array}$ & $2-3$ & $2-3$ & $2-3$ & $2-3$ & $2-3$ & $2-3$ & $2-3$ \\
\hline $\begin{array}{l}\text { Total fat ** } \\
\text { (grams) }\end{array}$ & 53 & 60 & 67 & 73 & 80 & 87 & 93 \\
\hline $\begin{array}{l}\text { Total added } \\
\text { sugars ** } \\
\text { (teaspoons) }\end{array}$ & 6 & 8 & 10 & 12 & 14 & 16 & 18 \\
\hline
\end{tabular}

How many servings do you need each day?

Children, ages 2 to 6 years, sedentary women, some older adults $=$ about 1,600 calories

Older children, teen girls, active women, most men $=$ about 2,220 calories

Teen boys, active men $=$ about 2,800 calories

*Keep in mind this a general guide.

* Women who are pregnant or breastfeeding, teenagers, and young adults to age 24 need 3 servings ** Values for total fat and added sugars include fat and added sugars include food choices that are in the five major food groups as well as fat and added sugars from foods in the Fats, Oils, and Sweets group 


\section{The Pyramid Guide To Daily Food Choices}

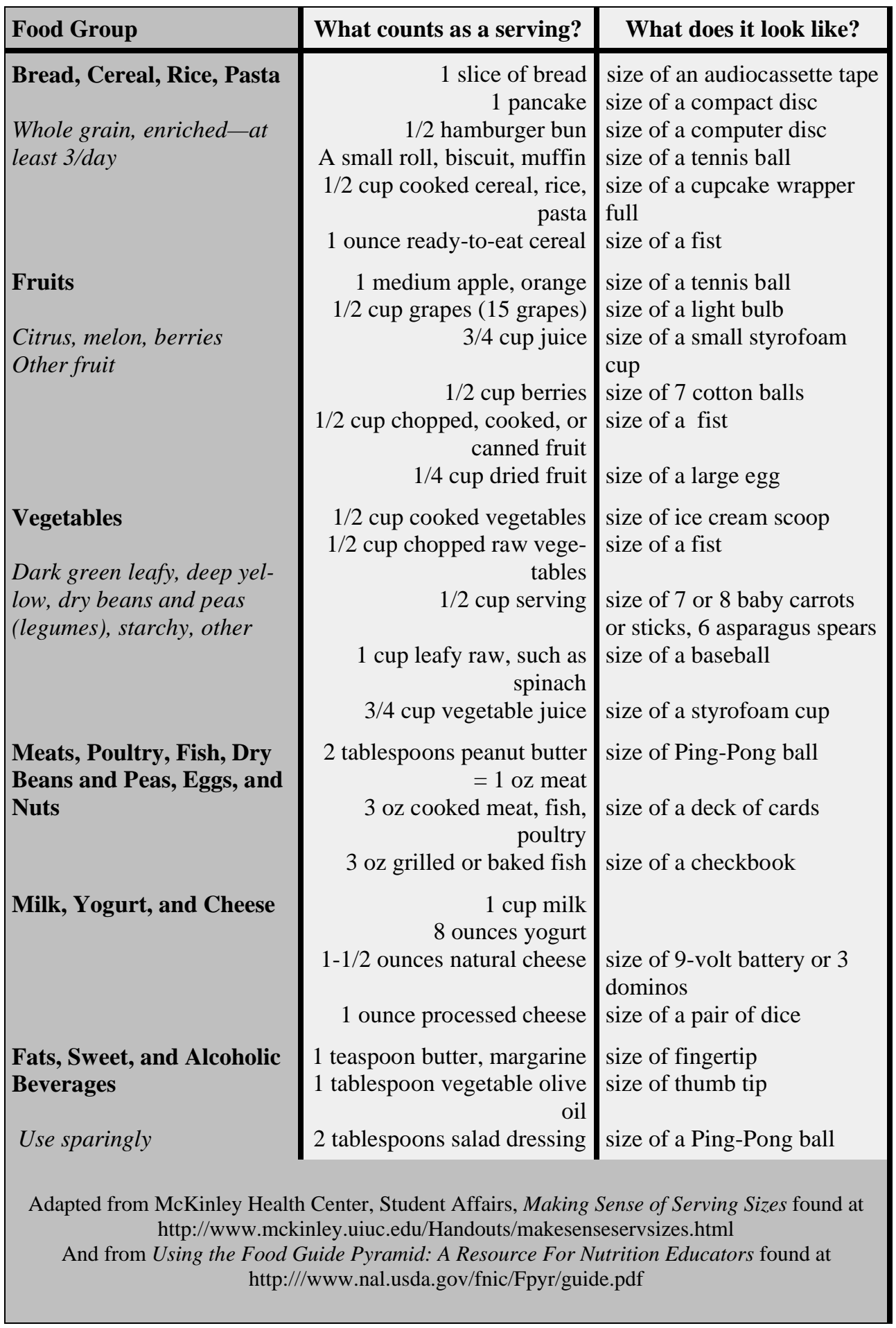

\section{Important!!}

$\mathrm{H}$ ands and finger

sizes vary from

person to

person...these are

guides only! 


\section{Variety From The Food Groups}

\begin{tabular}{|c|c|c|c|c|c|}
\hline \multicolumn{6}{|c|}{ Bread, Cereal, Rice, Pasta } \\
\hline \multicolumn{2}{|c|}{ Whole Grain } & \multicolumn{2}{|c|}{ Enriched } & \multicolumn{2}{|c|}{$\frac{\text { Grain Products with More Fat and }}{\underline{\text { Sugar }}}$} \\
\hline Brown rice & $\begin{array}{l}\text { Pumpernickel } \\
\text { bread }\end{array}$ & Bagels & $\begin{array}{l}\text { White bread \& } \\
\text { rolls }\end{array}$ & Biscuit & Danish \\
\hline Bulgur & $\begin{array}{c}\text { Whole grain ready } \\
\text {-to-eat } \\
\text { cereals }\end{array}$ & Cornmeal & Macaroni & Cake (unfrosted) & Doughnut \\
\hline Corn tortillas & $\begin{array}{l}\text { Rye bread \& } \\
\text { crackers }\end{array}$ & Crackers & English muffins & Cookies & Muffin \\
\hline Granola & $\begin{array}{l}\text { Whole wheat } \\
\text { bread }\end{array}$ & Flour tortillas & Noodles & Cornbread & Pie crust \\
\hline Oatmeal & $\begin{array}{l}\text { Whole-wheat } \\
\text { pasta }\end{array}$ & French bread & Rice & Croissant & Tortilla chips \\
\hline Popcorn & $\begin{array}{l}\text { Whole wheat } \\
\text { cereals }\end{array}$ & $\begin{array}{l}\text { Hamburger/hot } \\
\text { dog rolls }\end{array}$ & Spaghetti & & \\
\hline \multicolumn{6}{|c|}{ Fruits } \\
\hline \multicolumn{3}{|c|}{ Citrus, Melons, Berries } & \multicolumn{3}{|c|}{ Other Fruits } \\
\hline Blueberries & Honeydew & Strawberries & Apple & Guava & Pineapple \\
\hline Cantaloup & Kiwifruit & Tangerine & Apricot & Grapes & Plantain \\
\hline Citrus juices & Lemon & Watermelon & Asian pear & Mango & Plum \\
\hline \multirow[t]{5}{*}{ Cranberries } & Orange & Grapefruit & Banana & Nectarine & Prickly pear \\
\hline & Raspberries & & Cherries & Papaya & Prunes \\
\hline & & & Dates & Passion fruit & Raisins \\
\hline & & & Figs & Peach & Rhubarb \\
\hline & & & Fruit juices & pear & Star fruit \\
\hline \multicolumn{6}{|c|}{ Vegetables } \\
\hline \multicolumn{3}{|c|}{ Dark-Green Leafy } & Deep Yellow & \multicolumn{2}{|c|}{$\underline{\text { Starchy }}$} \\
\hline Broccoli & Romaine lettuce & Endive & Carrots & Corn & Lima beans \\
\hline Chard & Escarole & Chicory & Pumpkin & Potato & Green peas \\
\hline Kale & $\begin{array}{l}\text { Watercress } \\
\text { Spimach }\end{array}$ & Collard greens & $\begin{array}{l}\text { Sweet potato } \\
\text { Winter Squash }\end{array}$ & Hominy & Rutabaga \\
\hline \multicolumn{3}{|c|}{ Dry Beans and Peas (Legumes) } & \multicolumn{2}{|c|}{ Other Vegetables } & \\
\hline Black Beans & Lima beans & Artichoke & Cauliflower & Green pepper & Snow peas \\
\hline Black-eyed peas & $\begin{array}{l}\text { Chickpeas } \\
\text { (garbanzos) }\end{array}$ & Asparagus & Celery & Lettuce & Summer squash \\
\hline Pinto beans & Kidney beans & Beets & $\begin{array}{l}\text { Bean and alfalfa } \\
\text { sprouts }\end{array}$ & Radishes & Mushrooms \\
\hline Lentils & Navy beans & Brussels sprouts & Cucumber & Zucchini & Tomato \\
\hline & & Cabbage & Eggplant & Onions & Vegetable juices \\
\hline
\end{tabular}




\section{And More Variety!}

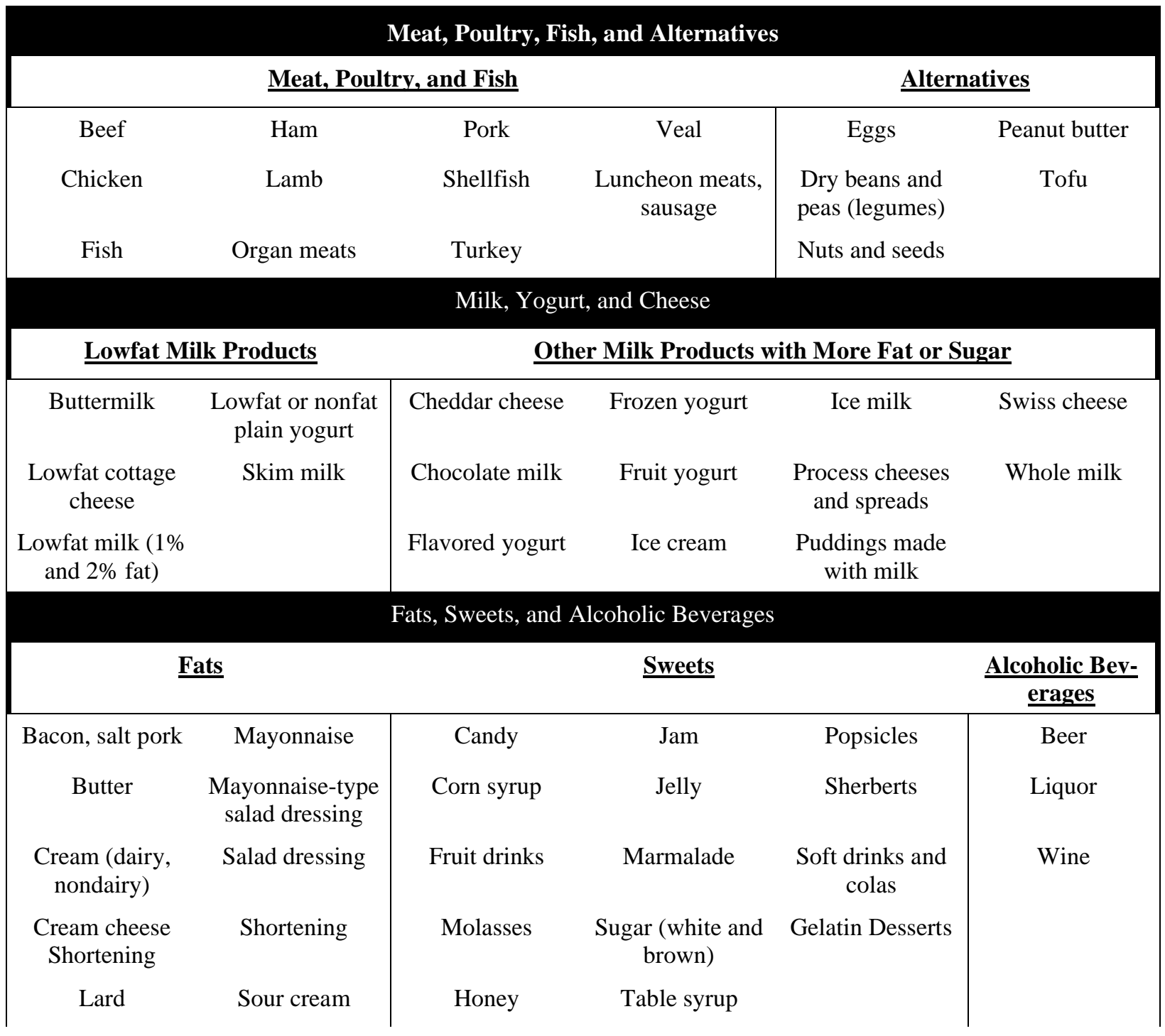

Be sure to choose a variety of foods from each of the food groups. Use these suggestions to create different combinations for meals and snacks. This will help you get all the nutrients you need to stay healthy and happy! Remember, variety is the spice of life! 


\section{Why Choose...}

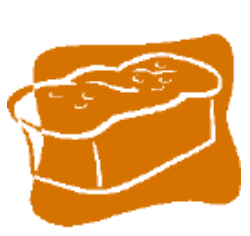

\section{Whole Grains?}

Vitamins, minerals and fiber accompany food that are made form whole grins like whole wheat, barley, oats, etc. These nutrients along with other protective substances are not found in refined grains such as white rice or white bread.. Eating foods that contain plenty of fiber, like whole grains will promote:

Proper bowel function

Felling of fullness with fewer calories

Protection against developing some chronic diseases

\section{Fnuits \& Vegetables?}

Like whole grains, fruits and vegetables provide essential vitamins and minerals, fiber and other protective substances that you can't get from other foods. Eating many different kinds of plant foods will get you closer to the proper amount of nutrients you need to promote good health.

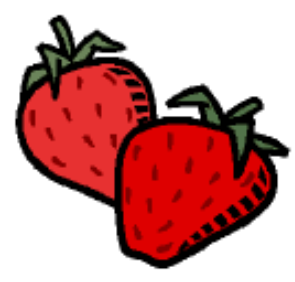

\section{Monounsaturated \& Polyunsaturated Fat?}

These types of fats are known as unsaturated fats and are found derived from plant sources such as vegetables oils, nuts and seeds. They are considered "good fats" and contain essential fatty acids that are necessary for proper health and functioning. They have also been linked to contributing to a healthy heart, whereas saturated fat and trans fatty acids, or the "bad fats" are linked to heart disease.

\section{Bottom Line...}

Use plant foods as the foundation of your meals. There are many ways to create a healthy eating pattern, but keep in mind that they all begin at the base of the pyramid, including grains, fruits and vegetables. Eating a variety of these foods is the basis of healthy eating. Enjoy meals that are based around whole grains, fruits and vegetables and then include a moderate amount of low-fat foods from the milk group and the meats and beans group. Remember, go easy on the foods high in fat and sugar. Choose monounsaturated and polyunsaturated fats over saturated and trans fatty acids.

Adapted from Adapted from the Department of Health and Human Service and Untied States D epartment of Agriculture, N utrition and Y our H ealth: D ietary G uidelines for A mericans found at http:/ / www.health.gov/ dietary guidelines/

And from the Harvard School of Public Health , Fats \& Cholesterol, found at http:/ / / www.hsph.harvard.edu/ nutritionsource/ fats.html

\section{Some I ast mi nutes suggestions...}

Eating should do more than fill you up. It's your source of energy throughout the day and affects most every other task you face. To get the most from the foods you eat, remember these pyramid pointers:

- Tiny top . The py ramid point is the smallest part because you need less of these foods. When it comes to fats, oils, and sweets, think small or not at all.

- 9:00 o'clock course. Use 3/ 4 of your plate - up to "9:00 o'clock" - for grains, vegetables, and fruits. The remaining $1 / 4$ can consist of foods from the top 2 layers of the pyramid.

- Portion distortion . A portion isn't a serving; it's often 2 or 3. For example, commercial bagels are at least 2 bread servings (sometimes 4!). Be careful you don't overeat because you're underestimating serving sizes.

- A little more often . Avoid becoming famished. D on't let yourself go more than 6 hours without eating keep low-fat snacks handy for late nights at work or a long commute home.

- Bottoms up . Make your food choices from the bottom 2 layers of the pyramid first. 


\section{What's On a Food Label?}

Serving size: Serving sizes are provided in familiar units, such as cups or pieces, followed by the metric amount, e.g., the number of grams. Serving sizes are based on the amount of food people typically eat, which makes them realistic and easy to compare to similar foods. This is the amount that constitutes a single serving and the portion that contains the nutrient amounts listed below. A serving of chips may be 10 chips, but if you eat 50 chips, you have consumed 5 times the amount of nutrients listed.

Servings per container: Number of servings or portions per box, can, package or other unit.

Calonies/ calories from fat: Total food energy per serving, and energy form fat per serving

Nutrient amounts and percentages of Daily Values: This section provides the core of information concerning these nutrients: Total fat, cholesterol, sodium, total carbohydrate, and protein. Notice that a breakdown of fat, specifically saturated fat, and a breakdown of carbohydrates, specifically fiber and sugar is provided.

Percentages of D aily Values for Vitamin A, Vitamin C, Calcium, and Iron must be stated and are given in terms of a person requiring 2,000 calories a day.

The \%DV shows you the percent (or how much) of the recommended daily amount of a nutrient is in a serving of food. By using the \% DV, you can tell if this amount is high or low. You, like most people, may not know how many calories you consume in a day, but use this as a reference of how much of a nutrient you are getting. A quick guide $t$ $0 \% \mathrm{DV}$ is $5 \% \mathrm{DV}$ or less is low and 20\%DV or higher is high.

Ingredients: The products ingredients must be listed in descending order of predominance by weight.

Remember when looking for whole grains, be sure that the first ingredient listed is a whole grain, such as whole wheat, oats, rye, etc. If it

1) start here says wheat flour or that the bread is wheat bread, it still may not be whole wheat. This

2) then here goes for juice as well. If the first ingredient is sugar or high fructose corn syrup, the juice is probably mostly

3) Look here next... the nutrients sugar instead of fruit juice.
Limit total fat, saturated fat, cholesterol, sodium, and sugars

Get enough fiber, Vitamin A \& C, calcium, and iron

Adapted from Center For Food Safety and Applied Nutrition found at http://vm.cfsan.fda.gov/ dms/foodlab.html and from Nutrition: Con cepts and Controversies by Sizer and Whitney.

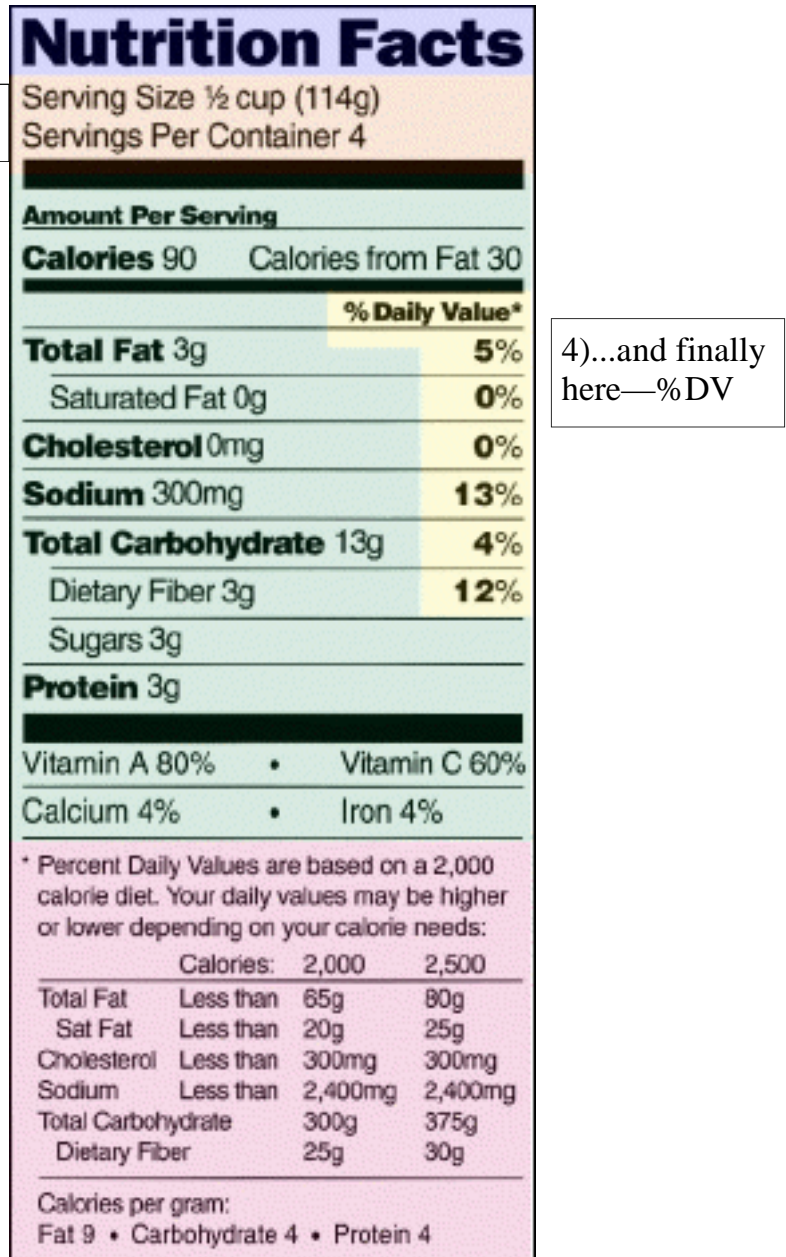




\section{A Little More Guidance}

\section{An Alternative Pyramid}

The Harvard School of Public Health has designed a food pyramid, the Healthy Eating Pyramid, that has gotten the attention of health professionals. Although it has not been accepted as a standard guide as the USDA's Food Guide Pyramid has, it has some interesting and noteworthy characteristics that are claimed to be based on the best dietary research available to date. Compare the two pyramidsand notice the differences.

\section{Healthy Eating Pyramid}
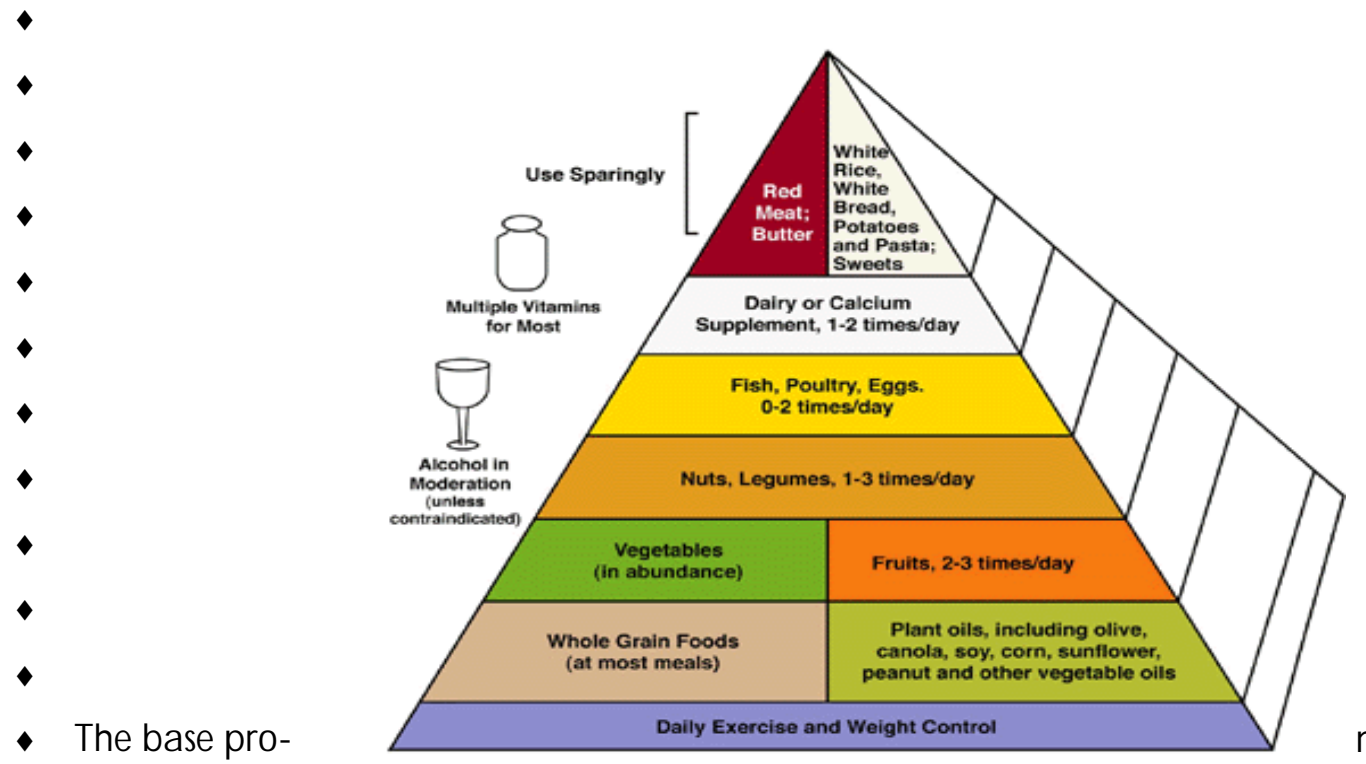

motes daily exer-

\section{Highlights of the Healthy Eating Pyramid}

cise and weight control.

- Whole grain foods are separated from more refined foods. The pyramid suggests whole grains should be part of most meals as they are found at the base, whereas white rice, white bread, pasta, etc., the more refined or processed foods are at the tip of the pyramid, indicating that they should be eaten sparingly

- Plant oilsare also at the base, indicating that fats are good to have...but notice what kind of fats are recommended-only those coming form plant foods. Foods that contain mostly saturated fat, such as animals products like red meat and butter are at the top of the pyramid suggesting that these should be consumed sparingly.

- There are more bricks or levels of the pyramid...notice what has been added or changed in the middle of the pyramid. Vegetables in abundance, nuts, and legumes have their own tier, as doesfish, poultry and eggs.

- A multi-vitamin is suggested and 12 drinks per day is suggested for good health.

Final note: The pyramid on the right (USDA's) is simpler to use, but be aware of the differences and the distinctions that are made between food groups. 


\section{The Goods, , and not as Goods!}

"GOOD FATS: Liquid oilsfound in most plants, as well as the fats in nuts, seedsand many fish.

Foods to Look For: fatty fish like salmon, mackerel, sardines, pecans, walnuts, almonds, etc; seeds, including sesame, sunflower, pumpkin; olives, avocados, plant oils including olive oil, peanut, canola, corn, soybean, and products made using these oils.

"NOT AS GOOD": Saturated animal fatsfound in meat and dairy products, and the trans fatty acidsfound in vegetable shortening, most margarines, and many processed foods (look for "partially hydrogenated" on the ingredient label).

Foods to Moderate: marbled red meats, full-fat dairy products such as butter; hydrogenated vegetable oils such asmargarine and other oils that are solid at room temperature; commercial deep fried foods, tropical oils such as coconut and palm oils.

"GOOD CARBS": Fruits, vegetables, bean and other legumes, and whole grains that are rich in fiber and nutrients and more sowly absorbed.

Foods to Look For: fruits and fibrous vegetables (the crunchy ones!) such as apples, melons, berries, greens, peppers, lettuce, carrots, cauliflower, beets, broccoli, asparagus, green beans, spinach; whole grain products such as whole wheat or oat bread, cereals, and pasta; brown and wild rice, oats, grains such barley, quinoa, millet.

"NOT AS GOOD": Sugary foodsand starches like many pastas, white bread, and potatoes that are quickly absorbed in our digestive system and quickly raise our blood sugar levels.

Foods to Moderate: sugared drinks such as soda, fruit juice; sugar, honey, molasses, syrups; refined white flour products like white bread, pretzels, pizza, bagels, white pasta, most cereals; starchy vegetables like potatoes and corn; white rice.

\section{Key Points}

Remember that there are always good foods and better foods...and they all have a place in a well-rounded, healthy diet. Being aware of those foods that can be consumed abundantly as well as those that should be consumed in moderation is one of the first steps to planning a healthy lifestyle. 


\section{Ways You Can Eat Healthier in the Next 30 Days}

Use these ideas (or create your own) to outline your daily strategy for achieving your goals.

- Snack on spoon-size shredded wheat or other whole-grain cereal

- Order a side vegetable as an appetizer when dining out

- Try to eat 1 cruciferous vegetable a day (broccoli, cabbage, cauliflower, Brussels sprouts, collards, kale)

- Choose romaine or loose-leaf lettuce for additional vitamin $C$ and beta carotene

- Snack on raw vegetables, including broccoli, carrots, celery, cucumber, zucchini, and cauliflower

- Eat frozen grapes, blueberries, or strawberries for a refreshing snack

- Drink skim or $1 \%$ milk

- Remove all visible fat from meat, chicken, and turkey before cooking

- Snack on assorted cut fruit - apple wedges, banana slices, melon balls, grapes, and grapefruit sections

- Broil, roast, stir-fry, steam, or poach instead of frying

- Substitute low-fat salad dressings for regular

- Select whole-grain products over processed

- Replace part or all of the meat with vegetables in casseroles, lasagna, meat loaf, stir-fry, pasta, and soup recipes

- Prepare a main dish using dried beans or legumes

- Substitute applesauce for the oil, margarine, or fat in baking recipes

- Drain browned hamburger and rinse with hot water to cut fat content in half

- Cook with olive or Canola oils

- Add canned pumpkin to soups, pancakes, bread, muffins, or cookies

- Select ready-to-eat cereals with 3-5 grams or more of fiber per serving and under 3 grams of fat

- Eat whole-grain pasta for a boost in complex carbohydrates and fiber

- Top waffles or pancakes with fresh fruit or warm applesauce

- Choose fruit or sherbet as dessert

- Have a breakfast shake of nonfat yogurt, fruit, and wheat germ

- Make salad dressings, sauces, and dips with nonfat yogurt

- Eat the skin of the potato for extra fiber, iron, potassium, and B vitamins

- Remove skin from poultry before cooking

- Drink 8 cups of water a day

- Switch to nonfat cream cheese, yogurt, sour cream, and cottage cheese

- Remove the fat from soups, stews, gravies, and sauces by refrigerating and then skimming the fat off the top

- Limit processed meats high in fat and sodium - hot dogs, bacon, salami, and bologna - to rare occasions. 


\section{Vitamins \& Minerals}

\section{The What, Why \& Where of Vitamins!}

\section{Vitamins:}

What?

- Essential for normal functioning of body

- Cannot be manufactured by the body

- Must be obtained from food and/or dietary supplements

- Crucial for growth, vitality, well-being.

Vitamin A \& Beta Carotene:

Why? Healthy eyes, skin and hair. Proper growth in children

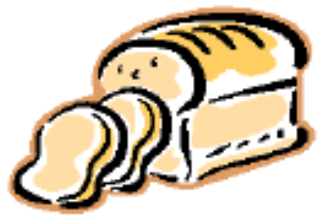

Where? Milk, eggs, dark green veggies, bright orange veggies, yellow veggies

Thiamin (B1):

Why? Healthy heart \& nervous system.

Where? Fish, meat, poultry, whole-grain cereals

Riboflavin (B2):

Why? Healthy skin, builds up body tissue

Where? Some cereal, green veggies, lean meats Niacin (B3):

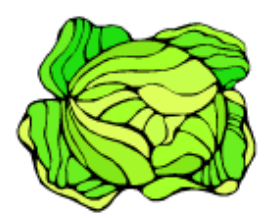

Why? Convertsfood into energy

Where? Some cereals, eggs, lean meats

Vitamin B6:

Why? Healthy teeth, gums, blood vessels, proper growth in children

Where? Whole grain cereals, broccoli, potatoes, bananas, some meats, poultry, fish

Vitamin BD:

Why? Healthy red-blood cells and nervous system, builds genetic material

Where? Lean meat, fish, oysters, eggs, milk

Vitamin C:

Why? Healthy teeth, gums, bones and blood vessels, strengthensimmune system

Where? Juices, citrus fruits, strawberries, green or red peppers, broccoli

Vitamin D:

Why? Strong bones \& teeth, help utilize calcium and phosphorus

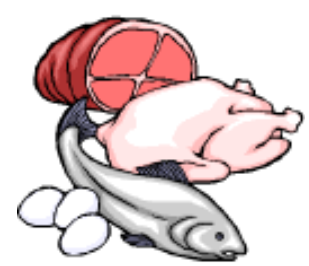

Where? Milk, salmon, tuna, egg yolk 


\section{The What, Why, \& Where of Minerals!}

\section{Minerals:}

\section{What?}

- Essential for normal functioning of body

- Cannot be manufactured by the body

- Must be obtained from food and/or dietary supplements

- Crucial for growth, vitality, well-being.

Calcium:

Why? Essential mineral-strong bones/teeth

Where? Milk, dairy products, broccoli, calcium fortified orange juice Chromium:

Why? Works with insulin for proper glucose metabolism

Where? Egg yolks, meat, whole grains

lodine:

Why? Proper functioning of thyroid gland

Where? Onions, seafood, salt Iron:

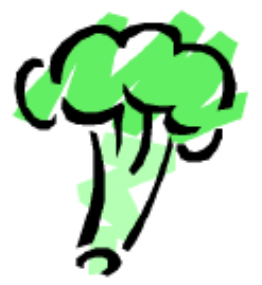

Why? Production of red blood cells, help to carry oxygen to body tissues, like muscles

Where? Red meat, seafood, \& fish, dried apricots dried beans, fortified

cereals

\section{Phosphorus:}

Why? Supports calcium to build \& maintain bone/teeth, also helps nervous system, helps convert food to energy

Where? Dairy products, egg yolks, meat, poultry, fish, legumes Potassium:

Why? Vital for muscle contractions \& nerve transmission, helps regulate fluid balance \& blood pressure, important for heart \& kidney functioning

Where? Milk \& yogurt, many fruits $\&$ vegetables, (esp.

oranges, bananas, potatoes)

Zinc:

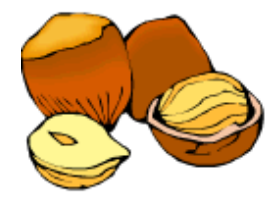

Why? Skeletal growth \& tissue repair

Where? Liver, beans, nuts, oysters

Adapted from McKinley Health Center, Student Affairs found at http://www.mckinley.uiuc.edu/Handouts/ vitaminmineral.html and from Stanford University found at

enhttp://www.stanford.edu/group/help/curriculum/Vitamin\%20Handout\%20and\%20 Nutrition\%20Quiz\%20

(Grades\%206,\%208\%20-\%202002).doc 


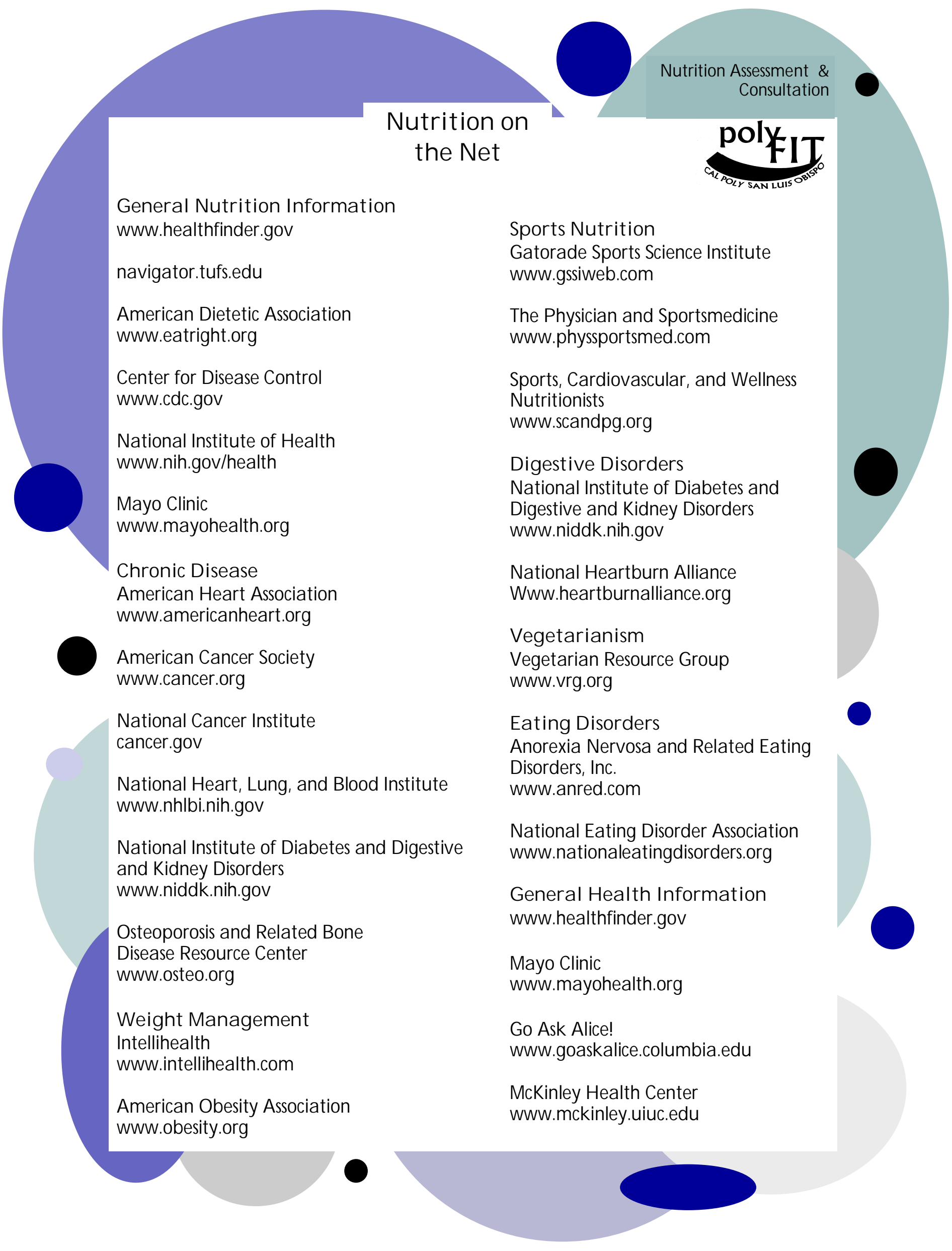




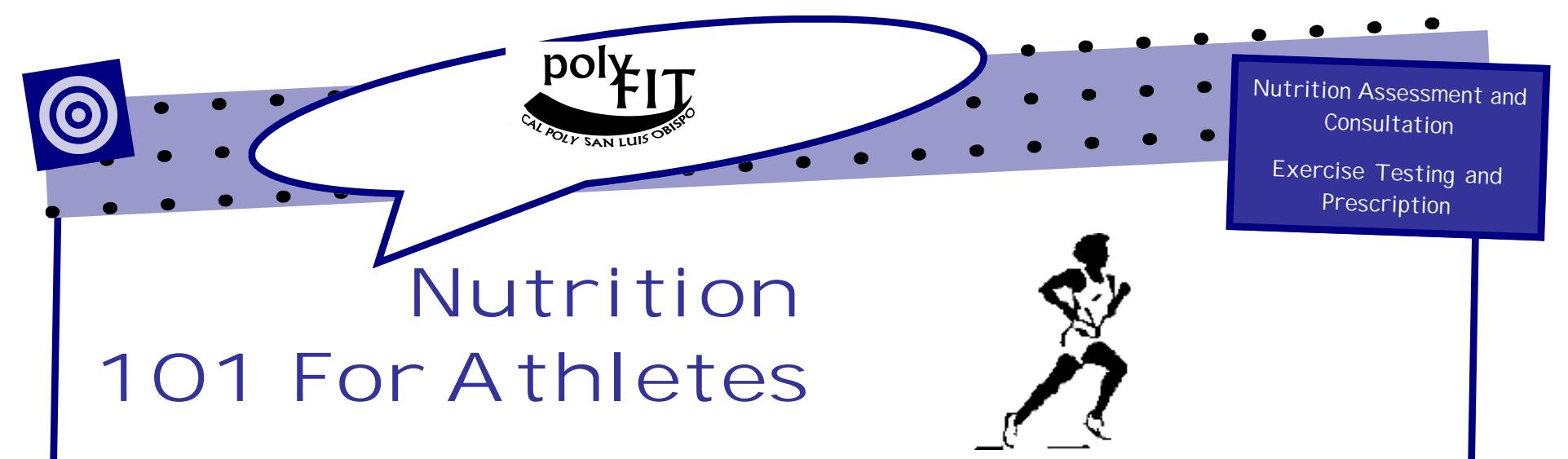

$\mathbf{N}$ utrition: "those properties of food that build sound bodies and promote health; a balanced diet containing adequate amounts of the essential nutritional elements that the body must have to function normally."

$\mathrm{N}$ utrition by any other name still means the same thing...nourishment, sustenance, FO OD! As an athlete, you know that nutrition plays a key role in your performance. But often, this component of training is misunderstood. There is a wealth of nutritional information out there and it can get pretty confusing.

\section{What is the best training diet?}

High or low carbohydrate? High or low protein? Low fat or no fat? 0 ne popular diet advises a dietary regimen of $40 \%$ carbohydrate, $30 \%$ protein, and $30 \%$ fat at each of three small meals (about 500 calories each) and two snacks (about 100 calories each) per day. Is this the best diet for optimum athletic performance? $\mathrm{W}$ ithout delving into a lot of scientific lingo, let's shed some light on these ideas.

By breaking down the daily requirements an athlete, both strength and endurance, should meet and the purpose of nutrients, it will become clear that the eating plan for an athlete is not that much different from the Guidelines for all Americans. Athletes just have to be more careful that they are eating properly. W hat is proper eating...well, let's find out.

\section{0 \\ Energy Requirements...Calories}

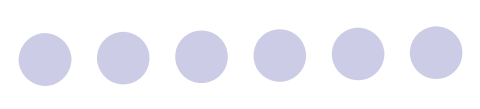

This is the number one concern for athletes. Achieving energy balance is essential for maintaining lean tissue or muscle mass, immune and reproductive function and optimum performance.

\section{Energy balance: Energy in = energy out}

If the athlete does not take in enough calories, lean tissue may be burned for fuel, thus a loss of muscle along with strength and endurance may occur.

To be sure that your energy needs are met, follow these general guidelines:

Endurance. Normally active people participating in activities such as running, biking, etc. are encouraged to consume $37-41 \mathrm{kcal} / \mathrm{kg}$ body weight per day ( $1 \mathrm{~kg}=2.2 \mathrm{lbs}$ ).

Resistance trained. Although resistance training does not require as much energy as endurance exercise, the needs of athletes participating in strength training have energy needs similar to those endurance athletes because of increased body size and high levels of fat-free mass. If an increase in lean body mass is the goal, strength athletes may need to consume 44 to $50 \mathrm{kcal} / \mathrm{kg}$ body weight per day. 


\section{Carbohydrates...}

The favored fuel for exercise. It is stored in the form of glycogen in your muscles and liver glycogen. You cannot train or compete well on a low carbohydrate, low calorie diet. You need to eat enough calories and carbohydrate to maintain muscle and liver glycogen stores. W hen your muscle glycogen is depleted, you "hit the wall" and feel overwhelmingly fatigued and ready to quit. W hen your liver glycogen is depleted you "bonk" (feel uncoordinated, light-headed, weak, unable to concentrate) because inadequate glucose is available to the brain. The bottom line is that the majority of your diet should come from carbohydrate sources to insure adequate fuel for training. The purpose of carbohydrates is to maintain blood glucose levels during exercise so as to continue and to replace muscle glycogen. The amount required depends upon the athlete's energy requirements for the day, the type of sport performed, sex of the athlete and environmental conditions.

All athletes. Recommendations range from $6-10 \mathrm{~g} / \mathrm{kg}$ body weight. A rough estimate might be $60-70 \%$ of total calories consumed.

\section{Protein}

Contrary to popular belief, exercise, not extra dietary protein, builds muscle. Today's popular high protein diets will not provide enough carbohydrate to fuel your muscles to allow you to exercise hard enough to meet your potential. A diet too high in protein may make you too full to eat adequate amounts of carbohydrate to fuel your muscles. High protein diets may also promote dehydration through excess urination when waste products from protein metabolism are excreted. Finally, a high protein intake may promote a high fat intake, because many high protein foods are also high in fat. Protein repairs the damage done to muscle fibers during exercise, supplies a very small amount of energy and supports gains in lean tissue or muscle mass. The amount of protein necessary depends upon the type of exercise, albeit endurance or resistance, intensity and duration of activity and maybe the sex of the participant.

Endurance. Athletes involved in endurance activities are recommended to consume $1.2 \mathrm{~g} / \mathrm{kg}$ body weight of protein daily.

Resistance. For strength athletes and bodybuilders, it is recommended that they consume $1.6-1.7 \mathrm{~g} / \mathrm{kg}$ body weight daily to increase and maintain muscle mass.

\section{Fat}

How much fat do you need? Most athletes tend to err on the conservative side when it comes to fat. W e avoid it like we avoid missing a workout. Fat has become the bad guy. Just about any food these days is available in a "fat free" version. Truth is, our bodies need some fat. A diet too low in fat can impair exercise performance. Fat is an essential part of hormones, cell membranes, and the nervous system and is needed for the absorption of fat soluble vitamins $A, D, E$, and $K$. Perhaps the most obvious function of fat in your diet is that it makes you feel full and satisfied after eating. W ithout some fat in your diet, you may feel hungry all the time.

O f course, as research has shown, the long term effects of a high-fat diet are less than appealing relative to health, however, too little fat can have negative effects on health, and there has been no proof a very low fat diet, less than $15 \%$ benefits performance.

All athletes. For optimal performance, about $30 \%$ of calories should come from fat. The breakdown is as follows:

$10 \%$ saturated, $10 \%$ polyunsaturated, $10 \%$ monounsaturated 


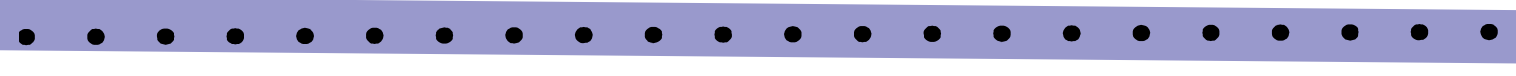

\section{Vitamins \& Minerals}

These micronutrients play many different roles in the body all of which are very important. Any type of exercise may alter or increase the needs of these nutrients due to biochemical adaptations, increased turnover and/or repair and maintenance of lean tissue. If consuming adequate energy from a variety of foods, there may not be any need for supplementation. If an athlete is

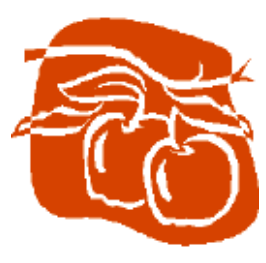
on an energy restricted diet, eliminating one or more food groups from the Food G uide Pyramid, or consuming a high-carbohydrate, low micronutrient dense diet may be at risk for deficiencies in certain micronutrients.

B-complex: The B-vitamins include thiamin, riboflavin B-6, niacin, pantothenic acid biotin, folate and B-12. These are involved in producing energy, production of red blood cells, protein synthesis and tissue repair and main tenance. Athletes or those who exercise may need to consume up to twice the recommendation which is usually met by the proper energy intakes that athletes already consume..

Antioxidants: Vitamins $A, E$, and $C$, beta carotene and selenium play an important role in protecting the cells from oxidative damage that may lead to cancer. A balanced diet that exhibits variety is probably sufficient for meeting recommended intakes. Those at risk may be athletes consuming a low fat diet, restricting energy intakes, or limiting fruits and vegetables.

Calcium, iron, zinc: Low intakes of these nutrients may result from restricting energy intakes or avoiding animal products such as meat, fish, poultry, and dairy products.

Note: Be aware that increasing protein intake to amounts greater than recommended is unlikely to result in additional increases in lean tissue because there is a limit to the rate at which tissue can be devel oped.

\section{Food is Fuel}

But food is also pleasure. Your body is pretty smart. If you eat a variety of wholesome foods most of the time, then you can afford to fit in your favorite dessert or gooey treat occasionally. All foods can fit into your diet. There is no such thing as a "good" or "bad" food, only better food choices. If you fuel your body properly, then it will be better equipped to help you meet your athletic potential.

Now let's put this in more practical terms.

The average calorie needs for a competitive endurance athlete training about seven hours a week is at least 3500 calories for a male and 2800 calories for a female. This is a general guideline, so don't worry about counting calories. Be more concerned with getting a balanced intake of a variety of healthful foods. $0 \mathrm{n}$ the following page is a sample 3000 calorie training diet to give you an idea of the appropriate amount of food to eat to keep you well-fueled for optimum performance. D epending on your calorie needs, add or take away foods if necessary. Remember, this is only a sample meal plan... use this as a guide to create your own food combinations.

The best training diet is composed of $60-70 \%$ carbohydrate, $10-20 \%$ protein, and $20-25 \%$ fat. Although supple-

\section{What does all this mean?}

ments may be convenient, there is no need to consume fancy protein powders or supplements. Save your money and spend it on good, healthful food. Eat plenty of whole grain breads, cereal, rice, pasta, potatoes, and fresh fruits/vegetables for carbohydrates; dried beans/peas, lean meats, and low fat dairy products for protein; and moderate amounts of fat from primarily unsaturated sources (olive/canola/peanut oils, nuts/seeds, avo cados, light margarine/salad dressing). And remember to drink plenty of non-caffeinated fluids.

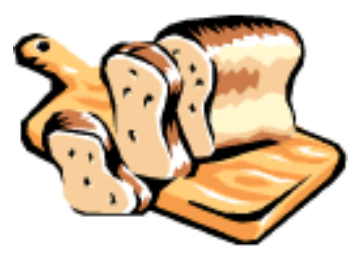




\section{Sample meal plan...}

\section{Breakfast:}

2 cups whole grain cereal

1 cup skim milk

1 slice whole wheat toast

1 Tbsp. Light Margarine \& 1 Tbsp. Jam

1 cup orange juice

1 banana

\section{M orning Snack:}

1 cup plain low-fat yogurt

1 cup strawberries sprinkled with 1 tsp sugar

2 graham cracker sheets

\section{Lunch:}

Turkey Sandwich-

2 slices whole wheat bread

3 ounces turkey

1 Tbsp. Light Mayonnaise

Lettuce and tomato

1 ounce baked chips or pretzels

1 cup grapes

1 cup raw baby carrots

\section{Afternoon Snack:}

1 cup skim milk

3 fig cookie bars

\section{Dinner:}

1.5 cups cooked pasta

1 cup to mato sauce mixed with $1 / 2$ cup cottage cheese

4 Tbsp Parmesan Cheese

3 cups mixed vegetable salad

2 Tbsp Light Salad D ressing

1 slice Garlic Bread

\section{Evening Snack:}

1 cup Light Frozen Yogurt

Total Calories: 3000

Total CHO : $475 \mathrm{~g}$ ( 63\% kcals)

Total fat: $72 \mathrm{~g}(\sim 22 \% \mathrm{kcals})$

Total pro: $116 \mathrm{~g}(\sim 15 \%$ kcals

Adapted from Sports, Cardiovascular and W ellness N utritionists, A Practice Group of the American Dietetic Association found at http://www.scandpg.org/nutr_info/ nutrition101.html\#protein

And The American Dietetic Association, D ieticians of C anada, and The American College of Sports Medicine- Position Statement on N utrition and Athletic Performance 


\section{Carbohydrate Loading}

NUTRITION

ASSESSMENT \&

CONSULTATION

FITNESS TESTING \& PERSCRIPTION

\section{What is carbohydrate loading?}

Carbohydrate loading is a strategy involving changes to training and nutrition that can maximise muscle glycogen (carbohydrate) stores prior to endurance competition. The technique was originally developed in the the late 1960 's and typically involved a 3-4 day 'depletion phase' and a 3-4 day 'loading phase'. Ongoing research hasallowed the method to be refined so that modern day carbohydrate loading is now more manageable for athletes.

\section{Does carbohydrate loading improve performance?}

Muscle glycogen levels are normally in the range of 3-4 grams per pound of body weight. Carbohydrate loading enables muscle glycogen levels to be increased by 50-100\%. This extra supply of carbohydrate has been demonstrated to improve endurance exercise by allowing athletes to exercise at their optimal pace for a longer time. It is estimated that carbohydrate loading can improve performance over a set distance by $2-3 \%$.

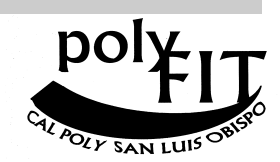

Anyone interested in sport is likely to have heard of the term 'carbohydrate loading'. However it is probably one of the most misunderstood terms in sports nutrition. People commonly think anyone involved in sport needs to 'carb up' and the way to do this is to eat 'flat out' in the days leading up to an event. Read on to get the facts on carbohydrate loading.

\section{Who should carbohydrate load?}

Anyone exercising continuously for 90 minutes or longer is likely to benefit from carbohydrate loading. Typically, sports such as cycling, marathon running, longer distance triathlon, crosscountry skiing and endurance swimming benefit from carbohydrate loading. Shorter term exercise is unlikely to benefit as the body's usual carbohydrate storesare adequate. Carbohydrate loading is generally not practical to achieve in team sports where gamesare played every 3-4 days. Although it might be argued that players in soccer and AFL have heavy demands on their muscle fuel stores, it would be impossible to achieve a full carbohydrate protocol within the weekly schedule of training and games. 


\section{How was carbohydrate loading originally achieved?}

Originally, carbohydrate loading involved a depletion phase. This required 3-4 hard training days plusa low carbohydrate diet. The depletion phase wasthought to be necessary to stimulate the enzyme glycogen synthase. The depletion phase wasfollowed by a loading phase which involved 3-4 days of rest combined with a high carbohydrate diet. The extra carbohydrate combined with the now-activated glycogen synthase was shown to boost carbohydrate stores beyond their usual resting levels.

\section{How do modern day athletes carbohydrate load?}

Today's endurance athletes use a modified carbohydrate loading method. Ongoing research has demonstrated that the depletion phase is no longer necessary. This is a bonus for athletes as the depletion phase was very difficult. Australian marathon runner, Steve Moneghetti has described the depletion phase as making him feel like "death warmed up". Today, 3-4 days of exercise taper while following a high carbohydrate diet ( $3-5 \mathrm{~g} / \mathrm{lb}$ body weight) is sufficient to elevate mus cle glycogen levels.

\section{How do modern day athletes carbohydrate load?}

The following diet is suitable for a $70 \mathrm{~kg}$ athlete aiming to carbohydrate load.

Breakfast 3 cups of low-fibre breakfast cereal with $\mathbb{1} / 2$ cups of reduced fat milk 1 medium banana $250 \mathrm{ml}$ orange juice

Snack toasted muffin with honey $500 \mathrm{ml}$ sports drink

Lunch $\quad 2$ sandwiches (4 sices of bread) with filling as desired $200 \mathrm{~g}$ tub of low-fat fruit yoghurt $375 \mathrm{ml}$ can of soft drink

Snack banana smoothie made with low-fat milk, banana and honey cereal bar

Dinner $\quad$ lcup of pasta sauce with 2 cups of cooked pasta 3 sices of garlic bread 2 glasses of cordial

Late snack toasted muffin and jam $500 \mathrm{ml}$ sports drink

This sample carbohydrate loading meal plan provides roughly 3,400 kcal, 590 grams of carbohydrate, $\mathbf{2 5}$ grams of protein and 60 grams of fat. 


\section{Are there any special considerations for females?}

Most studies of glycogen storage have been conducted on male athletes. However, some studies suggest that females may be less responsive to carbohydrate loading, especially during the follicular phase of the menstrual cycle. Further research needs to be conducted specifically on females.

\section{What are the common mistakes made when carbohydrate loading?}

Research indicates that many athletes who attempt to carbohydrate load fail to achieve their goal. The method sounds simple, so what are so many athletes doing wrong? The most common mistakes are outlined below:

- Carbohydrate loading requires an exercise taper. Athletes can find it difficult to back off and not train hard for 3-4 days before competition. Failing to rest will compromise carbohydrate loading.

- Many athletes fail to eat enough carbohydrate. It sounds easy to increase your carbohydrate intake but many athletes fall short of the mark. It seems athletes don't have a good understanding of the amount of food required to carbohydrate load. Working with a sports dietitian or using a carbohydrate counter can be useful.

- In order to consume the necessary amount of carbohydrate, it is necessary to cut back on fibre and make use of compact sources of carbohydrate such as sugar, cordial, soft drink, sports drink, jam, honey, jelly and tinned fruit. Athletes who include too many high fibre foods in their carbohydrate loading menu may suffer stomach upset or find the food too bulky to consume.

- Carbohydrate loading will most likely cause body mass to increase by approximately $2 \mathrm{~kg}$. This extra weight is due to extra muscle glycogen and water. For some athletes, a fear of weight gain may prevent them from carbohydrate loading adequately.

- Athletes commonly use carbohydrate loading as an excuse to eat everything and anything in sight. Consuming too many high fat foods will make it difficult to consume sufficient carbohydrate. It may also result in gain of body fat. It is important to stick to highcarbohydrate, low- fat foods while carbohydrate loading.

\section{Carbohydrate Counter}

\section{Each of the following suggestions provide approximately 50 grams of carbohydrates}

\section{Cereals}

Wheat biscuit cereal (e.g. Weetabrix)

Light breakfast cereal (Cornflakes, Wheaties, etc.)

Rolled oats
5 biscuits

2 cups

1cup 


\section{Carbohydrate Counter Continued ...}

\section{Cereals}

Rice

1cup

Pasta or noodles

113 cups

Bread

3 sices of white or 2 thick whole grain

Bread Rolls

1large, 2 medium

Pita

2 pita

English muffin

2 full muffins

Pancakes

2 medium

scones

3 medium

Fruit

Fruit packed in heavy syrup

$11 / 3$ cups

Fruit packed in light syrup

2 cups

Fresh fruit salad

2.5 cups

Bananas

2 medium-large

Mangos, pears, grapefruit and other large fruit

$2-3$

Oranges, apples and other medium size fruit

3-4

Nectarines, apricots and other small fruit

12

Grapes

2 cups

Melon

6 cups

strawberries

12 cups

Raisins

4 tablespoons

Dried apricots

22 halves

\section{Vegetables and Legumes}

Potato

1very large or 3 medium

Sweet potato

2.5 cups

Lentils

2 cups

Soy beans, kidney beans

2 cups

Dairy Products and Desserts

Diet yogurt, natural yogurt

3 containers

Flavored non-fat yogurt

15 containers

Rice pudding

15 cups

Milk

1 liter

Sugars and confectionery

Jam

3 tbsp

Honey

3 tbsp

Jellybeans

$60 \mathrm{~g}$ 


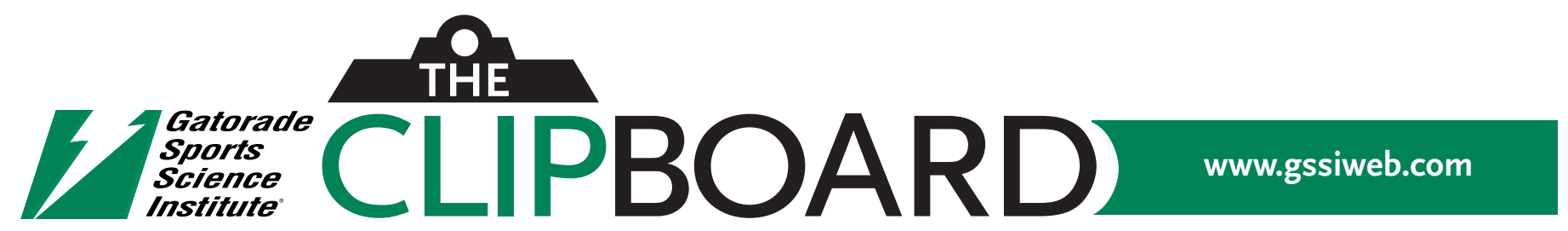

\section{Soccer: Energy for Tournaments}

By MICHELE MACEDONIO, M.S., R.D. L.D.

Nutrition consultant and freelance writer, Nutrition Strategies (Loveland, $\mathrm{OH}$ )

Tournaments present unique opportunities and challenges for the individual soccer player and the team as a whole. One of the most important challenges is supplying adequate fluid and food to fuel the athlete participating in multiple matches throughout the tournament period. What makes the challenge especially complex is the two-fold nature of the dilemma, that of supply and demand.

\section{Multiple matches mean increased demand}

\section{for energy}

A single soccer match may deplete most of a player's fluid and nutrition reserves. During a tournament, matches may be as close as an hour apart, leaving little time to rebuild fuel stores. Consequently, fatigue sets in sooner; speed, skills, accuracy and concentration are compromised; and the risk of dehydration increases. In warm environments, the degree of dehydration and its associated dangers are even higher.

Planning ahead will ensure an adequate supply of "sport-friendly" foods

Immediately after a match, the hunger sensation may be blunted so it is crucial that foods or beverages consumed at this time be high in carbohydrate $(\mathrm{CHO})$, the preferred fuel for the physical demands of soccer. In order to store those carbohydrates as muscle glycogen, the body also needs sufficient fluid.

Tournament concession stands offer limited selections, often with many high-fat foods. Fast food restaurants may be an option but careful selection is necessary to ensure adequate amounts of carbohydrates. When possible, the best bet is to bring a supply of "sport-friendly" foods and beverages to the tournament. Even when traveling far from home, there are some simple tips for ensuring a supply of portable foods and fluids that meet the high-energy demands of soccer tournaments.

Beverages and Carbohydrate-rich foods that power soccer players and travel well

\section{Beverages}

- Choose a sports drink. Gatorade supplies $14 \mathrm{~g}$ CHO per $8 \mathrm{oz}$, a good choice for quickly replenishing fluids and electrolytes lost in sweat and supplying carbohydrates during exercise. Follow these guidelines from the National Athletic Trainers' Association:

$\checkmark 17$ to 20 oz fluid 2 to 3 hours before the match

7 to 10 oz fluid 10 to 20 minutes before the match
28 to 40 oz fluid per hour during the match (7 to $10 \mathrm{oz}$ fluid every 10 to 15 minutes of play)

20 oz fluid per pound of weight lost during the match, within 2 hours of finishing the match. Players should weigh themselves before and after several games to estimate weight loss during matches.

Water alone doesn't cut it. It blunts thirst and doesn't supply needed nutrients to fuel the body.

Skip the soda. The carbonation makes it harder to gulp down enough fluid plus carbonation can bloat the stomach causing indigestion.

- Cut the caffeine. Caffeine is a diuretic increasing fluid loss, impairing rehydration.

\section{Carbohydrate-rich Foods}

To quickly restore lost muscle glycogen, soccer players should consume $2 \mathrm{~g} \mathrm{CHO}$ per $\mathrm{kg}(.9 \mathrm{~g} \mathrm{CHO} / \mathrm{lb})$ body weight within the first 2 hours after a match. Pre-game meals should be eaten 2 to 3 hours before a match to allow food to empty from the stomach. Frequently, the interval between games may be too close to digest a standard high-carbohydrate meal. In that case, athletes are wise to select easy to digest, carbohydrate-rich foods that will provide quick energy for the next match.

Try combining several of the items below:

$\checkmark$ Energy or fruit bars

$\checkmark$ Fresh fruit

$\checkmark$ Fruited yogurt

$\checkmark$ Bagels, muffins, cereal mixes with dried fruit and nuts

If an athlete feels uncomfortable eating solid food between matches, consider these convenient liquid options:

\footnotetext{
$\checkmark$ Carbohydrate-rich drink

$\checkmark$ Liquid meal
}

If a soccer team can meet the challenge of supplying enough fluid and nutrition throughout the tournament, the opportunities for success are great! 


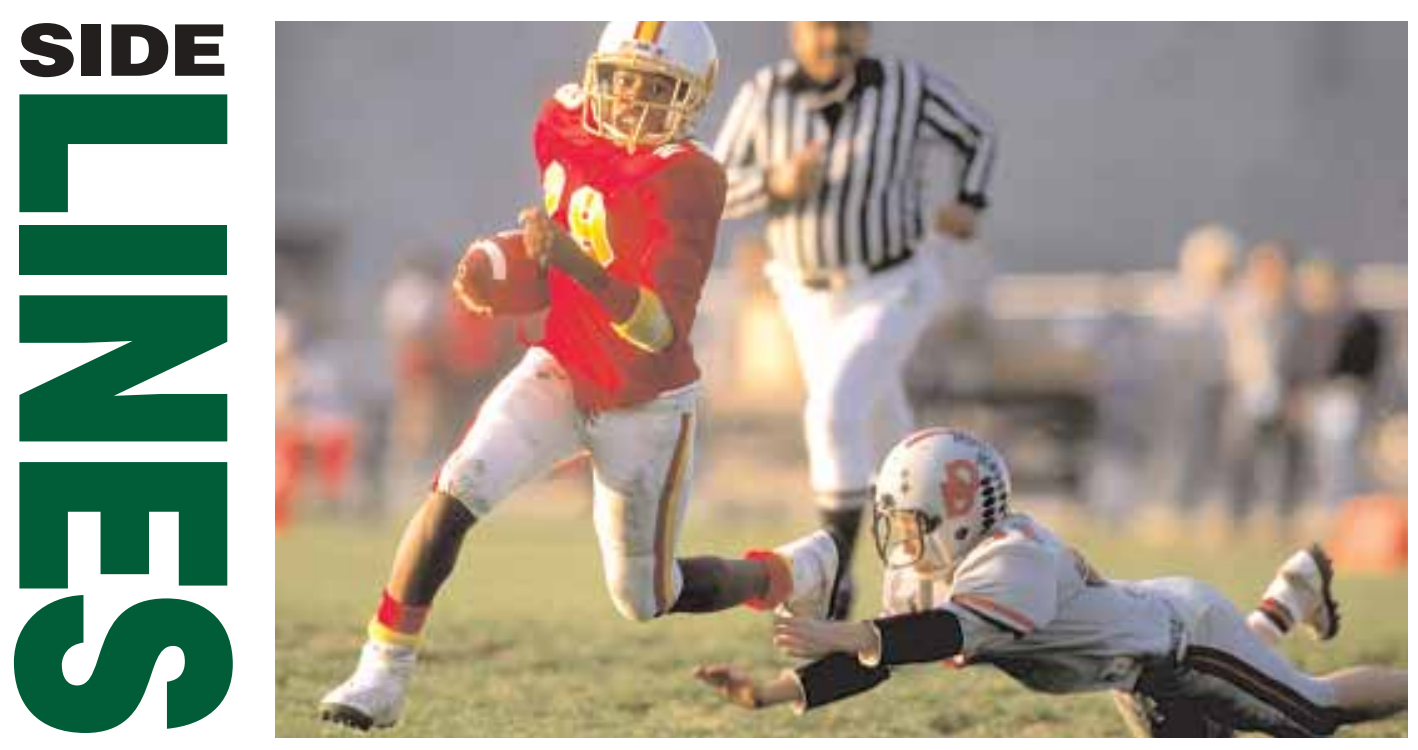

\section{Keep Your Motor Running: Fuel Before and After Competition}

\begin{abstract}
Jacqueline Berning, PhD, RD Assistant Professor, U. of Colorado

Nutrition Consultant

Dr. Berning is a sports nutritionist who teaches sports nutrition and consults several sports teams including the Denver Broncos, Denver Nuggets, Colorado Rockies and Cleveland Indians.
\end{abstract}

$\mathrm{M}$ ANY HIGH SCHOOL STUDENT athletes skip meals before they train or work out, especially if the workout happens to be in the early morning. Skipping meals or not eating before a workout can impair athletic performance, and not eating after a workout or competition leaves the athlete running on empty. Make nutrition a priority for your athletes before, during and after exercise.

\section{The Pre-Exercise Meal}

The pre-event meal serves two purposes. First it keeps athletes from feeling hungry and sluggish before and during the game, and secondly it helps to maintain optimal levels of energy (blood glucose) for the exercising muscles during training and competition.

Eating before exercise can be challenging for athletes. While they need fuel to perform, they should not exercise on a full stomach. Food that remains in the stomach during training or competition may cause indigestion, nausea, and possibly vomiting. A good recommendation is to eat a meal 2-4 hours before exercise. If an athlete is nervous about his or her performance, the digestive process may take even longer.

The ideal pre-exercise meal should be primarily carbohydrates, moderate in protein and low in fat. Carbohydrates are digested rapidly. Protein and fat take longer to digest. Pre-exercise meals high in fat (like a lot of options at school and fast food restaurants) can cause stomach upset, gas and bloating.

\section{Hydration During Exercise}

The importance of nutrition does not stop with the pre-exercise meal. During practice or competition, remind athletes to drink sports drinks to avoid dehydration and provide energy for working muscles.

The Post-Exercise Meal

Eating for peak performance also includes making wise food choices postexercise. The right post-game meal replenishes athletes' muscles for the event or competition around the corner. In fact, muscles are most receptive to recovery during the first 30 minutes after competition. Athletes should follow these tips:

To completely restore muscle energy, eat within 30 minutes after exercise and then eat small meals at 2 hours and again at 4 hours.

If you can't take solid foods 30 minutes after exercise, or they are not available, try drinking 2-4 cups of a sports drink or eating an energy bar, then eat more solid foods 2 and 4 hours later.

Be sure to hydrate after a workout or game. Weigh yourself and drink 3 cups of fluid for each pound lost during the competition.

Choose high-carbohydrate, moderate protein foods like the examples shown.

\section{Get in the Habit Know WHAT to eat and WHEN \\ Keep a snack supply in a backpack or locker to prevent exercising on empty. The same kind of high-car- bohydrate, power-packed foods are recommended for BOTH before and after an event or competition: \\ 4 or more hours before AND 4 hours after \\ 口 Grilled chicken/rice/fruit \\ - Turkey sandwich/raw carrots \\ 2-3 hours before AND 2 hours after \\ - Cereal/lowfat milk \\ Fresh fruit \\ 1 hour or less before AND 30 minutes after \\ 口 Yogurt \\ Energy bar \\ $\square$ Spaghetti with meat sauce \\ 口 String cheese/grapes/crackers \\ 口 Energy bar/sports drinks \\ B Bagel with peanut butter \\ S Sports drink \\ - Energy bar \\ 口 Sports drink \\ 口 Pretzels \\ 口 Raisins}




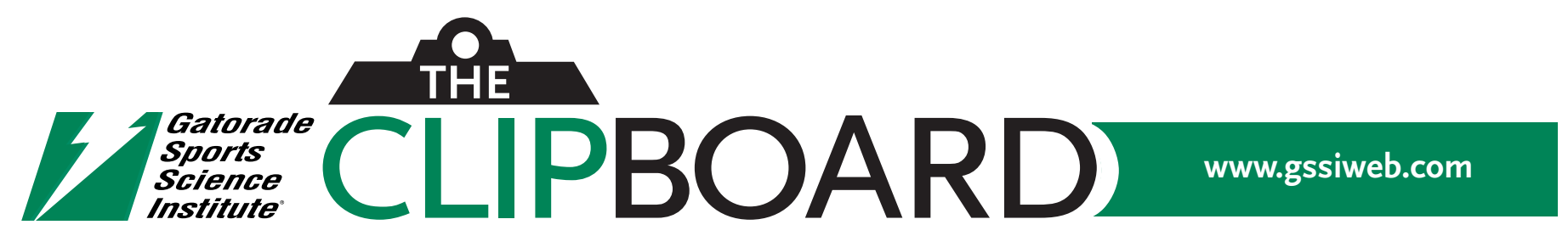

\section{First-Class Fuels}

By JULIE BURNS, M.S., R.D.

Founder of SportFuel, Inc. and sports nutrition consultant for the Chicago Bears, Chicago Blackhawks, Chicago Bulls and

Northwestern University athletes

The hours athletes spend in practices, training and competing place large demands on the physical conditioning of players. The peak energy level and power needed to compete in any sport can be maximized with a balanced diet focused on whole-grain carbohydrates, high-quality protein and healthy fats.

To fuel power workouts, enhance stamina, energy, strength and quickness, athletes need to eat and drink the proper foods. Use these recommendations to assist the athlete in reaching their goals:

Eat adequate dietary carbohydrates daily to fuel training and competition

Many athletes need help identifying foods that contain carbohydrates. They may know that pasta is a good source of carbohydrates, but they are not aware that fruits, vegetables, dried peas and beans, whole-grain cereals, breads and potatoes also contain carbohydrates.

\section{Choose mostly whole-grain carbs, when possible}

Some athletes rely heavily on highly processed foods with refined ingredients rather than whole-grains. Whole-grain bagels, breads, muffins and cereals contain more nutrients and less unhealthy fats than highly processed products.

\section{Choose high-quality protein}

$\checkmark$ While protein is not a primary fuel for working muscles, it is a component of muscles, organs, enzymes, and oxygen-carrying hemoglobin. Amino acids are the building blocks of protein. High-quality protein foods contain all the essential amino acids needed to build and repair body tissues.

Athletes should consume a wide variety of high-quality protein foods, such as chicken, turkey, beef, pork, soybeans, milk, eggs, legumes (beans) and nuts.

$\checkmark$ Fat is needed in the diet. Aside from being a concentrated source of dietary energy, fats form essential tissue-building blocks and hormone-regulating substances.
Athletes should incorporate a variety of natural fats into their daily diet, such as nuts, nut butters, oils and seeds, cold water fish, olives and avocados. Large amounts of saturated fat (from animal products, such as dairy and meat), and "trans" fats (from hydrogenated and partially hydrogenated oils in many packaged products) should be avoided.

\begin{tabular}{|l|l}
\hline INSTEAD OF THIS... & TRY THIS... \\
\hline Donut or sweet roll & Whole-grain bagel with nut butter \\
\hline Chips and dip for a snack & $\begin{array}{l}\text { Albacore tuna on whole wheat } \\
\text { bread }\end{array}$ \\
\hline $\begin{array}{l}\text { Sugar cereal with 2\% milk } \\
\text { and a fruit bar }\end{array}$ & $\begin{array}{l}\text { Whole-grain cereal with non-fat milk } \\
\text { or soy milk, handful of nuts, and a } \\
\text { piece of fresh fruit }\end{array}$ \\
\hline Hamburger on a white bun & $\begin{array}{l}\text { Salmon, turkey or veggie burger on } \\
\text { a whole-grain roll with lettuce and } \\
\text { tomato }\end{array}$ \\
\hline Cake or cookies & $\begin{array}{l}\text { Fresh fruit dipped in natural } \\
\text { peanut butter }\end{array}$ \\
\hline Sausage or pepperoni pizza & Vegetable pizza and garden salad \\
\hline
\end{tabular}

Nutrition practices can have a significant impact on the overall development of a first-class athlete. The proper fuel can help athletes reach their potential. 


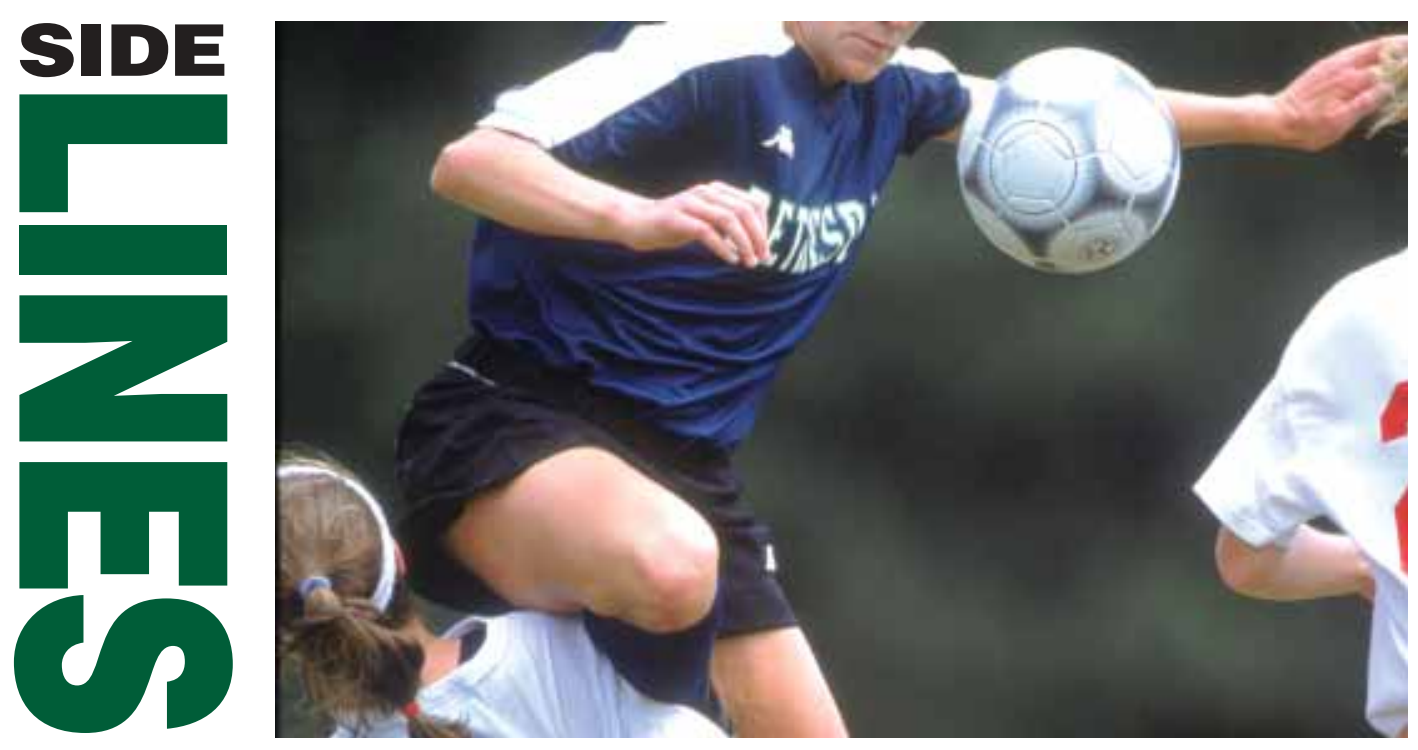

\section{Hydration: Critical to Athletic Performance}

\section{David R. Lamb, PhD}

The Ohio State University

Dr. Lamb is a professor emeritus of exercise physiology. His research has focused on the effects of dietary carbohydrate and patterns of beverage consumption on athletic performance.

\section{工 IGH SCHOOL ATHLETES}

1 train hard, they play to win, and they sweat through it all. In the intensity of a practice or game, athletes don't realize the amount of sweat they lose, and that puts them head to head with a nasty competitor - dehydration. It's critical to beat dehydration so athletes can play at their best even in the final minutes of the game.

Hydration is critical to athletic performance. In fact, fluid losses of as little as $2 \%$ of body weight (less than 4 pounds in a 200-pound athlete) can impair performance by increasing fatigue. This is important because it's common for some athletes to lose between 5-8 pounds of sweat during a game. So it's easy for athletes to become dehydrated if they don't drink enough to replace what is lost in sweat.

Considering sports drinks versus water for your athletes? Research shows that sports drinks out-perform water because sports drinks:

- Encourage voluntary drinking when athletes are hot and thirsty. Sports drinks with a light flavor and small amount of sodium encourage athletes to drink, and drinking fluids is the firstline of defense against dehydration.

- Stimulate rapid fluid absorption. Gatorade has the right mix and amount of carbohydrates and electrolytes to speed fluid and carbohydrate into the bloodstream.

- Help keep athletes in the game. Sports drinks can help athletes avoid dehydration and other heat-related problems such as early fatigue, heat cramps, lightheadedness and heat exhaustion.
- Aid performance. Carbohydrate in sports drinks helps athletes perform better in both power and endurance efforts.

- Speed recovery. The carbohydrates and electrolytes in sports drinks help refuel muscles and speed rehydration.

With a game plan to help your athletes drink the right fluids at the right times, you're giving them the strategy for a high-powered performance that matches their will to win.

For more information, please visit www.gssiweb.com

\section{The National Athletic Trainers' Association "Fluid Replacement for Athletes" Position Statement}

Educate athletes on the effects of dehydration on physical performance.

Inform athletes on how to monitor hydration status.

Encourage coaches to mandate rehydration during practices and competitions, just as they require other drills and conditioning activities. Fluid replacement should approximate sweat and urine losses and at least maintain hydration at less than $2 \%$ body weight reduction.

During events, when a high rate of fluid intake is necessary to sustain hydration, the $\mathrm{CHO}$ (carbohydrate) composition should be kept low (e.g., less than $7 \%$ ) to optimize gastric emptying and fluid absorption.

A proper hydration protocol considers each sport's unique features. If rehydration opportunities are frequent (eg, baseball, football, track and field), the athlete can consume smaller volumes at a convenient pace based on sweat rate and environmental conditions. If rehydration must occur at specific times (eg, soccer, lacrosse, distance running), the athlete must consume fluids to maximize hydration within the sport's confines and rules. 


\section{Optimizing Hydration}

By DOUGLAS J. CASA, Ph.D., ATC, FACSM

Assistant professor and director of athletic training education at the University of Connecticut (Storrs, CT)

During the Spring of 2000 the National Athletic Trainers' Association released a Position Statement titled Fluid Replacement for Athletes. ${ }^{1}$ This document provides extensive recommendations for all levels of athletics and six key concepts of the position statement are highlighted below:

\section{Educate athletes and fellow staff about hydration process}

The perpetual struggle to keep athletes properly hydrated is much easier to accomplish when the athletes and staff are aware of the role that proper hydration plays in optimizing athletic performance and minimizing the incidence of heat illness. Also, all athletes should become active participants in their own hydration process and be educated about monitoring hydration status and encouraged to rehydrate based on individual needs.

\section{Individualize the rehydration process}

This entails three important considerations.

1 Athletes lose fluids via sweat and urine at different rates for many reasons and thus should replace fluids based on individual requirements. Determine athletes sweat rate if possible by this calculation for a range of environmental conditions, practices and competitions.

Sweat Rate $=$

(pre-exercise body weight

- post-exercise body weight

+ fluid intake

- urine volume)

$\div$ exercise time in hours

2. Athletes choose to drink different amounts and should be encouraged to monitor how much they drink to be sure it matches the amount that is being lost.

3. The confines of different sports and positions dictates how an athlete optimizes the rehydration process based on individual access to fluids.

3. Drink appropriate amounts before, during and after exercise

Pre-Exercise

$\checkmark$ Approximately 17 to $20 \mathrm{oz}, 2$ to 3 hours before activity

$\checkmark$ Consume another 7 to $10 \mathrm{oz}$ after the warm-up (10 to 15 minutes before activity)

\section{During Exercise}

$\checkmark$ Approximately 28 to $40 \mathrm{oz}$ every hour of play (7 to 10 oz every 10 to 15 minutes)

$\checkmark$ Develop a hydration process that includes drinking based on fluid needs (see above), monitoring fluid intake and having a plan based on the confines of sport

\section{Post Exercise}

$\checkmark$ Encourage athletes to rapidly replace lost fluids (sweat and urine) within two hours after activity to enhance recovery by drinking 20 to 24 oz for every pound body weight lost through sweat

\section{Choosing a beverage}

Provide the optimal oral rehydration solution (water, carbohydrates, electrolytes) before, during and after exercise. The ideal fluid replacement solution should include approximately 70 to $166 \mathrm{mg}$ sodium/8 oz and 14 to $17 \mathrm{~g}$ carbohydrates/8 oz (6\% to $7 \%$ carbohydrate solution).

\section{Make sure fluids are accessible and cooled}

Hydration is much more likely to be maintained if the fluids are conveniently located for the athletes to drink during practice and rest periods. Keep individual containers on ice in a cooler so an athlete can access it during practice and increase fluid intake.

\section{Recognize dehydration}

All coaches, athletes and medical staff need to recognize the common signs and symptoms associated with dehydration. They include:

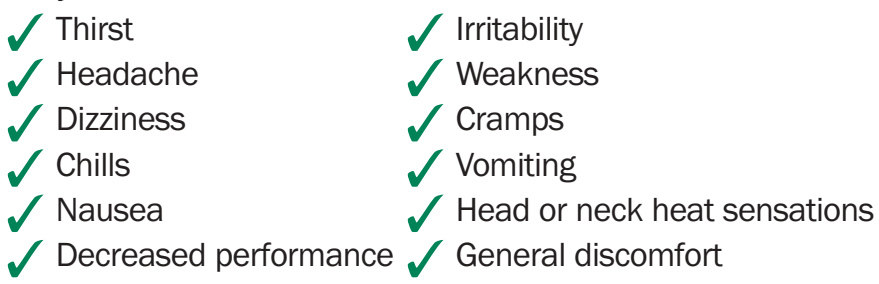

Be aware that an athlete will likely only exhibit a few of these signs and symptoms.

${ }^{1}$ Casa, D. et al. J Athl Train 35(2):212-224, 2000. 

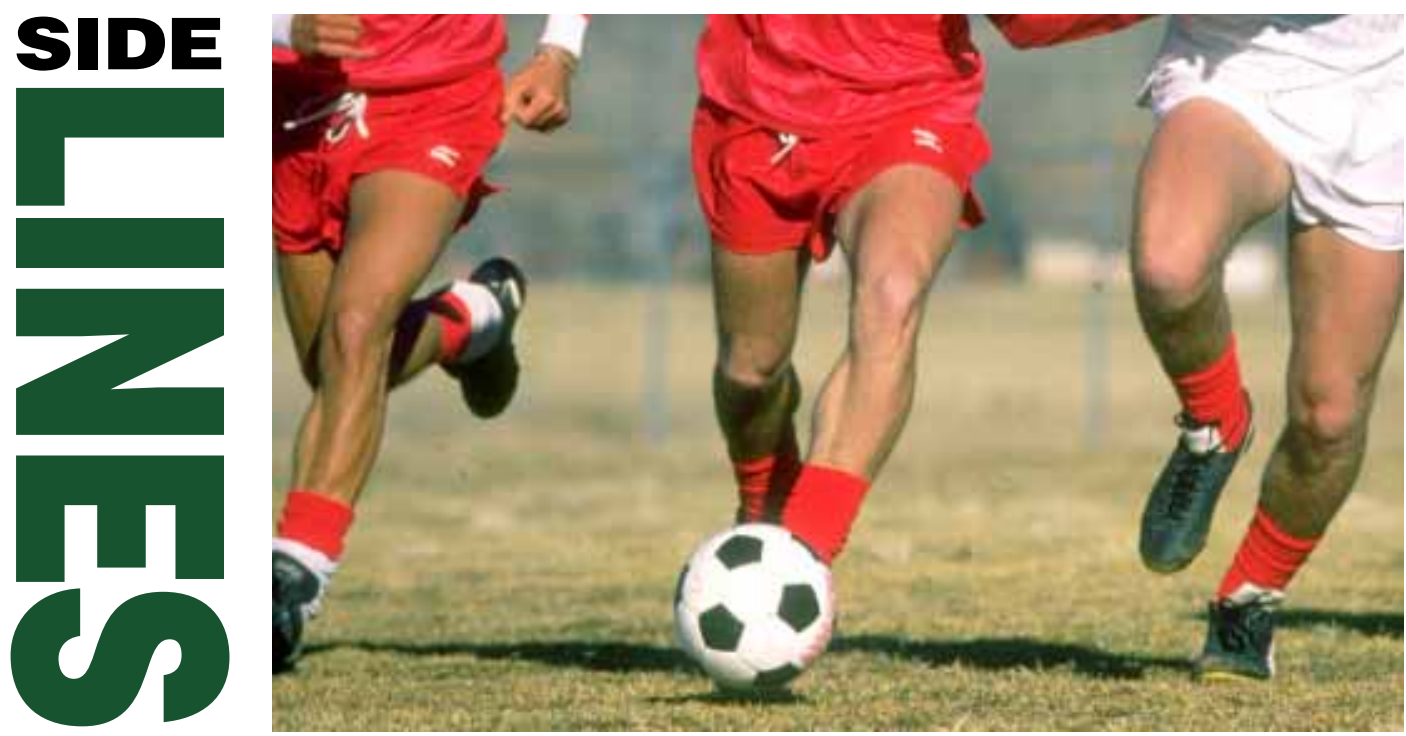

\section{Power Play: Protein's Role as a Team Player}

Melinda M. Manore, PhD, RD, FACSM

Professor and Chair, Dept. of Nutrition and Food Management, Oregon State University

D ating the right foods is essential to

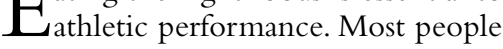
know that food provides athletes with the energy and nutrients required to reach their peak performance, but the variety of supplements, fad diets and misinformation out there can be misleading.

Protein has been a particularly hot topic lately, because of its role in building and maintaining muscle tissue. Among the topics up for debate: How much protein is required to build healthy muscles in high school athletes? Which foods help athletes meet protein requirements? What's the best nutrition game plan for building a strong, healthy body?

Before plunging into the protein plan, make sure your athletes understand the importance of carbohydrates in getting adequate energy to fuel their bodies. During exercise the muscles use carbohydrate as their primary energy source not protein. Thus it is important that athletes, including athletes in explosive sports, eat adequate carbohydrate before, during and after exercise. Protein, while vital to a healthy diet, will not bring them to victory on its own.
Athletes build muscle through the combination of exercise and a diet adequate in calories and protein. But how much protein do growing athletes - like those at the high school level - need to support their training?

In general, athletes, regardless of their sport, should consume 0.55-.80 grams of protein per pound of body weight. This means that an athlete who eats 3000 calories per day and weighs 180 pounds would need about 100-140 grams per day.

This may sound like a lot of protein, but it's not difficult for most high school players to eat enough protein in their typical diet to meet the requirements. Just make sure they pack in the right foods lean beef, poultry, low-fat dairy and peanut butter are all protein rich - and balance them with fruits, vegetables and whole grains (see table). With the help of a balanced diet, most athletes do not need to go on a special protein diet or con-

\section{sume protein supplements.}

Keep in mind that food is fuel and athletes should not come into a practice or game without having had enough food to support their exercise. To keep your players properly fueled and meeting their protein needs, remind them to EAT:

Eat breakfast. It's the best way to start the day well fueled. Include foods that contain protein such as low-fat milk, yogurt or an egg.

Add protein and carbohydrate to postexercise meals. Some energy bars provide carbohydrate to replenish the muscle glycogen stores and protein to help build and repair muscles.

Toss the supplements. Encourage your athletes to get protein from foods instead of supplements. This helps ensure their diet is balanced in nutrients they need.

Remind your players that eating well and staying well hydrated is a winner every time.

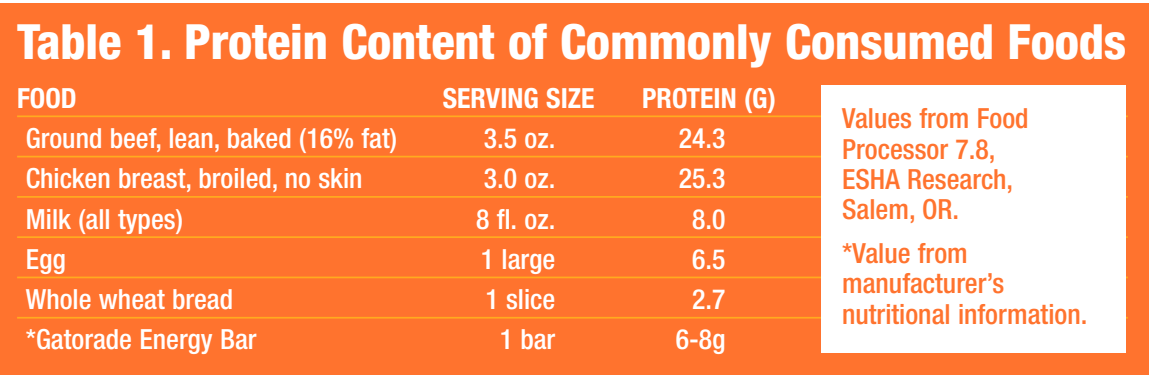




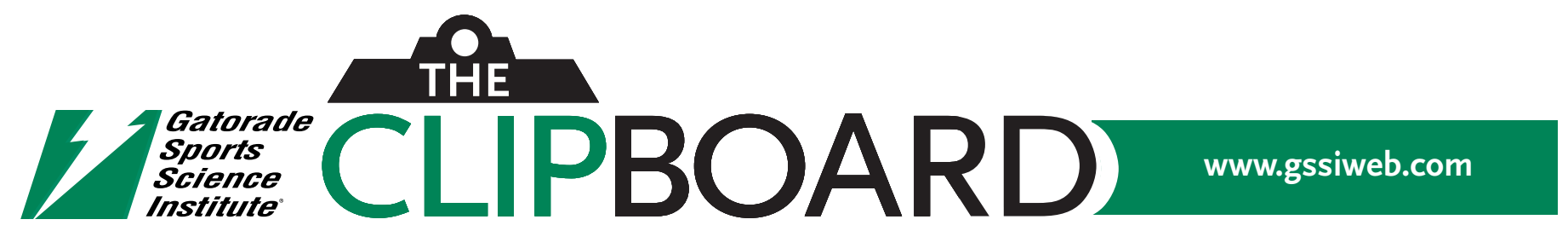

\section{Sports Nutrition Myths}

By CHRISTINE ROSENBLOOM, Ph.D., R.D.

Department chair in the department of nutrition at Georgia State University and

nutrition consultant for the Georgia Tech Athletic Association (Atlanta, GA)

Athletes are always looking for a secret edge against the competition and what an athlete chooses for fuel can help. Because sports nutrition is an evolving area of sports science, it is prone to myths and misconceptions. You've probably heard all of these myths, but do you know the real facts?

\section{Myth \# 1: Sugar should be avoided} before training and competition

Sugar eaten before competition increases blood levels of glucose and insulin, which is not a bad thing. Sugar is a type of carbohydrate. Carbohydrate, whether in food or drink, taken before exercise can improve performance. An athlete who is not fueled is a tired athlete who can't perform at his or her best.

\section{Myth \# 2: Sports drinks are only needed for} exercise lasting more than an hour

Sports drinks can be beneficial in activities that last less than one hour, especially if the exercise is intense or occurs in hot, humid conditions. Professional athletes aren't the only ones who benefit from sports drinks. Competitive athletes who play stop-and-go sports such as, football, soccer, tennis, field hockey or basketball can benefit from the carbohydrate and electrolytes in sports drinks. Drinking sports drinks encourages athletes to drink more, which is important since dehydration can occur in exercise lasting less than one hour. Using sports drinks is an easy way to improve performance and fight dehydration.

\section{Myth \# 3: Body image distortion is only} a women's issue

Men are increasingly exposed to super male images - from the bodies of professional wrestlers to the covers of men's magazines. Men are increasingly dissatisfied with their body's appearance. Body dysmorphic disorder, the preoccupation with an imagined or slight defect in one's appearance, is recognized as a psychological disorder. Many coaches and athletes may be unaware that it occurs in both males and females.

\section{Myth \# 4: Vitamins and minerals give athletes extra energy}

Vitamins and minerals act as co-factors to unlock the chemical energy stored in food, but by themselves they do not give an athlete extra energy. A meal plan rich in grains, vegetables, fruits, meat and dairy give athletes energy. This food is also a vehicle of entry for the vitamins and minerals the body needs to unlock food energy. A multi-vitamin mineral supplement might be necessary for some athletes, but by itself, it will not provide extra energy.

\section{Myth \# 5: The ideal ratio of nutrients is $40 \%$ carbohydrate, $30 \%$ protein and $30 \%$ fat}

Some diet plans recommend that $40 \%$ of daily energy come from carbohydrate, $30 \%$ protein, and $30 \%$ fat. Diets with these ratios can be detrimental to performance because they are low in calories and carbohydrates. Research shows a better diet plan for athletes is one that provides roughly $55 \%$ to $58 \%$ energy from carbohydrate, $12 \%$ to $15 \%$ protein and $25 \%$ to $30 \%$ fat.

\section{Fight sports nutrition myths}

Be wary of information provided on commercial web sites if the company's goal is to sell product and the product is not backed by published research.

$\checkmark$ Look for information provided by respected organizations, such as the American College of Sports Medicine (ASCM) and the American Dietetic Association (ADA).

$\checkmark$ Bring in a sports nutritionist for a workshop with your team on translating the science of nutrition into food plans.

Check the Gatorade Sports Science Institute web site at www.gssiweb.com for information. 


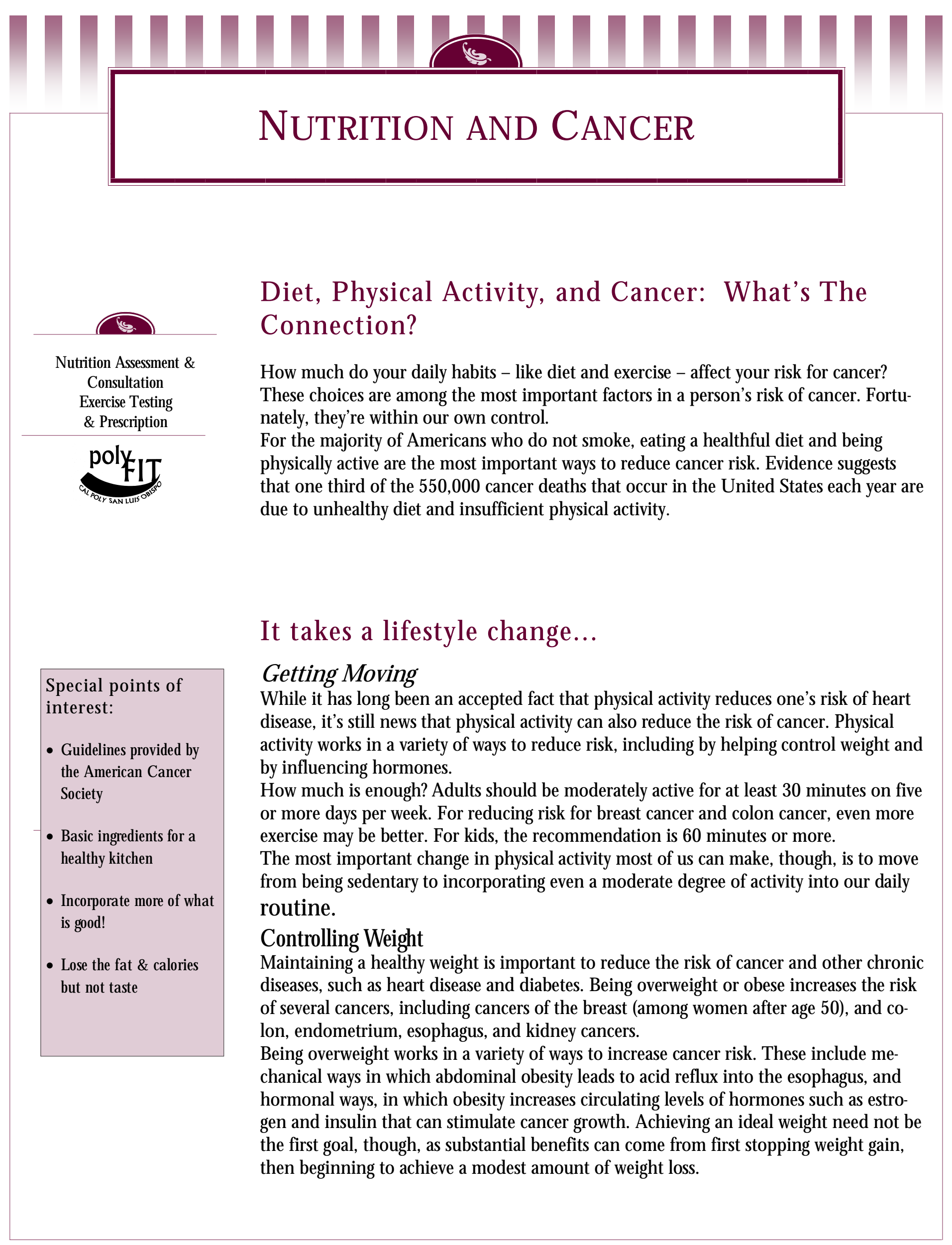




\section{The Complete Guide To Nutrition And Physical Activity from the American Cancer Society}

Eat a variety of healthful foods, with an emphasis on plant sources.

Eat five or more servings of a variety of vegetables and fruits each day.

- Include vegetables and fruits at every meal and for snacks.

- Eat a variety of vegetables and fruits.

- Limit French fries, snack chips, and other fried vegetable products.

- Choose $100 \%$ juice if you drink fruit or vegetable juices.

Choose whole grains in preference to processed (refined) grains and sugars.

- Choose whole grain rice, bread, pasta, and cereals.

- Limit consumption of refined carbohydrates, including pastries, sweetened cereals, soft drinks, and sugars.

Limit consumption of red meats, especially those high in fat and processed.

- Choose fish, poultry, or beans as an alternative to beef, pork, and lamb.

- When you eat meat, select lean cuts and smaller portions.

- Prepare meat by baking, broiling, or poaching, rather than by frying or charbroiling.

Choose foods that help maintain a healthful weight.

- When you eat away from home, choose food low in fat, calories, and sugar and avoid large portions.

- Eat smaller portions of high-calorie foods. Be aware that "low fat" or "fat free" does not mean "low calorie" and that low-fat cakes, cookies, and similar foods are often high in calories.

- Substitute vegetables, fruits, and other low-calorie foods for caloriedense foods such as French fries, cheeseburgers, pizza, ice cream, doughnuts, and other sweets.

Balance caloric intake with physical activity.

Lose weight if currently overweight or obese.

Adopt an physically active lifestyle.

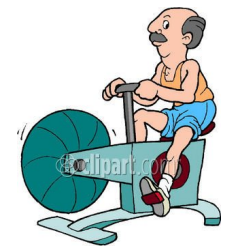

Adults: Engage in at least moderate activity for 30 minutes or more on 5 or more days of the week; 45 minutes or more of moderate to vigorous activity on 5 or more days per week may further reduce the risk of breast and colon cancer.

\section{Helpful Ways to Be More Active}

- U se stairs rather than an elevator.

- If you can, walk or bike to your destination.

- Exercise at lunch with your workmates, family, or friends.

- Take a 10-minute exercise break at work to stretch or take a quick walk.

- W alk to visit co-workers instead of sending an email.

- Go dancing with your spouse or friends.

- Plan active vacations rather than only driving trips.

- W ear a pedometer every day and watch your daily steps increase.

- Join a sports team.

- U se a stationary bicycle while watching TV.

- Plan your exercise routine to gradually increase the days per week and minutes per session. 


\section{B asic ingredients for a healthy kitchen!}

The first step to cooking healthy is to stock your kitchen with a variety of foods that you can throw together for healthy meals in a hurry. Keep these foods on hand for fast meals on busy nights.

In the Cupboard

- Pasta: spaghetti, fettuccini, penne, bowties, ramen noodles

- Rice: white, brown, rice mixes

- Beans: black, pinto, kidney, chick peas, lentils, fat-free refried

- $\quad$ ther grains: couscous, orzo, cornmeal, whole wheat crackers, bread sticks, bread crumbs

- Potatoes and onions

- Canned tomatoes: diced, whole, seasoned, sun-dried, sauce, salsa

- Canned vegetable: mixed vegetables, green beans, mushrooms, other favorites

- Canned and dried fruits: applesauce, peaches, pineapple, raisins, cranberries, other favorites

- Sauces: pasta, pizza, low-fat cheese sauce, low-fat gravy

- Soups: Low-fat canned soups, broth and bouillon and dried soup mixes

- Meats: canned tuna in water, salmon, minced clams, and chicken

- Peanut butter

- Evaporated skim milk

- Vinegars: cider, red and white wine, flavored, balsamic

- Oils: olive and canola, nonfat cooling spray

In the Refrigerator

- Fruits and vegetables

- $100 \%$ fruit and vegetables juices

- Fruit spreads

- Reduced-fat or fat-free milk and yogurt

- Reduced-fat cheeses: cheddar, mozzarella, Swiss, M onterey Jack, cottage, Parmesan

- Tortillas

- Eggs

- Minced garlic

- Sauces: W orcestershire, soy, and chili

- Catsup and mustard (spicy and Dijon)

- Reduced-fat or fat-free salad dressings

In the Freezer

- Frozen fruits, vegetables, and $100 \%$ juices

- Frozen chopped onions and chopped green pepper

- Breads: whole grain breads, dinner rolls, English muffins, bagels

- M eats: chicken breast, ground turkey breast, extra lean hamburger

- Fish: red snapper, salmon, orange roughy, cod, flounder, sole

- Frozen yogurt or fruit sorbet

W hole $G$ rains vs. Refined G rains

A whole grain is made up of three parts: the bran, endosperm and germ. Refined grains are made from the endosperm. Because the bran and germ contain much of the vitamins, minerals and all of the fiber found in grains, whole grains have more fiber and nutrients than refined (or processed) grains. Shoot for at least three servings of whole grain foods each day.

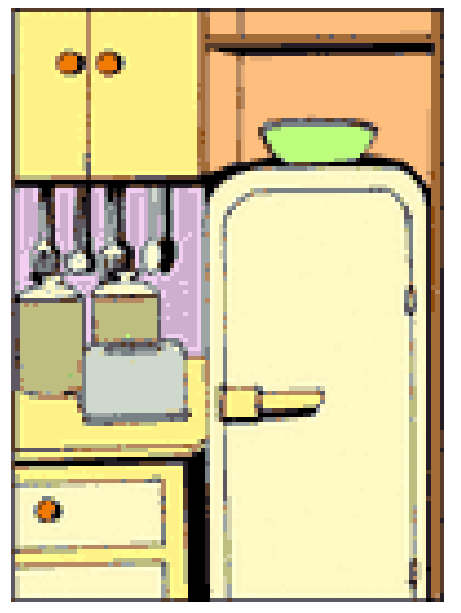




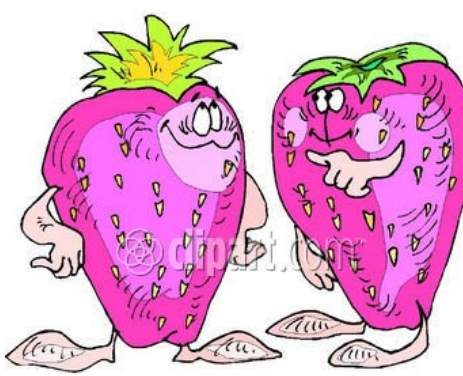

\section{H ow to incorporate more of what is good!}

Your kitchen is stocked and you're ready to go. N ow it's time to think about how you can add more vegetables, fruits, and whole grains to your day while watching your refined carbohydrates,

sugar, and fat intake.

Fruits and Vegetables

- Add fresh or dried fruits like chopped apples, raisins, prunes, kiwi, or orange sections to green leafy salads.

- Add chopped carrots, broccoli, or a mix of your favorite vegetables to soups, salads, meat loaf, and casseroles.

- Substitute applesauce for oil in muffins, quick breads, and cakes. U se pureed prunes or baby food prunes instead of oil in brownies or chocolate cake.

Beans and Peas

- Add your favorite canned beans to soups, stews, and salads.

- Flavor beans with onion, garlic, and herbs for added flavor without added fat.

- Try different bean dishes: split pea soup, vegetarian chili with kidney beans or white bean chili, black beans over rice, bean tostados, and tacos, blackeyed peas with garlic and red pepper, or three-bean salad made with green beans, chickpeas, and kidney beans.

Grains

- Substitute whole-wheat flour for up to half of the white flour called for in a recipe.

- Add 1/ 4 cup bran or quick-cooking oatmeal to your meat loaf or casserole.

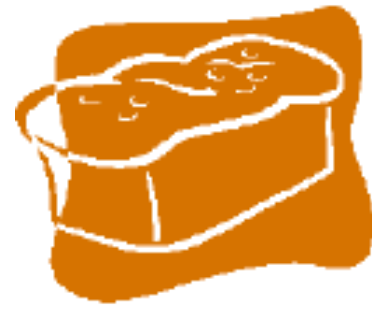

- Make muffins using oatmeal, bran, or whole-wheat flour.

- Try wholewheat pasta for a fiber boost.

- U se whole cornmeal when making cornbread.

Milk, Cheese, and Yogurt

- U se evaporated skim milk instead of whole milk or cream in baked goods, sauces, and soups.

- U se low-fat or non-fat yogurt to replace all or part of the sour cream or mayonnaise in a recipe. Replace all or part of ricotta cheese with low-fat cottage cheese. U se a puree of cooked potatoes, onion, and celery as a creamy base for soups instead of dairy cream or half-and-half.

- Sharp cheese gives extra flavor so that less can be used. This helps trim the fat.

- Select yogurt or milk products without added sugar or flavorings. Mix in fresh fruit for a flavor boost.

M eats, Poultry, and Fish

- Let vegetables, beans, rice and pasta be the stars of your main dished - use meats as the side dish.

- Choose lean meats - look for the words "loin" or "round" in the name. Trim meat of all visible fat before cooking. Cook poultry with the skin on to keep it moist, but remove skin before eating to reduce the fat.

- Choose canned fish packed in water instead of oil. D rain thoroughly before mixing with your favorite dressing or condiment.

- U se low-fat cooking methods like roasting, baking, broiling, steaming, or poaching. Limit deep fat frying and saut,ing in a lot of oil or margarine. U se either a cooking spray, broth, water or a well-seasoned cast iron pan to saut, meats. If you must use oil or margarine, cut the amount in half. 


\section{Less calories \& fat, more flavor!}

Adding more vegetables and less meat to chili, chicken soup, or a C hinese-style stir-fry is a great way to make meals that are lower in calories and higher in cancer-fighting nutrients. To make the calorie count tumble further, look for ways to cut the fat in your cooking and baking. Fats pack more calories per gram than proteins or carbohydrates. Ask yourself: "C an I reduce or replace oil? C an I use low-fat milk instead of cream?" This will assist you in maintaining your weight at a healthy level which will reduce your risk of

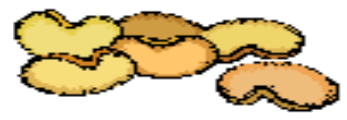
cancer.

Try the strategies below to limit fat, then read on for healthful foods that can substitute for rich ingredients and snacks.

- Fats like oil, butter, or margarines can usually be cut by one-third to one-half in recipes. Try a small cut-back at first, then increasingly cut back little by little.

- To replace some moisture and flavor loss when fat is reduced, make up the difference with broth, non-fat milk, fruit juice, and extra herbs, spices and vegetables.

- $\quad$ For a moist baked product when fat is reduced, add dried fruits or applesauce.

- Remember to use measuring spoons and cups to avoid pouring or guessing the amount of oil to use. Any extra teaspoon of oil is 45 calories and 5 grams of fat.

- U se only small amounts of fatty foods like avocados, coconuts, cheese and nuts.

Instead of....

Whole milk

$2 \%$ milk

Cheddar cheese

Ice cream

Sour cream

Potato chips

Butter popcorn

Ice cream bar

Pepperoni pizza
Try this...

$1 \%$ (low-fat)

Skim milk (nonfat)

Reduced-fat cheddar cheese

Ice milk or frozen yogurt

N on-fat sour cream

Baked potato chips

Light popcorn

Fudgesicle

Vegetable pizza
And save... grams of fat!

5 grams per cup

5 grams per cup

8 grams per ounce

4.5 grams per $1 / 2$ cup

2 grams per tablespoon

10 grams per ounce

7 grams per serving

12 grams per bar

7 grams per slice

A dapted form the A merican C ancer Societ found at http://www.cancer.org/docroot/home/index.asp

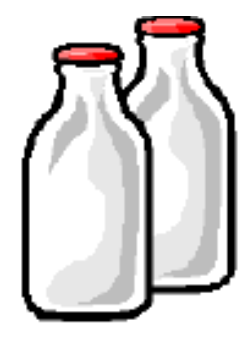




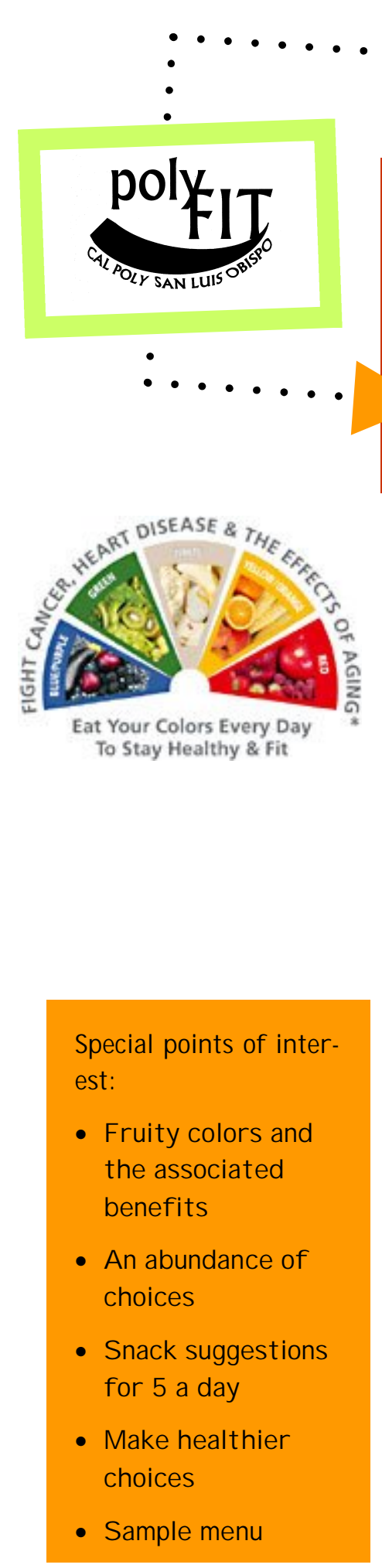

Fruits \& VeggiesGet Morel

Nutrition Assessment \& Consultation

Exercise Testing \& Prescription

\section{Why 5 a day the color way}

Eating 5 or more servings of colorfulfruits and vegetables a day is part of an essential plan for healthier living. That's because deeply hued fruits and vegetables provide the wide range of vitamins, minerals, fiber, and phytoche micals your body needs to maintain good health and energy levels, pro. tect against the effects of aging, and reduce the risk of cancer and heart dise ase. .

* Low-fat diets rich in fruits and vegetables and low in saturated fat and cholesterol may reduce the risk of heart disease and some types of can-

\section{Before we begin...}

GLOSS ARY

You probably will wonder what many of the terms mean to you and your diet? Here are some quick explanations before we begin:

$\mathcal{N}$ utrients:

Vitamins and mine rals: Natural substances contained in a wide variety of foods that have long been recognized as essential to maintaining healthy body systems. $S$ cientists have defined specific daily amounts of vitamins and minerals that are necessary for good health.

Carbohydrates, proteins, and fats: Compounds found in foods that the body uses to generate energy or build cells.

Phytochemicals: Natural plant compounds that may provide a variety of health benefits. Many of the bright colors in fruits and vegetables come from phytochemicals.

Antioxidants: Plant substances that protect the body by neutralizing free radicals, or unstable oxygen molecules, which can damage cells and lead to poor health. Here we go! 


\section{Choose the colors of health}

It's all about color-6lue/purple, green, white, yellow/orange, and red-and the power of colorful fruits and vegetables to promote good health. So when you're grocery shopping, planning your meals or dining out, think color.

And for variety, make it $5 \mathcal{A}$ Day The Color Way:

\section{BLUE/PURPLE}

Boost the level of BLUE/PURPLE in your low-fat diet to help maintain:

- $\quad \mathcal{A}$ lower risk of some

cancers

- Urinary tract health

- Memory function

- $\quad H e a l t h y$ aging

\section{Be at the Effects of Aging}

Blue/purple fruits and vegetables contain varying amounts of health-promoting phytochemicals such as anthocyanins and phenolics, currently being studied for their antioxidant and anti-aging benefits. Get blue/purple every day with foods such as:

$\begin{array}{lll}\text { Blackberries } & \text { Purple grapes } & \text { Purple cabbage } \\ \text { Blueberries } & \text { Purple figs } & \text { Purple carrots } \\ \text { Blackcurrants } & \text { Plums } & \text { Eggplant } \\ \text { Dried plums } & \text { Raisins } & \text { Purple Belgian endive } \\ \text { Elderberries } & \text { Purple asparagus } & \text { Purple peppers } \\ \text { Potatoes (purple fleshed) } & \text { Blacksalsify] }\end{array}$

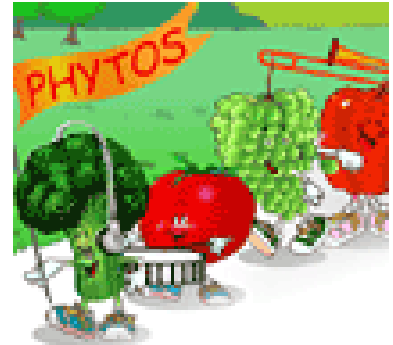

\section{WHIT $\mathcal{T}$}

Working $\mathcal{W} \mathcal{H} I \mathcal{T E}$ into your low-fat diet helps maintain:

- Heart health

- Cholesterol levels that are already healthy

- $A$ lower risk of some cancers

\section{White for Wellness}

White, tan, and brown fruits and vegetables contain varying amounts of phytochemicals of interest to scientists. These include allicin, found in the onion family. Get all the health benefits of white by including foods such as:

\begin{tabular}{|c|c|c|c|c|}
\hline Bananas & Cauliflower & Garlic & Ginge $r$ & Jicama \\
\hline Brown pears & White peaches & gerusalem artickoke & Onions & Mushrooms \\
\hline Dates & White nectarines & Koflrabi & Parsnips & White $\operatorname{Cor} n$ \\
\hline Shallots & Potatoes (white $f l$ & & Turnips & \\
\hline
\end{tabular}




\section{The colors of health continued...}

\section{DELLOW/ORANGE}

Make YELLOW/ORANGE a part of your low-fat diet to help maintain:

- $A$ healthy heart

- Vision health

- $\mathcal{A}$ healthy immune system

- $A$ lower risk of some cancers

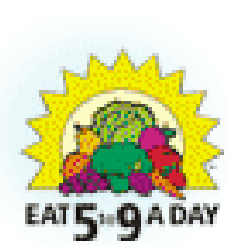

\section{Powerful Antioxidants}

Orange and yellow fruits and vegetables contain varying amounts of antioxidants such as vitamin $C$ as well as carotenoids and bioflavonoids, two classes of phytochemicals that scientists are studying for their health-promoting potential. Every day, include orange and yellow fruits and vegetables like these:

$\begin{array}{llll}\text { Yellow apples } & \text { Oranges } & \text { Nectarines } & \text { Lemon } \\ \text { Mangoes } & \text { Papayas } & \text { Yellowpears } & \text { Golden Kiwifruit } \\ \text { Yellowfigs } & \text { Persimmons } & \text { Cantaloupe } & \text { Tangerines } \\ \text { Yellowbeets } & \text { Apricots } & \text { Peaches } & \text { Pineapples } \\ \text { Grapefruit } & \text { Yellowwatermelon } & \text { Butternut squash } & \text { Carrots } \\ \text { Yellowpeppers } & \text { Yellowpotatoes } & \text { Pumpkin } & \text { Rutabagas } \\ \text { Yellowsummer squash } & & \text { Sweet corn } & \text { Sweet potatoes } \\ \text { Yellow tomatos } & \text { Yellow winter squash } & & \end{array}$

Yellow tomatoes gellow winter squash

\section{GREEN}

Add GREEN to your low-fat diet to maintain:

- $A$ lower risk of some cancers

- Vision health

- Strong bones and teeth

Go Green. Go Healthy.

Green fruits and vegetables contain varying amounts of potent phytochemicals such as lute in and in. doles, which interest researchers because of their potential antioxidant, health-promoting benefits. Go green every day with fruits and vegetables like these:

$\begin{array}{llll}\text { Avocados } & \text { Green apples } & \text { Greengrapes } & \text { Honeydew } \\ \text { Kizifruit } & \text { Limes } & \text { Green pears } & \text { Asparagus } \\ \text { Artichokes } & \text { Arugula } & \text { Broccoflower } & \text { Broccoli } \\ \text { Broccolirabe } & \text { Brussels sprouts } & \text { Chinese cabbage } & \text { Greenbeans } \\ \text { Greencabbage } & \text { Celery } & \text { Chayote squash } & \text { Cucumbers } \\ \text { Endive } & \text { Leafygreens } & \text { Leeks } & \text { Lettuce } \\ \text { Green onion } & \text { Okra } & \text { Peas } & \text { Green pepper } \\ \text { Sugar snap peas } & \text { Spinach } & \text { Watercress } & \text { Zucchini }\end{array}$




\title{
Even more...
}

\author{
$R \mathcal{L D}$ \\ Be sure to include RED in your low-fat diet to help maintain: \\ - A healthy heart \\ - Memory function \\ - A lower risk of some cancers \\ - Urinary tract health
}

\section{Red-hot and Healthy}

The specific phytochemicals in the red group being studied for the ir health-promoting properties include lycopene and anthocyanins. Get your reds every day by eating fruits and vegetables such as:

$\begin{array}{llll}\text { Red apples } & \text { Redgrapes } & \text { Red pears } & \text { Raspberries } \\ \text { Blood oranges } & \text { Pink/Redgrapefruit } & \text { Pomegranates } & \text { Strawberries } \\ \text { Cherries } & \text { Watermelon } & \text { Cranberries } & \\ \text { Radishes } & \text { Red peppers } & \text { Radichio } & \text { Rhubarb } \\ \text { Red onions } & \text { Tomatoes } & \text { Beets } & \text { Red potatoes }\end{array}$

\section{5 or more the easy way}

Try the snacksuggestions below to help reach the goal of eating at le ast 5 servings of fruits and vege tables each day. When you substitute low-calorie, high-fiber fruits and vegetables for less healthful snacks, you'll save on calories and feelfuller, too. It's easy to get 5 to 9 servings of fruits and vegetables into your diet every day. I ust remember to think color!

- Keep mixed nuts and vegetable juice boxes in your deskdrawer and glove compartment.

- Keep a bowl full of fresh veggies and fruits on your kitchen counter for an easygrab ogo.

- $\quad$ Try dipping fresh fruit in a low-fat yogurt and pudding dip.

- Fruits packaged in their own juice, frozen fruits and vegetables, and low-sodium canned vegetables provide the same healthfulbenefits as fresh produce.

- Try dried fruits as a tasty and energizing snackyou can take anywhere.

- Short on time? Lookfor pre-washed, pre-cut vegetables such as baby carrots and broccoli florets at the grocery store. Dip them in nonfat ranch dressing for extra zip.

- Limit your consumption of French fries, snackchips, and other fried vegetable products when nibbling, as well as at mealtimes.

- Toss fruit into your green salad for extra flavor, variety, color, and crunch.

- Expand your palate and your palette with green, red, orange, yellow, and purple peppers.

- Thinkfrozen! Frozen fruits and vegetables are just as healthy as fresh, and they're ready when you need them.

- Add apples, raisins, or pine apple chunks to delisalads like chicken, tuna, or pasta.

- Make a quicksmoothie using frozen fruit. 


\section{Healthier choices...}

Here are some smart substitutions to keep in mind when dining - at fome or at a restaurant:

When Youre At Home...

Choose

$100 \%$ juice

Dried fruit or veggie snacks

$1 / 2$ cup applesauce for baking

Fruit sorbet

\author{
Instead of \\ Soda or coffee \\ Chips, candy, or cookies \\ $1 / 2$ cup oil \\ Ice cream
}

When Youre Eating Out...

Choose

Portobello mushroom burger

Plain baked potato

Leafy green salad

Fruit-based desserts
Instead of Ground beef burger

French fries

Pasta salad

Cakes or sweets

Adapted from the Produce for Better Health Foundation's 5-a-day The Color Way Campaigns found at http://www.5aday.org/html/colorway/colorway_home.php

\section{Sample menu to include 5 a day}

Breakfast: Ulsually do cereal? S lice a medium or half a large banana on top. Above all else, don't forget your morning juice. I ust 6 ounces of $100 \%$ fruit juice or low-sodium vegetable juice counts as a serving toward your $5 \mathcal{A}$ Day.

Tally: 2 servings.

Midmorning snack: Unswe tened portable applesauce counts as a serving and is easy to snackon anywhere. Like those baby carrots? Eat just five or six baby carrots and you have another serving. $\mathcal{A}$ handful of dried fruit (1/4 cup) will do the trick too.

Tally: 3 servings.

Lunch: When you need a quicklunch, try ordering a pita sandwich or wrap loaded with vegetables, or a cup of hearty vegetable soup. Add a small side salad with low-fat dressing, and feelyour energy rise. Tally: 5 servings.

Dinner: Even if you only have 5 minutes, dinner veggies are easy and delicious. Consider cooking canned or frozen peas or cauliflower in the microwave for a quick dinner side dish. Or, make a quick and delicious meal out of a microwave-cooked sweet potato with 1 te aspoon of 6 utter, a splash of apple juice or sque ze of lemon, and a light sprinkling of cinnamon and brown sugar. $\mathcal{A} 1 / 2$ cup of berries counts as one serving.

Tally: 7 servings.

Dessert: S tockyour freezer with $100 \%$ juice Popsicles or place $1 / 2$ cup of berries, peaches, or other favorite fruit on low-fat frozen yogurt and you have added another serving to your day.

Daily total: 8 servings. 


\section{Food and Your Blood Glucose}

\section{How Food Affects Your Blood Gluc ose}

Whether you have type 1 or type 2 diabetes, what, when, and how much you eat all affect your blood glucose. Blood glucose is the ma in sugar found in the blood and the body's main source of energy.

If you have diabetes (or impaired gluc ose tolerance), your blood glucose can go too high if you eat too much. If your blood glucose goes too high, you can get sick.

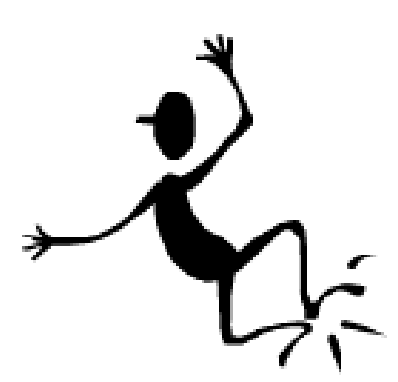

Yourblood glucose can also go too high or drop too low if you don't take the right amount of diabetes medicine.

If your blood gluc ose stays high too much of the time, you can get hea rt, eye, foot, kidney, and other problems. You can also have problems if your blood glucose gets to o low (hypoglycemia).

Keeping your blood gluc ose at a healthy level will prevent or slow down diabetes problems. Ask your doctor or diabetes tea cher what a healthy blood glucose level is for you.

\section{How Can I Keep My Blood Glucose at a Healthy Level?}

How can I keep my blood glucose at a healthy level?

- Eat about the same amount of food each day.

- Eat your meals and snacks at about the same times each day.

- Do not skip meals or snacks.

- Take your medic ines at the same times each day.

- Exerc ise at about the same timeseach day.

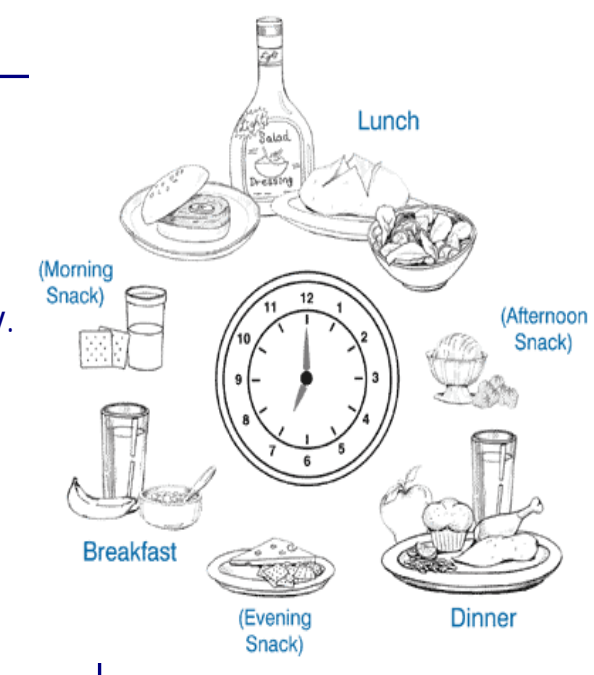

Nutrition Assessment \& Consultation

Exercise Testing \& Prescription

Special points of interest:

- The Food Guide Pyramid

- The scoop on food groups

- What are healthy ways to...

- How can I satisfy my sweet tooth?

- Measuring Your Food 


\section{Why should I eat about the same amount at the same times each day?}

Your blood glucose goesup after you eat. If you eat a big lunch one day and a small lunch the next day, your blood glucose levels will change too much.

Keep your blood glucose at a healthy level by eating about the same a mount of carbohydrate foods at about the same times each day. Carbohydrate foods, also called carbs, provide glucose for energy. Sta rc hes, fruits, milk, sta rchy vegeta bles such as com, and sweets a re all ca rbohydra te foods.

\section{The Food Pyramid}

Eat a variety of food to get the vitaminsand minerals you need. Eat more from the groups at the bottom of the pyramid, and less from the groups at the top.

\section{Starches}

Sta rches a re bread, grains, cereal, pasta, or starchy vegeta bles like com and pota toes. They give your body energy have very little fat, saturated fat, or cholesterol. Whole gra in sta rc hes a re healthier beca use they have more vita mins, minerals, and fiber. Yes, foods with carbohydrate -- sta rc hes, vegetables, fruits, and dairy products -- will raise your blood glucose more quic kly than meats and fats, but they are the healthiest foods for you. Your doctor may need to adjust your medic ations when you eat more carbohydrates. You may need to increase your activity level or try spacing carbohydrates throughout the day.

Eat some starches at each meal. People might tell you not to eat starches, but that is not correct. Eating starches is healthy for everyone, including people with diabetes.

Examples of starches include:

bread pasta com potatoes rice crackers tortillas beans yams

\section{What are healthy ways to eat starches?}

- Buy whole grain breads with at least 2-3 grams of fiber and hot and cold cereals with at least 4 grams of fiber.

- Eat fewer fried and high-fat sta rches such as regular tortilla chips and potato chips, french fries, pastries, or bisc uits. Try pretzels, fat-free popcom, baked tortilla or potato chips, baked potatoes, or low-fat muffins.

- Use low-fat or fat-free yogurt or fat-free sour cream instead of regular sour cream on a baked potato.

- Use mustard instead of mayonnaise on a sandwich.

- Use the low-fat or fat-free substitutes such as low-fat mayonnaise or light margarine on bread, rolls, or toast. 


\section{Vegetables}

Vegeta bles give you vitamins, minera ls, and fiber, with very few calories

Examples of vegetables include:

Spinach broccoli vegetable juice peppers carrots green beans salsa

\section{What are healthy ways to eat vegetables?}

- Eat raw and cooked vegetables with little or no fat, sauces, or dressings.

- Try low-fat or fat-free salad dressing on raw vegetables or salads.

- Steam vegetables using a small a mount of wa ter or low-fat broth.

- Mix in some chopped onion orgarlic.

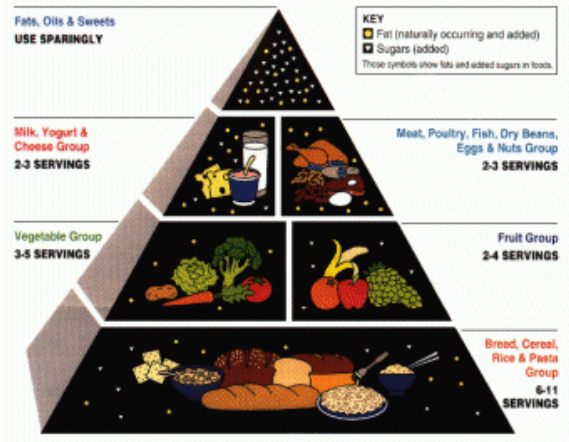

- Use a little vinegar or some lemon or lime juice.

- Add a small piece of lean ham or smoked turkey instead of fat to vegetables when cooking.

- $\quad$ Sprinkle with herbs and spices. These flavorings add a Imost no fat or calories.

- If you do use a small amount of fat, use canola oil, olive oil, or soft marga rines (liquid or tub types) instead of fat from meat, butter, or shortening

- In a tomato sauce, cut the amount of meat you use in half, and add more vegetables-- onions, peppers, mushrooms, eggplant, zucc hini or others.

- Add vegetables into sandwic hes -- not just the old lettuce and toma to, try a lfa Ifa sprouts, sliced red onion, sliced cucumbers, slic ed yellow squa sh or zuc chini, red peppers, or leftover grilled vegetables.

- Toss extra sautéed vegetables on a frozen pizza.

\section{How to Find Help}

Diabetes Teachers (nurses, dietitians, pha mac ists, a nd other hea lth professionals)

To find a diabetes tea cher near you, call the American Association of Dia betes Educators toll-free at 1-800TEAMUP4 (1-800-832-6874) or see www.diabeteseduc ator.org and click on "Find a Dia betes Educator."

Recognized Diabetes Education Programs (tea ching programs a pproved by the Americ an Diabetes Association)

To find a program near you, call toll-free 1-800-DIABEIES (1-800-342-2383) or see www.diabetes.org/ education/edustate2.asp $? \mathrm{loc}=\mathrm{x}$. 


\section{Fruits}

Fruit gives you energy, vita mins, minerals, and fiber.

All carbohydrates, whether rice, potatoes or fruit juice, ra ise blood glucose about the same. In general, an equal a mount of carbohydrate ( 15 grams) such as $1 / 2$ cup grapefruit juice or 4 slices of Melba toast, should raise blood glucose at about the same speed and about the same amount.

However, that va ries based on several factors -- whether you eat a piece of fruit after a high-fat meal or sip fruit juice on an empty stomach, what your blood gluc ose is when you eat the fruit, whether the fruit is cooked or raw, how much diabetes medic ation you have in your body, etc. Use blood glucose monitoring to answer your questions about how fruit works in yourbody.

Examples of fruit include:

apples bananas mango fruitjuice raisins oranges strawberies mango

\section{What are healthy ways to eat fruit?}

- Eat fruits raw or cooked, as juice with no sugar added, canned in their own juice, or dried.

- Buy smaller pieces of fruit.

- Eat piec es of fruit rather than d rinking fruit juice. Pieces of fruit a re more filling.

- Put slices of banana or peaches on cold cereal.

- Drink fruit juice in small a mounts.

- Toss a few ra isins, pieces of apple, dried a pric ot, or pineapple chunks on a salad.

- Save high-sugar and high-fat fruit desserts such as peach cobbler or chemy pie for special occasions.

\section{How to Find More Help}

\section{Dietitians}

- To find a dietitian nearyou, call the American Dietetic Association's National C enter for Nutrition and Dietetic s toll-free at 1-800-366-1655 or see www.eatright.org and click on "Find a Nutrition Professional'

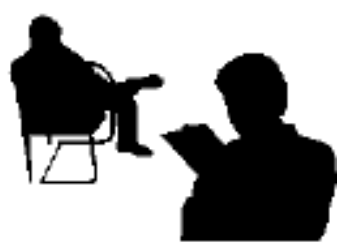




\section{Milk \& Yogurt}

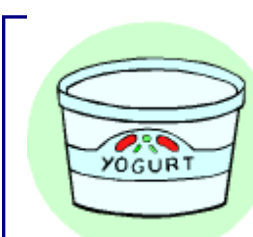

Milk and yogurt give you energy, protein, fat, calcium, vita min A, and other vita mins and minerals.

\section{What are healthy ways to have milk and yogurt?}

- Drink fat-free (skim or nonfat) or low-fat (1\%) milk.

- Eat low-fat or fat-free fruit yogurt sweetened with a low-calorie sweetener.

- Use low-fat plain yogurt as a substitute for sour cream.

- Keep conta iners of yogurt in the refrigerator to use as a quick and convenient snack orpart of a meal

- Eat more hot cereal, use milk to substitute for at least half (if not all) the water, use more milk on the cereal as you eat it.

- Eat more high fiber dry cereal, it is a way to drink more milk and get a good boost of fiber. It is a great way to work in a nother fruit serving.

- Put a serving of milk or yogurt in a blender, toss in a serving of fruit -- banana, strawbemies, or peaches, add a bit of extract, vanilla, rum or maple -- blend it up and sip it

\section{Meat \& Meat Substitutes}

The meat and meat substitutes group includes meat, poultry, eggs, cheese, fish, and tofu. Eat small a mounts of some of these foods each day.

Meat and meat substitutes help your body build tissue and muscles. They also give your body energy and vitamins and minerals.

Examples of meat and meat substitutes a re:

chicken fish meat pork ham cheese peanutbutter eggs tofu

\section{What are healthy ways to eat meat or meat substitutes?}

- Buy cuts of beef, pork, ham, and lamb that have only a little fat on them. Trim off extra fat.

- $\quad$ Eat chic ken or turkey without the skin.

- Cook meat or meat substitutes in low-fat ways: broil, grill, stir fry, steam, roast, stew

- Limit the a mounts of nuts, pea nut butter, and fried chicken that you eat. They a re high in fat.

- Choose low-fat orfat-free cheese. 


\section{Fats \& Sweets}

Limit the a mounts of fats and sweets you eat. They have calories, but not much nutrition. Some contain saturated fats and cholesterol that inc rease your risk of heart disease. People with diabetes have more frequent heart disease. One of the most important diabetes nutrition guidelines is to hold saturated fat to less than $10 \%$ of calories. Limiting these foods will help you lose weight and keep your blood glucose and blood fats under control lowering your risk for this diabetes complication. Also, some people with abno mal blood lipids (fat) and a high triglyceride might benefit from increasing the amount of monounsaturated fats they eat. As for cholesterol, keep it to $300 \mathrm{mg}$ or less each day.

Examples of fats are:

salad dressing oil butter margarine

Note: a serving of fat equals 1 teaspoon of oil, 1 strip of bacon

Examples of sweets are:

regularsoda cake cookies ice cream candy pie

Note: a serving of sweet is 13 -inch cookie, 4 choc olate kisses, 1 tablespoon ma ple syrup

\section{How can I satisfy my sweet tooth?}

It's okay to have sweets once in a while. Try having sugar-free popsicles, diet soda, fatfree ice cream or frozen yogurt, or sugar-free hot cocoa mix.

Other tips:

- Share desserts in restaurants.

- Order sma ll or child-size servings of ice cream or frozen yogurt.

- Divide homemade desserts into small servings and wrap each individually. Freeze extra servings.

- Don't keep dishes of candy in the house or at work.

Remember, fat-free and low-sugar foods still have calories. Talk with your diabetes teacher about how to fit sweets into your meal plan. 


\section{How can I c ut down on saturated fat?}

Concentrate on decreasing the amount of:

\section{Meats:}

- Purchase lean cuts.

- Cut off all visible fat prior to cooking.

- Use preparation methods that get rid of more fat, such as grilling.

- Eat 2-3 ounce portions (cooked). This serving is about the size of the palm of your ha nd, a deck of cards, or a mayonnaise jar lid.

\section{Poultry:}

- Take off the skin either before or after cooking.

\section{Seafood:}

- Prepare with small a mounts of fat.

- $\quad$ Eat 2-3 ounce portions (cooked).

\section{Cheese:}

- Limit the a mount you eat.

- Buy part skim, or reduced fat cheeses.

\section{Butter:}

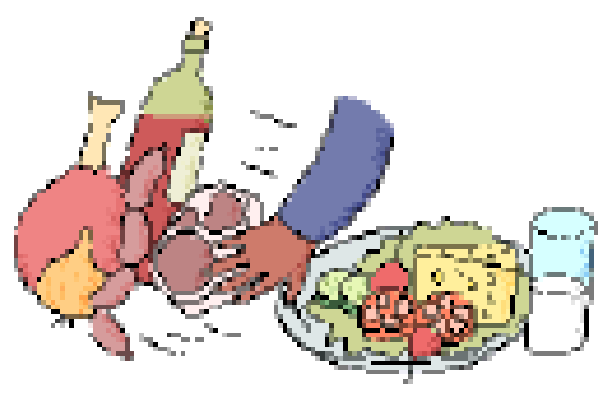

- Use tub margarine.

- Use butter on occasion, maybe in a recipe.

\section{Milk/Yogurt}

- Use the fat-free (skim) varieties.

\section{Proc essed Foods:}

- Read the labels of processed foods and check for tropic al oils (such as pa Im or coc onut), and see how fardown on the ingredient list they fall. Ingredients a re listed in descending order of predominance in the product. The ingredient used in the greatest qua ntity is listed first, and the ingredient used in the smallest quantity is listed last. 


\section{Easy ways to spare and skim the fat}

- If a recipe calls for cheese and you want to use a regulartype, buy a sharp va riety and use a smaller quantity. The sharper taste gives more flavor with a smalleramount.

- Buy the low-fat, light, and fat-free products that taste good to you. You might have to experiment with several -- margarine, butter (or blends), cream cheese, cottage cheese, mayonnaise, and sour cream. Remember, these products are not calorie-free. Be sure to read the Nutrition Facts label to leam more about the product.

- Buy the low-fat, reduced-calorie or fat-free salad dressing that has the taste you like. No matter what salad dressing you use, don't pour on too much. Remembera 1/4 of a cup can contain as many carbohydrates as a slice of bread.

- Use low or no sugar jelly or jam instead of ma rga rine or cream cheese on bagel, toast, or muffins.

- Use plain, fat-free yogurt orfat-free sour cream instead of regular sour cream -- add herbs and seasonings to make it tasty. Use it on baked potatoes, vegetables, chicken and fish.

- Always keep fresh lemon and lime on hand to squirt on vegetables and fish at the table instead of adding more fat (such as sa uces, butter or ma rgarine).

- When you buy meats, buy lean cuts; trim off excess fat; prepare in low fat a nd moist ways.

- Marinate meats and vegetables in wine, vinegars, seasonings and spices to a dd fla vors without adding fat.

\section{Measuring Your Food}

To make sure your food servings a re the right size, use

- $\quad$ measuring cups

- $\quad$ measuring spoons

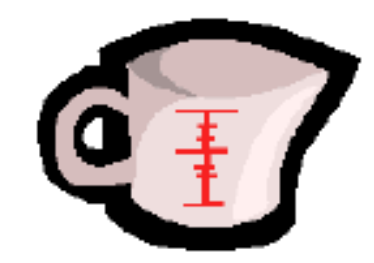

- a food scale

Also, the Nutrition Facts label on food packages tells you how much of that food is in one serving.

Weigh or measure foods to make sure you eat the right a mounts.

Adapted from the National Institute of Diabetes and Digestive and Kidney Disorders, National Institute of Health found at http://diabetes.niddk.nih.gov/dm/pubs/eating_ez/ind ex.htm\#affects

And the American Diabetes Association found at http:// www.diabetes.org/main/health/nutrition/ food pyra mid/food pyra mid.jsp 


\section{How to Prevent Diabetes}

If type 2 dia betes was an infectious disease, passed from one person to a nother, public health officials would say we're in the midst of an epidemic. This diffic ult disea se, once called adult-onset diabetes, is striking a n ever-growing number of adults. Even more ala ming, it's now beginning to show up in teenagers and children.

If the spread of type 2 diabetes continues at its present rate, the number of people affected in the United States will inc rease from about 14 million in 1995 to 22 million in 2025. Worldwide, the number of ad ults with dia betes will rise from 135 million in 1995 to 300 million in the year 2025 .

The problems behind the numbers are even more ala ming. Diabetes is the leading cause of blindness and kidney failure a mong a dults. It causes mild to severe nerve damage that, coupled with diabetes-related circulation problems, often leads to the loss of a leg or foot. Diabetes signific antly increa ses the risk of heart disea se. And it's the sixth leading cause of death in the U.S., directly causing almost 70,000 deaths each year and contributing to thousands more.

The good news is that type 2 diabetes is largely preventable. About 9 cases in 10 could be avoided by taking several simple steps: keeping weight under control,

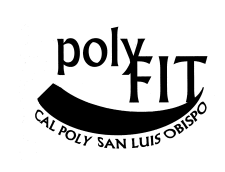

Nutrition Assessment \& Consultation

Exercise Testing \& Prescription

Special points of interest:

- Lifestyle habits shown to prevent diabetes

- The Bottom Line

- Steps Towards Prevention

\section{What is Type 2 Diabetes?}

Our cells depend on a single simple sugar, gluc ose, for most of their energy needs. That's why the body has intric ate mechanisms in place to make sure gluc ose levels in the bloodstream don't go too low or soar too high.

When you eat, most digestible carbohydrates a re converted into glucose and rapidly absorbed into the bloodstream. Any rise in blood sugar signals the pancreas to make and relea se insulin. This hormone instructs cells to sponge up gluc ose. Without it, gluc ose floats a round the bloodstream, unable to slip inside the cells that need it.

Diabetes occurs when the body can't make enough insulin orcan't properly use the insulin it makes.

One form of diabetes occ urs when the immune system attacks and perma nently disables the insulinmaking cells in the pancreas. This is type 1 diabetes, once called juvenile-onset or insulin-dependent diabetes. It affects about one million Americans.

The other form tends to creep up on people, taking years to develop into full-blown diabetes. It begins when musc le and other cells stop responding to insulin's open-up-for-glucose signal. The body responds by making more and more insulin, essentially trying to ram blood sugar into cells. Eventually, the insulinmaking cells get exhausted and begin to fail. This is type 2 diabetes. 


\section{Type 2 Diabetes Can Be Prevented}

In a ddition to the 16 million a dults with type 2 diabetes, a nother 13 million have "pre-diabetes." This early waming sign is characterized by high blood sugar levels on a glucose tolerance test or a fasting glucose test. Whether pre-dia betes expands into full-blown type 2 diabetes is la rgely up to the individual-ma king changes in weight, exercise, and diet can not only prevent pre-diabetes from becoming diabetes, but can also retum blood gluc ose levels to the nomal range.

Although the genes you inherit may influence the development of type 2 diabetes, they take a back seat to behavioral and lifestyle factors. Data from the Nurses' Health Study suggest that $90 \%$ of type 2 diabetes in women can be attributed to five such factors: excess weight, lack of exercise, a less-than-hea lthy diet, smoking, and abstaining from alc ohol.

Among 85,000 maried female nurses, 3,300 developed type 2 diabetes over a 16-year period. Women in the low-risk group were $90 \%$ less likely to ha ve developed diabetes than the rest of the women. Low-risk mea nt a hea lthy weight (body-mass ind ex [BMI] less than 25), a healthy diet, 30 minutes or more of exerc ise daily, no smoking, and having about three alcoholic drinks per week.

Similar factors are at work in men. Data from the Health Professionals Follow-up Study indica te that a "westem" diet combined with lack of physic al ac tivity and excess weight dramatica lly increa ses the risk of type 2 dia betes in men.

Information from several c linic al tria ls strongly support the idea that type 2 diabetes is preventable. The Diabetes Prevention Program examined the effect of weight loss and increased exerc ise on the development of type 2 diabetes among men and women with high blood sugar rea dings that hadn't yet crossed the line to diabetes. In the group assigned to weight loss and exercise, there were $58 \%$ fewer cases of diabetes after a lmost three years than In addition to the 16 million in the group assigned to usual care. Similar results were seen in a Finnish study of weight loss, exerc ise, and dietary change.

\section{The Bottom Line}

Lifestyle changes as simple as hea lthier eating habits, a little less weight (if necessary), and a lot more activity will help prevent the development of Type 2 diabetes. These changes will also help reduce your risk of other chronic disea ses such a shea rt dise ase, obesity and cancer. In addition, you will feel better physic ally, have more energy, feel less stress, and overall be a healthier person.

Take the steps now to begin your travels on the path to a healthier you.

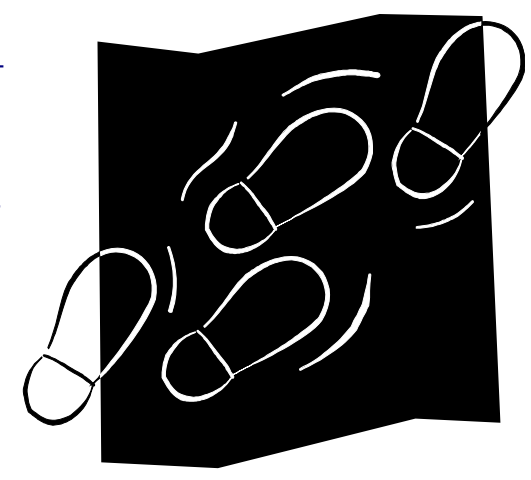




\section{Simple Steps To Preventing Diabetes}

Making a few changescan dramatic ally lower the chances of developing type 2 diabetes. The same changescan also lower the chances of developing hea t disea se and some cancers.

Control your weight. Exc ess weight is the single most importa nt ca use of type 2 diabetes. Being overweight increases the chances of developing type 2 diabetes seven-fold. Being obese makes you 20 to 40 times more likely to develop diabetes than someone with a healthy weight.

Losing weight can help if your weight is above the healthy-weight range. Losing $7-10 \%$ of your current weight can cut in half your chances of developing type 2 diabetes.

Get moving. Inactivity promotes type 2 diabetes. Every two hours you spend watching TV instead of pursuing so mething more active increases the changes of developing diabetes by $14 \%$. Working your musc les more often and making them work harder improves their a bility to use insulin and absorb glucose. This puts less stress on your insulin-ma king cells.

Long bouts of hot, sweaty exercise aren't necessary to reap this benefit. Findings from the Nurses' Health Study and Hea lth Professiona Is Follow-up Study suggest that wa lking briskly for a half hour every day reduces the risk of developing type 2 diabetes by $30 \%$

This a mount of exerc ise has a va riety of other benefits as well. Of c ourse, even greater cardiova sc ula rand other benefits can be attained by more, and more intense, exercise.

Tune-up your diet. Two dietary changescan have a big impact on the risk of type 2 dia betes.

1) Choose whole grains and whole-gra in products over highly processed carbohydrates. White bread, white rice, mashed potatoes, donuts, bagels, and many breakfast cerea ls have what's called a high glycemic index. That means they cause susta ined spikes in blood sugar and insulin levels. Carbohyd rates that a ren't a s ea sily digested cause lower, slower increases in blood sugar and insulin. As a result, they stress the body's insulin-making mac hinery less, a nd so help prevent type 2 diabetes. Such foods have a low glycemic index. Examples include whole wheat, brown rice, most beans and nuts, couscous, and whole grain breakfast cereals.

2) Choose good fats instead of bad fats. The types of fats in your diet can also affect the development of diabetes. Good fats, such as the polyunsaturated fats found in tuna, salmon, liquid vegetable oils, and many nuts, can help ward off type 2 diabetes. Trans fats do just the opposite. These bad fats are found in many margarines, packaged baked goods, fried foods in most fast-food restaurants, and any product that lists "partially hydrogenated vegetable oil" on the la-

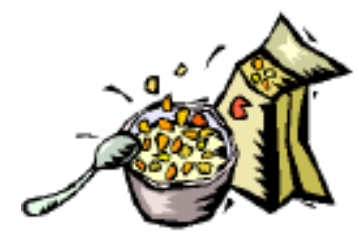
bel. If you a lrea dy have diabetes, eating fish can help protect you against a heart attack ordying from heart disease. 


\section{Steps To Prevention Continued...}

If you smoke, try to quit. Add type 2 diabetes to the long list of health problems linked with smoking. Smokers a re $50 \%$ to $90 \%$ more likely to develop diabetes than nonsmokers.

Alc ohol now and then may help. A growing body of evidence links moderate alc ohol consumption with reduced risks of heart disease. The same ma y be true for type 2 diabetes. Moderate amounts of alcohola drink a day for men, a drink every other day for women-inc reases the effic iency of insulin at getting glucose inside cells. And some studies indicate that moderate alcohol consumption decrea ses the risk of type 2 dia betes. If you a lready drink a lcohol, the key is to keep your consumption in the moderate range. If you don't drink a lcohol, there's no need to start-you can get the same benefits by losing weight, exercising more, and changing your eating pattems.

\section{The bottom line}

They key to preventing type 2 diabetescan be boiled down to five words: Stay lean and sta y active.

Adapted from the Harvard School of Public Health Nutrition Source. For full article and references go to http://www.hsph.harva rd .edu/nutritionsource/dia betes.html

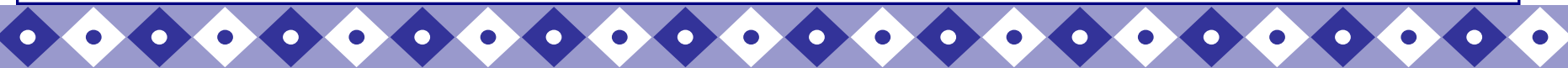




\section{Diverticulosis \& Diverticulitis}

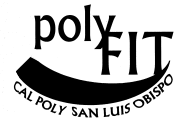

Many people have small pouches in their colons that bulge outward through weak spots, like an inner tube that pokesthrough weak places in a tire. Each pouch is called a diverticulum. Pouches (plural) are called diverticula. The condition of having diverticula iscalled diverticulosis. About half of all Americansage 60 to 80 , and almost everyone over age 80 , have diverticulosis.

When the pouches become infected or inflamed, the condition iscalled diverticulitis. This happens in 10 to 25 percent of people with diverticulosis. Diverticulosis

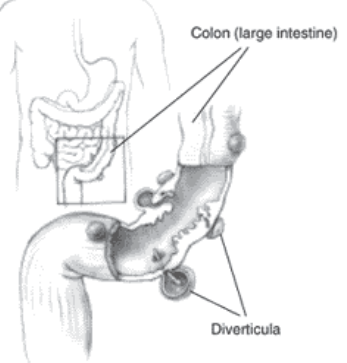
and diverticulitis are also called diverticular disease.

Special points of i nterest:

- What are the symptoms?

- Are there any complications?

- How is it diagnosed?

- What is the treatment?

\section{What causes diverticular disease?}

Though not proven, the dominant theory is that a low-fiber diet is the main cause of diverticular disease. The disease was first noticed in the United States in the early $1900 \mathrm{~s}$. At about the same time, processed foods were introduced to the American diet. Many processed foods contain refined, low-fiber flour. Unlike whole-wheat flour, refined flour has no wheat bran.

Diverticular disease is common in developed or industrialized countriesparticularly the United States, England, and Australia--where low-fiber diets are common. The disease is rare in countries of Asia and Africa, where people eat high-fiber vegetable diets.

Fiber is the part of fruits, vegetables, and grains that the body cannot digest. Some fiber dissolves easily in water (soluble fiber). It takes on a soft, jelly-like texture in the intestines. Some fiber passes almost unchanged through the intestines (insoluble fiber). Both kinds of fiber help make stools soft and easy to pass. Fiber also prevents constipation.

Constipation makes the muscles strain to move stool that is too hard. It is the main cause of increased pressure in the colon. The excess pressure might be the cause of the weak spots in the colon that bulge out and become diverticula.

Diverticulitis occurs when diverticula become infected or inflamed. Doctors are not certain what causes the infection. It may begin when stool or bacteria are caught in the diverticula. An attack of diverticulitis can develop suddenly and without warning. 
A high-fiber diet and, occasionally, mild pain medications will help relieve symptoms in most cases.

\section{What are the symptoms?}

\section{Diverticulosis}

Most people with diverticulosis do not have any discomfort or symptoms. However, symptoms may include mild cramps, bloating, and constipation. Other diseases such as irritable bowel syndrome (IBS) and stomach ulcers cause similar problems, so these symptoms do not always mean a person has diverticulosis. You should vist your doctor if you have these troubling symptoms.

\section{Diverticulitis}

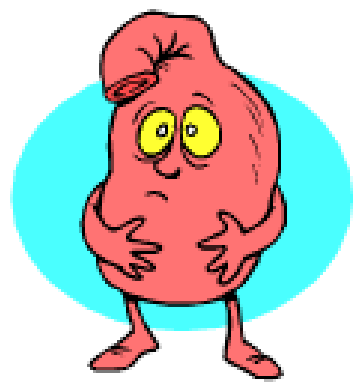

The most common symptom of diverticulitisisabdominal pain. The most common sign istenderness around the left side of the lower abdomen. If infection is the cause, fever, nausea, vomiting, chills, cramping, and constipation may occur as well. The severity of symptoms depends on the extent of the infection and complications.

\section{Are there complications?}

Diverticulitis can lead to complications such as infections, perforations or tears, blockages, or bleeding. These complications always require treatment to prevent them from progressing and causing seriousillness.

\section{How does the doctor diagnose diverticular disease?}

To diagnose diverticular disease, the doctor asks about medical history, does a physical exam, and may perform one or more diagnos tic tests. Because most people do not have symptoms, diverticulosis is often found through tests ordered for another ailment.

When taking a medical history, the doctor may ask about bowel habits, symptoms, pain, diet, and medications. The physical exam usually involvesa digital rectal

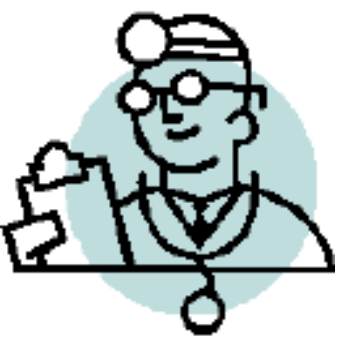
exam. To perform this test, the doctor inserts a gloved, lubricated finger into the rectum to detect tenderness, blockage, or blood. The doctor may check stool for signs of bleeding and test blood for signs of infection. The doctor may also order $x$ rays or other tests. 
The doctor may also recommend taking a fiber product such as Citrucel or Metamucil once a day. These products are mixed with water and provide about 2 to 3.5 grams of fiber per tablespoon, mixed with 8 ounces of water.

Until recently, many doctors suggested avoiding foods with small seeds such as tomatoes or strawberries because they believed that particles could lodge in the diverticula and cause inflammation. However, this is now a controversial point and no evidence supportsthis recommendation. Individuals differ in the amounts and types of foods they can eat.

If cramps, bloating, and constipation are problems, the doctor may prescribe a short course of pain medication. However, many medications affect emptying of the colon, an und esirable side effect for people with diverticulosis.

\section{What is the treatment for diverticular disease?}

A high-fiber diet and, occasionally, mild pain medicationswill help relieve symptoms in most cases. Sometimesan attack of diverticulitis is serious enough to require a hospital stay and possibly surgery.

\section{Diverticulosis}

Increasing the amount of fiber in the diet may reduce symptoms of diverticulosis and prevent complications such as diverticulitis. Fiber keeps stool soft and lowers pressure inside the colon so that bowel contentscan move through easily. The American Dietetic Association recommends 20 to 35 grams of fiber each day. The table below showsthe amount of fiber in some foods that you can easily add to your diet.

\section{Amount of fiber in some foods}

\section{Fruits}

apple

peach

pear

$\begin{array}{lll}\text { 1medium } & = & 4 \text { grams } \\ \text { 1medium } & = & 2 \text { grams } \\ 1 \text { medium } & = & 4 \text { grams }\end{array}$

\section{Vegetables}

acorn squash, fresh, cooked asparagus, fresh, cooked

broccoli, fresh, cooked

cabbage, fresh, cooked

carrot, fresh, cooked

$\begin{array}{lll}3 / 4 \text { cup } & = & 7 \text { grams } \\ 12 \text { cup } & = & 15 \text { grams } \\ 12 \text { cup } & = & 2 \text { grams } \\ 12 \text { cup } & = & 2 \text { grams } \\ 1 & = & 15 \text { grams } \\ 12 \text { cup } & = & 2 \text { grams } \\ 1 \text { cup } & = & 1 \text { gram } \\ 12 \text { cup } & = & 2 \text { grams } \\ 1 & = & 1 \text { gram } \\ 1 \text { cup } & = & 2.5 \text { grams }\end{array}$

\section{Starchy Vegetables}

black-eyed peas, fresh, cooked $1 / 2$ cup = 4 grams

kidney beans, fresh, cooked $1 / 2$ cup = 6 grams

potato, fresh, cooked $\quad 1=3$ grams

\section{Grains}

bread, whole-wheat $\quad$ sdice 2 grams

brown rice, cooked lcup $\quad 3.5$ grams

cereal, bran flake $\quad 3 / 4$ cup $=5$ grams

oatmeal, plain, cooked $3 / 4$ cup $=3$ grams

white rice, cooked lcup = 1gram

Source: United States Department of Agriculture (USDA). USDA Nutrient Database for standard reference. Available at www.nal.usda.gov/fnic/cgi-bin/nut_search.pl. Accessed September 19, 2001 


\section{Treatment continued...}

\section{Diverticulitis}

Treatment for diverticulitisfocuses on clearing up the infection and inflammation, resting the colon, and preventing or minimizing complications. An attack of diverticulitis without complications may respond to antibiotics within a few days if treated early.

To help the colon rest, the doctor may recommend bed rest and a liquid diet, along with a pain reliever.

An acute attack with severe pain or severe infection may require a hospital stay. Most acute cases of diverticulitis are treated with antibiotics and a liquid diet. The antibiotics are given by injection into a vein. In some cases, however, surgery may be necessary.

\section{Points to Remember}

- Diverticulosis occurs when small pouches, called diverticula, bulge outward through weak spots in the colon (large intestine).

- The pouches form when pressure inside the colon builds, usually because of constipation.

- Most people with diverticulosis never have any discomfort or symptoms.

- The most likely cause of diverticulosis is a low-fiber diet because it increases constipation and pressure inside the colon.

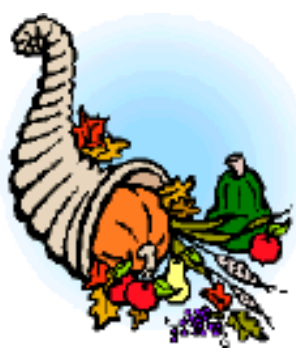

- $\quad$ For most people with diverticulosis, eating a high-fiber diet is the only treatment needed.

- $\quad$ You can increase your fiber intake by eating these foods. whole grain breadsand cereals, fruit like apples and peaches; vegetables like broccoli, cabbage, spinach, carrots, asparagus, and squash; and starchy vegetables like kidney beans and lima beans. inflamed and cause pain and tenderness around the left side of the lower abdomen.

Adapted from the National Digestive Diseases Information Clearing House (NDDIC) of the National Institute of Diabetes and Digestive and Kidney Disorders (NIDDK) found at http:// digestive.niddk.nih.gov/ddiseases/pubs/diverticulosis/index.htm 


\section{Nutrition for the Heart}

\section{Ways to \\ lower satu- rated fat \& cholesterol!}

\section{Special points of interest:}

- American Heart Association Guidelines Summary

- Understanding Fats \& Oils

- Understanding Carbohydrates \& Sugars

- Understanding Milk Products

- Understanding Meat, Poultry \& Fish

- Other ways to lower cholesterol \& saturated fat

- Trans-fatty acids

\section{Fat \& Cholesterol}

Eating foods that are high in fat (especially saturated fat) and cholesterol isn't good for you. The reason is that a high-saturated-fat, high-cholesterol diet can raise the level of cholesterol in your blood. This can speed the development of artherosclerosis, which is the buildup of fatty deposits in the inner walls of arteries. If your arteries become narrowed by fatty deposits, they may close or become blocked by a blood clot. When one of the heart's arteries is blocked, a heart attack results.

There are four kinds of fats in the foods we eat: saturated, polyunsaturated, monounsaturated,

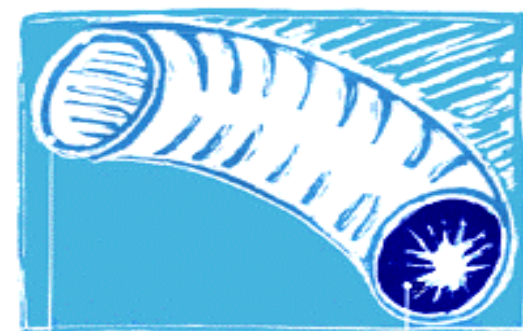

Normal artery wall
Abnormal narrowed artery opening and trans. Most foods contain the first three types of fat, but in varying amounts. Saturated fatty acids, trans fats and dietary cholesterol raise blood cholesterol. A high level of cholesterol in the blood is a major risk factor for coronary heart disease, which causes heart attacks.

Of course, many factors affect a person's risk of heart disease. But eating a low-fat, low-cholesterol diet may reduce one of your risks for heart attack.

\section{AHA Dietary Guidelines for Healthy American Adults}

- Total fat intake should be less than $30 \%$ of energy

- Saturated fatty acid intake should be less than $10 \%$ of total energy

- Polyunsaturated fatty acid intake should be no more than $10 \%$ of total energy

- Monounsaturated fatty acid intake should make up the rest of total fat intake, about $10 \%$ to $15 \%$ of total energy

Cholesterol intake should be no more than $300 \mathrm{mg} / \mathrm{d}$

Cholesterol is found in animal products

Sodium intake should be no more than $3000 \mathrm{mg}(3 \mathrm{~g})$ per day

Beware of salt, monosodium glutamate, baking powder \& bak ing soda 


\section{AHA Guidelines Continued for Food Selection}

- No more than 5 to 8 teaspoons of fats and oils per day, including the fats used in cooking and baking and in salad dressings and spreads

- Six ounces or less of lean meat, fish, or skinless poultry

. No more than three or four egg yolks per week

- Two to four servings of nonfat or low-fat milk and dairy products per day

- Five or more servings of fruits and vegetables per day

- Six or more servings of breads, cereals, rice, pasta, other grains, and starchy vegetables per day

\section{Understanding Fats \& Oils}

Fats, oils and nuts have the lowest serving size of all the food groups on the food pyramid. Here are some important facts that help illustrate why you should limit your intake of items from this food group:

Fats and oils high in saturated fat tend to become hard at room temperature. These include butter, lard and tallow made from animals, as well as coconut, palm and palm kernel oils from plants. These fats raise cholesterol, so you'll want to avoid them.

Nuts and seeds contain lots of fat, but most of it is unsaturated. However, while nuts and seeds contain no cholesterol, these tasty snacks also are loaded with calories.

\section{Daily Recommendation and Serving Size needs) \\ No more than 5-8 servings (varies with caloric}

\section{Serving Sizes}

Serving sizes for this food group vary depending upon the items you select.

Here's a sample of typical serving sizes:

1 tsp. vegetable oil or regular margarine

2 tsp. diet margarine

1 Tbsp. salad dressing

2 tsp. mayonnaise or peanut butter

3 tsp. seeds or nuts

$1 / 8$ of medium avocado

10 small or 5 large olives
Here is a handy guide that will help you easily work the recommended 5-8 servings of fats, oils, nuts and seeds per day into your diet.

Each suggestion counts as one serving.

Vegetable Oils

Safflower, corn, sunflower, soybean, cottonseed, olive, canola, peanut (1 tsp.)

\section{Shortening}

Soybean and cottonseed oil (1 tsp.)

Margarines

Diet margarine (2 tsp.)

Margarine with no more than 2 grams of saturated fatty acids per tablespoon (1 tsp.)

Nuts and Seeds

Chopped nuts, except coconut (1 Tbsp.)

Seeds, any variety, without shells (1 Tbsp.)

Salad Dressings

French, Italian, Thousand Island or mayonnaise-type salad dressing (1 Tbsp.)

Mayonnaise (2 tsp.)

Other Fats

Avocado (1/2 medium)

Olives (10 small or 5 large)

Peanut butter (2 tsp.) 


\section{Understanding Carbohydrates \& Sugars}

The American Heart Association's recommended level of dietary fat is no more than 30 percent of total calories. Reducing the intake of dietary fat to this level will require a modest increase in carbohydrates. When the proportion of calories from fat in the diet is reduced, carbohydrates should make up the caloric difference.

\section{AHA Recommendation:}

Carbohydrate intake should be 55-60 percent or more of total calories. The emphasis should

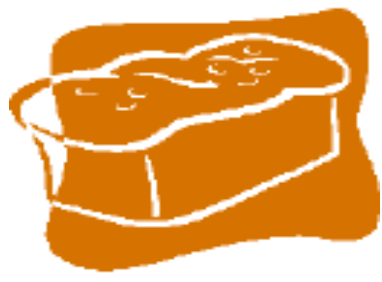
be on increasing the use of complex carbohydrates - vegetables, fruits and grains. This is preferable to increasing the intake of simple carbohydrates found in sugars. The complex carbohydrates avoid surges of hyperglycemia and add more roughage to the diet.

Foods high in complex carbohydrates are usually low in calories and have a wide variety of vitamins and minerals.

\section{Complex Carbohydrates}

Here are some examples of foods that are rich in complex carbohydrates:

\section{Starches}

Flour, bread, rice, corn, oats, barley, potatoes, legumes, fruits and vegetables

\section{Fiber, Insoluble}

Whole-wheat breads and cereals, wheat bran, cabbage, beets, carrots, Brussels sprouts, turnips, cauliflower and apple skin (pectin)

\section{Fiber, Soluble}

Oat bran, oats, legumes, citrus fruits, strawberries, apple pulp, psyllium, rice bran and barley. The AHA recommends 25-30 grams of fiber per day.

\section{Simple Carbohydrates}

Here are some examples of foods that are sources of simple carbohydrates:

Sucrose Table sugar, brown sugar, confectioners sugar, raw sugar and turbinado

Glucose Dextrose, corn syrup and glucose syrup

Fructose Fruits, vegetables and honey

High Fructose Corn Syrup Liquid sweetener which contains

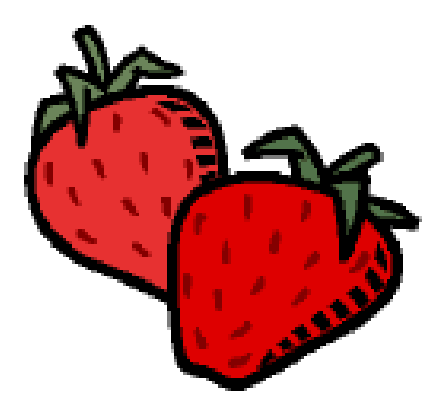

$42-90 \%$ fructose

Honey Made up of glucose, fructose and water

Sugar Alcohols Sorbitol, mannitol, xybitol

Lactose Milk and milk products

Maltose, Dextrose Cereals and some baked goods 


\section{Understanding Milk Products}

Hooray! You can have the dairy products you love and still lower your cholesterol! A simple switch to low-fat and fatfree milk products makes eating the rich, creamy milk products you love satisfying and heart-healthy. If you use whole milk (3.5\% fat) products, you may find it easier to taper off slowly. Try low-fat, $1 \%$ fat milk first, then change to $1 / 2 \%$ fat milk. Soon you'll be able to switch to fat-free milk with no trouble.

\section{Sensational Suggestions}

Here's a handy guide that will help you easily work the recommended servings of milk products into your daily low-fat diet. Each of the following is a serving and has an average of 100 calories.

\section{Milk}

Use fat-free, $1 / 2 \%$ fat or $1 \%$ fat milk fortified with vitamins $A$ and $D$. ( 1 cup)

Nonfat or low-fat plain yogurt (1 cup)

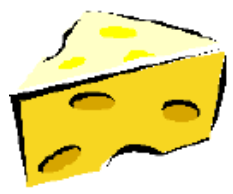

Cheese

Cottage cheese, $1 \%$ fat or dry curd ( $1 / 2$ cup)

Mozzarella, part-skim milk (1 oz.)

Ricotta cheese, low-fat (1 oz.)

Low-fat cheese, $3 \mathrm{~g}$ fat or less per oz. ( $1 / 4$ cup diced) $(1 \mathrm{oz}$.)

Dry, grated cheese, e.g., dry Parmesan or "Sap Sago" (1 Tbsp.) (1/4 Oz.)

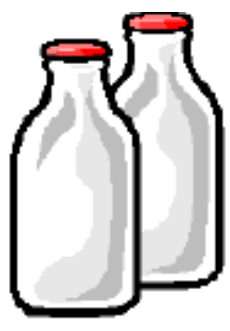

\section{Frozen Dairy Desserts}

Frozen nonfat or low-fat yogurt ( $1 / 2$ cup)

Nonfat or low-fat ice cream (3 g fat or less) ( $1 / 2$ cup)

Sherbet (1/3 cup)

\section{Savory Substitutions}

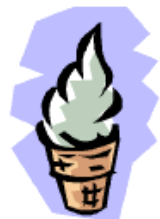

Making the right food choices - and cutting out the fat in your diet - is easy when you are familiar with the world of delicious food options available. The next time you crave an item from this food group that is higher in fat, keep these savory substitutions in mind:

Instead of

Regular cheese

Ice cream bars

Pudding made with whole milk Ice cream

Ice cream (16\% fat)

\section{Try}

Nonfat or low-fat cheese: Skim milk mozzarella cheese, cottage cheese and reduced-fat ricotta cheese

Frozen fruit bars

Pudding made with skim or fat-free milk

Frozen low-fat yogurt

Ice Milk (10\% fat)

\section{Understanding Meat, Poultry \& Fish}

When it comes to meat, aim for a total of 5-6 ounces per day, served in one or two portions. That's really all the poultry, seafood or lean meat your body needs. And remember, most fish and poultry have fewer calories than fatty cuts of red meat. They do contain cholesterol, though, so keep portions the same as for red meat. Lean red meat is available; look for it at your meat counter.

\section{Savory Substitutions}

The next time you crave an item from the meat, poultry and fish food group that is higher in fat, keep these savory substitutions in mind:

Instead of

Tuna packed in oil

Deep-fried fish

Dark-meat poultry
Try

Tuna packed in water

Baked fish

White-meat poultry

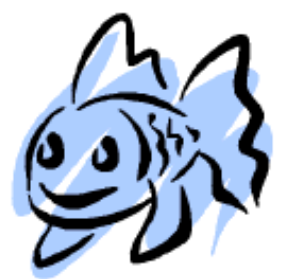




\section{Other Ways to Lower Cholesterol}

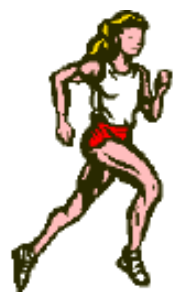

Be more physically active.

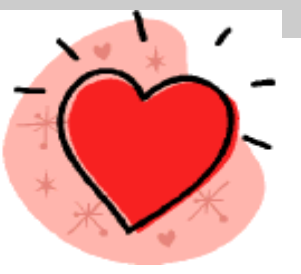

Physical activity/exercise. Regular physical activity may lower LDL ("bad") cholesterol and raise HDL ("good") cholesterol levels.

Lose weight if you are overweight.

Weight. Excess weight tends to increase your LDL ("bad") cholesterol level. If you are overweight and have a high LDL-cholesterol level, losing weight may help you lower it. Weight loss also helps to lower triglycerides and raise HDL ("good") cholesterol levels.

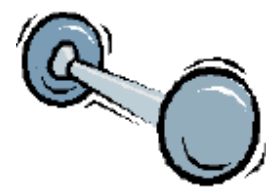

\section{Other Ways to Lower Saturated Fat...}

Keep animal foods and tropical oils to a minimum.

Foods such as beef, beef fat, veal, lamb, pork, lard, poultry fat, butter, cream, milk, cheeses and other dairy products made from whole milk and plant foods such as coconut, palm, palm kernel oils are high in satu rated fat.

\section{The low down on trans-fatty acids}

To make foods that will stay fresh on the shelf or to get a solid fat product, such as margarine, food manufacturers hydrogenate polyunsaturated oils. Hydrogenate means to add hydrogen. When unsaturated fatty acids are hydrogenated, some of the hydrogen atoms are added on opposite sides of the molecule to the already attached hydrogen. Certain bonds convert to what are called trans double bonds, and the fatty acids become saturated.

In clinical studies, trans fatty acids or hydrogenated fats tend to raise total blood cholesterol levels but not as much as more saturated fatty acids. Trans fatty acids also tend to raise LDL ("bad") cholesterol and lower HDL ("good") cholesterol when used instead of cis fatty acids or natural oils. These changes may increase the risk of heart disease. Some tips...

- Use naturally occurring, unhydrogenated oil such as canola or olive oil when possible.

- Look for processed foods made with unhydrogenated oil rather than hydrogenated or saturated fat.

- Use margarine as a substitute for butter, and choose soft margarines (liquid or tub varieties) over harder, stick forms. Shop for margarine with no more than 2 grams of saturated fat per tablespoon and with liquid vegetable oil as the first ingredient.

- French fries, donuts, cookies and crackers are examples of foods that are high in trans fatty acids. 


\section{A Little Bit About Saturated Fat...}

\section{Saturated Fatty Acids}

Saturated fatty acids have all the hydrogen the carbon atoms can hold. Saturated fats are usually solid at room temperature and they are more stable that is, they do not combine readily with oxygen. Saturated fatty acids are the main dietary culprit in raising blood cholesterol. The main sources of saturated fatty acids in the typical American diet are foods from animals and some plants.

\section{Special points of} interest:

- How much fat is recommended?

- Decrease the amount of...

- Easy ways to skim and spare the fat
- Foods from animals that have high amounts of saturated fatty acids include beef, beef fat, veal, lamb, pork, lard, poultry fat, butter, cream, milk, cheeses and other dairy products made from whole milk. These foods also contain dietary cholesterol.

- Foods from plants that contain high amounts of saturated fatty acids include coconut oil, palm oil and palm kernel oil (often called tropical oils) and cocoa butter.

\section{Dietary Guidelines...}

The American Heart Association has established some Dietary Guidelines relative to the amount of fat one should take in on a daily basis. Keep these guidelines in mind when shopping and preparing meals.

- Total fat intake should be adjusted to appropriately meet an individual's caloric needs. People who are overweight or obese should limit their intake of fat to no more than 30 percent of total calories.

- Saturated fatty acid and trans fats intake should be 8 to 10 percent of calories for healthy adults. 


\section{Concentrate on decreasing the amount of:}

\section{Meats:}

Purchase lean cuts.

Cut off all visible fat prior to cooking.

Use preparation methods that get rid of more fat, such as grilling.

Eat 2-3 ounce portions (cooked). This serving is about the size of the palm of your hand, a deck of cards, or a mayonnaise jar lid.

\section{Poultry:}

Take off the skin either before or after cooking.

\section{Seafood:}

Prepare with small amounts of fat.

Eat 2-3 ounce portions (cooked).

\section{Cheese:}

Limit the amount you eat.

Buy part skim, or reduced fat cheeses.

\section{Butter:}

Use tub margarine.

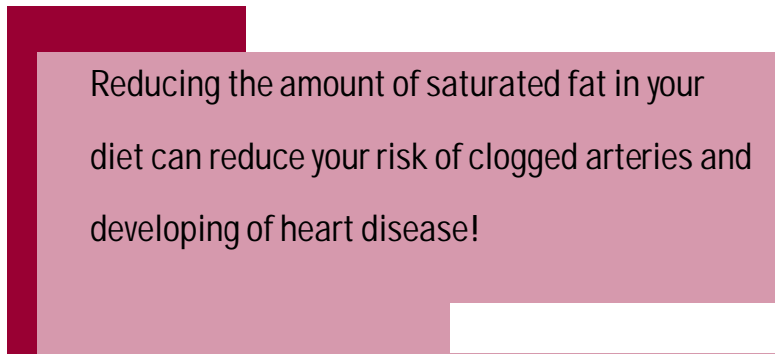

Use butter on occasion, maybe in a recipe.

\section{Milk/ Yogurt:}

Use the fat-free (skim) varieties.

\section{Processed Foods:}

Read the labels of processed foods and check for tropical oils (such as palm or coconut), and see how far down on the ingredient list they fall. Ingredients are listed in descending order of predominance in the product. The ingredient used in the greatest quantity is listed first, and the ingredient used in the smallest quantity is listed last. 


\section{Easy ways to spare and skim the saturated fat:}

- If a recipe calls for cheese and you want to use a regular type, buy a sharp variety and use a smaller quantity. The sharper taste gives more flavor with a smaller amount.

- Buy the low-fat, light, and fat-free products that taste good to you. You might have to experiment with several -- margarine, butter (or blends), cream cheese, cottage cheese, mayonnaise, and sour cream. Remember, these products are not calorie-free. Be sure to read the Nutrition Facts label to learn more about the product.

- Buy the low-fat, reduced-calorie or fat-free salad dressing that has the taste you like. No matter what salad dressing you use, don't pour on too much. Remember a $1 / 4$ of a cup can contain as many carbohydrates as a slice of bread.

- Use low or no sugar jelly or jam instead of margarine or cream cheese on bagel, toast, or muffins.

- Use plain, fat-free yogurt or fat-free sour cream instead of regular sour cream -.- add herbs and seasonings to make it tasty. Use it on baked potatoes, vegetables, chicken and fish.

- Always keep fresh lemon and lime on hand to squirt on vegetables and fish at the table instead of adding more fat (such as sauces, butter or margarine).

- Add at least 2 servings of fish to your diet each week

- When you buy meats, buy lean cuts; trim off excess fat; prepare in low fat and moist ways, such as bak-

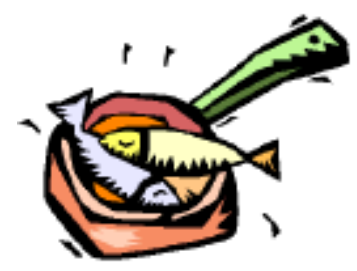
ing,steaming, roasting, boiling or broiling.

- Marinate meats and vegetables in wine, vinegars, seasonings and spices to add flavors without adding fat.

- Eat a meatless meal at least once a week

- Consider using applesauce, prune puree or other dried fruit puree to replace fat in baked goods recipes. Check the back of boxes for some recipes or write to the manufacturer to request recipes.

- Try substituting two egg whites for one whole egg in baked good recipes

- Watch out for frostings and sauces...they are hidden sources of fat!

Adapted from the American Heart Association's Delicious Decisions found at http:l / www.deliciousdecisions.org/ eel wbd_acids_tips.html and the American Diabetes Association found at http: / www.diabetes.org/ main/ health/ nutrition/ foodpyramid/ fat.jsp 


\section{How to tank up on monounsaturated fats:}

- Monounsaturated fats are known as the good guys. Monounsaturated fats offer the benefit of lowering cholesterol, while not decreasing the body's good cholesterol (HDL).

- Stock canola and/or olive oil in your cupboard. Use these oils to sauté,

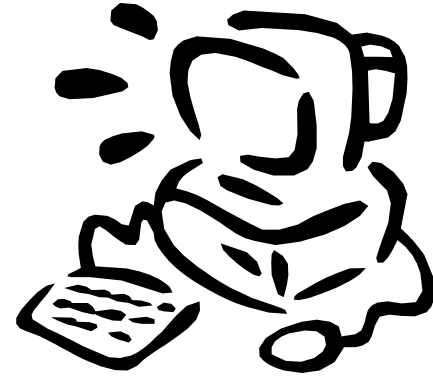

Caption describing picture or graphic. cook, prepare salad dressing or bake.

- Throw a few nuts on foods -- salads, desserts, stir-fries.

- Use a slice or two of avocado on a salad, to garnish a casserole, or for guacamole as a Mexican topping.

- Use a few olives on a relish plate, to toss in a salad, as a garnish

- Buy canola or olive oil-based commercial salad dressings, canola-based margarine and mayonnaise or make your own with olive or canola oil.

Adapted from the American Diabetes Association found at

http://www.diabetes.org/main/health/nutrition/foodpyramid/fat.jsp

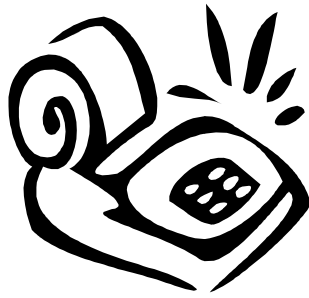

Caption describing picture or graphic. 


\section{Ways to keep the heart healthy}

\section{Tips}

To start a low-saturated-fat, low-cholesterol eating program, check off six tips to try and post it in a place in your kitchen where you can't miss it. Take time to establish these six tips as new habits. When you've become comfortable with your first six, try the other tips!

q Reduce your overall fat intake to no more than 30 percent of total calories and your saturated fat intake to 8-10 percent of calories.

q Buy lean cuts of meat and trim off any visible fat before cooking. Also, before cooking poultry, remove the skin.

q Add fish to your diet.

q Eat a meatless meal at least once a week.

q Enjoy pasta, rice, bread and cereal. They're low in fat and rich in nutrients. Choose whole grain products more often than refined or processed products.

q Instead of frying foods, bake, steam, roast, boil or broil them.

q Try substituting two egg whites for one whole egg in baked good recipes.

q Substitute fat-free milk, low-fat cheeses and low-fat and nonfat yogurt for their high-fat counterparts.

q Instead of using butter and sauces, add new flavor to vegetables with herbs and seasonings. q Try fruits and low-fat cookies and cakes instead of gooey, high -fat desserts.

q Watch out for frostings and sauces! They're hidden sources of fat.

\section{Preparation Perfec- tion}

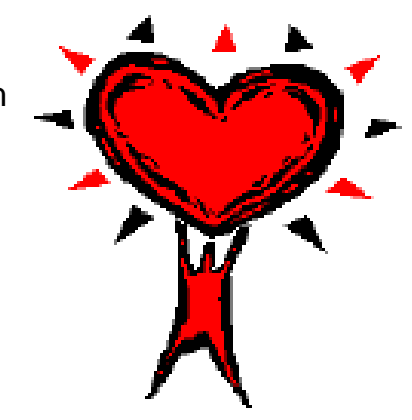

Preparing and enjoying tasty dishes while remaining within the daily recommendations for fat and cholesterol is simple with these handy tips:

Use fats and oils sparingly - and use the ones lowest in saturated fatty acids and cholesterol.

Use cooking styles that add little or no fat to food and ask for them when eating out. Boil, broil, bake, grill, roast, poach, steam, sauté, stir-fry or microwave foods for low-fat cooking.

Trim off the fat you can see before cooking meat and poultry. Drain off all the fat after browning.

Chill soups and stews after cooking so you can remove the hardened fat from the top.

Use nonstick vegetable oil cooking sprays.

Fill most of your plate with plant foods such as whole grains, fruits and vegetables. The remaining portion of the plate, about $1 / 4-1 / 3$, will be from meat group. 


\section{Heart- Saving Ingredient Substitutions}

By adjusting the ingredients you use, virtually every recipe you create can become a low-fat, lowsodium and low-cholesterol specialty. To help you convert some of your own favorite recipes to more heart-healthy fare, look to this list for heart-smart substitutions.

When Your Own Recipe Calls For:

Whole Milk (1 cup)

Heavy Cream (1 cup)

Sour Cream

Cream Cheese

Butter

Shortening (1 cup)

Oil (1 cup)

Eggs (1 egg)

Unsweetened Baking Chocolate

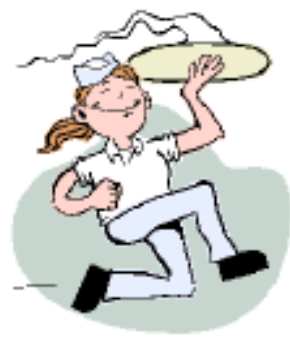

Use:

1 cup of skim or nonfat milk plus 1 tablespoon of unsatu rated oil.

1 cup evaporated skim milk or $1 / 2$ cup low-fat yogurt and $1 / 2$ cup low-fat cottage cheese.

Low-fat cottage cheese plus low-fat yogurt for flavor; ricotta cheese made from partially skimmed milk (thinned with yo gurt or buttermilk, if desired); one can of chilled evaporated skim milk whipped with one teaspoon of lemon juice; or lowfat buttermilk or low-fat yogurt.

4 tablespoons of margarine blended with 1 cup dry low-fat cottage cheese. Add a small amount of skim milk if needed in the blending mixture. Add chopped chives or pimiento and herbs and seasonings for variety.

1 tablespoon polyunsaturated margarine or (1 tablespoon) 3/4 tablespoon polyunsaturated oil.

2 sticks polyunsaturated margarine.

11/4 cups polyunsaturated margarine.

1 egg white plus 2 teaspoons of unsaturated oil or Commer cially produced cholesterol-free egg substitute according to package directions. 3 egg whites for 2 whole eggs; 2 egg whites for 1 whole egg in baking recipes.

3 tablespoons unsweetened cocoa powder or carob powder plus 1 tablespoon of (1 ounce) polyunsaturated oil or marga rine. (Carob is sweeter than cocoa, so reduce the sugar in the recipe by one-fourth.)

\section{Happy Cooking!}

Adapted from the American Heart Association, Delicious Decisions found at http:// www.deliciousdecisions.org/

For more ideas, go here! 


\section{C ooking for a $\mathrm{H}$ ealthy $\mathrm{H}$ eart}

F illing your grocery cart is just the beginning of the process. Y ou want the lo w-fat foods you buy to stay that way until they reach your plate.

S ome cooking methods are guaranteed to add loads of fat to any food: D eep-fat frying is a good example. 0 ther cooking methods help retain vitamins and minerals and keep fat and calories to a minimum. T hese include roasting, baking, broiling, grilling, braising, sautéing, stir-frying and microwaving. F or specific tips on cooking methods and ways to cook specific foods, visit T he A merican H eart A ssociation at www.deliciousdecisions.org/cb/hhc_cook_main.html

T he idea is to stay away from any cooking method that adds fat or allows food to cook in its own fat. L ook for techniques that enhance flavor and preserve nutrients instead. $B$ e miserly when it comes to adding fat and sodium.

\section{$H$ eart $H$ ealthy $R$ ecipes}

\section{A PPLE COFFE C A KE $S$ erves 9}

$\checkmark$ egetable oil spray

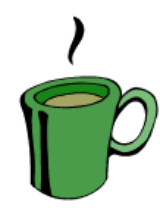

$1 / 3$ cup firmly packed dark brown sugar

$1 / 3$ cup quick-cooking oatmeal

$11 / 2$ tablespoons all-purpose flour

1 teaspoon cinnamon

$11 / 2$ tablespoons acceptable margarine, melted

$11 / 2$ cups sifted all-purpose flour

$21 / 2$ teaspoons baking powder

$1 / 2$ teaspoon cinnamon

$1 / 2$ cup sugar

1 egg white, beaten until frothy

$1 / 4$ cup acceptable vegetable oil

$3 / 4$ cup skim milk

$1 \mathrm{G}$ ranny $S$ mith apple, grated

$1 / 4$ teaspoon vanilla extract
P reheat oven to 375 of . L ightly spray a $9-x-9-x-2$-inch square $p$ an with vegetable oil spray.

$M$ ix to gether brown sugar, o atmeal, $11 / 2$ tablespo ons flour and 1 teaspoon cinnamon. A dd melted margarine to form crumb topping. $S$ et aside.

In a large bowl, sift to gether remaining flour, baking powder,

$1 / 2$ teaspoon cinnamon and sugar. $S$ et aside.

In a medium bowl, combine egg white, oil, milk, apple and vanilla. M ix until well blended. A dd to dry ingredients. $S$ tir lightly, just until dry ingredients are mo istened. P our into prepared pan. $S$ prinkle topping over cake and bake 30 to 35 minutes.

R emove from oven, cut into 9 squares and serve hot.

C alories: 247 Protein: $4 \mathrm{~g} \mathrm{C}$ arbohydrates: $40 \mathrm{~g} \mathrm{~T}$ otal $\mathrm{F}$ at: $8 \mathrm{~g} \mathrm{~S}$ aturated $\mathrm{F}$ at: $1 \mathrm{~g}$ P olyunsaturated $\mathrm{F}$ at: $4 \mathrm{~g} M$ onounsaturated F at: $2 \mathrm{~g} C$ holesterol: $0 \mathrm{mg} \mathrm{S}$ odium: $122 \mathrm{mg}$ 
B A KE D C H IC KEN PARMESA N $S$ erves 6

$\checkmark$ egetable oilspray

6 bo neless chicken breast fillets (approximately 4 ounces each), skinned, all visible fat removed

4 slices whole-wheat bread

$3 / 4$ teaspoon garlic powder

$11 / 2$ teaspoons paprika

6 tablespoons grated P armesan cheese

$11 / 2$ tablespoons finely chopped parsley

$1 / 2$ teaspoon thyme

$1 / 2$ cup low-fat buttermilk

2 tablespoons acceptable margarine, melted

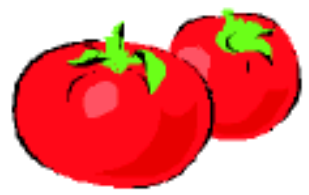

TOMATO - M O ZZARE LLA SA LA D

\section{$S$ erves 4}

1 medium red onion, very thinly sliced

4 large to matoes, preferably vine-ripened or greenhouse, sliced about

$1 / 2$ inch thick

$1 / 2$ pound nonfat or part-skim mozzarella, thinly sliced or shredded

$1 / 4$ cup chopped fresh parsley

2 teaspoons finely chopped fresh basil

3 to 4 cloves garlic, minced

B lack pepper to taste

2 tablespoons extra-virgin olive oil

2 teaspoons red wine vinegar, or to taste
P reheat oven to $450^{\circ} \mathrm{F}$. L ightly spray with vegetable oil spray a rectangular baking sheet and a rectangular cakecooling rack of a slightly smaller size.

Place rack onto baking sheet. $S$ et aside.

$R$ inse chicken and pat dry. $S$ et aside. $P$ lace bread in blender or the work bowl of a food processor. Process into fine crumbs.

Pour crumbs into a shallow bowl. A dd garlic powder, paprika, cheese, parsley and thyme. $S$ tir to mix well.

Pour buttermilk into a shallow bowl.

$D$ ip fillets into buttermilk, shake off excess and then dip into crumbs.

P lace fillets on prepared rack. D rizzle each with a teaspoon melted margarine.

$B$ ake 15 minutes; turn fillets 0 ver and bake 10 minutes more.

C alories: 256 Protein: $30 \mathrm{~g} \mathrm{C}$ arbohydrates: $11 \mathrm{~g} \mathrm{~T}$ otal

$F$ at: $10 \mathrm{~g} S$ aturated $F$ at: $3 \mathrm{~g}$ Polyunsaturated $F$ at: $2 \mathrm{~g}$

M onounsaturated $\mathrm{F}$ at: $3 \mathrm{~g}$ C holesterol: $69 \mathrm{mg} \mathrm{S}$ odium:

P lace a layer of onion in a glass or ceramic serving dish.

$C$ over with a layer of to matoes and a layer of mozzarella.

$S$ prinkle with some of the parsley, basil, garlic, salt, and pepper. D rizzle with a little oil and a splash of vinegar. $C$ ontinue layering the rest of the ingredients (the number of layers will depend on the size of your dish). R efrigerate until well chilled.

$C$ alories: 210 Protein: $20 \mathrm{~g} \mathrm{C}$ arbohydrates: $16 \mathrm{~g} \mathrm{~T}$ otal $F$ at: $8 \mathrm{~g} \mathrm{~S}$ aturated $F$ at: $1 \mathrm{~g} P$ olyunsaturated $F$ at: 1 M onounsaturated $\mathrm{F}$ at: $5 \mathrm{~g}$ C holesterol: $1 \mathrm{mg} \mathrm{S}$ odium: $418 \mathrm{mg}$ 
S U G AR-D USTED MOCHA B ROWN IE S

$S$ erves 12

$1 / 2$ cup all-purpose flour

$1 / 2$ cup unsweetened cocoa powder

In a small bowl, comb ine flo ur, cocoa powder, and baking powder.

$1 / 2$ teaspoon baking powder

4 tablespoons light margarine ( $1 / 4$ cup)

$S$ et aside. In a medium saucepan over medium-low heat, melt marga-

1 tablespoon instant coffee crystals

1 cup sugar rine.

A dd coffee crystals and stir until $d$ is solved. $R$ emove from heat and let cool slightly.

E gg substitute equivalent to 2 eggs, or 2 eggs

$U$ sing a wooden spoon, add sugar, egg substitute, prune baby

$1 / 4$ cup prune baby food

2 teaspoons vanilla

$\checkmark$ egetable oil spray

2 tablespoons powdered sugar

Preheat oven to $350^{\circ} \mathrm{F}$. food, and vanilla to coffee mixture. $S$ tir until well combined. $F$ old cocoa mixture into sugar mixture until well co mb ined.

$S$ pray an $8 \times 8 \times 2$-inch cake pan with vegetable oil spray. $S$ poon batter into baking pan.

$B$ ake, uncovered, for 18 to 20 minutes, or until a to othpick inserted near the center comes out almost clean (it should have a few fudgy crumbs on it).

C oolbrownies in the pan on a wire rack. S ift powdered sugar over brownies.

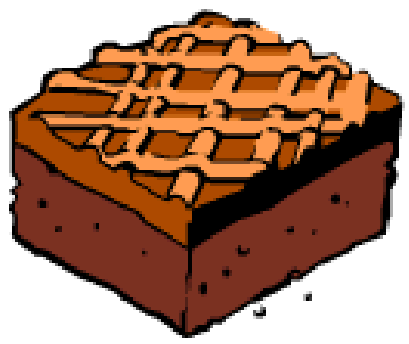

C ook's T ip: F or a decorative topping, place a doily on to $p$ of the brownies before sifting powdered sugar. R emove doily before cutting brownies.

C alories: 124 Protein: $2 \mathrm{~g} \mathrm{C}$ arbohydrates: $25 \mathrm{~g} \mathrm{~T}$ otal $\mathrm{F}$ at: $2 \mathrm{~g}$ $S$ aturated $F$ at: $1 \mathrm{~g}$ P olyunsaturated $F$ at: $1 \mathrm{~g} M$ onounsaturated F at: $1 \mathrm{~g} \mathrm{C}$ holesterol: $0 \mathrm{mg} S$ odium: $82 \mathrm{mg}$

F or more yummy recipes that are low-fat and low-cholesterolas well as substitutions, visit $\mathrm{T}$ he A merican $\mathrm{H}$ eart A ssociation at www.deliciousdecisions.org/ cb/ index.html. 


\section{Heartburn}

\section{What Does Heartburn Feel Like?}

People with heartburn generally describe one or more of the following symptoms.

- a burning chest pain that begins at the breastbone and moves up toward the throat

- a feeling that food or liquid is coming back into the mouth or throat

- an acid or bitter taste at the back of the throat

- $\quad$ an increase in severity of pain behind the breastbone when lying down or bending over

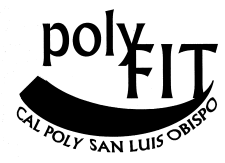

Nutrition Assessment \& Consultation

Exercise Testing \&

Prescription

What is heartburn?

Heart burn is a burning discomfort generally felt in the chest behind the breastbone. This burning sensation results form stomach juices come into contact with and irritate the lining of the esophagus, the tube-like structure that connects the stomach to the mouth.

\section{What Can Cause Heartburn?}

\section{Eating/Dietary Habits}

- Eating foods such as citrus fruits, chocolate, peppermint, spearmint, tomatoes or tomato-based products, raw onions, garlic, black pepper, vinegar and fatty or spicy foods

- Drinking beverages such as coffee, citrus juices, and caffeinated, carbonated or alcoholic beverages

- $\quad$ Eating large portions

- Eating before bedtime

\section{Lifestyle habits}

\section{Certain positions}

- Lying down, especially after eating

- Bending over

\section{Medical reasons}

- Pregnancy

- Hiatal Hernia

- Taking certain medications
- $\quad$ Being overweight

- Smoking

- Certain types of exercise/body positions

- Hectic lifestyle

- Wearing restrictive clothing 


\section{Self- Care Strategies To Relieve Heartburn}

Heartburn sufferers should take heart-relief from this troublesome condition is often achievable through lifestyle and dietary changes as well as medication. The National Heartburn Alliance offers the following tips for sufferers who yearn to stop the burn:

\section{Limit foods that fan the flames}

Avoid foods and beverages that trigger symptoms and may irritate lining of the esophagus or affect the LES which controls the flow of acid from the stomach into the esophagus. These items include chocolate, peppermint, fatty foods, alcoholic beverages, citrus fruits and juices, garlic and raw onion, tomato sauce, vinegar, caffeinated and carbonated beverages.

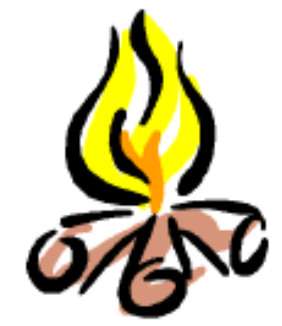

\section{Eat smaller dinners.. and eat earlier}

Decrease the size of portions at mealtimes and eat meals at least 2-3 hours before lying down to lessen the likelihood of reflux.

\section{Monitor your meds}

Check with your doctor or pharmacist to see if one of the medications you are taking might be triggering your heartburn. Aspirin and other pain medications (other than acetaminophen), some antibiotics and iron tablets are $a$ few of the common culprits. N ever stop taking any medication prescribed by your doctor without consulting with him or her.

\section{Feel the burn without the burn}

Certain types of exercise that increase abdominal pressure can aggravate heartburn symptoms, but don't give up this healthy habit. Talk to your trainer or fitness expert at the local gym about exercise substitutes and try not to eat just before, during or just after exercise.

\section{Shed some pounds}

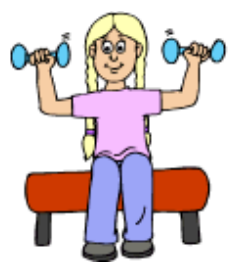

Extra pounds can increase heartburn incidence. Some heartburn sufferers find their symptoms improve by losing weight through a healthy weight-loss plan.

\section{Stop or decrease smoking}

Cigarette smoking inhibits saliva, one of the body's natural protective barriers against damage to the esophagus. Smoking also may stimulate acid production and weaken the important valve that prevents stomach acid from entering the esophagus.

\section{Fight acid creep while you sleep}

Elevate the head of your bed four to six inches using blocks to prevent acid from creeping up the esophagus. Also, try seeping on your left side, which may decrease reflux symptoms.

\section{Loosen up}

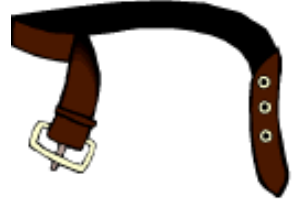

Reduce abdominal pressure by not wearing tight belts or binding clothing. 


\section{Self-Care Strategies continued...}

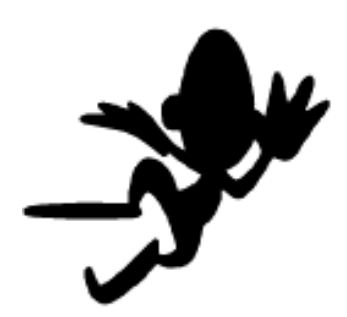

Try a non-prescription medication and take as directed for heartburn.

Ask your pharmacist for a recommendation and be sure to learn about how the different types of medication work.

Relax

Stress does not cause acid reflux but it can make you more aware of your heartburn symptoms. Also, because of stress, one may engage in behaviors that trigger heartburn-eating high-fat foods, smoking, drinking caffeinated beverages.

\section{Linger over lunch}

Slow down and eat less. Gulping down food in a hurry can result in eating more before you feel satisfied. Over-filling the stomach can result in reflux and heartburn.

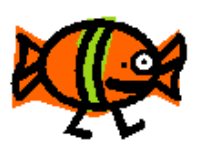

\section{Candy is dandy}

Sucking on hard candy encourages production of saliva, which actsas a natural barrier to acid. Just be sure to avoid mint candies, which can stimulate acid reflux.

\section{Keep a reflux record}

Try to keep a diary noting when heartburn hits and the specific activities that seem to trigger the incidents. The diary can help you identify what you should avoid and may be a helpful tool for your doctor or pharmacist to evaluate your condition and needs.

\section{Ask "what'sup, doc?"}

If you are consistently taking medicine for heartburn or if you still have symptoms after taking medication, you should see a health care professional. You might have gastroesophageal reflux disease, or GERD, which, if left untreated, may be potentially serious. If you have alarm symptoms consult your doctor immediately

This information was printed from the National Heartburn Alliance site, located at http://www.heartburnalliance.org/ 


\section{Stock The Pantry To Relieve Heartburn}

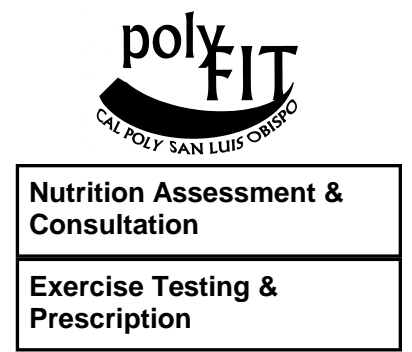

\section{Stocking the Pantry}

A well-stocked pantry is key to avoiding heartburn. Trigger foods- fats, oils, chocolate or citrus products - can be less tempting when there's a supply of "safe" ingredients in your kitchen cabinets. The added benefit is healthier eating for the entire family.

Grains - Try to purchase whole grains vs, refined grains whenever possible. Be sure to store in an airtight container after opening.

$\begin{array}{ll}\text { Brown rice } & \text { Basmati rice (aromatic long-grain rice) } \\ \text { Short-grain rice } & \text { Wehani rice (dark, Basmati-type from California) } \\ \text { Bulgur } & \text { Kasha } \\ \text { Farina } & \text { Stone-ground cornmeal } \\ \text { Quick-cooking oats } & \text { Polenta (instant and regular) } \\ \text { Quick-cooking grits } & \text { Ready-to-eat whole-grain cereals }\end{array}$

Pasta - Be sure to prepare these with a light "broth-type" sauce (not tomato-based or

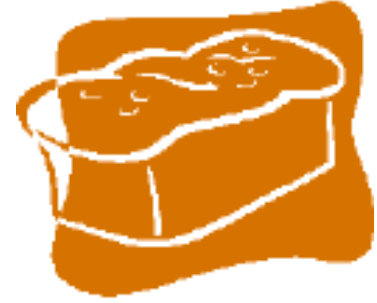
high-fat). Perk up the dish with herbs like basil and tarragon.

Bow-tie Linguine

$\begin{array}{ll}\text { Fettuccine } & \text { Cappellini (angel hair) } \\ \text { Spaghetti } & \text { Penne }\end{array}$

Orzo (rice-shaped pasta) Rigatoni

Beans, peasand lentils - All these items provide a good source of vegetable protein, B-vitamins, and minerals such as calcium and iron. They are also an excellent source of fiber. Keep both dried and canned varieties on your shelf, and toss them into soups, salads, pasta and casserole dishes.
Red kidney beans
Black beans
White kidney beans
Split peas (yellow, green)
Navy beans
Chickpeas (garbanzo beans)
Scarlet runners
Lentils

Oils - Use oils in moderation. The darker oils (like sesame) have wonderful flavor, and a little goesa long way in adding good taste and enjoyment to dishes.

Extra-virgin olive - experiment, as the taste of olive oils varies from mild to very flavorful.
Sesame - light and dark
Walnut
Peanut
Canola

Note: Keep cooking-oil sprays (like Pam ${ }^{\circledR}$ ) in the cupboard. There are several flavored varieties available too. This is a handy way to cut down extra fat, keep food from sticking to pans and add a little flavor.

Vinegars - These can be problem items for severe heartburn sufferers because of the acid content. However, cider vinegar and rice vinegar are often tolerated better by many people, and both add nice flavor to food. Use other vinegars with discretion if there hasn't been a problem with them in the past. 


\section{Stocking The Pantry continued...}

Condiments and Canned Goods- Most people with heartburn can eat mustard, and some can handle ketchup (in small amounts) fairly well. These are handy items to perk up recipes, and quick add-ons to a meal.

Ketchup

Soy sauce

Dried mushrooms

Fat-free salad dressings

Dried fruits

Canned fruits

Canned (and dried) soups
Mustard

Chicken and vegetable broth

Reduced-fat mayonnaise

Reduced-fat peanut butter

Fruit spreads

Canned vegetables

Spices and Herbs - Keep lots of dried spices and herbs on the shelf. They are generally less likely to promote heartburn - though each individual's system will respond differently. Dried/dehydrated forms of onion and garlic are more user-friendly than fresh!

$\begin{array}{ll}\text { Ground cinnamon } & \text { Garlic powder } \\ \text { Ground mace } & \text { Basil } \\ \text { Ground ginger } & \text { Thyme } \\ \text { Coriander } & \text { Tarragon } \\ \text { Dill } & \text { Onion powder, and dried onion pieces }\end{array}$

Parsey

Note: There are several spices that are generally irritating to the gastric (stomach) lining and are especially troublesome for heartburn sufferers. The spices listed below may be troublesome for some sufferers, but pose no problem for others. The best advice is to listen to one's own body.
Black pepper
Mint
Crushed red pepper flakes
Cloves
Tabasco sauce
Chili powder
Mustard seeds
Curry powder
Nutmeg
Fresh garlic (raw or cooked)

Baking supplies - Muffins and quick breads made from scratch can be made from less fat and without other troublesome ingredients such as pep per or spice. Whole grain breads are made more simply with a bread machine. Here are some of the basic ingredients:

$\begin{array}{ll}\text { Whole-wheat flour } & \text { Baking powder } \\ \text { Unbleached flour } & \text { Baking soda } \\ \text { Rye flour } & \text { Yeast } \\ \text { Wheat bran } & \text { Cream of tartar } \\ \text { Oat bran } & \text { Molasses } \\ \text { Vanilla extract } & \text { Granulated sugar } \\ \text { Almond extract } & \text { Brown sugar } \\ \text { Evaporated skim milk } & \text { Honey }\end{array}$

This information was printed from the National Heartburn Alliance site, located at http://www.heartburnalliance.org/ 


\section{The Stop and Select Guide}

The key to a smooth ride around heartburn is to find the right mix of foods and beverages. This guide assigns a color code to common foods and beverages according to the food's tendency to create acid, irritate the gastric lining and/or relax the lower esophageal sphincter. You can assess the likelihood of a heartburn episode based on the color code of foods you consume. Itemsare listed by standard USDA food pyramid groupings and are categorized by one of the following colors.

The more "yellows" and "reds" you consume, the more likely you may be to experience heartburn.

Tolerance for foods and beverages listed below will vary from person to person. Eight ounces of lemonade may be tolerable for one person and a heartburn disaster for another. Pay close attention to portion size for all foods consumed and note what quantities, if any, are bearable for your stomach. Use your "personal serving sizes" as a guide. For portions that are excessive, move up one level on the color continuum (i.e., green to

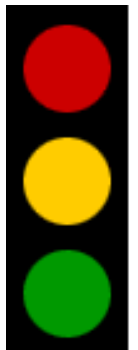
- STOP, you may want to reconsider this choice yellow, yellow to red).

$\begin{array}{ll}\text { Frurrs } & \text { VECETABLES } \\ \text { Orange juice } & \text { Mashed potatoes } \\ \text { Lemon } & \text { French fries } \\ \text { Lemonade } & \text { Onion, raw } \\ \text { Grapefruit juice } & \text { Potato salad } \\ \text { Cranberryjuice } & \text { Garlic } \\ \text { Tomato } & \text { Onion, cooked } \\ \text { Lowracid orange juice } & \text { Leeks } \\ \text { Apple cider } & \text { Sauerkraut } \\ \text { Peach } & \text { Scallions } \\ \text { Blueberries } & \text { Carrots } \\ \text { Raspberries } & \text { Cabbage } \\ \text { Grawberries } & \text { Peas } \\ \text { Granberries, dried } & \text { Broccoli } \\ \text { Apple, fresh } & \text { Green beans } \\ \text { Apple, dried } & \text { Bpple juice } \\ \text { Banana } & \\ & \end{array}$

$\begin{array}{ll}\text { GRAuns } & \text { DAIRY } \\ \text { Macaroniand cheese } & \text { Sour cream } \\ \text { Spaghetti with } & \text { Milkshake } \\ \text { marinara sauce } & \text { Icecream } \\ \text { Garlic bread } & \text { cottage cheese, } \\ \text { Muffin } & \text { regular } \\ \text { Granclacereal } & \text { Yogurt } \\ \text { Multi-grain bread } & \text { Milk, 2 percent } \\ \text { White bread } & \text { Milk, skim } \\ \text { corn bread } & \text { Frozen yogurt } \\ \text { Brown rice } & \text { Cottage cheese, } \\ \text { White rice } & \text { low-fat } \\ \text { Grahamcrackers } & \text { Cheddar cheese } \\ \text { Saltinecrackers } & \text { Mozzarellacheese } \\ \text { Pretzels } & \text { Creamcheese, } \\ \text { Rice cakes } & \text { fat-free } \\ \text { Oatmeal cereal } & \text { Fetacheese } \\ \text { Frosted cereal } & \text { Goatcheese } \\ \text { Bran-based cereal } & \text { Sour cream, fat-free } \\ & \text { Soycheese, low-fat } \\ & \end{array}$

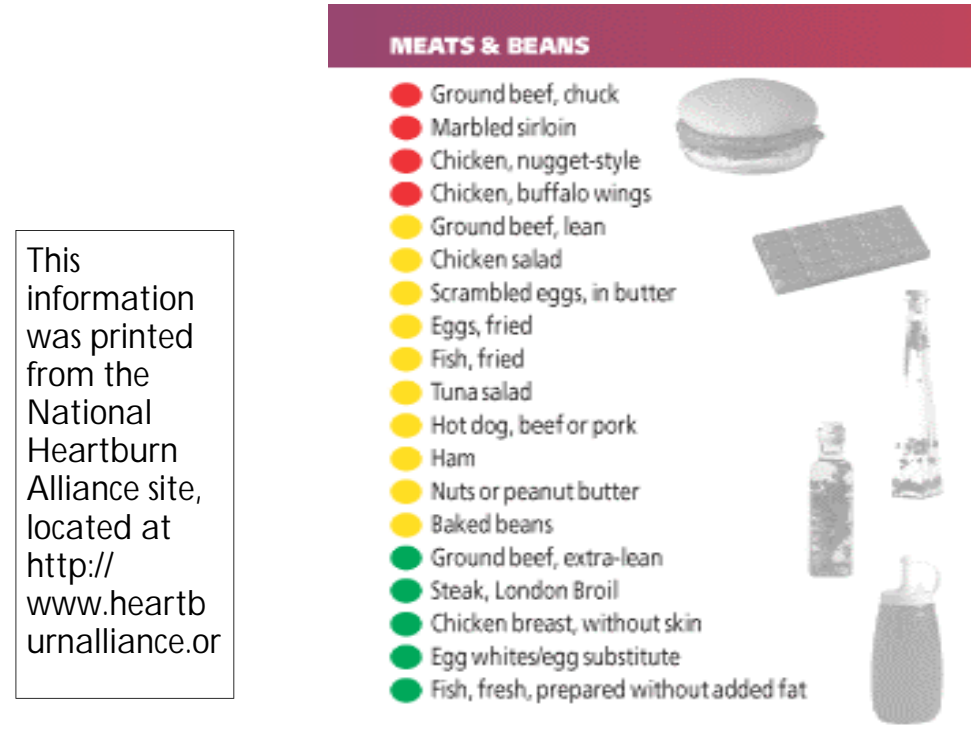

\section{FATS, OILS \& SWEETS BEVERAGES}

Chocolate

Com chips

Potato chips, regular

Butter cookie, high-fat

Brownie

Doughnut

- Salad dressing, creamy

Salad dressing, oil \& vinegar

Cookie, low. fat

Ketchup

Potato chips, baked

Cookie, fat-free

Jelly beans

Red licorice

Salad dressing, low-fat

L Liquor

Wine

Coffee

Tea

Non-alcoholic

wine

Beer

Non-alcoholic

beer

Cola

Root beer

Mineral water

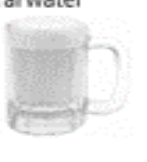




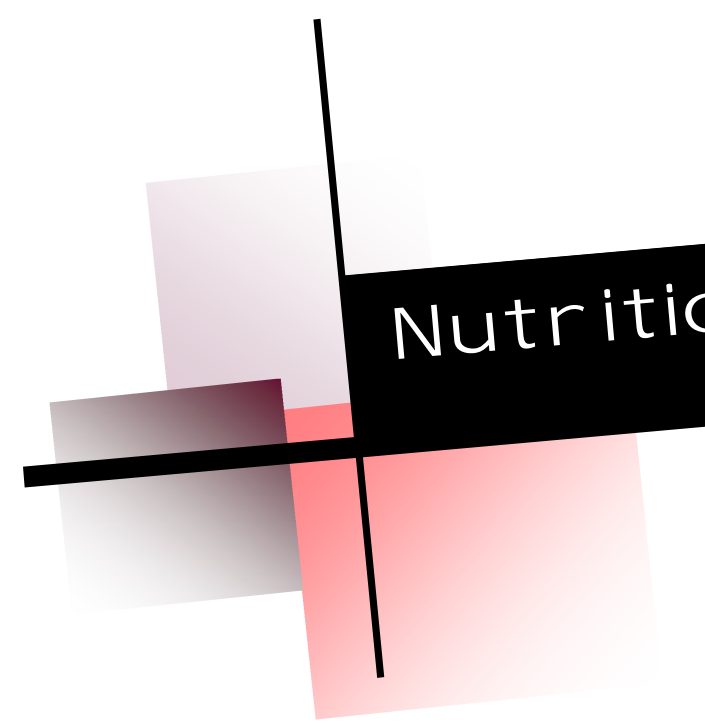

\section{Nutrition Assessment \& Consultation}

Exercise Testing \& Prescription

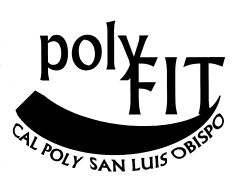

\section{Why is High Blo od Pr essur e Important?}

High blood pressure is dangerous because it makes the heart w ork too hard. It also makes the walls of the arteries hard. High blood pressure increases the risk for heart disease and stroke, the first- and third-leading causes of death for Americans. High blood pressure can also cause other problems, such as heart failure, kidney disease, and blindness.

\section{Healthy Eating}

Research has show $n$ that following a healthy eating plan can both reduce the risk of developing high blood pressure and lower an already elevated blood pressure.

For an overall eating plan, consider the DASH eating plan. "DASH" stands for "Dietary A pproaches to Sto $\mathrm{p} \mathrm{Hy-}$ pertension," a clinical study that tested the effects of nutrients in food on blood pressure. Study results indicated that elevated blood pressures were reduced by an eating plan that emphasizes fruits, vegetables, and low fat dairy foods and is low in saturated fat, total fat, and cholesterol. The DASH eating plan includes whole grains, poultry, fish, and nuts and has reduced amounts of fats, red meats, sweets, and sugared beverages.
A second clinical study, called "DASH Sodium," looked at the effect of a reduced dietary sodium intake on blood pressure as people followed either the DASH eating plan or a typical American diet. Results showed that reducing dietary sodium low ered blood pressure for both the DASH eating plan and the typical American diet. The biggest blood pressure-low ering ben efits were for those eating the DASH eating plan at the low est sodium level (1,500 milligrams per day).

The DASH-Sodium study shows the importance of lowering sodium intake w hatever your diet. But for a true winning combination, follow the DASH eating plan and lower your intake of salt and sodium.
Special points of interest:

- Healthy Eating W ith DASH

- Getting Started W ith DASH

- Other W ays To Control High Blood Pressure 


\title{
Healthier Eating with DASH
}

\author{
The DASH Eating Plan
}

The DASH eating plan show $n$ below is based on 2,000 calories a day. The number of daily servings in a food group may vary from those listed depending on your caloric needs.

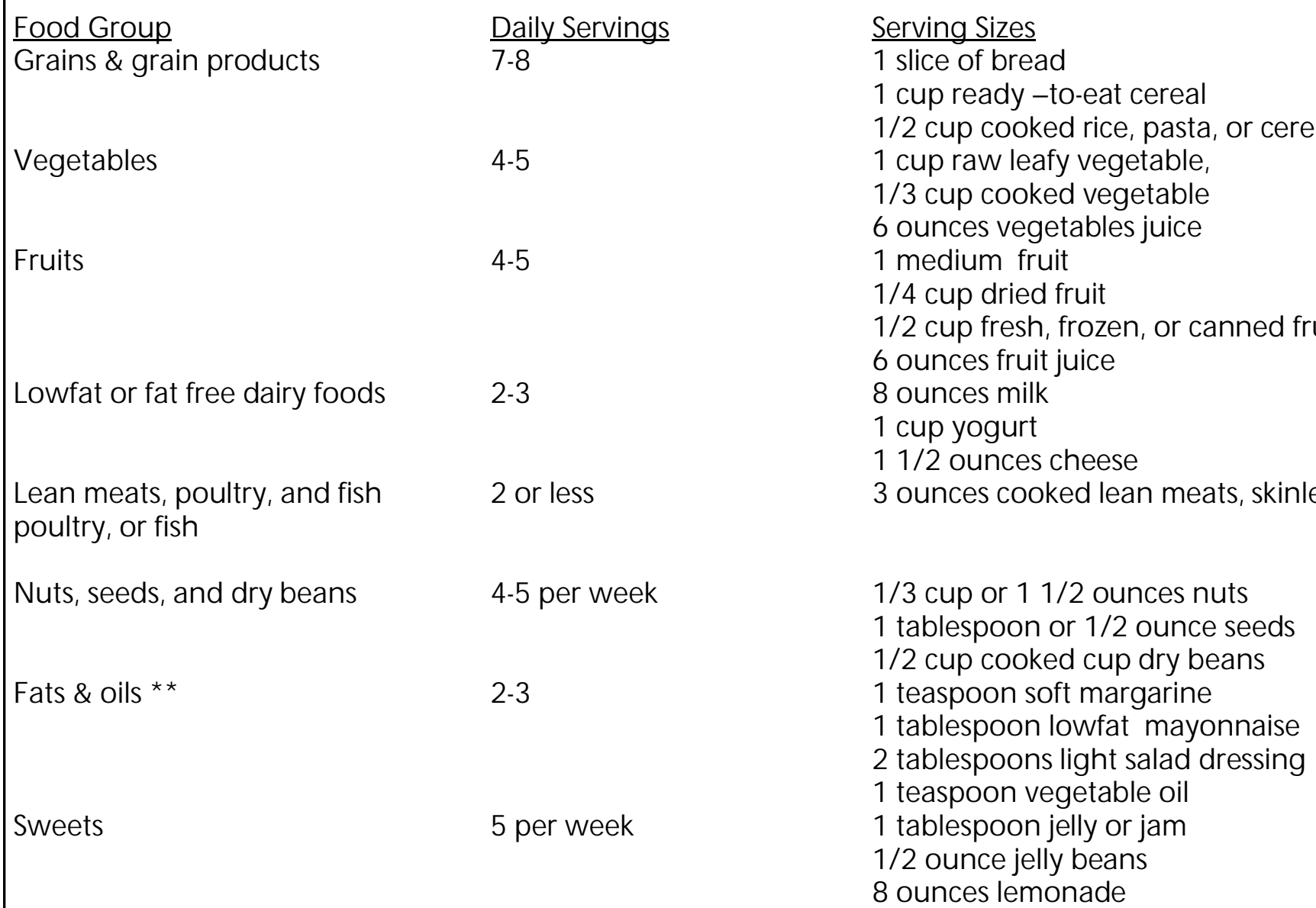

Serving sizes vary between $1 / 2$ cup -11 / 4 cups. Check the product's nutrition label.

** Fat content changes serving counts for fats and oils: For example, 1 tablespoon of regular salad dressing equals 1 serving; 1 tablespoon of a low fat dressing equals serving; 1 tablespoon of a fat free dressing equals 0 servings. 


\section{Get $t$ ing St a rted Wit h DASH}

\section{Change gradually}

If you now eat one or two vegetables a day, add a serving at lunch and another at dinner.

If you don't eat fruit now or have only juice at breakfast, add a serving to your meals or have it as a snack.

Use only half the butter, margarine, or salad dressing you do now.

Try low fat or fat free condiments, such as fat free salad dressings.

Gradually increase dairy products to three servings per day. For example, drink milk with lunch or dinner, instead of soda, alco hol, or sugar-sw eetened tea.

Choose low fat (1 percent) or fat free (skim) dairy products to reduce total fat Intake.

\section{Use fruits or lowfat foods as desserts}

Fruits and low fat foods offer great taste and variety. Use fruits canned in their ow $n$ juice. Fresh fruits require little or no preparation. Dried fruits are easy to carry with you.

\section{Red u ce salt $\&$ so dium in}

A key to healthy eating is choosing foods lower in salt and sodium. Most Americans consume more salt than they need. The current recommendation is to consume less than 2.4 grams $(2,400$ milligrams [mg] ) of so dium a day. That equals 6 grams (about 1 teaspoon) of table salt a day. The 6

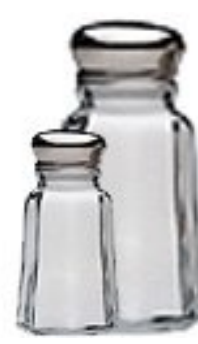
grams include ALL salt and sodium consumed, including that used in cooking and at the table. For someone with high blood pressure, the doctor may advise eating less salt and sodium, as recent research has show $n$ that people consuming diets of $1,500 \mathrm{mg}$ of sodium had even bet-
Try meat as one part of the whole meal instead of the focus

Buy less meat. If it's not there, you w on't eat it.

Limit meat to 6 ounces a day (two serv ings)--all that's needed. Three to four ounces is about the size of a deck of cards.

If you now eat large portions of meat, cut them back gradually--by a half or a third at each meal.

Include two or more vegetarian-style (meatless) meals each w eek.

Increase servings of vegetables, rice, pasta, and dry beans in meals.

Try casseroles and pasta, and stir-fry dishes, having less meat and more vegetables, grains, and dry beans.

Try these snack ideas: unsalted pretzels or nuts mixed with raisins; graham crackers low fat and fat free yo gurt and frozen yogurt; plain popcorn with no salt or butter added; and raw vege tables.

\section{your d iet}

ter blood pressure low ering benefits. These lowersodium diets also can keep blood pressure from rising and help blood pressure medicines w ork better.

Check out the tips to reduce sodium in Reducing Sodium in Your Diet handout. 


\section{Maint aining a healthy weight}

Being overw eight increases your risk of developing high blood pressure. In fact, blood pressure rises as body w eight increases. Losing even 10 pounds can low er blood pressure - and it has the greatest effect for those who are overw eight and already have hypertension.

Being overw eight or obese are also risk factors for heart disease. They increase your chance for developing high blood cholesterol and diabetes - tw o more major risk factors for heart disease.

\section{Ph ysical Activity}

Being physically active is one of the most important steps you can take to prevent or control high blood pressure. It also helps reduce your risk of heart disease. It doesn't take a lot of effort to become physically active.

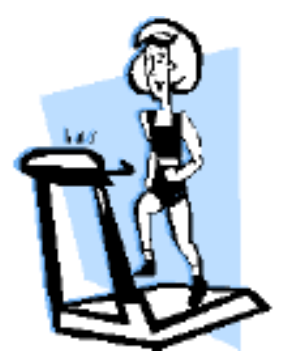

\section{Limit alcohol}

Drinking too much alcohol can raise blood pressure. It also can harm the liver, brain, and heart. Alcoholic drinks also contain calories, which matter if you are trying to lose weight. If you drink alcoholic beverages, have only a moderate amount - one drink a day for women; two drinks a day for men

What counts as a drink:

12 ounces of beer

5 ounces of wine

$11 / 2$ ounces of 80-proof alcohol

\section{Qu it smoking}

Smoking injures blood vessel walls and speeds up the process of hardening of the arteries. This applies even to filtered cigarettes. So even though it does not cause high blood pressure, smoking is bad for anyone, especially those with high blood pressure. If you smoke, quit. If you don't smoke, don't start. Once you quit, your risk of having a heart attack is reduced after the first year. So you have a lot to gain by quitting.

\section{Treat ment for High blood pressure}

It is important to take steps to keep your blood pressure under control. The treatment goal is blood pressure below 140/90 and lower for people with other conditions, such as diabetes and kidney disease. Adopting healthy lifestyle habits is an effective first step in both preventing and controlling high blood pressure. If lifestyle changes alone are not effective in keeping your pressure controlled, it may be necessary to add blood pressure medications. Contact your doctor for more information.

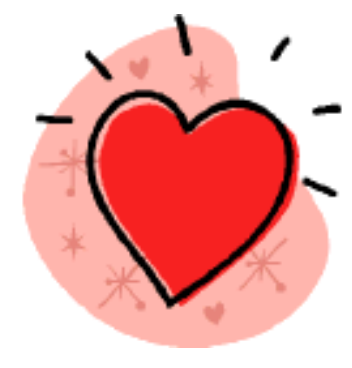

Adapted form theNational Heart, Blood, and Lung Institute found at http:// w w w .nhlbi.nih.gov/ $\mathrm{hbp} /$ index.html 


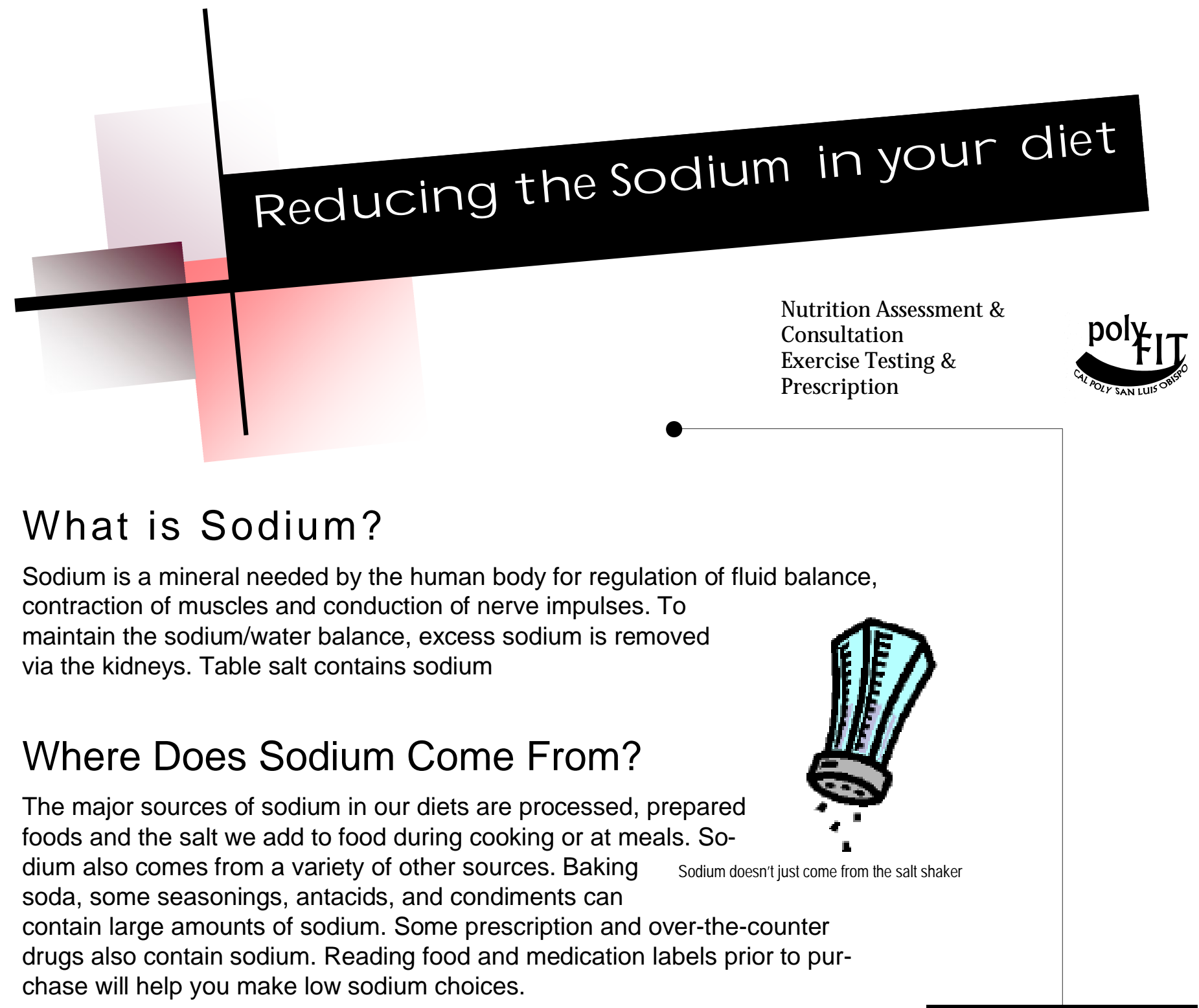

\section{Why Is It Necessary To Follow A Low Sodium Diet?}

The human adult needs 500 to 1000 milligrams of sodium per day. A daily sodium intake between 1,100 and 3,300 milligrams is considered safe and adequate. This is equal to the amount of sodium in approximately $1 / 2$ to $1 \frac{1}{2}$ teaspoons of table salt. In actuality, the average American consumes 2,500 to 5,000 milligrams per day. Reducing sodium in the diet may reduce high blood

Special points of interest:

- Get the low down on sodium

- W ays to decrease sodium in your diet

- Label lingo

- Salt Tips pressure in some people. This in turn can decrease the likelihood of heart or kidney disease and stroke. A low-sodium diet may need to be combined with weight loss and exercise or medication to decrease blood pressure.

Taste for salt is acquired. Like drinking diet soft drinks and decreasing use of sugar, taste for salt can be relearned. By cutting down on salt use gradually, the taste buds have time to adjust. 


\section{Ways To Decrease Your Sodium Intake}

The best way to cut back on sodium is to cut back on salt and salty foods and seasonings. When reading a Nutrition Facts Label, look for the sodium content.

Additionally:

- Cook from scratch. De-emphasize the use of processed foods.

- Use the salt shaker sparingly. Taste your food before adding salt. Remove the salt shaker from your table or get a shaker with smaller holes.

- Choose fresh, frozen, or canned vegetables without added salt.

- Choose fresh or frozen fish, shellfish, poultry, and meat more often than canned or processed forms.

- Snack on fresh fruits and vegetables, which are low in sodium.

- Balance a high sodium food with others of low sodium content. Limit processed, cured or pickled foods.

- $\quad$ Read the Nutrition Facts Label to compare the amount of sodium in processed foods - such as frozen dinners, packaged mixes, cereals, cheese, breads, soups, salad dressings, and sauces. The amount of sodium in different types and brands often varies widely.

- $\quad$ Ask your grocer or supermarket to offer more low-sodium foods.

- Try to keep your daily sodium intake below $2500 \mathrm{mg}$.

- Read food labels. Buy products low in sodium, MSG, baking soda and other sodiumcontaining compounds.

- Choose foods labeled "low-sodium, " "reduced sodium" or "sodium free."

- Take note of the sodium content of your favorite condiments, particularly meat tenderizer, steak sauce, soy sauce, salsa, and catsup.

- Use alternate spices and herbs to season your food. Fresh vegetable and citrus juices work great too.

- Some people can use salt substitutes. These are high in potassium so people with kidney or other medical problems may not be able to use them. Ask your physician first.

- Try seasoning mixes such as Mrs. Dash or Mr. Pepper.

- Choose nonprescription medications low in sodium. Ask your pharmacist about the sodium content of your prescription medication.

- When you go out to eat, choose low sodium menu items and ask that they prepare your meal without salt or MSG. Use pepper instead of salt to season your meal.

- Cook rice, pasta, and hot cereals without salt. Cut back on instant or flavored rice or pastas and cereal mixes which have a lot of extra salt.

- Rinse canned products such as tuna, to remove sodium.

Adapted from McKinley Health Center, Students Affairs, University of Illinois, found at http://www.mckinley.uiuc.edu/Handouts/ and National Heart, Blood, and Lung Institute found at http://www.nhlbi.nih.gov/hbp/index.html 


\section{What do Food Labels Tell us?}

Do the terms "sodium" or "salt" appear on the front of the food label? If so, here's what the descriptions mean. For the specific sodium content in a serving, check the Nutrition Facts panel.

\section{LABEL TERM}

Sodium free

Very low sodium

Low sodium

Reduced or less sodium

Light in sodium

Salt free

Low sodium meal

Unsalted or no added

\section{MEANS}

Less than 5 milligrams sodium per serving

35 milligrams or less sodium per serving

140 milligrams or less sodium per serving

At least $25 \%$ less sodium*

$50 \%$ less sodium*; restricted to foods with more than 40 calories per serving or more that 3 grams fat per serving

Less than 5 milligrams sodium per serving

140 milligrams or less sodium per 100 grams

No salt added during processing; does not necessarily mean sodium free

\section{EXAMPLES of FOODS}

Crackers

Chips

Soup, cereal, crackers

Soy sauce, soup, bacon, pretzels, crackers

\section{Crackers}

Herb blends

Frozen dinner

Peanuts, butter, canned vegetable, microwave popcorn,, crackers, breakfast cereals

*as compared with a standard serving size of the traditional food

References: American Dietetic Association, Complete Food and Nutrition Guide, RL Duyff, 1998.

Adapted from McKinley Health Center, Students Affairs, University of Illinois, found at http:// www.mckinley.uiuc.edu/Handouts/reducesodiumdiet.html

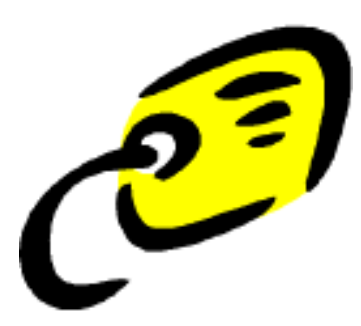

\section{Quick Facts on Salt}

- Most sodium is consumed in the form of sodium chloride which is table salt. Other forms of sodium are also found in food, so watch out for salt AND sodium.

- Try to have less than 2,400 milligrams of sodium a day - that's the same as 6 grams of salt a day, or about 1 teaspoon

- That includes ALL sodium and salt - what's in the product, and added in cooking and at the table

- Processed foods account for most of the sodium and salt consumed

- Check food labels - sodium is in some foods you might not expect, such as soy sauce and some antacids Kosher salt and sea salt are just that — salt. Don't forget to include them in adding up your sodium intake for the day

- Reducing salt in the diet can lower blood pressure

Adapted form theNational Heart, Blood, and Lung Institute found at http://www.nhlbi.nih.gov/hbp/index.html 


\section{What is IBS?}

Irritable bowel syndrome, or IBS, is a problem that affects mainly the bowel, which is also called the large intestine. The bowel is the part of the diges tive system that makes and storesstool. The word syndrome meansa group of symptoms. IBS is a syndrome because it can cause several symptoms. For example, IBS causes cramping, bloating, gas, diarrhea, and constipation.

IBS is not a disease. It's a functional disorder, which means that the bowel doesn't work as it sh ould.

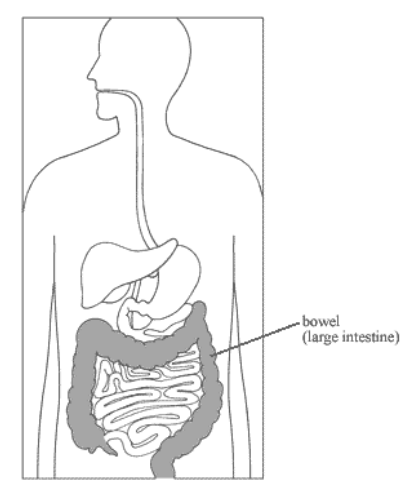

With IBS, the nerves and muscles in the bowel are extra-sensitive. For example, the musclesmay contract too much when you eat. These contractions can cause cramping and diarrhea during or shortly after a meal. Or the nerves can be overly sensitive to the stretching of the bowel (because of gas, for example). Cramping or pain can result.

IBS can be painful. But it does not damage the bowel or cause any other diseases

points o

interest:

- What are the symptoms of IBS?

- What is the treatment?

- Dietary changes

- Points to remember

\section{Does Stress Cause IBS?}

Emotional stress will not cause a person to develop IBS. But if you already have IBS, stress can trigger symptoms. In fact, the bowel can overreact to all sorts of things, including food, exercise, and hormones.

Foods that tend to cause symptoms include milk products, chocolate, alcohol, caffeine, carbonated drinks, and fatty foods. In some cases, simply eating a large meal will trigger symptoms.

Women with IBS often have more symptoms during their menstrual periods. 


\section{What are the symptoms of IBS?}

The main symptoms of IBS are

- crampy pain in the stomach area (abdomen)

- painful diarrhea or constipation

Most people have either diarrhea or constipation, but some people have both.

Other symptoms are

- mucusin the stool

- swollen or bloated abdomen

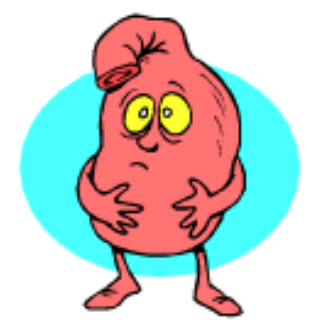

- the feeling that you have not finished a bowel movement

The following have been associated with a worsening of IBS symptoms:

- $\quad$ large meals

- bloating from gas in the colon

- medicines

- wheat, rye, barley, chocolate, milk products, or alcohol

- drinks with caffeine, such as coffee, tea, or colas

- stress, conflict, or emotional upsets

Researchers have also found that women with IBS may have more symptoms during their menstrual periods, suggesting that reproductive hormones can exacerbate IBS problems.

\section{How is IBS diagnosed?}

The doctor will suspect that you have IBS because of your symptoms. But the doctor may do medical tests to make sure you don't have any other diseases that could cause the symptoms. 
What is the treatment?

IBS has no cure, but you can do things to relieve symptoms. Treatment may involve

- diet changes

- medicine

- stress relief

You may have to try a combination of things to see which works best for you.

\section{Diet Changes}

\section{Some foods make IBS worse.}

Here are some foods that may cause symptoms.

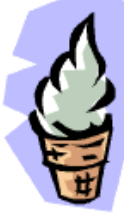

- fatty foods like french fries

- milk products like cheese or ice cream

- chocolate

- alcohol

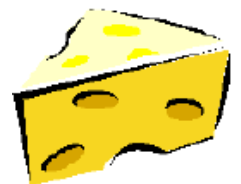

- caffeine (found in coffee and some sodas)

- carbonated drinks like soda

If certain foods cause symptoms, you should eat less of them or stop eating them.

To find out which foods are a problem, write down this information:

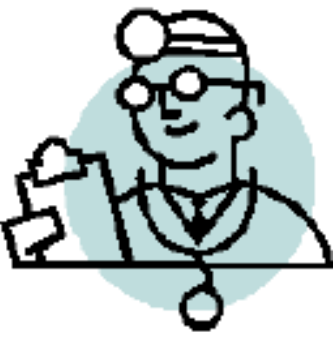

- what you eat during the day

- what symptomsyou have

- when symptoms occur

- what foods always make you feel bad

Take your notes to the doctor to see if you should stop eating certain foods 


\section{Diet Changes continued...}

\section{Some foods make IBS better.}

Fiber reduces IBS symptoms- especially constipation-- because it makes stool soft, bulky, and easier to pass. Fiber isfound in bran, bread, cereal, beans, fruit, and vegetables.

Here are some examples of foods with fiber:

$\begin{array}{lll}\text { Fruits } & \text { Vegetables } & \text { Breads, cereals, and beans } \\ \text { Apples } & \text { Cabbage } & \text { Whole-grain bread } \\ \text { Peaches } & \text { Broccoli, raw } & \text { Whole-grain cereal } \\ & \text { Carrots, raw } & \text { Peas } \\ & & \text { Kidney beans }\end{array}$

Add foods with fiber to your diet a little at a time to let your body get used to them. Too much fiber all at once might cause gas, which can trigger symptoms in a person with IBS.

Besides telling you to eat more foods with fiber, the doctor might also tell you to get more fiber by taking a fiber pill or drinking water mixed with a special high-fiber powder.

Drinking six to eight glasses of plain water a day is important, especially if you have diarrhea. But drinking carbonated beverages, such as sodas, may result in gasand cause discomfort. Chewing gum and eating too quickly can lead to swallowing air, which again leads to gas.

\section{How much you eat matters, too.}

Large meals can cause cramping and diarrhea in people with IBS. If this happensto you, try eating four or five small mealsa day. Or, have your usual three meals, but eat less at each meal.

\section{Points to Remember...}

- IBS is a functional disorder in which the bowel doesn't work as it should.

- IBS can cause cramping, bloating, gas, diarrhea, and constipation.

- IBS doesn't damage the bowel.

- The doctor will diagnose IBS based on your symptoms. You might have some medical teststo rule out other diseases.

- Stress doesn't cause IBS, but it can trigger symptoms.

- Fatty foods, milk products, chocolate, caffeine, carbonated drinks, and alcohol can trigger symptoms.

- Eating foods with fiber and eating smaller meals can reduce symptoms.

- Treatment for IBS may include medicine, stress relief, or changes in eating habits. 


\title{
Lactose \\ Intolerance
}

\section{What is lactose intolerance?}

\begin{abstract}
Lactose intolerance is the inability to digest significant amounts of lactose, the predominant sugar of milk. This inability results from a shortage of the enzyme lactase, which is normally produced by the cells that line the small intestine. Lactase breaks down milk sugar into simpler forms that can then be absorbed into the bloodstream. When there is not enough lactase to digest the amount of lactose consumed, the results, although not usually dangerous, may be very distressing. While not all persons deficient in lactase have symptoms, those who do are considered to be lactose intolerant.
\end{abstract}

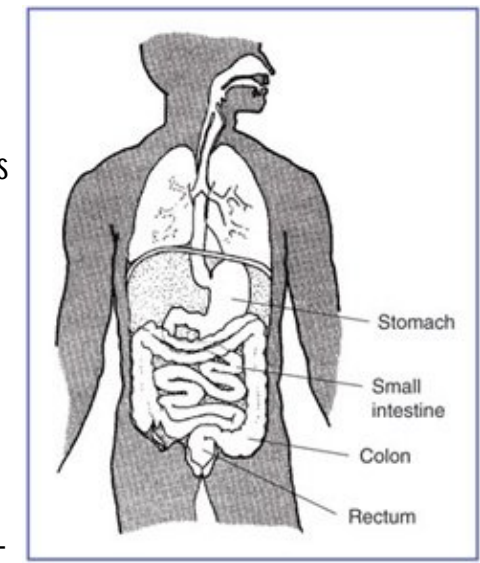

Common symptoms include nausea, cramps, bloating, gas, and diarrhea, which begin about 30 minutes to 2 hours after eating or drinking foods containing lactose. The severity of symptoms varies depending on the amount of lactose each individual can tolerate.

Special points of interest:

- How is lactose intolerance treated?

- How is nutrition balanced?

- Amount of calcium in foods

- What is hidden lactose?
Some causes of lactose intolerance are well known. For instance, certain digestive diseases and injuries to the small intestine can reduce the amount of enzymes produced. In rare cases, children are born without the ability to produce lactase. For most people, though, lactase deficiency is a condition that develops naturally over time. After about the age of 2 years, the body beginsto produce less lactase. However, many people may not experience symptoms until they are much older.

Between 30 and 50 million Americans are lactose intolerant. Certain ethnic and racial populations are more widely affected than others. Asmany as 75 percent of all African Americans and American Indiansand 90 percent of Asian Americansare lactose intolerant. The condition is least common among persons of northern European descent.

Researchers have identified a genetic variation associated with lactose intolerance; this discovery may be useful in developing a diagnostic test to identify people with this condition. 


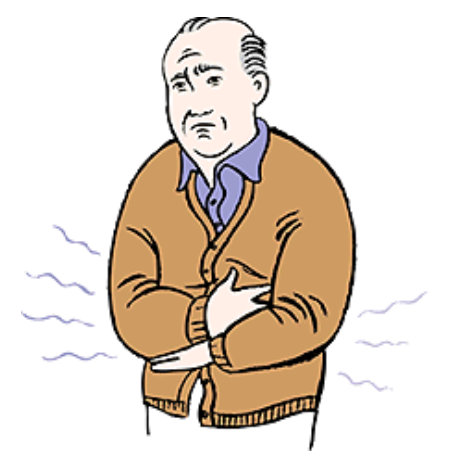

\section{How is lactose intolerance treated?}

Fortunately, lactose intolerance is relatively easy to treat. No treatment can improve the body's ability to produce lactase, but symptoms can be controlled through diet.

Young children with lactase deficiency should not eat any foods containing lactose. Most older children and adults need not avoid lactose completely, but people differ in the amountsand types of foods they can handle. For example, one person may have symptoms after drinking a small glass of milk, while another can drink one glass but not two. Others may be able to manage ice cream and aged cheeses, such as cheddar and Swiss, but not other dairy products. Dietary control of lactose intolerance depends on people learning through trial and error how much lactose they can handle.

For those who react to very small amounts of lactose or have trouble limiting their intake of foods that contain it, lactase enzymes are available without a prescription to help people digest foods that contain lactose. The tablets are taken with the first bite of dairy food. Lactase enzyme is also available as a liquid. Adding a few drops of the enzyme will convert the lactose in milk or cream, making it more digestible for people with lactose intolerance.

Lactose-reduced milk and other products are available at most supermarkets. The milk containsall of the nutrientsfound in regular milk and remains fresh for about the same length of time, or longer if it is super-pasteurized.

\section{How is nutrition balanced?}

Milk and other dairy products are a major source of nutrients in the American diet. The most important of these nutrients is calcium. Calcium is essential for the growth and repair of bones throughout life. In the middle and later years, a shortage of calcium may lead to thin, fragile bones that break easily, a condition called osteoporosis. A concern, then, for both children and adults with lactose intolerance, is getting enough calcium in a diet that includeslittle or no milk.

In 1997, the Institute of Medicine released a report recommending new requirements for daily calcium intake. How much calcium a person needs to maintain good health varies by age group. Recommendations from the report are shown in the following table.

\section{Age group}

Amount of calcium to consume daily, in milligrams ( $\mathrm{mg}$ )

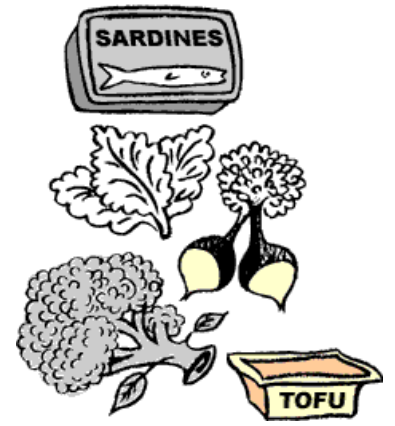

\section{0-6 months}

$210 \mathrm{mg}$

7- 22 months

$270 \mathrm{mg}$

13 years

$500 \mathrm{mg}$

4-8 years

$800 \mathrm{mg}$

9- 18 years

1,300 mg

19-50 years

$1,000 \mathrm{mg}$ 


\section{Balanced nutrition continued...}

Also, pregnant and nursing women under 19 need 1,300 mg daily, while pregnant and nursing women over 19 need $1,000 \mathrm{mg}$.

In planning meals, making sure that each day's diet includes enough calcium is important, even if the diet does not contain dairy products. Many nondairy foods are high in calcium. Green vegetables, such as broccoli and kale, and fish with soft, edible bones, such as salmon and sardines, are excellent sources of calcium. To help in planning a high-calcium and low-lactose diet, the table that follows lists some common foods that are good sources of dietary calcium and shows how much lactose they contain.

Recent research shows that yogurt with active cultures may be a good source of calcium for many people with lactose intolerance, even though it is fairly high in lactose. Evidence shows that the bacterial cultures used to make yogurt produce some of the lactase enzyme required for proper digestion.

Some people with lactose intolerance may think they are not getting enough calcium and vitamin D in their diet. Consultation with a doctor or dietitian may be helpful in deciding whether any dietary supplements are needed. Taking vitamins or minerals of the wrong kind or in the wrong amounts can be harmful. A dietitian can help in planning meals that will provide the most nutrients with the least chance of causing discomfort.

\section{Calcium and Lactose in Common Foods}

\section{Food}

Calcium-fortified orange juice, 1cup

Sardines, with edible bones, $3 \mathrm{oz}$.

Salmon, canned, with edible bones, $3 \mathrm{oz}$.

Soymilk, fortified, 1cup

Broccoli (raw), 1cup

Orange, 1medium

Pinto beans, $1 / 2$ cup

Tuna, canned, $3 \mathrm{oz}$.

Lettuce greens, $1 / 2$ cup

\section{Dairy Products}

Yogurt, plain, low-fat, 1cup

Milk, reduced fat, 1cup

Swiss cheese, $10 z$.

Ice cream, 12 cup

Cottage cheese, $1 / 2$ cup

\section{Calcium Content}

308-344 mg

$270 \mathrm{mg}$

$205 \mathrm{mg}$

$200 \mathrm{mg}$

$90 \mathrm{mg}$

$50 \mathrm{mg}$

$40 \mathrm{mg}$

$10 \mathrm{mg}$

$10 \mathrm{mg}$

$415 \mathrm{mg}$ $5 \mathrm{~g}$ $295 \mathrm{mg}$ $11 \mathrm{~g}$ $270 \mathrm{mg}$ $85 \mathrm{mg}$ $75 \mathrm{mg}$

\section{Lactose Content}

0

0

0

0

0

0

0

0

0
Adapted from Manual of Clinical Dietetics. 6th ed. American Dietetic Association, 2000; and Soy Dairy Alternatives. Available at: www.soyfoods.org. Accessed March 5, 2002.

Clearly, many foods can provide the calcium and other nutrients the body needs, even when intake of milk and dairy products is limited. However, factors other than calcium and lactose content should be kept in mind when planning a diet. Some vegetables that are high in calcium (Swiss chard, spinach, and rhubarb, for instance) are not listed in the chart because the body cannot use the calcium they contain. They also contain substances called oxalates, which stop calcium absorption. Calcium is absorbed and used only when there is enough vitamin $D$ in the body. A balanced diet should provide an adequate supply of vitamin D. Sources of vitamin D include eggsand liver. However, sunlight helps the body naturally absorb or synthesize vitamin D, and with enough exposure to the sun, food sources may not be necessary. 


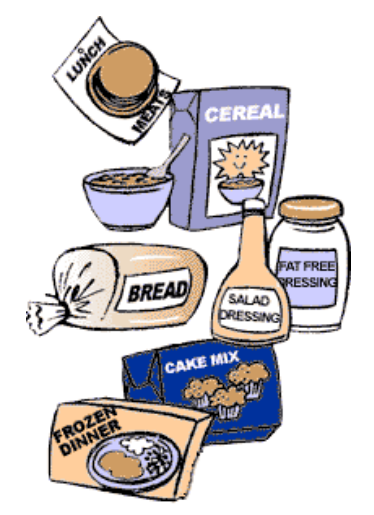

\section{What is hidden lactose?}

Although milk and foodsmade from milk are the only natural sources, lactose is often added to prepared foods. People with very low tolerance for lactose should know about the many food products that may contain even small amounts of lactose, such as

- bread and other baked goods

- processed breakfast cereals

- instant potatoes, soups, and breakfast drinks

- margarine

- lunch meats (other than kosher)

- salad dressings

- candies and other snacks

- mixesfor pancakes, biscuits, and cookies

- powdered meal-replacement supplements (i.e. whey)

Some productslabeled nondairy, such aspowdered coffee creamer and whipped toppings, may also include ingredients that are derived from milk and therefore contain lactose.

Smart shoppers learn to read food labels with care, looking not only for milk and lactose among the contents, but also for such words as whey, curds, milk byproducts, dry milk solids, and nonfat dry milk powder. If any of these are listed on a label, the product containslactose.

In addition, lactose is used as the base for more than 20 percent of prescription drugs and about 6 percent of over-the-counter medicines. Many types of birth control pills, for example, contain lactose, as do some tablets for stomach acid and gas. However, these productstypically affect only people with severe lactose intolerance.

Adapted from the National Digestive Diseases Information Clearing House (NDDIC) National Institute of Diabetes and Digestive and Kidney Disorders found at http:// diges tive.niddk.nih.gov/ ddiseases/pubs/

\section{Summary}

Even though lactose intolerance is widespread, it need not pose a seriousthreat to good health. People who have trouble digesting lactose can learn which dairy products and other foods they can eat without discomfort and which ones they should avoid. Many will be able to enjoy milk, ice cream, and other such products if they take them in small amounts or eat other food at the same time. Others can use lactase liquid or tablets to help digest the lactose. Even older women at risk for osteoporosisand growing children who must avoid milk and foods made with milk can meet most of their special dietary needs by eating greens, fish, and other calciumrich foods that are free of lactose. A carefully chosen diet, with calcium supplements if the doctor or dietitian recommends them, is the key to reducing symptoms and protecting future health. 


\section{Osteoporosis}

Osteoporosis, or porous bone, is a disease characterized by low bone mass and structural deterioration of bone tissue, leading to bone fragility and an increased susceptibility to fractures of the hip, spine, and wrist. Men as well as women suffer from osteoporosis, a disease that can be prevented and treated.

Peak bone mass (maximum bone density and strength) is reached around age 30 . After age 30 , bone removal slowly begins to exceed bone formation. Bone loss is most rapid in the first few years after menopause but persists into the postmenopausal years. Osteopo-

Special points of interest:

- Nutrients that affect calcium balance

- The role of soy and isoflavones

- Specifics on how to make your bones stronger rosis develops when bone removal occurs too quickly or if replacement occurs too slowly. Osteoporosis is more likely to develop if you did not reach optimal bone mass during your bone building years.

Building strong bones during childhood and adolescence can be the best defense against developing osteoporosis later. There are four steps to prevent osteoporosis. No one step alone is enough to prevent osteoporosis but all four may. They are:

- A balanced diet rich in calcium and vitamin D;

- Weight-bearing exercise;

- A healthy lifestyle with no smoking or excessive alcohol intake; and

- Bone density testing and medication, when appropriate

\section{Bone and Nutrition}

Nutrition is one of many factors that influence bone mass. Dietary intake can also impact the tendency to fall and plays a significant role in maintaining a soft tissue cushion to protect the skeleton from the impact of a fall.

\section{Calcium and Calcium Balance}

Bone serves as the reservoir for $99 \%$ of the body's total calcium. Calcium is an essential nutrient for bone health. It is also needed for the heart, muscles and nerves to function properly and for blood to clot normally. The body loses calcium every day through urine, feces, sweat and shed skin, hair and nails. The lost calcium is normally replaced by calcium in the diet. When the diet does not contain enough calcium to offset such losses, the body breaks down bone to release calcium needed to accommodate these physiologic demands.

Many other nutrients affect bone health, too, because they impact the absorption or excretion of calcium. Calcium balance-not just intake-is necessary for healthy bones. This balance is dependent on the absorption rate of calcium consumed as well as the rate of (mostly urinary) calcium excretion.

The nutrients that affect calcium balance include Vitamin D, protein, sodium, oxalate, phosphorus, caffeine, and fiber. Each of these plays a different role relative to calcium. Although many of these nutrients are good for our bodies and essential for functioning, too much or too little can offset the balance and the bones pay the price. Some times too much of a good thing is harmful! 


\section{A little about these nutrients...}

...that can significantly influence calcium balance.

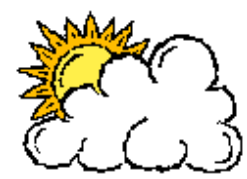

- Vitamin D has a positive impact on calcium balance, as it increases calcium absorption in the gastrointestinal tract. It is essential for calcium absorption and normal bone mineralization. The most readily available source of vitamin $D$ is exposure to direct sunlight. Vitamin $D$ is also found in fatty fish, tuna, eggs, liver, butter, fortified foods such as milk and multivitamins. Vitamin D deficiency may be a problem among some elderly, those in institutional settings, and some people with chronic neurological or gastrointestinal diseases and has been linked to low bone density.

- Protein is essential in our diets to build tissue during growth and to repair and replace tissue throughout the life cycle. It is also needed for fracture healing and proper function of the immune system. Protein deficiency is an important factor contributing to death, institutionalization, and loss of independence among the elderly following hip fracture.

However, protein also increases the body's need for calcium by increasing calcium excretion. Excess protein in the diet is used by the body for energy, just like fats and carbohydrates. However, as protein is burned for energy, it produces a chemical called sulfate, which the body excretes through the kidneys. Sulfate increases the excretion of calcium. Therefore, if protein is increased, the requirement for calcium is also increased.

It is generally believed that most Americans exceed the recommended intake for protein-44 grams for women and 56 grams for men.

- Sodium (and chloride), the components of table salt, increase the calcium requirement by increasing urinary calcium excretion. Individuals with low salt intakes may be able to maintain calcium balance at low calcium intakes, while those with more typical U.S. salt intakes will have higher calcium requirements.

- Oxalate is a nutrient that increases the calcium requirement by interfering with calcium absorption in the same food (not in others). Spinach, for example, is an extremely nutritious food, but its calcium is not absorbed because it is chemically bound to the oxalates that are present. However, eating spinach with cheese would not affect the absorption of calcium from the cheese. Foods high in oxalates include spinach, rhubarb and sweet potatoes.

- Phosphorous. Some concern has been expressed that there may be too much phosphorous in the North American diet, particularly since phosphorous (in the form of phosphoric acid) is a constituent of cola beverages and because phosphate is added to many processed foods. Phosphorous may increase the body's need for calcium by interfering with calcium absorption. There is no scientific consensus that current levels of phosphorous intake are, by themselves, harmful. There is, however, general agreement that today's higher phosphorous intakes would be entirely safe in individuals with normal kidney function if calcium intakes were at recommended levels.

- Caffeine. The amount of caffeine in a cup of coffee can reduce calcium absorption by a few milligrams, but that loss can be easily offset by adding a tablespoon or two of milk. Much of the apparently harmful effect of caffeine appears to be due not to the caffeine itself, but to the fact that caffeine-containing beverages are often substituted for milk in the diet.

- Fiber. Adequate fiber intake is necessary to aid digestion and prevent several chronic diseases such as colon cancer and heart disease. Fiber has a minimal effect on the absorption of calcium. The fiber in wheat bran is most likely to interfere, but unless the intake level is extreme, this is not a significant problem. 


\section{Other important nutrition aspects...}

\section{Soy and Isoflavones}

The soybean plant, a legume, contains specific phytochemicals known as isoflavones. Phytochemicals are nonnutritive substances, in that they contain no vitamins or minerals. Isoflavones are also phytoestrogens. Phytoestrogens are compounds that have mild estrogenic effects.

Chick peas and legumes are good sources of isoflavones. The legume, soy, has the greatest concentration of these chemicals.

Isoflavones have received a good deal of attention for their possible cancer and heart disease-preventive traits. Because of their estrogen-like properties, many believe that isoflavones and other phytoestrogens may one day play a role in postmenopausal health.

One isoflavone derivative, ipriflavone, is currently used outside of the United States as an osteoporosis therapy. Ipriflavone has had a bone-protective effect in several studies. Further research is needed to understand the systemic effects of this compound before it can be considered a therapeutic approach for osteoporosis prevention and treatment.

\section{Nutrition and Weight}

Nutritional status and body weight are additional considerations in skeletal health. Nutritional status can influence one's tendency to fall and is a factor in the maintenance of adequate soft tissue mass to protect the bones from a fall-related fracture. Of particular concern are thin, undernourished, elderly individuals who may lack sufficient muscle and fat mass in the hip region.

Body weight, is an important determinant of bone density. The skeleton of heavy individuals tends to benefit from it's increased load-carrying role. Studies have demonstrated that body weight is positively correlated with bone mineral density, and that weight loss is associated with bone loss. (Increasing calcium intake appears to reduce the bone loss that accompanies weight loss.)

Weight loss in older individuals has been linked to an increase in fracture risk. Researchers found that "extreme" weight loss ( $10 \%$ or more) beginning at age fifty, increased the risk of hip fracture in older women and men. Conversely, a weight gain of $10 \%$ or more decreased hip fracture risk. Such studies suggest that maintaining weight in later life may have a protective effect on bone.

Adapted from the National Institutes of Health, National Resource Center for Osteoporosis and Bone Related Diseases found at http://www.osteo.org/ osteolinks.asp\#gen

\section{How to make your bones stronger...}

- Pack your shopping cart with dark green and leafy vegetables, low-fat dairy products such as milk, yogurt, cottage cheese, etc., fatty fish, such as salmon, eggs, calcium fortified orange juice, foods low in sodium and adequate in protein

- Prepare a salad with lots of dark green vegetables like leafy greens and broccoli

- For any meal, make a spinach omelet or a smoothie with milk and yogurt and your favorite fruit

- Make a tuna sandwich...eat it outside!

- Have your coffee... with a splash of milk.... drink it outside!

- Have cookies...got milk?

- Add cottage cheese to your baked potato, mix it with fruit, or top it with cinnamon and a little bit of brown sugar

- Make your hot cereal with milk instead of water...make your hot chocolate with milk too! 


\section{만,

\section{Calcium}

\section{Why WE NEED CALCIUM}

Y ou may know that calcium plays an important role in building healthy teeth and bones. What you may not know is that calcium is vital to every cell of the body for muscle function, nerve transmission, blood clotting and many other uses. When you don't get enough calcium in your diet, the

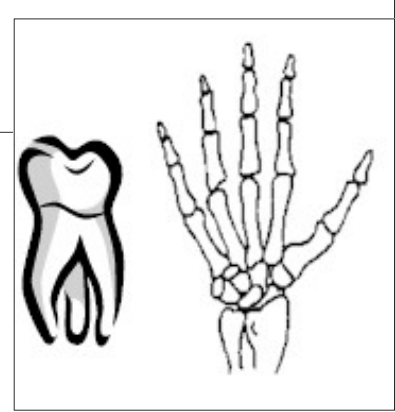
calcium stored in your bones is "stolen" to supply the rest of your body. Hence, your bones suffer the consequences of a low-calcium diet and they become more susceptible to fractures.

\section{RECOMMENDATIONS}

SPECIAL POINTS OF INTEREST:

- Sources of Calcium

- How Much Calcium Do Certain Foods Have?

- Fortified Foods

- Suggestions For How to Incorporate More Calcium
The D ietary R eference Intakes (D R I's) for calcium vary by age and stage of life:

\section{A ge/ L ifestage G roup}

\section{New Calcium G oal (mg/ day)}

1-3 years old 500

4-8 years old 800

9-18 years old 1300

19-50 years old 1000

$51+$ years old 1200

Pregnant and/ or lactating

(18 years old and younger) 1300

Pregnant and/ or lactating (19+ years old)

1000

The Institute of $\mathrm{M}$ edicine of the $\mathrm{N}$ ational A cademy of Sciences, W ashington, DC: N ational A cademy Press, 2101 Constitution A ve. N W, W ashington, DC 20418; 1997. 


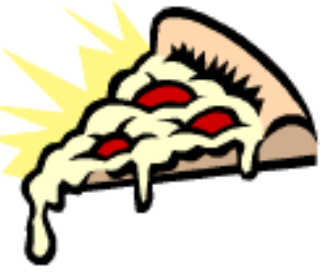

"Easy on the cheese please!"

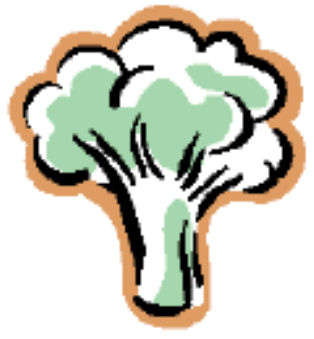

\section{SOURCES OF CALCIUM}

There are many different sources of calcium that can be found in almost all of the food groups.

Dairy: milk (skim \& 1\%), low-fat and non-fat yogurt, low-fat and non-fat cheese

M eats/ beans: sardines/ salmon with bones, calcium-set tofu

F ruits \& Vegetables: collard greens, broccoli, fortified orange juice

G rains: calcium fortified breads and cereals, pancakes

Combination foods: pizza, soups prepared with skim milk

H ere are some of the BEST sources of calcium and the amount of calcium they pack in!

\section{Dairy Foods}

Food

(mg)

M ilk, skim

Y ogurt, low-fat fruit

Y ogurt, plain

Y ogurt, frozen

Cheese, A merican

Cheese, low-fat cottage

Cheese, cream

Cheese, cheddar

Cheese, mozzarella

Cheese, swiss

Cheese, parmesan

Cheese, colby/monterey jack

Ice cream, low-fat

Pudding

Serving Size

$8 \mathrm{oz}$

$80 z$.

$8 \mathrm{oz}$.

$8 \mathrm{oz}$.

$10 z$.

4 oz./ 1/ 2 cup

$1 \mathrm{oz}$.

$10 z$.

$10 z . \quad 203$

$10 z . \quad 273$

$1 / 4$ cup 250

$10 z . \quad 200$

4 oz./ 1/ 2 cup $\quad 100$

4 oz./ 1/ 2 cup 150

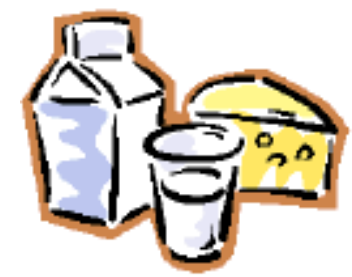

N on-D airy Sources \& Others

\section{Food}

Broccoli, cooked

Spinach, cooked*

$\mathrm{G}$ reens, cooked

Tofu, raw, firm -

calcium - set

Instant Oatmeal

Pancakes, buttermilk

Sardines

Salmon, canned,

with bones

Taco with cheese

\section{Serving Size}

4 oz./ 1/ 2 cup

4 oz./ 1/ 2 cup

4 oz./ 1/ 2 cup

4 oz./ 1/ 2 cup

1 package

1

2

$30 z$.

1 large
Calcium (mg)

47

122

55

258

150

80

90

203

340 


\section{FORTIFIED FOODS}

Fortified foods are a great way to get dietary calcium. W hen looking for a calcium-fortified version of a product, look for words on the packaging like "calcium-fortified," "excellent source of calcium (more than $200 \mathrm{mg}$ of calcium)" or "good source of calcium (110-190 mg/ serving)."

Some examples of calcium fortified foods include: Total Cereal ${ }^{\mathrm{TM}}$, select varieties of Crystal $\mathrm{Light}^{\mathrm{TM}}$ drink, Honey $M$ aid $^{\mathrm{TM}}$ Graham Crackers, Cheez-It ${ }^{\mathrm{TM}}$ Juniors, K ellogg's Fruit Loops $^{T M}$, Special K Plus ${ }^{T M}$, Eggo W affles ${ }^{T M}$, Country Crock Spread ${ }^{T M}$-tub only,

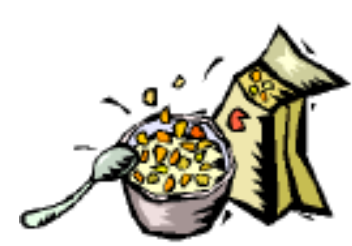
select varieties of soy milks, select varieties of orange juice ( $M$ inute $M$ aid ${ }^{\mathrm{TM}} \&$ Tropicana $^{\mathrm{TM}}$ ), select varieties of cranberry juices (O ceanSpray ${ }^{\mathrm{TM}}$ ), some grapefruit juices (Ruby Red G rapefruit J uice ${ }^{\mathrm{TM}}$ ), and some apple juices, W onder Bread ${ }^{\mathrm{TM}}$, and $\mathrm{H}$ ostess $\mathrm{M}$ ini-muffins ${ }^{\mathrm{TM}}$. Check packages for exact calcium content.

\section{SUGGESTIONS FOR INCORPORATING MORE CALCIUM}

- D rink skim or $1 \%$ milk with meals or as a snack.

- Increase your intake of calcium-rich foods when under stress.

- A sk your doctor about your medications (some decrease calcium absorption).

- Don't smoke - it decreases calcium absorption.

- Do exercise - it increases bone density (especially weight-bearing exercise).

- Use skim milk in soup instead of water.

- Limit caffeine intake, it can decrease calcium absorption.

- Add low-fat cheese to sandwiches, salads, casseroles, etc.

- Eat low-fat yogurt or cheese as a snack.

- Choose calcium-rich desserts.

- A void or limit alcohol - it can increase calcium loss.

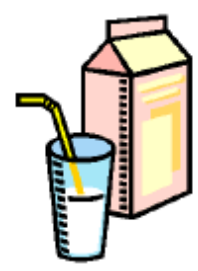




\section{Nutrition and}

\section{Your Weight}

\section{Embrace Your Health!}

Exercise Testing \&

Prescription

Nutrition Assessment \&

Consultation

\section{A Healthy Weight}

When it comes to nutrition, it's easy to spend a lot of time worrying about what to eat. But how much you eat puts an even greater stamp on your long-term health than picking the right kind of fats or choosing exactly the right mix of vitamins.

How much you weigh (in relation to your height), your waist size, and how much weight you've gained since your mid-20s strongly influence your chances of:

- dying early

- having, or dying from, a heart attack, stroke, or other type of cardiovascular disease

- developing diabetes

- developing cancer of the colon, kidney, breast, or endometrium

- having arthritis

- developing gallstones

- being infertile

- developing asthma as an adult

- snoring or suffering from sleep apnea, or

- developing cataracts.

Despite the substantial impact of weight on individual health, and the soaring rates of obesity in the United States, relatively few Americans see excess weight as a problem. In a survey conducted by researchers at Harvard's Kennedy School of Government, almost 1,000 Americans ranked obesity low on the list of serious health problems. Equally alarming, only 9 percent said their weight was a problem, even though more than half were overweight. That's a shocking finding, given that excess weight leads to at least 300,000 deaths per year and costs more than $\$ 70$ billion each year in direct costs alone. Obesity now accounts for more deaths and chronic disorders, and poorer health-related quality of life, than either smoking or problem drinking.

If your weight is in the healthy range and isn't more than 10 pounds over what you weighed when you turned 21, great. Keeping it there-and keeping it steady-by watching what you eat and exercising will limit your risk of developing one or more of these chronic conditions noted above. If you are overweight, doing whatever you can to prevent gaining more weight is a critical first step. Then, when you're ready, shedding some pounds and keeping them off will be important steps to better health.

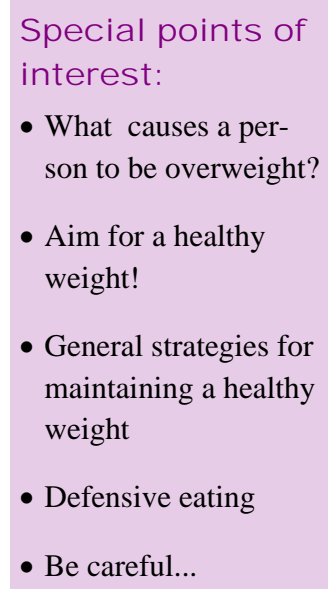

- What causes a person to be overweight?

- Aim for a healthy weight!

- General strategies for maintaining a healthy weight

- Defensive eating

- Be careful... 


\section{Thinking about losing weight...}

Maybe you've been thinking about losing weight for some time now. Perhaps you have even tried to lose weight before. Reading this shows you have the motivation to get started again. Use the following information to help you form good habits to keep you going until you reach your goal

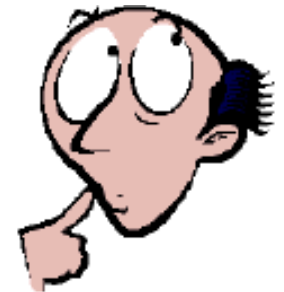
weight.

\section{What causes a person to be overweight?}

Two common reasons for being overweight are eating too much and not being active enough. If you eat more calories than your body burns up, the extra calories are stored as fat. Everyone has some stored fat. Too much fat results in being overweight.

Whether or not your weight changes depends on a simple rule:

Weight change $=$ calories in - calories out

If you burn as many calories as you take in each day, there's nothing left over for storage in fat cells and weight remains the same. Eat more than you burn, though, and you end up adding fat and pounds.

Many things influence what and when you eat and how many calories you burn. These turn what seems to be a straightforward pathway to excess weight into a complex journey that may start very early in life.

\section{Genes}

Some people are genetically predisposed to gain weight more easily than others or to store fat around the abdomen and chest. It's also possible that humans have a genetic drive to eat more than they need for the present in order to store energy for future. This is called the thrifty gene hypothesis. It suggests that eating extra food whenever possible helped early humans survive feast-or-famine conditions. If such thrifty genes still exist, they aren't doing us much good in an environment in which food is constantly available.

Diet

At the risk of stating the obvious, the quantity of food in your diet has a strong impact on weight. The composition of your diet, though, seems to play little role in weight-a calorie is a calorie, regardless of its source.

Physical activity

The "calories burned" part of the weight-change equation often get short shrift. The more active you are, the more calories you burn, which means that less energy will be available for storage as fat. Exercising more also reduces the chances of developing heart disease, some types of cancer, and other chronic diseases. In other

\section{Aim For a Healthy Weight!}

Use this chart to find out if your weight is within the healthy weight range suggested for people of your height. Weights above the healthy weight range are less healthy for most people.

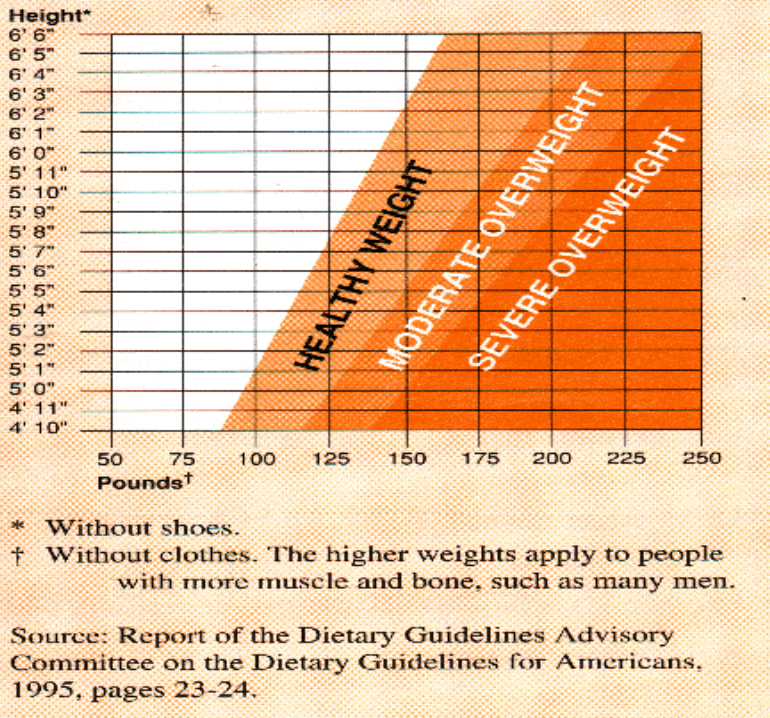

Nutrition and Your Weight 


\section{General Strategies For Re-establishing or Maintaining a Healthy Weight}

How can you lose weight if you need to? Here are some suggestions that work:

Set a realistic goal. Many people pick weight goals they'll have a hard time achieving, like fitting into a size 8 dress or a wedding tuxedo from 20 years ago. A better initial goal is 5-10 percent of your current weight. This may not put you in league with the "beautiful people" profiled in popular magazines, but it can lead to important improvements in weightrelated conditions such as high blood pressure and diabetes. You don't have to stop there, of course. You can keep aiming for another 5-10 percent until you're happy with your weight. By breaking weight loss into more manageable chunks, you'll be more likely to reach your goal.

Slow and steady wins the race. Dieting implies deprivation and hunger. You don't need either to lose weight if you're willing to take the time to do it right. If you cut out just 100 calories a day, the equivalent of a single can of soda or a bedtime snack, you would weigh 10 pounds less after a year. If, at the same time, you added a brisk 30-minute walk 5 days a week, you could be at least 20 pounds lighter.

Exercise more. The amount of energy the body uses to breathe, pump blood, keep muscles ready for action, and other mundane but vital tasks is called resting metabolism. It accounts for two-thirds of your daily energy expenditure. The more you work your muscles--especially with strength training exercises--the more blood sugar they sponge from the blood and the more calories they burn even when you aren't active. If you don't exercise, try a walking program. Start out with something simple--get off your bus a stop early and walk the rest of the way to work, park your car at the far end of the company or mall parking lot, or take a brisk walk at lunch or when you come home. Gradually increase the amount of time you walk each day until you do 30 or more minutes a day. A pedometer can help you keep track of your daily activity. These watch-like devices hang from a belt and record how many steps you take. A good goal is 10,000 steps a day. If you already exercise, try to increase its intensity or duration.

Keep track. It's easy to eat more than you plan to. A daily food diary can make you more aware of exactly how much you are eating. Include everything, no matter how small or insignificant it seems. Small noshes and drinks of juice add up to real calories.

Bring on the water. When you are thirsty, reach for water. Drinking juice or sugared soda can give you several hundred calories a day without even realizing it.

Don't be afraid of good fats. Fat in a meal or in snacks such as nuts helps you feel full. Good fats such as olive or canola oil can also help improve your cholesterol levels when you eat them in place of saturated or trans fats or highly processed carbohydrates.

Choose lower fat, lower calorie foods.

- Prepare food by broiling, baking, roasting or steaming more often instead of frying.

- $\quad$ Eat fewer breaded and fried foods. Breading and frying foods like fish, shrimp, chicken, and vegetables add fat and calories.

- Eat lean meat, fish, and poultry without skin. Choose poultry breasts and drumsticks more often than the wings and thighs.

- Eat more fruits, whole grain, and vegetables. If you are a nibbler, choose fruits and vegetables as snacks more often.

- Use the food label to choose lower calorie foods.

- Drink fewer alcoholic and high-calorie beverages. 


\section{Defensive Eating...}

In our society, food is everywhere--the mall and gas station, the ballpark and drug store. Super size meals in fast food restaurants are almost too good a bargain to pass up, and servings in all but the most trendy restaurants are often enough to feed two. In the face of such plenty, it's important to learn how to avoid overeating. Here are some strategies that help defend against eating too much:

Stop before you are stuffed. Learn your body's signals and practice stopping before you feel full.

Be selective. It's easy to eat food just because it's put in front of you. Be mindful of what you are eating, and make sure that you are choosing what to eat.

Select small portions. Portions in most restaurants are over-sized. If you are eating with someone else,

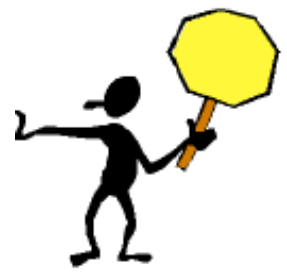
try sharing an entrée, or order two appetizers instead of an entree. If you're eating alone, eat half and take the rest home for another meal. If you are at home, try not going back for seconds. Try eating only one serving of higher fat, higher calorie foods such as pizza, ice cream or chips.

Beware of desserts. A single slice of The Cheesecake Factory's Original Cheesecake packs almost 800 calories and an incredible 49 grams of fat ( 28 of them saturated, or 50 percent more than is recommended maximum per day). Either share such a rich dessert several ways or skip it altogether and finish your meal with a piece of fruit or other lowercalorie option.

Slow down. Eating fast short-circuits the signals that your digestive system generates to signal that it's getting full. Slowing down gives your stomach and intestines time to send these messages to your brain.

Spoil your appetite. Having a snack or appetizer before a meal can dull your hunger and help you eat less at the meal.

Be aware of why you are eating. Sometime we eat when we're bored, anxious, or angry. Try not to soothe your negative feelings with food. Dealing with them in other ways --talking to friends, listening to music, taking a walk, meditating, or working--can help you relieve stress without gaining weight.

\section{Throughout the Day...}

Eat only when you are hungry.

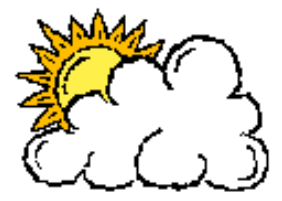

Eat breakfast-it is the most important meal of the day!

Eat 5-6 "mini" meals instead of 3 large meals-this will keep you from getting too hungry.

Keep meals balanced-use the Food Guide Pyramid to help plan meals.

Add fiber to your meals-it will keep you feeling fuller longer. 


\section{Looking for a quick and easy way to lose weight?}

Don't be fooled. Be wary of misleading programs that offer quick weight loss. Some famous phrases like, "Eat all you want and still lose weight," or "Melt fat away--while you sleep," may Some other phrases to be wary of are:

- Breakthrough

- Easy

- Effortless

- $\quad$ Fast Guaranteed
- $\quad$ Quick

- New

- $\quad$ Discovery

- Miracle Cure come to mind.

\section{Do Not Restrict...}

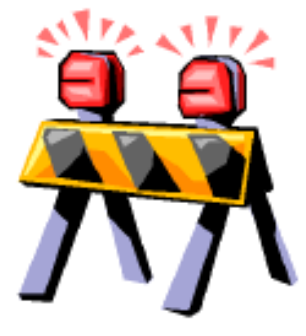

Use caution!

By taking in most calories from one source, the body won't operate efficiently because there will be deficiencies in other areas. Damage from insufficient nutrient intake can occur long before effects are felt. The following list offers some health problems that can result from specific nutrient restricted diets:

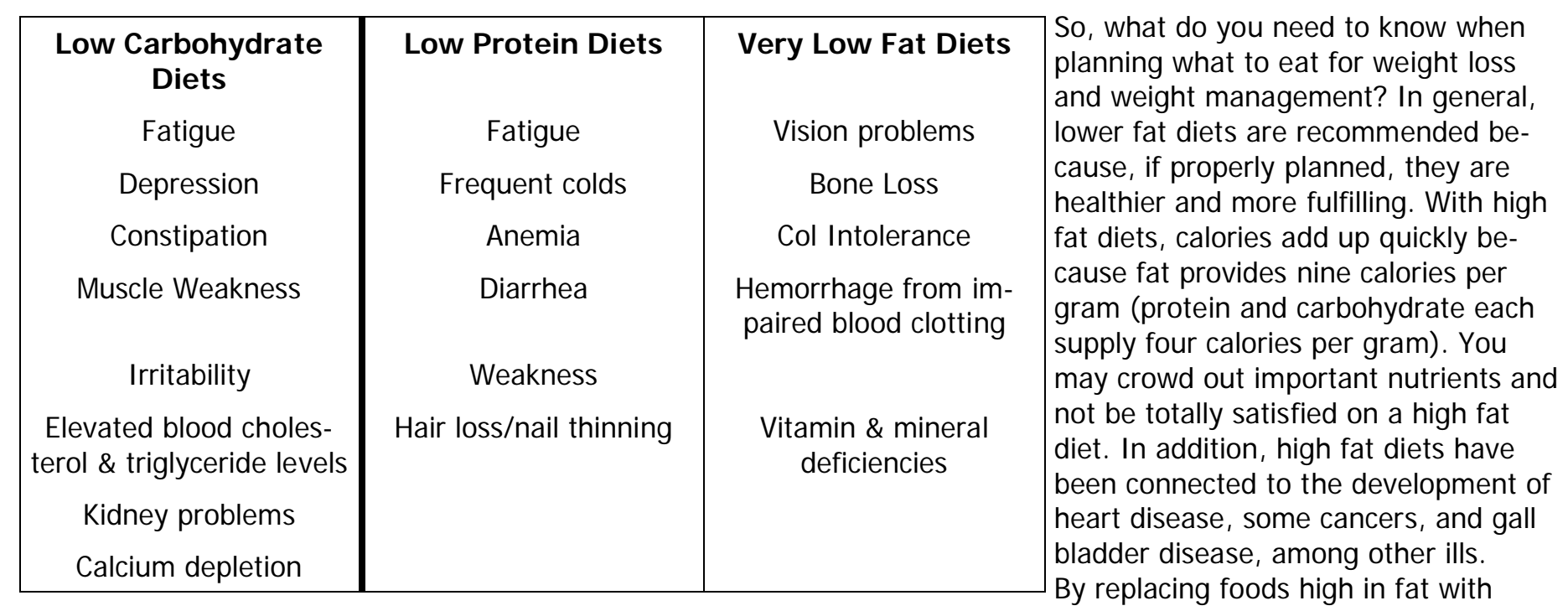

foods low in fat, but higher in protein or carbohydrates, the number of calories are automatically cut down (if you don't eat a greater quantity). Substituting a high fat food with a high fiber food will help keep you feeling full and content with fewer calories as well. Many carbohydrate-rich foods are also high in fiber. Since humans can't digest fiber, it adds bulk and is filling and satisfying, which are among its healthy benefits.

\section{The Bottom Line}

For safe and effective long term weight loss to occur, a change of lifestyle must happen. By planning your diet using the Food Guide Pyramid, making a variety of different food choices that are low in fat, especially saturated fat, high in fiber, and moderate in portion size, as well as including daily activity, the amount of calories you take in are bound to be less than the amount of calories you expend. The weight will begin to melt away and you will be on your way to a healthier you!

Adapted from the Harvard School of Public Health. For complete document and references go to http://www.hsph.harvard.edu/nutritionsource/ weight.html. Also adapted from National Institutes of Health, National Heart, Lung, and Blood Institute, and Office of Research on Minority Health found at http://www.nhlbi.nih.gov/health/public/heart/other/chdblack/embrace.pdf 


\section{Overweight and Obesity: At a Glance}

\section{THE FACTS ABOUT OVERWEIGHT AND OBESITY}

- $61 \%$ of adults in the United States were overweight or obese (BMI > 25)* in 1999.

- $13 \%$ of children aged 6 to 11 years and $14 \%$ of adolescents aged 12 to 19 years were overweight* in 1999. This prevalence has nearly tripled for adolescents in the past 2 decades.

- The increases in overweight and obesity cut across all ages, racial and ethnic groups, and both genders.

- 300,000 deaths each year in the United States are associated with obesity.

- O verweight and obesity are associated with heart disease, certain types of cancer, type 2 diabetes, stroke, arthritis, breathing problems, and psychological disorders, such as depression.

- The economic cost of obesity in the United States was about $\$ 117$ billion in 2000.

\section{HEALTH DISPARITIES}

Based on national survey data collected between 1988 and 1994:

- The prevalence of overweight and obesity increases until about age 60 , after which it begins to decline.

- In women, overweight and obesity are higher among members of racial and ethnic minority populations than in non-Hispanic white women.

- In men, Mexican Americans have a higher prevalence of overweight and obesity than non-Hispanic whites or non-Hispanic blacks. The prevalence of overweight and obesity in non-Hispanic white men is greater than in non-Hispanic black men.

- $69 \%$ of non-Hispanic black women are overweight or obese compared to $58 \%$ of non-Hispanic black men.

- $62 \%$ of non-Hispanic white men are overweight or obese compared to $47 \%$ of non-Hispanic white women. However, when looking at obesity alone (BMI > 30*), slightly more non-Hispanic white women are obese compared to non-Hispanic white men $(23 \% ; 21 \%)$.

- For all racial and ethnic groups combined, women of lower socioeconomic status (income $<130$ percent of poverty threshold) are approximately 50\% more likely to be obese than those of higher socioeconomic status.

- Mexican American boys tend to have a higher prevalence of overweight than nonHispanic black or non-Hispanic white boys.

- Non-Hispanic black girls tend to have a higher prevalence of overweight than Mexican American or non-Hispanic white girls.

- Non-Hispanic white adolescents from lower income families experience a greater prevalence of overweight than those from higher income families. 


\section{CAUSES OF OVERWEIGHT AND OBESITY}

- O verweight and obesity result from an imbalance involving excessive calorie consumption and/ or inadequate physical activity.

- For each individual, body weight is the result of a combination of genetic, metabolic, behavioral, environmental, cultural, and socioeconomic influences.

- Behavioral and environmental factors are large contributors to overweight and obesity and provide the greatest opportunity for actions and interventions designed for prevention and treatment.

\section{PHYSICAL ACTIVITY AND INACTIVITY}

- It is recommended that Americans accumulate at least 30 minutes (adults) or 60 minutes (children) of moderate physical activity most days of the week. More may be needed to prevent weight gain, to lose weight, or to maintain weight loss.

- Less than $1 / 3$ of adults engage in the recommended amounts of physical activity.

- Many people live sedentary lives; in fact, $40 \%$ of adults in the United States do not participate in any leisure time physical activity.

- $43 \%$ of adolescents watch more than 2 hours of television each day.

- Physical activity is important in preventing and treating overweight and obesity and is extremely helpful in maintaining weight loss, especially when combined with healthy eating.

Reprinted from the O ffice of the Surgeon $\mathrm{G}$ eneral found at http:/ / www.surgeongeneral.gov/ topics/ obesity/ default.htm 


\section{polfit}

Nutrition Assessment \& Consultation

Exercise Testing \& Prescription

Lose weight fast! We'll tell you how!"

Try the low-carbohydrate diet, the high-protein diet, the green tea diet, and the cabbage soup diet--or drink a shake and lose 10 pounds in 10 days.

And so on, and so on, and so on. With so many products and weight-loss theories out there, it's easy to get confused.

This fact sheet will help clear up some of the confusion about weight loss and nutrition and be a guide for making good decisions about your health. If you have any other questions, or if you want to lose weight, talk to a health care professional. Your doctor, a registered dietitian, or other qualified health professional can give you advice on how to eat a healthy diet and lose weight safely.

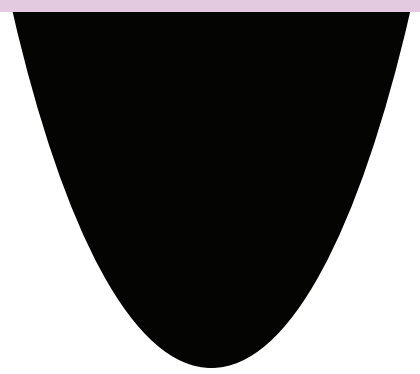

\section{Weight Loss and Nutrition Myths - How much do you really know?}

Myth: Fad diets work for permanent weight loss.

Fact: Fad diets are not the best ways to lose weight and keep it off. These eating plans often promise to help you lose a lot of weight quickly, or tell you to cut certain foods out of your diet to lose weight. Although you may lose weight at first while on these kinds of diets, they can be unhealthy because they often keep you from getting all the nutrients that your body needs. Fad diets may seriously limit or forbid certain types of food, so most people quickly get tired of them and regain the lost weight.

Research suggests that losing $1 / 2$ to 2 pounds a week by eating better and exercising more is the best way to lose weight and keep it off. By improving your eating and exercise habits, you will develop a healthier lifestyle and control your weight. You will also reduce your chances of developing heart disease, high blood pressure, and diabetes.

Myth: Skipping meals is a good way to lose weight.

Fact: Your body needs a certain amount of calories and nutrients each day in order to work properly. If you skip meals during the day, you will be more likely to make up for those missing calories by snacking or eating more at the next meal. Studies show that people who skip breakfast tend to be heavier than those who eat a nutritious breakfast. A healthier way to lose weight is to eat many small meals throughout the day that include a variety of nutritious, low-fat, and low-calorie foods.

Myth: "I can lose weight while eating anything I want."

Fact: This statement is not always true. It is possible to eat any kind of food you want and lose weight. But you still need to limit the number of calories that you eat every day, usually by eating smaller amounts of food. When trying to lose weight, you can eat your favorite foods-as long as you pay attention to the total amount of food that you eat. You need to use more calories than you eat to lose weight. 


\section{Myth: "I can lose weight while eating anything I want."}

Fact: This statement is not always true. It is possible to eat any kind of food you want and lose weight. But you still need to limit the number of calories that you eat every day, usually by eating smaller amounts of food. When trying to lose weight, you can eat your favorite foods-as long as you pay attention to the total amount of food that you eat. You need to use more calories than you eat to lose weight.

Nutrition Assessment \& Consultation

Exercise Testing \& Prescription

Lose weight fast! Well tell you how!"

Try the low-carbohydrate diet, the high-protein diet, the green tea diet, and the cabbage soup diet--or drink a shake and lose 10 pounds in 10 days.

And so on, and so on, and so on. With so many products and weight-loss theories out there, it's easy to get confused.

This fact sheet will help clear up some of the confusion about weight loss and nutrition and be a guide for making good decisions about your health. If you have any other questions, or if you want to lose weight, talk to a health care professional. Your doctor, a registered dietitian, or other qualified health professional can give you advice on how to eat a healthy diet and lose weight safely.

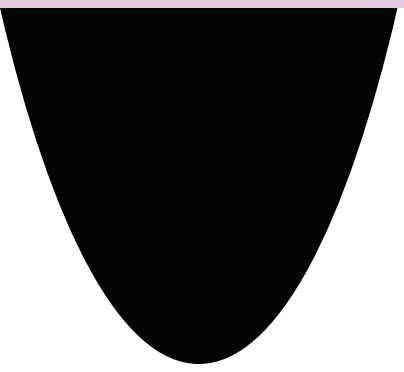
Myth: Eating after 8 p.m. causes weight gain.

Fact: It doesn't matter what time of day you eat--it's how much you eat during the whole day and how much exercise you get that make you gain or lose weight. No matter when you eat your meals, your body will store extra calories as fat. If you want to have a snack before bedtime, make sure that you first think about how many calories you have already eaten that day.

Try not to snack while doing other things like watching television, playing video games, or using the computer. If you eat meals and snacks in the kitchen or dining room, you are less likely to be distracted and more likely to be aware of what and how much you are eating. (If you want to snack while watching TV, take a small amount of food with you--like a handful of pretzels or a couple of cookies-not the whole bag.)

Myth: Certain foods, like grapefruit, celery, or cabbage soup, can burn fat and make you lose weight.

Fact: No foods can burn fat. Some foods with caffeine may speed up your metabolism (the way your body uses energy, or calories) for a short time, but they do not cause weight loss. The best way to lose weight is to cut back on the number of calories you eat and be more physically active.

Myth: Natural or herbal weight-loss products are safe and effective.

Fact: A product that claims to be "natural" or "herbal" is not necessarily safe. These products are not usually tested scientifically to prove that they are safe or that they work. 


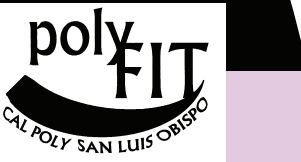

Nutrition Assessment \&

Consultation

Exercise Testing \& Prescription

Lose weight fast! We'll tell you how!"

Try the low-carbohydrate diet, the high-protein diet, the green tea diet, and the cabbage soup diet--or drink a shake and lose 10 pounds in 10 days.

And so on, and so on, and so on. With so many products and weight-loss theories out there, it's easy to get confused.

This fact sheet will help clear up some of the confusion about weight loss and nutrition and be a guide for making good decisions about your health. If you have any other questions, or if you want to lose weight, talk to a health care professional. Your doctor, a registered dietitian, or other qualified health professional can give you advice on how to eat a healthy diet and lose weight safely.

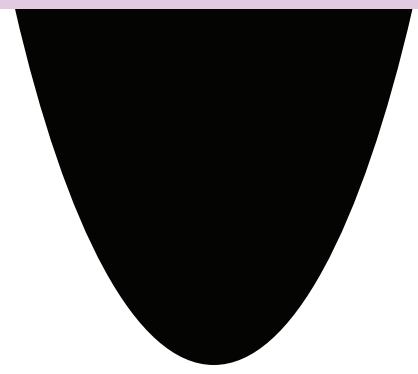

other drugs or may hurt people with certain medical conditions. Check with your doctor or other qualified health professional before using any herbal or natural weight-loss product.

Myth: Nuts are fattening and you shouldn't eat them if you want to lose weight.

Fact: Although high in calories and fat, most (but not all) types of nuts have low amounts of saturated fat. Saturated fat is the kind of fat that can lead to high blood cholesterol levels and increase the risk of heart disease.

Nuts are a good source of protein and fiber, and they do not have any cholesterol. In small amounts, nuts can be part of a healthy weightloss program. (A 1-ounce serving of mixed nuts, which is about $1 / 3$ cup, has 170 calories.)

other drugs or may hurt people with certain medical conditions. Check with your doctor or other qualified health professional before using any herbal or natural weight-loss product.

Myth: Eating red meat is bad for your health and will make it harder to lose weight.

Fact: Red meat, pork, chicken, and fish contain some saturated fat and cholesterol. But they also have nutrients that are important for good health, like protein, iron, and zinc.

Eating lean meat (meat without a lot of visible fat) in small amounts can be part of a healthy weight-loss plan. A serving size is 2 to 3 ounces of cooked meat, which is about the size of a deck of cards. Choose cuts of meat that are lower in fat such as beef eye of the round, top round, or pork tenderloin, and trim any extra fat before cooking. The "select" grade of meat is lower in fat than "choice" and "prime" grades.

Myth: Fresh fruits and vegetables are more nutritious than frozen or canned.

Fact: Most fruits and vegetables (produce) are naturally low in fat and calories. Frozen and canned fruits and vegetables can be just as nutritious as fresh. Frozen or canned produce is often packaged right after 


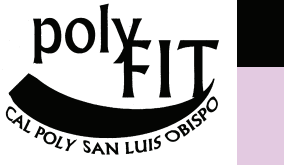

Nutrition Assessment \&

Consultation

Exercise Testing \& Prescription

Lose weight fast! Well tell you how!"

Try the low-carbohydrate diet, the high-protein diet, the green tea diet, and the cabbage soup diet--or drink a shake and lose 10 pounds in 10 days..

And so on, and so on, and so on. With so many products and weight-loss theories out there, it's easy to get confused.

This fact sheet will help clear up some of the confusion about weight loss and nutrition and be a guide for making good decisions about your health. If you have any other questions, or if you want to lose weight, talk to a health care professional. Your doctor, a registered dietitian, or other qualified health professional can give you advice on how to eat a healthy diet and lose weight safely.

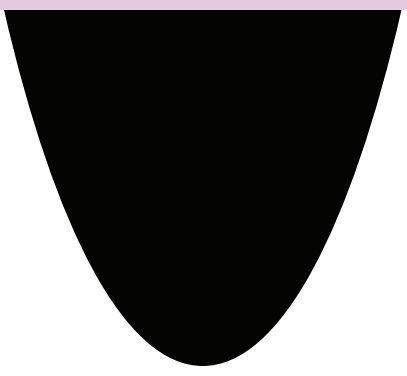

it has been picked, which helps keep most of its nutrients. Fresh produce can sometimes lose nutrients after being exposed to light or air.

Myth: Starches are fattening and should be limited when trying to lose weight.

Fact: Potatoes, rice, pasta, bread, beans, and some vegetables (like squash, yams, sweet potatoes, turnips, beets, and carrots) are rich in complex carbohydrates (also called starch). Starch is an important source of energy for your body.

Foods high in starch can be low in fat and calories. They become high in fat and calories when you eat them in large amounts, or they are made with rich sauces, oils, or other high-fat toppings like butter, sour cream, or mayonnaise. Try to avoid high-fat toppings and choose starchy foods that are high in fiber, like whole grains, beans, and peas.

The Dietary Guidelines for Americans recommends 6 to 11 servings a day from the bread, cereal, rice, and pasta group, even when trying to lose weight. A serving size can be one slice of bread, 1 ounce of readyto-eat cereal, or $1 / 2$ cup of pasta, rice, or cooked cereal.

Myth: Fast foods are always an unhealthy choice and you should not eat them when dieting.

Fact: Fast foods can be part of a healthy weight-loss program with a little bit of know-how. Choose salads and grilled foods instead of fried foods, which are high in fat and calories. Use high-fat, high-calorie toppings, like full-fat mayonnaise and salad dressings only in small amounts.

Eating fried fast food (like french fries) or other high-fat foods like chocolate once in a while as a special treat is fine--but try to split an order with a friend or order a small portion. In small amounts, these foods can still be part of a healthy eating plan.

Myth: Fish has no fat or cholesterol.

Fact: Although all fish has some fat and cholesterol, most fish is lower in saturated fat and cholesterol than beef, pork, chicken, and turkey. Fish is a good source of protein. Types of fish that are higher in fat (like salmon, mackerel, sardines, herring, and anchovies) are rich 


\section{polfit}

Nutrition Assessment \&

Consultation

Exercise Testing \& Prescription

Lose weight fast! We'll tell you how!"

Try the low-carbohydrate diet, the high-protein diet, the green tea diet, and the cabbage soup diet--or drink a shake and lose 10 pounds in 10 days..

And so on, and so on, and so on. With so many products and weight-loss theories out there, it's easy to get confused.

This fact sheet will help clear up some of the confusion about weight loss and nutrition and be a guide for making good decisions about your health. If you have any other questions, or if you want to lose weight, talk to a health care professional. Your doctor, a registered dietitian, or other qualified health professional can give you advice on how to eat a healthy diet and lose weight safely.

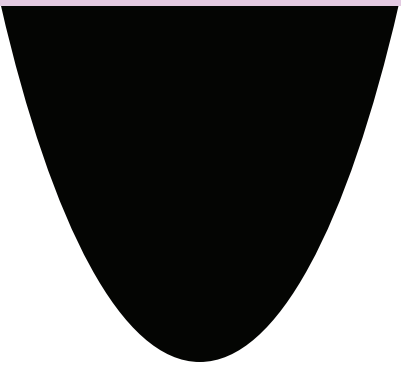

in omega-3 fatty acids. These fatty acids are being studied because they may be linked to a lower risk for heart disease. Grilled, baked, or broiled fish (instead of fried) can be part of a healthy weight-loss plan.

Myth: High-protein/low-carbohydrate diets are a healthy way to lose weight.

Fact: A high-protein/low-carbohydrate diet provides most of your calories each day from protein foods (like meat, eggs, and cheese) and few calories from carbohydrate foods (like breads, pasta, potatoes, fruits, and vegetables). People often get bored with these diets because they crave the plant-based foods they are not allowed to have or can have only in very small amounts. These diets often lack key nutrients found in carbohydrate foods.

Many of these diets allow a lot of food high in fat, like bacon and cheese. High-fat diets can raise blood cholesterol levels, which increases a person's risk for heart disease and certain cancers.

High-protein/low-carbohydrate diets may cause rapid weight loss-but most of it is water weight and lean muscle mass--not fat. You lose water because your kidneys try to get rid of the excess waste products of protein and fat, called ketones, that your body makes.

This is not a healthy way to lose weight! It overworks your kidneys, and can cause dehydration, headaches, and bad breath. It can also make you feel nauseous, tired, weak, and dizzy. A buildup of ketones in your blood (called ketosis) can cause your body to produce high levels of uric acid, which is a risk factor for gout (a painful swelling of the joints) and kidney stones. Ketosis can be very risky for pregnant women and people with diabetes.

By following a reduced-calorie diet that is well-balanced between carbohydrates, proteins, and fats, you will still lose weight--without hurting your body. You will also be more likely to keep the weight off.

\section{Myth: Dairy products are fattening and unhealthy.}

Fact: Dairy products have many nutrients your body needs. They have calcium to help children grow strong bones and to keep adult bones strong and healthy. They also have vitamin D to help your body use calcium, and protein to build muscles and to help organs work properly. 


\section{polfit cream.}

Low-fat and nonfat dairy products are as nutritious as whole milk dairy products, but they are lower in fat and calories. Choose low-fat or nonfat milk, cheese, yogurt (frozen or regular), and reduced-fat ice

For people who can't digest lactose (a type of sugar found in milk and other dairy products), lactose-free dairy products can be used. These are also good sources of protein and calcium. If you are sensitive to some dairy foods, you may still be able to eat others, like yogurt, hard cheese, evaporated skim milk, and buttermilk. Other good sources of calcium are dark leafy vegetables (like spinach), calcium-fortified

Lose weight fast! We'll tell you how!"

Try the low-carbohydrate diet, the high-protein diet, the green tea diet, and the cabbage soup diet--or drink a shake and lose 10 pounds in 10 days...

And so on, and so on, and so on. With so many products and weight-loss theories out there, it's easy to get confused.

This fact sheet will help clear up some of the confusion about weight loss and nutrition and be a guide for making good decisions about your health. If you have any other questions, or if you want to lose weight, talk to a health care professional. Your doctor, a registered dietitian, or other qualified health professional can give you advice on how to eat a healthy diet and lose weight safely.

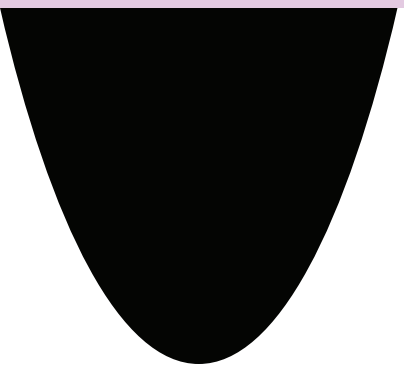
juice, bread, and soy products (like tofu), and canned fish with soft bones (like salmon).

Many people are worried about eating butter and margarine. Eating a lot of foods high in saturated fat (like butter) has been linked to high blood cholesterol levels and a greater risk of heart disease. Some research suggests that high amounts of "trans fat" can also cause high blood cholesterol levels. Trans fat is found in margarine, and in crackers, cookies, and other snack foods made with hydrogenated vegetable shortening or oil. Trans fat is formed when vegetable oil is hardened to become margarine or shortening, a process called "hydrogenation." More research is needed to find out the effect of trans fat on the risk of heart disease. Foods high in fat, like butter and margarine, should be used in small amounts.

\section{Myth: Low-fat or no fat means no calories.}

Fact: Remember that most fruits and vegetables are naturally low in fat and calories. Other low-fat or nonfat foods may still have a lot of calories. Often these foods will have extra sugar, flour, or starch thickeners to make them taste better. These ingredients can add calories, which can lead to weight gain.

A low-fat or nonfat food is usually lower in calories than the same size portion of the full-fat product. The number of calories depends on the amount of carbohydrate, protein, and fat in the food. Carbohydrate and protein have about 4 calories per gram, and fat has more than twice that amount ( 9 calories per gram).

Myth: "Going vegetarian" means you are sure to lose weight 


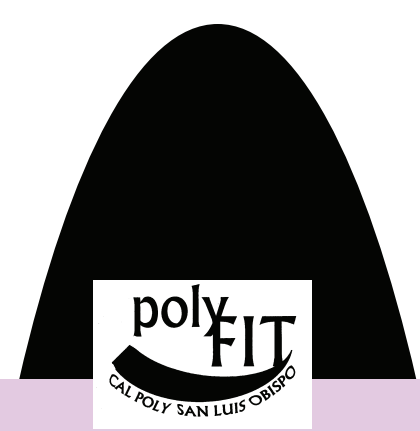

Nutrition Assessment \&

Consultation

Exercise Testing \& Prescription

Lose weight fast! We'll tell you how!"

Try the low-carbohydrate diet, the high-protein diet, the green tea diet, and the cabbage soup diet--or drink a shake and lose 10 pounds in 10 days..

And so on, and so on, and so on. With so many products and weight-loss theories out there, it's easy to get confused.

This fact sheet will help clear up some of the confusion about weight loss and nutrition and be a guide for making good decisions about your health. If you have any other questions, or if you want to lose weight, talk to a health care professional. Your doctor, a registered dietitian, or other qualified health professional can give you advice on how to eat a healthy diet and lose weight safely.

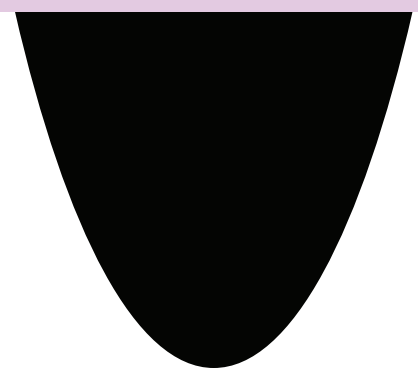

Fact: Vegetarian diets can be healthy because they are often lower in saturated fat and cholesterol and higher in fiber. Choosing a vegetarian diet with a low fat content can be helpful for weight loss. But vegetarians--like non-vegetarians--can also make poor food choices, like eating large amounts of junk (nutritionally empty) foods. Candy, chips, and other high-fat, vegetarian foods should be eaten in small amounts.

Vegetarian diets need to be as carefully planned as non-vegetarian diets to make sure they are nutritious. Vegetarian diets can provide the recommended daily amount of all the key nutrients if you choose foods carefully. Plants, especially fruits and vegetables, are the main source of nutrients in vegetarian diets. Some types of vegetarian diets (like those that include eggs and dairy foods) contain animal sources, while another type (the vegan diet) has no animal foods. Nutrients normally found in animal products that are not always found in a vegetarian diet are iron, calcium, vitamin $D$, vitamin $B_{12}$, and zinc. Here are some foods that have these nutrients:

S Iron: cashews, tomato juice, rice, tofu, lentils, and garbanzo beans (chick peas).

S Calcium: dairy products, fortified soymilk, fortified orange juice, tofu, kale, and broccoli.

S Vitamin D: fortified milk and soymilk, and fortified cereals (or a small amount of sunlight).

S Vitamin $B_{12}$ : eggs, dairy products, and fortified soymilk, cereals, tempeh, and miso. (Tempeh and miso are foods made from soybeans. They are low in calories and fat and high in protein.)

S Zinc: whole grains (especially the germ and bran of the grain), eggs, dairy products, nuts, tofu, leafy vegetables (lettuce, spinach, cabbage), and root vegetables (onions, potatoes, carrots, celery, radishes).

Vegetarians must eat a variety of plant foods over the course of a day to get enough protein. Those plant foods that have the most protein are lentils, tofu, nuts, seeds, tempeh, miso, and peas.

From the Weight-control Information Network of the National Institute of Diabetes and Digestive and Kidney Disorders (NIDDK) found at 


\section{Nutrition Assessment \& Consultation \\ Exercise Testing \& Prescription

Think of your body as the vehicle to your dreams. Honor it. Respect it. Fuel it.

2. Create a list of all the things your body lets you do. Read it and add to it often.

3. Become aware of what your body can do each day. Remember it is the instrument of your life, not just an ornament.

4. Create a list of people you admire: people who have contributed to your life, your community, or the world. Consider whether their appearance was important to their success and accomplishments.

5. Walk with your head held high, supported by pride and confidence in yourself as a person.

6. Don't let your weight or shape keep you from activities that you enjoy.

7. Wear comfortable clothes that you like and that feel good to your body.

8. Count your blessings, not your blemishes.

9. Think about all the things you could accomplish with the time and energy you currently spend worrying about your body and appearance. Try one!

10. Be your body's friend and supporter, not its enemy.

11 Consider this: your skin replaces itself once a month, your stomach lining every five days, your liver every six weeks, and your skeleton every three months.

12. Every morning when you wake up, thank your body for resting and rejuvenating itself so you can enjoy the day.

13. Every evening when you go to bed, tell your body how much you appreciate what it has allowed you to do throughout the day.

14. Find a method of exercise that you enjoy and do it regularly. Don't exercise to lose weight or to fight your body. Do it to make your body healthy and strong and because it makes you feel good.

15. Think back to a time in your life when you felt good about your body. Tell yourself you can feel like that again, even in this body at this age.

16. Keep a list of 10 positive things about yourself- - without mentioning your appearance. A dd to it!

17. Put a sign on each of your mirrors saying, "I'm beautiful inside and out."

18. Choose to find the beauty in the world and in yourself.

19. Start saying to yourself, "Life is too short to waste my time hating my body this way."

20. Eat when you are hungry. Rest when you are tired. Surround yourself with people that remind you of your inner strength and beauty.
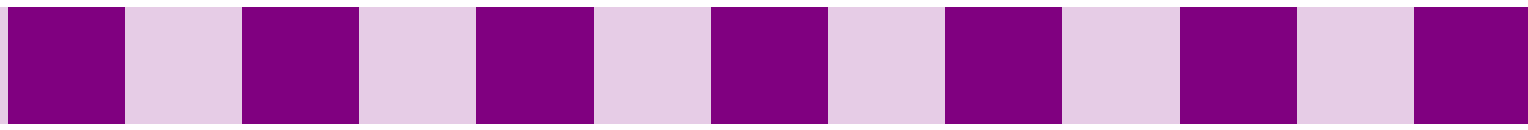


\section{Vegetarianism}

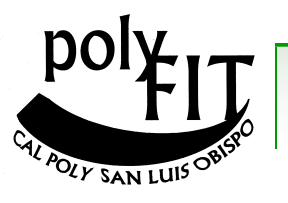

Nutrition Assessment \& Consultation Exercise Testing \& Prescription

\section{Vegetarian diet: a healthy alternative}

\section{What is a vegetarian diet?}

Some people follow a "vegetarian" diet, but there's no single vegetarian eating pattern. The vegan or total vegetarian diet includes only foods from plants: fruits, vegetables, legumes (dried beans and peas), grains, seeds and nuts. The lactovegetarian diet includes plant foods plus cheese and other dairy products. The ovo-lactovegetarian (or lacto-ovovegetarian) diet also includes eggs. Semivegetarians don't eat red meat but include chicken and fish with plant foods, dairy products and eggs.

\section{Are vegetarian diets healthful?}

The health benefits of a vegetarian lifestyle are numerous:

A vegetarian diet is consistent with many nutritional recommendations. For instance, the American Cancer Society's 1996 guidelines on diet, nutrition and cancer prevention include these suggestions: Get most of your food from plant sources and limit high-fat foods - especially those from animals. They're also usually lower than nonvegetarian diets in total fat, saturated fat and cholesterol.

- Vegetarians may enjoy health benefits. In numerous studies it has been shown that following a plant-based diet is associated with lower cholesterol levels, less heart disease, lower risk of many cancers, lower blood pressure, decreased weight and even stronger bones.

- It's easy to get enough protein. At one time dietitians thought vegetarians had to eat certain food combinations at one meal, such as rice and beans, to get enough protein. Today that view no longer holds. Studies have shown that as long as you eat a variety of vegetable proteins throughout the day, you can get all the protein your body needs.

Vegetarian diets can be healthful and nutritionally sound if they're carefully planned to include essential nutrients. However, a vegetarian diet can be unhealthy if it contains too many calories and not enough important nutrients.
Special points of interest:

- Important nutrients you don't want to miss

- Sources and amount of certain nutrients

- The Food Guide To Vegetarian Meal Planning

- Guidelines and Suggestions 


\section{Get enough of these nutrients...}

- Protein: Vegetarians who eat eggs or dairy products have convenient sources of protein. Although, you don't need to eat foods from animals to have enough protein in your diet. Plant proteins alone can provide enough of the essential and non-essential amino acids, as long as sources of dietary protein are varied and caloric intake is high enough to meet energy needs.

- Whole grains, legumes, vegetables, seeds and nuts all contain both essential and non-essential amino acids. You don't need to consciously combine these foods ("complementary proteins") within a given meal.

- Soy protein has been shown to be equal to proteins of animal origin. It can be your sole protein source if you choose. Many foods marketed as natural, such as veggie burgers and hot dogs, are made from soy products or tofu. Tempeh, a fermented soy food, is a source of protein that some people prefer to tofu.

- Iron: Iron is an important nutrient in the making of red blood cells. Vegetarians may have a greater risk of iron deficiency than nonvegetarians. The richest sources of iron are red meat, liver and egg yolk -- all high in cholesterol. However, dried beans, spinach, enriched products, such as breads and cereals, brewer's yeast, peaches, and dried fruits, such as apricots and raisins are all good plant sources of iron. To increase the amount of iron absorbed at a meal eat a food containing vitamin $\mathrm{C}$, such as citrus fruit or juices, tomato, or broccoli. Cooking food in iron cookware also adds to iron intake.

- Vitamin B-12: Your body needs vitamin B-12 to produce red blood cells and prevent anemia. This comes naturally only from animal sources. Vegans need a reliable source of vitamin B-12. It can be found in some fortified (not enriched) breakfast cereals, fortified soy beverages, some brands of nutritional (brewer's) yeast and other foods (check the labels), as well as vitamin supplements.

- Vitamin D: Vegetarians who eat dairy products may not have a problem getting enough vitamin D. Vegans should have a reliable source of vitamin D. Vegans who don't get much sunlight may need a supplement.

- Calcium: Studies show that vegetarians absorb and retain more calcium from foods than nonvegetarians do. Vegetable greens such as spinach, kale and broccoli, and some legumes and soybean products, are good sources of calcium from plants.

- Zinc: Zinc is needed for growth and development. Good plant sources include grains, nuts and legumes. Shellfish are an excellent source of zinc. Take care to select supplements containing no more than 15-18 mg zinc. Supplements containing 50 mg or more may lower HDL ("good") cholesterol in some people.

\section{Quick Facts!}

Veggie facts:

- Over 30 million Americans have explored a vegetarian eating pattern.

- Aging baby boomers are taking a proactive approach to their health by eating more meatless meals.

- About one-third of U.S. teenagers think that being a vegetarian is "in".

- Health and taste are the top two reasons consumers are eating more meat-free meals. 
Iron

Breads, cereals, and grains

Whole wheat bread, 1 slice

White bread, 1 slice

Bran flakes, $1 \mathrm{c}$

Cream of wheat, $1 / 2$ c cooked

Oatmeal, instant, 1 packet

Wheat germ, 2 Tbsp

Vegetables (1/2 c cooked)

Beet greens

Sea vegetables

Swiss chard

Tomato juice, $1 \mathrm{c}$

Legumes ( $1 / 2$ c cooked)

Baked beans, vegetarian

Black beans

Garbanzo beans

Kidney beans

Lentils

Navy beans

Soyfoods ( $1 / 2$ c cooked)

Soybeans

Tempeh

Tofu

Soymilk, $1 \mathrm{c}$

Nuts/seeds (2 Tbsp)

Cashews

Pumpkin seeds

Tahini

Sunflower seeds

Other foods

Blackstrap molasses, 1 Tbsp

\section{Zinc}

Breads, grains, and cereals

Bran flakes, $1 \mathrm{c}$

Wheat germ, 2 Tbsp

Legumes (1/2 c cooked)

Chickpeas

Lima beans

Lentils

Soyfoods (1/2 c cooked)

Soybeans

Tempeh

Tofu

Textured vegetable protein

Vegetables (1/2 c cooked)

Corn

Sea vegetables

Dairy foods

Cow's milk, 1 c

Cheddar cheese, 1 oz

Yogurt, $1 \mathrm{C}$
Milligrams per serving

0.9

0.7

11.0

5.5

6.3

1.2

1.4

18.1-42.0

1.9

1.3

0.74

1.8

3.4

1.5

3.2

2.5

4.4

1.8

6.6

1.8

1.0

2.5

1.2

1.2

3.3

Milligrams per serving

5.0

2.3

1.3

1.0

1.2

1.0

1.5

1.0

1.4

0.9

1.0

1.1-2.0

1.0

0.9

1.8
Calcium

Legumes (1 c cooked)

Chickpeas

Great northern beans

Navy beans

Pinto beans

Black beans

Vegetarian baked beans

Soyfoods

Soybeans, 1 c cooked $\quad 175$

Tofu, 1/ 2 c

Tempeh, $1 / 2 \mathrm{c}$

$120-350$

77

Textured vegetable protein, $1 / 2 \mathrm{c} \quad 85$

Soymilk, $1 \mathrm{c}$

Soymilk, fortified, 1 c $\quad 250-300$

Soynuts, $1 / 2$ c 252

Nuts and seeds (2 Tbsp)

Almonds 50

Almond butter 86

Vegetables (1/2 c cooked)

Bok choy $\quad 79$

Broccoli 89

Collard greens $\quad 178$

Kale $\quad 90$

Mustard greens $\quad 75$

Turnip greens $\quad 125$

Fruits Dried figs, 5

Calcium-fortified orange juice, $1 \mathrm{C} \quad 300$

Other Foods

Blackstrap molasses, 1 Tbsp $\quad 187$

Cow's milk, $1 \mathrm{c} \quad 300$

Yogurt, $1 \mathrm{c}$

$275-400$

Vitamin D

Fortified,

Micrograms per serving

ready-to-eat cereals,

$3 / 4 \mathrm{c}$

1. $0-2.5$

Fortified soymilk or

other nondairy milk, $1 \mathrm{c}$

1. $0-2.5$

Vitamin B-12

Ready-to-eat

breakfast cereals, 3/ 4 c

Meat analogs ( 1 burger

or 1 serving according

to package)

Fortified soymilk or

other nondairy milks, $8 \mathrm{oz}$

Micrograms per serving

Nutritional yeast (Red Star

$1.5-6.0$

Vegetarian Support

Formula, formerly T6635ª 1 T Tbsp

4.0 


\section{Your Guide...}

Similar to the USDA's Food Guide Pyramid, the following pyramid can assist in planning a healthy eating plan that ensures the adequacy, balance, calorie control, moderation, and variety that are characteristic of a nutritious diet.

Adequacy: the foods provide enough of each essential nutrient, fiber, and energy.

Balance: the choices do not overemphasize on nutrient or food type at the expanse of another.

Calorie control: the foods provide the amount of energy you need to maintain appropriate weightnot more, not less.

Moderation: the foods do not provide excess fat, salt, sugar or other unwanted constituents.

Variety: the foods chosen differ from one day to the next

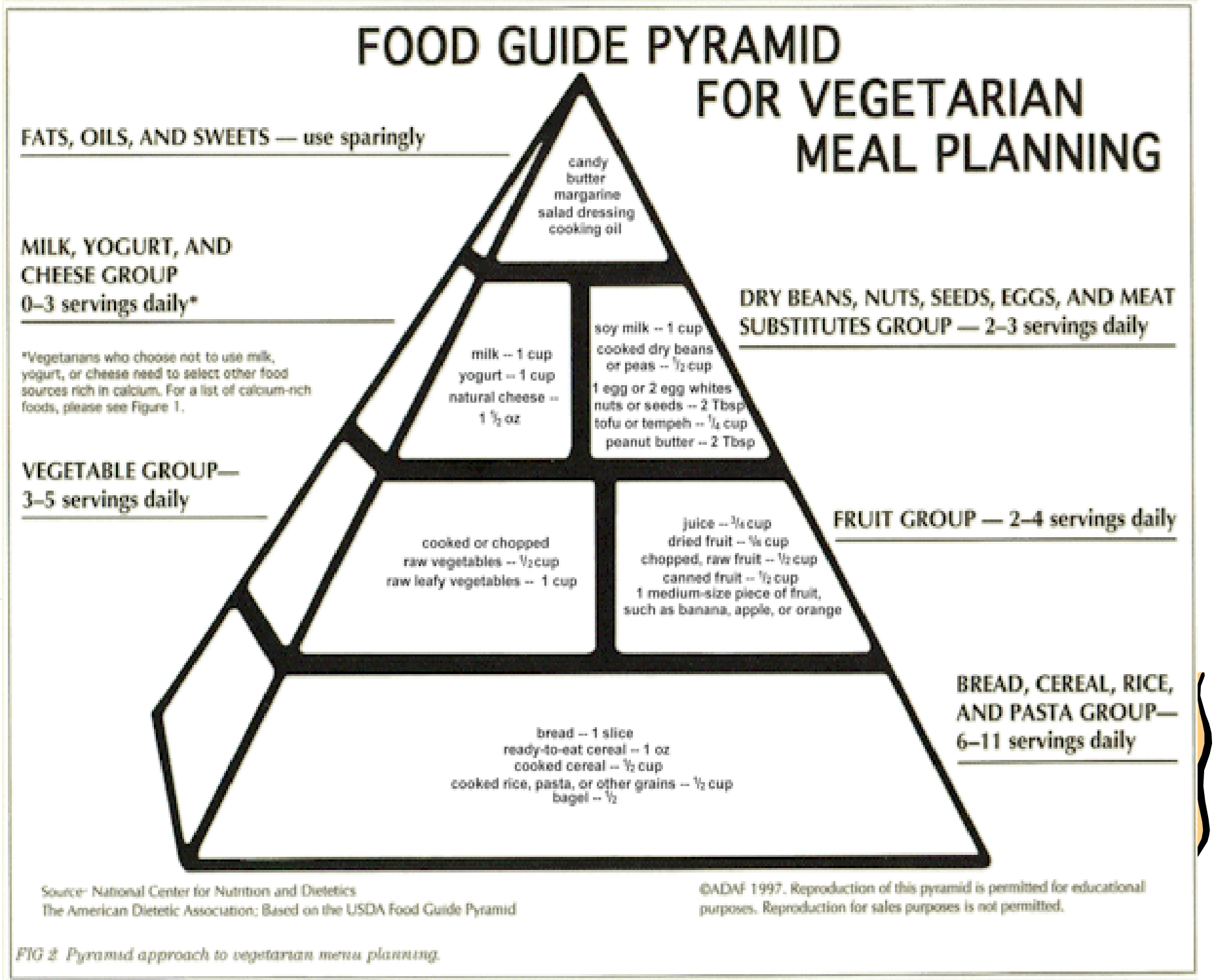




\section{Meal Planning For Vegetarian Diets}

A variety of menu-planning approaches can provide vegetarians with adequate nutrition. In addition, the following guidelines can help vegetarians plan healthful diets.

- Choose a variety of foods, including whole grains, vegetables, fruits, legumes, nuts, seeds and, if desired, dairy products and eggs.

- Choose whole, unrefined foods often and minimize intake of highly sweetened, fatty, and heavily refined foods.

- Choose a variety of fruits and vegetables.

- If animal foods such as dairy products and eggs are used, choose lower-fat versions of these foods. Cheeses and other high-fat dairy foods and eggs should be limited in the diet because of their saturated fat content and because their frequent use displaces plant foods in some vegetarian diets.

- Vegans should include a regular source of vitamin B-12 in their diets along with a source of vitamin $D$ if sun exposure is limited.

- Solely breast-fed infants should have supplements of iron after the age of 4 to 6 months and, if sun exposure is limited, a source of vitamin D. Breast-fed vegan infants should have vitamin B-12 supplements if the mother's diet is not fortified.

- Do not restrict dietary fat in children younger than 2 years. For older children, include some foods higher in unsaturated fats (eg., nuts, seeds, nut and seed butters, avocado, and vegetable oils) to help meet nutrient and energy needs.

\section{Some Final Suggestions...}

Versatility is the Key

When you think of meatless food products, you may only think of "veggie burgers. "However, consumer demand for more variety has expanded the range of vegetarian choices in the supermarket.

Planning nutritious family meals with meat-free products is quick, easy, and economical. For example, ground meat substitutes are easily incorporated into your favorite family recipes for chili, spaghetti sauces, or casseroles.

Food manufacturers offer familiar, pre-cooked and convenient meat-free products such as burgers, hot dogs, "chicken" nuggets, corn dogs, and prepared breakfast foods that easily fit into American eating patterns.

Getting a J ump Start

- Explore new foods at your grocery store. Pick out a different meat-free product from the variety located in the freezer section, to try at home each week.

- Load up on fresh fruits and vegetables. Reach for a piece of fruit or cut up fresh veggies when the urge to munch calls you.

- Buy a new cookbook or look for meatless recipes in the newspaper or food magazines. Try one new recipe each week. In just a few months, you will have tried at least a dozen new recipes.

- Be adventurous and try a vegetarian entrée at a restaurant. You may be pleasantly surprised at the number of meat-free dishes there are and at their delicious tastes, too.

Adapted from ADA Position Paper on Vegetarian Diets found at http:/ / www.vrg.org/ nutrition/ adapaper.htm, the American Heart Association found at http:// www. americanheart.org/ presenter.jhtml?identifier $=4777$, and the Mayo Clinic found at http:/ / www. mayoclinic. com/ invoke. cfm?objectid=89AFCCB3-E1F7-4541-9A90745760BAA899 


\section{HIGH ON FIBER}

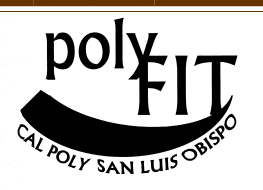

\section{W hat is D ietary Fiber?}

\section{Special points of in-} terest:

- Sources of soluable \& insoluable fiber

- How much do I need?

- Dietary fiber content in foods

- Sample high fiber meal
Dietary fiber is found only in plant foods. It is composed of a group of structurally related substances: cellulose, hemicelluloses, lignin, gums and pectins. Good sources of dietary fiber include whole grains, vegetables, fruit, nuts and seeds. M eat, fish, poultry, eggs, dairy products, fats, oils and sugar contain no dietary fiber.

\section{Why should we include dietary fiber in our diets?}

Some of the benefits of dietary fiber are to increase fecal bulk, soften stools, stimulate the healthy movement of foodstuffs through the digestive tract and assist the muscles of the digestive tract. Consuming high fiber foods thus may help prevent and treat constipation. In addition, researchers have shown that dietary fiber can play an important role in the prevention or treatment of various diseases and disorders. These include obesity, diabetes, cardiovascular disease, coIon cancer, diverticular disease and irritable bowel syndrome, as well as constipation.

W hat are soluable and insoluable fibers?

Dietary fiber is frequently classified as soluble or insoluble. Soluble fibers dissolve in water and consist of pectins, gums and some hemicelluloses. Insoluble fibers do not dissolve in water and consist of cellulose, lignin and some hemicelluloses. Soluble fiber has been shown to be effective in reducing the risk of cardiovascular disease and diabetes by re ducing total blood cholesterol and regulating blood sugar levels. Insoluble fiber has been shown to be effective in reducing the risk of colon cancer, preventing diverticular disease and treating constipation 


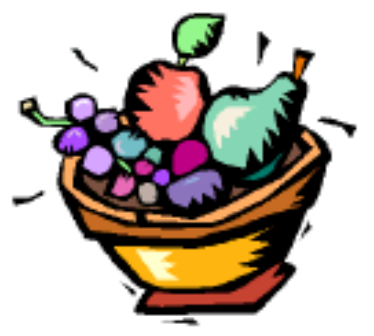

W hat Are Some Sources of Soluable and Insoluable Fibers?

Ideally, we should incorporate both soluble and insoluble fibers in our diets. Good sources of soluble fiber include oats, barley, legumes (dried beans and peas) and some vegetables and fruits. Good sources of insoluble fiber include whole grain products (breads, cereals, rice, pasta), nuts, seeds and some vegetables.

\section{H ow Much Dietary Fiber Should We Consume Each Day?}

Experts are now recommending a dietary fiber intake in the range of 20 $35 \mathrm{grams} /$ day for the healthy adult. The average A merican consumes between 10 - 20 grams/ day - well below the current recommendations.

\section{C an Problems A rise From Eating Too M uch Dietary}

The average A merican consumes well below the daily

recommended amount of fiber $y$

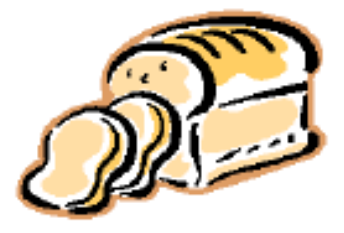

\section{Fiber?}

Yes. Dietary fiber, if increased suddenly, can cause gas, diarrhea and bloating. It should be added gradually, allowing time for your body to adjust to the extra fiber. For example, begin by increasing your fiber intake to 20 grams/ day; allow a few days for adjustment, and then increase it to $25 \mathrm{grams} /$ day. As you add fiber to your diet, it is very important to drink plenty of fluids, since fiber draws water into the intestines. H ealth care providers recommend at least eight glasses of water each day. Although excessive intakes of dietary fiber may interfere with the absorption of some nutrients, moderate intakes (i.e., 20 - 35 grams/ day) do not appear to pose a problem for the healthy adult.

\section{Example of a high fiber meal}

B reakfast: 1 cup water, 1 bran muffin, 1 cup milk, $3 / 4$ cup oatmeal, 1 orange

Lunch: 2 slices pumpernickel bread, 2 oz. turkey w/ sprouts and tomato, 1 apple, 1 cup yogurt w/ fruit, 2 Fig N ewtons(, 1 cup iced tea

D inner: 1 chicken breast, 1 cup brown rice, $1 / 2$ cup broccoli, 1 serving carrot salad, 1 whole wheat dinner roll, 1 cup herbal tea

Snacks. 3 cups popcorn, 1 cup lemonade, 4 graham crackers, 1 cup milk 


\section{Dietary Fiber C ontent in Foods}

\section{Grain Products}

Bagels

(Cinnamon Raisin,

Plain, Blueberry, Egg)

Bran Muffins

Bread, French

Bread, 0 atmeal

Bread, Pita

Bread, Whole W heat

Cornbread

English M uffin, Whole W heat

Popcorn, air-popped, no butter

Rice, Brown (cooked)

Roll, W hole W heat

Spaghetti (cooked)

Spaghetti, W hole W heat

Tortilla (C orn)

\section{Breakfast Cereals}

All-Bran ${ }^{\text {TM }}$

All-Bran Extra Fiber ${ }^{\mathrm{TM}}$

Bran Buds ${ }^{\text {TM }}$

Bran Chex ${ }^{\text {TM }}$

Bran Flakes

Corn Bran ${ }^{\mathrm{TM}}$

Corn Flakes

$\mathrm{Cracklin} \mathrm{O}$ at $\mathrm{Bran}^{\mathrm{TM}}$

Fiber O ne ${ }^{\text {TM }}$

Frosted M ini-W heats $^{\text {TM }}$

Grape N uts ${ }^{\text {TM }}$

Granola-type

G ranola-type (low fat)

Kashi M edley ${ }^{\mathrm{TM}}$

N utri-Grain ${ }^{\text {TM }}$

0 atmeal

Smart Start ${ }^{\mathrm{TM}}$

Raisin Bran

Wheaties $^{\mathrm{TM}}$

Legumes (B eans)

Baked (cooked), canned

Black Beans (cooked)

Kidney (cooked)

Lentils (cooked)

Lima (cooked)

N avy (cooked)

Pinto Beans (cooked)

\section{Amount}

1 whole bagel

1 muffin

1 slice

1 slice

1 pocket

1 slice

$2 \times 2$ piece

1 whole

3 cups

1 cup

1 roll

1 cup

1 cup

1

\section{Amount (cup)}

$1 / 3$

$1 / 2$

$1 / 3$

$2 / 3$

$3 / 4$

2/3

1

$3 / 4$

$1 / 2$

$1 / 2$

$1 / 2$

$1 / 4$

$1 / 4$

$1 / 2$

$2 / 3$

$3 / 4$

1

$3 / 4$

1

Amount (cup)
1
1
1
1
1
1
1

Dietary Fiber (g)

2.0

Calories

280

$0.0-4.0 \sim$

0.6

0.6

0.3

1.6

.95

4.4

4.5

3.3

1.6

2.2

4.5

1.0

Dietary Fiber (g)

10.0

13.0

8.0

6.1

5

5.4

1.0

6

2

3.0

5

2.0

$.0-3.2$

2

3.0

1.6

2

5.0

3.0

Dietary Fiber (g)

$6.0-10.0$

7.2

6.4

7.9

13.5

6.6

6.8
104

81

71

106

61

141

134

115

216

101

197

174

67

\section{Calories}

70

50

70

90

100

109

100

190

180

100

200

120

120

100

140

108

180

120

110

\section{Calories}

250

227

225

231

217

259

235 


\section{Crackers}

Saltines

Triscuit $^{\text {TM }}$

Wheatables ${ }^{\text {TM }}$

Wheat Thins ${ }^{\mathrm{TM}}$

Whole W heat $\mathrm{C}$ rackers

\section{Nuts and Seeds}

Almonds

Cashews

Filberts (hazelnuts)

Peanuts

Peanut butter

Pecans

Popcorn, popped with oil 2

Sunflower seeds

Walnuts

\section{Vegetables}

Asparagus

Broccoli (raw)

Carrot (raw)

Cauliflower

Celery (raw)

Corn

Cucumber (sliced)

Green Beans

Greens, Collard

Lettuce (shredded)

Potato (with skin)

Mushrooms

Spinach (boiled)

Tomato (raw)

Zucchini (raw)

\section{Fruit}

Apple (with skin)

Banana

Cantaloupe

Grapefruit

Grapes

Honeydew melon

Peach (with skin)

Pear (with skin)

Pineapple

Strawberries

\section{Amount}

8 crackers

7 crackers

16 crackers

16 crackers

7 crackers

Amount

22 nuts/ 1 oz.

18 nuts/ 1 oz.

$10 \mathrm{z}$.

$1 \mathrm{oz}$.

2 tbsp.

15 halves/ $1 \mathrm{oz}$.

$1 / 2$ cups

$10 \mathrm{z}$.

14 halves/ $10 z$.

Amount

1/2 cup

$1 / 2$ cup

1 medium

1/ 2 cup

1 stalk

1/2 cup

1/2 cup

1/2 cup

1/2 cup

1 cup

1 large

1/2 cup

1/ 2 cup

1 medium

1/2 cup

\section{Amount}

1 medium

1 medium

1 cup

$1 / 2$ medium

1 cup

3/ 4 cup

1 medium

1 medium

1 cup

1 cup
D ietary Fiber (g)

.74

4

1

2

2.9

D ietary Fiber (g)

3.1

1.7

1.8

2.2

1.9

1.8

2.8

1.9

1.3

D ietary Fiber (g)

1.9

1.2

2.3

1.3

0.6

1.7

0.5

1.9

2.0

0.4

8.52

.34

2.0

1.6

0.3

\section{D ietary Fiber (g)}

3.0

1.8

1.3

0.7

1.6

.8

1.4

4.3

1.8

3.9

\section{Calories}

100

140

150

140

134

\section{Calories}

176

163

187

184

190

190

142

75

182

\section{Calories}

23

12

31

13

6

67

7

23

30

6

310

13

21

26

9

A dapted from the M CKinley H ealth Center, Student Affairs, U niversity of Illinois found at

http:/ / www.mckinley.uiuc.edu/ H andouts/ highfiber/ hifiber.html
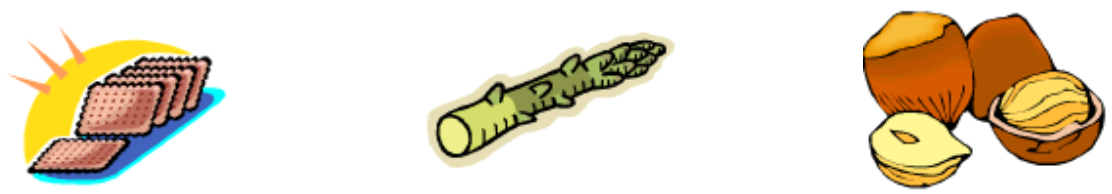

Calories

81

105

57

37

114

46

37

98

76

45 at 
Nutrition Assessment \&

Consultation

Exercise Testing \& Prescription

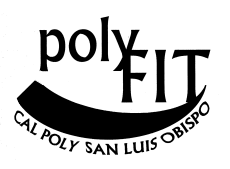

\section{How To Get \\ More \\ Iron}

\section{Dietary Sources Of Iron}

Special points of interest:

- Recommendations

- Heme and non-heme sources of iron

- Vegetarians- Watch out!

- Specific tips for increasing iron consumption
I ron is essential to all body cells. It is part of the hemoglobin that is in red blood cells and carries oxygen form the lungs to the tissues of the body. I ron deficiency anemia occurs when there is not enough iron in the red blood cells. T his is a common problem often caused by pregnancy, blood loss or a diet low in iron. The typical symptoms of iron deficiency - lack of energy or tiredness, both physically and mentally - have many causes. Diagnosis by a blood test confirms the presence of iron deficiency anemia.

If your blood iron level is low, your heal th care provider may refer you to a dietitian to discuss a dietary increase in iron-rich foods. He or she may also recommend a multivitamin pill or prescribe an iron supplement. Although iron is found in a variety of different foods and supplements, its availability to the body varies significantly. In general, iron is not readily absorbed by the body. A vailability is partially determined by whether the iron is found in the form of HEME or NON-HEME iron.

HEME iron (Group A) is found only in meat, fish and poultry and is absorbed much more easily than NON-HEME iron (Group B), which is found primarily in fruits, vegetables, dried beans, nuts and grain products.

T he following factors will increase the iron absorption from nonheme foods:

\section{a good source of vitamin C (ascorbic acid) - i.e., kiwi, oranges, grapefruits, strawberries, tomatoes, broccoli, peppers, cabbage, and potatoes cooked in their skin eaten with a Group B food \\ - a G roup A food eaten with a G roup B food \\ - Group B foods cooked in iron pots, such as a cast iron skillet}

The following factors will decrease non-heme iron absorption:

- large amounts of tea or coffee consumed with a meal (the polyphenols bind the iron)

- excess consumption of high fiber foods or bran supplements (the phytates in such foods inhibit absorption )

- High intake of calcium - take your calcium supplement at a different time from your iron supplement. 


\section{Recommendations}

The Recommended Dietary Allowance (RDA) for iron for non-vegetarian premenopausal women is $18 \mathrm{mg} /$ day. T he RDA for non-vegetarian men and postmenopausal women is $8 \mathrm{mg} /$ day. Because of iron absorption issues in a healthful, high-fiber vegetarian diet, the RDAs for vegetarians are higher - $14 \mathrm{mg} /$ day for vegetarian men and $33 \mathrm{mg} /$ day for vegetarian women. T he upper level of intake should not exceed $45 \mathrm{mg} /$ day.

GROUP A - Heme iron sources

\begin{tabular}{|l|c|c|}
\hline \multicolumn{1}{|c|}{ Food Source } & Serving Size (oz.) & Iron (mg) \\
\hline beef, liver & 3.0 & 7.5 \\
\hline beef, corned & 3.0 & 2.5 \\
\hline beef, lean ground; 10\% fat & 3.0 & 3.9 \\
\hline *beef, round & 3.0 & 4.6 \\
\hline${ }^{*}$ beef, chuck & 3.0 & 3.2 \\
\hline *beef, flank & 3.0 & 4.3 \\
\hline chicken, breast w/ out bone & 3.0 & 0.9 \\
\hline chicken, leg w/ bone & 2.0 & 0.7 \\
\hline chicken, liver & 3.0 & 7.3 \\
\hline chicken, thigh w/ bone & 2.3 & 1.2 \\
\hline cod, broiled & 3.0 & 0.8 \\
\hline flounder, baked & 3.0 & 1.2 \\
\hline${ }^{*}$ pork, lean ham & 3.0 & 1.9 \\
\hline *pork, loin chop & 3.0 & 3.5 \\
\hline salmon, pink canned & 3.0 & 0.7 \\
\hline shrimp, 10 - 2 1/2 inch & 1.1 & 0.5 \\
\hline tuna, canned in water & 3.5 & 1.0 \\
\hline turkey, dark meat & 3.0 & 2.0 \\
\hline turkey, white meat & 3.0 & 1.2 \\
\hline
\end{tabular}

* Lean, trimmed of separable fat

\section{Watch out...}

Do vegetarians get enough iron? Vegetarians who do not eat meat may have difficulty meeting their iron needs. This is especially true for growing individuals whose iron needs are greater, such as infants, children, adolescents, and pregnant women. Vegetarians should be especially car eful about being attentive to the amount of iron they are consuming and may consider talking to their doctor about taking an iron supplement. 


\section{GROUP B - Non-heme sources}

\begin{tabular}{|l|c|c|}
\hline \multicolumn{1}{|c|}{ Food Source } & Serving Size (oz.) & Iron (mg) \\
\hline almonds, raw & 10 - 12 each & 0.7 \\
\hline apricots, dried, med.-size & 10 each & 1.7 \\
\hline bagel & 1 whole & 1.5 \\
\hline baked beans, canned & $1 / 2$ cup & 2.0 \\
\hline bread, white & 2 slices & 1.4 \\
\hline bread, whole wheat & 2 slices & 1.7 \\
\hline broccoli, cooked & $1 / 2$ cup & 0.6 \\
\hline broccoli, raw & 1 stalk & 1.1 \\
\hline dates & 10 each & 1.6 \\
\hline kidney beans & $1 / 2$ cup & 3.0 \\
\hline ima beans & $1 / 2$ cup & 1.8 \\
\hline macaroni, enriched, cooked & 1 cup & 1.9 \\
\hline molasses, blackstrap & 1 tbsp. & 2.3 \\
\hline oatmeal, instant & 1 pouch & 3.5 \\
\hline peas, frozen and prepared & $1 / 2$ cup & 1.3 \\
\hline raisins, not packed & $1 / 4$ cup & 1.0 \\
\hline rice, brown, cooked & 1 cup & 1.0 \\
\hline rice, white enriched, cooked & 1 cup & 1.8 \\
\hline spaghetti, enriched, cooked & 1 cup & 1.6 \\
\hline spinach, cooked & $1 / 2$ cup & 2.0 \\
\hline vitamin supplements & varies & varies \\
\hline
\end{tabular}

In addition, many breakfast cereals are iron-fortified. Check nutrition information on package label for specific iron content.

\section{Specific tips...}

- Combine vitamin-C rich foods with iron sources, such as drinking orange juice with breakfast cereal in the morning.

- E at non-heme and heme sources of iron together such as adding meat sauce to pasta or add chicken or shrimp to a vegetable and rice stir fry.

- E at a variety of iron rich foods everyday.

- A void drinking tea or coffee with iron-rich food sources.

- E at nuts and dried fruit such as trail mix and dried apricots for snacks. Also, add these to cereal and baking.

- Add dried beans, peas, or lentils to soups, salads, casseroles, chili, spaghetti sauce and other pasta dishes.

- Cook in cast iron or stainless steel pots and pans. This will increase the amount of iron in the foods you are cooking.

Adapted from the M CKinley H ealth Center, Student A ffairs, U niversity of IIlinois found at http:/ / www.mckinley.uiuc.edu/ $\mathrm{H}$ andouts/ dietiron.html and from the Calgary H ealth R egion found at http:/ / www.cal garyhealthregion.ca/ hlthconn/ items/ ironhlth.pdf 


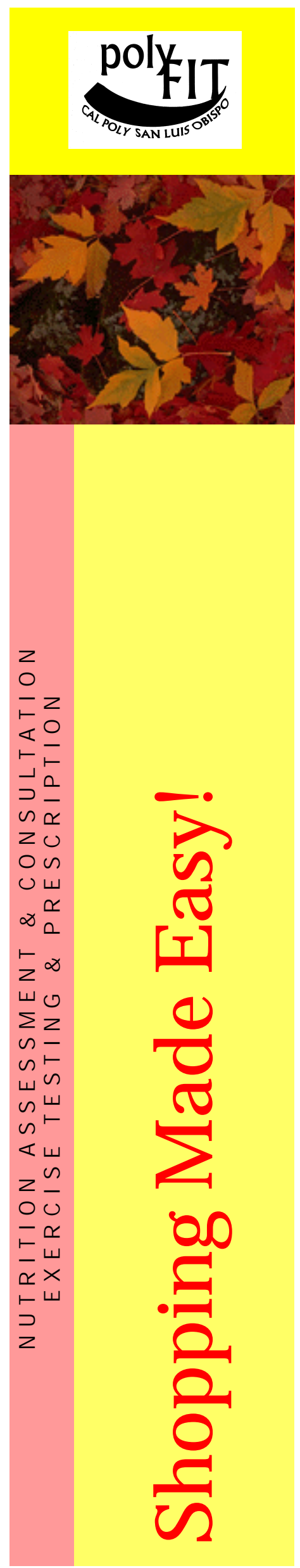

\section{0 secrets to shopping smart}

1. Do not shop on an empty stomach.

You tend to buy ite ms on impulse when you are fungry, and you are less likely to stick to your shopping list.

2. Head straight for the fruit er vegetable aisle.

Fresh fruits and vegetables are essential to a healthy diet, and the best way to fill up your cart with the $m$ and have lots around when you are cooking or reaching for a snack.

3. When buying fruit juice, look for 100 percent unsweetened juice Fruit drinks, herbal te as and other flavored drinks contain a lot of sugar, but little nutrients. 100 percent juices are best value for your money in terms of nutrient content.

4. If you are buying canned food, look for fruits canned in juice and tuna packed in water.

Avoid the fruits packed in syrup or fish canned in oil. The added sugar and fat contribute extra calories which you do not need.

5. Buy whole-grain breads, rolls and cereals whenever possible. Whole wheat bread obuns are a good way to get much needed fiber in our diet.

6. Choose lower fat meat and poultry and more fish.

Avoid meat that have a thick layer of fat on the outer edge or have a lot of fat in between the muscle (known as marbling). If they are present, remove as much as possible before cooking. Duck has more fat than chicken, so have it less often. Fish is low in fat and some contain omega-3 fatty acid which offer benefits for a healthy heart.

7. Think about alternatives to meat such as tofu, lentils, nuts, and beans. Ulse these in place of meat a couple of times per weekor add them to your meat dishes so that you use less meat.

8. Learn to read food labels.

Lookfor ingredients such as salt, sugar, and fats - ingredients listed first are present in the largest amount. Some items have a nutrition information panel which lists the amount of calories, protein, carbohydrate and fat per serving. This helps you compare the nutrients be twe n two similar products, for example the fat content. Certain food items list fiber, sodium, sugar and other nutrient content as well.

9. Try something new.

Buy a new kind of food every week as they add varie ty to your die $t$ and provide you with different nutrients.

10. Refrigerate perishable items promptly after purchase.

$\mathcal{T}$ avoid any potential problems with de terioration of food and food poisoning especially in fot climate, refrigerate meats odairy products as soon as you get home.

Adapted from $\mathcal{X u t r i t i o n w e r k s . c o m ~ f o u n d ~ a t ~ h t t p : / / w w w . n u t r i t i o n w e r k s . c o m / h e / ~}$ heshopping.asp 


\section{Basic ingredients for a healthy kitchen!}

In the Cupboard

- Pasta: spaghetti, fettuccini, penne, bowties, ramen noodles

- Rice: white, Grown, rice mixes

- Beans: black pinto, kidney, chick peas, lentils, fat-free refried

- Othergrains: couscous, orzo, cornmeal, whole wheat crackers, bread sticks, bread crumbs

- Potatoes and onions

- Canned tomatoes: diced, whole, seasoned, sun-dried, sauce, salsa

- Canned vegetable: mixed vegetables, green beans, mushrooms, other favorites

- Canned and dried fruits: applesauce, peaches, pineapple, raisins, cranberries, other favorites

- Sauces: pasta, pizza, low-fat cheese sauce, low-fat gravy

- Soups: Low-fat canned soups, broth and bouillon and dried soup mixes

- Meats: canned tuna in water, salmon, minced clams, and chicken

- Pe anut butter

- Evaporated skim milk

- Vinegars: cider, red and white wine, flavored, balsamic

- Oils: olive and canola, nonfat cooling spray

In the Refrigerator

- $\quad F r u i t s$ and vege tables

- $100 \%$ fruit and vegetables juices

- $\quad$ Fruit spreads

- Reduced-fat or fat-free milk and yogurt

- Reduced-fat cheeses: cheddar, mozzarella, S wiss, Monterey Jack cottage, Parmesan

- Tortillas

- $\quad$ Eggs

- Minced garlic

- Sauces: Worcestersfire, soy, and chili

- Catsup and mustard (spicy and Dijon)

- Reduced-fat or fat-free salad dressings

In the Freezer

- Frozenfruits, vegetables, and $100 \%$ juices

- Frozen chopped onions and chopped green pepper

- Breads: whole grain breads, dinner rolls, English muffins, bagels

- Meats: chicken 6reast, ground turkey breast, extra le an fiamburger

- Fish: red snapper, salmon, orange roughy, cod, flounder, sole

- Frozen yogurt or fruit sorbet

Whole Grains vs. Refined Grains

$\mathcal{A}$ whole grain is made up of three parts: the 6ran, endosperm and germ. Refined grains are made from the endosperm. Because the Gran and germ contain much of the vitamins, minerals and all of the fiber found in grains, whole grains have more fiber and nutrients than refined (or processed) grains. Shoot for at least three servings of whole grain foods each day.

Adapted from Adapted form the American Cancer Societ found at

http://www.cancer.org/docroot/home/index.asp 


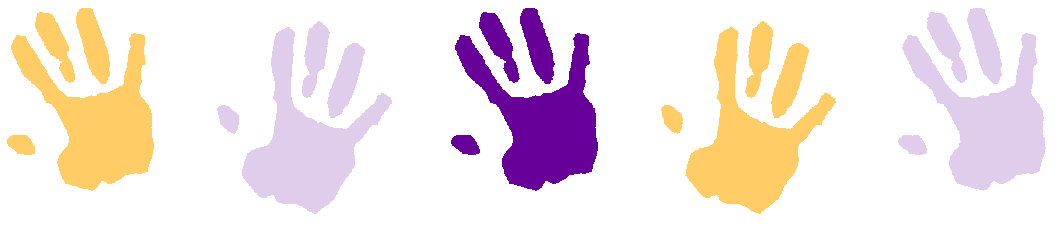

\section{Snack Attacks!}

$\mathcal{N}$ utrition Assessment o\% Consultation Exercise Testing o Prescription

Did you know that...

- Munching on just one carrot will meet your vitamin $\mathcal{A}$ needs for the entire day?

- Preschoolers get nearly one third of their energy from snacks?

- Snacking is on the rise: 75 percent of us eat at least one snack a day?

- A planned snack can help prevent ove reating?

- Television watching tends to increase snacking--particularly on high-fat, high-calorie "goodies"?

Snacking can help or hurt a healthfuldiet. The difference depends on what you choose and how much you eat. Whether you like to munch, nibble, or simply quench the mid-afternoon "hungries," you can make snacking workfor you. It just takes a little planning.

Benefits of snacking...

Snacks can give you an energy boost to help fuel your body between meals. Your body uses up the carbohydrate stores in your liver (which help maintain a normallevelof blood sugar) in 4 to 6 hours. You need food to replace them.

Many people can benefit from eating snacks. Growing children with tiny appe tites may not be able to fulfill their energy needs with only three meals a day. Snacks can provide what may be missing from their meals.

Athletes of all ages have increased energy demands. They especially need energy in the form of carbohydrates, which help power exercising muscles. Snacks such as sandwiches, bread, 6uns, fruit and raw vegetable can help give athletes the additional energy they need.

Teenagers are well known for their snack at tacks and for good reason. They also have high energy and nutrient needs to support their growing bodies. Carefully chosen snacks can help fuel theirgrowth.

Carrying a baby places additional nutrient and energy demands on the mother. Selective snacking can help pregnant women meet their extra nutrition needs. Small, frequent snacks can be especially helpfulfor women who have morning sickness or who always feel full.

Older adults who can eat only small portions of food at a time may find it easier to maintain their health by eating snacks to supplement the ir meals.

Snacks can offer nutritional advantages, but they also can become liabilities, depending on the types and quantities of food they contain. Mindless nibbling canlead to trouble in the form of unwanted calories. Some snacks--such as chips, chocolate, and shakes-.can add a fat burden to the diet. And high-fat diets are clearly linked with such chronic diseases such as heart dise ase and cancer. 


\section{Don't feel guilty...snacking myths}

Removing The Guilt: Snacking Myths Despite the benefits that snacking can offer, many people think of snacks as something extra they should not eat. Here are five myths worth challenging:

Myth-S nacks are fattening.

Fact - Eating a snack during a long stretch between meals can take the edge off hunger, which might le ad to overeating otherwise. Of course, specific snackfood choices will make a difference.

Myth - S nacks spoil your appetite for meals.

Fact. Eating a small amount of food--maybe an apple or half of a turkey sandwich-. 2 to 3 hours before a me al will not spoil an appetite. But it may keep you from becoming ravenously hungry. By eating a snack, you can be more in control of your food choices and less inclined to overeat at your next meal.

Myth - Snacking causes cavities.

Fact. While snacks expose the teeth to food (and decay-producing bacteria) more often, choosing foods that are not sticky and brushing your teeth afterward help prevent cavities. Some foods such as cheese have been found to have properties that prevent cavity formation.

Myth - Snacking is the same as eating junkfood.

Fact-Snacking does not have to equate junkfood, choosing better alternatives can help fill in the gaps in meals to comple te a healthfuldiet.

Myth - Healthful snacking means I can never eat potato chips again.

Fact. It's possible to eat fun foods and still follow a diet that is low in fat, but it requires a little planning. If you have a high fat snack you need to balance that out with lower-fat choices at other meals.

One snack one meal, or one day of eating cannot make or breakyour health. It is what you eat consistently over time that counts.

\section{Make the most out of snacking}

Follow these guide lines to help make snacking work for your health:

- Plan ahead so that you have the desired food at hand when you need it. You don't want to be forced to choose from the limited selections in a corner store, or a randomly stocked refrige ra. tor.

- Instead of munching absent-mindedly, make snacking a conscious activity. Ideally, this means eating without doing anything else at the same time (for example, watching $\mathcal{T} \mathcal{V})$. Otherwise, you can easily overeat without realizing it.

- Choose lower-fat snacks:

Inste ad of potato chip, try pretzels. Instead of ice cream, try low fat frozen yogurt. Instead of a milkshake, try a fruit smoothie. Instead of sour cream based dip, try salsa 


\section{What kind of snack attack?}

When youget the urge to reach for a snack, it's of ten the food's appearance and texture that appeal to you as much as its actual taste characteristics.

When it's time to make a delicious snack decision, take a little time to think about what will really satisfy your snackcraving. In other words, do you want something smooth or crunchy, fiot or chilled?

If you are not sure, use this list to help you identify and select the perfect snack. Select the category that most appeals to you to receive tasty, heart-healthy snacksuggestions that will satisfy your crav. ing.

\section{Cruncties}

Apples and pears

Breadsticks

Carrot and celery sticks

Green peppersticks

Zucchinicircles

Radishes

Broccolispears

Cauliflowe re ts

Unsalted rice cakes

\section{Muncties}

Unsalted sunflower seeds

Whole-grain breads

Mozzarella (part-skim)

Ricotta (part-skim)

Plain low-fat yogurt

Bage ls

Almonds, walnuts and other nuts
Hot $S$ tuff

Clear soups - homemade vegetable or tomato

(commercially canned soups may be high in sodium)

Cocoa made with nonfat mil

Thirst Quenchers

Nonfat milk or buttermilk

Uns we e te ne d juices

Tomato or mixed vegetable juice (commercially canned vegetable juices may be high in sodium)
Sweet Stuff

Uns we e te ned canned fruit

Thin slice of angelfood cake

Baked apple

Raisins

Dried fruit ge latinge ms

Frozen Bananas

Frozen Grapes

Fresh fruit
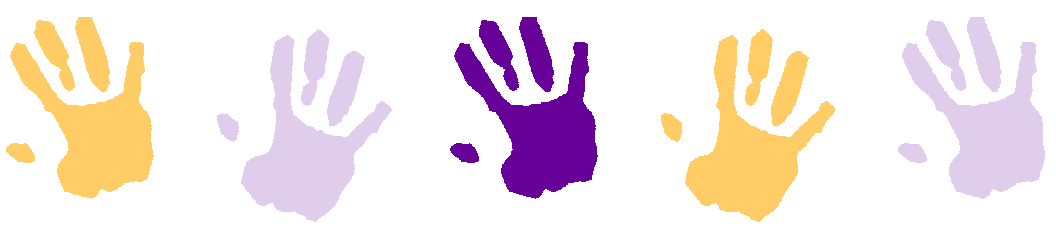

\footnotetext{
Adapted from Xutritionwerks.com found at http://www.nutritionwerks.com/he/hesnack.asp and from $\mathcal{D e}$ licious $\mathcal{D e c}$ isions of the $\mathcal{A}$ merican $\mathcal{H e}$ art $\mathcal{A}$ ssociation found at

http://www.deliciousdecisions.org/oa/asn_ident_main.html
} 


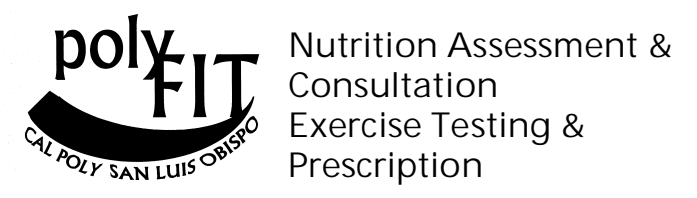

\section{When Eating Out...}

\section{Lead Story Headline}

This story can fit 175-225 words.

The purpose of a new sletter is to provide specialized information to a targeted audience. New sletters can be a great way to market your product or service, and also create credibility and build your organization's identity among peers, members, employees, or vendors.

First, determine the audience of the new sletter. This could be anyone who might benefit from the information it contains, for example, employees or people interested in purchasing a product or requesting you

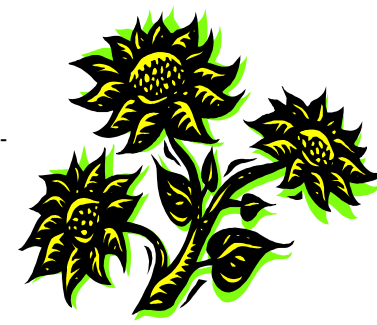

Caption describing picture or graphic. service.

You can compile a mailing list from business reply cards, customer information sheets, business cards collected at trade show s, or membership lists. You might consider purchasing a mailing list from a company.

If you explore the Publisher catalog, you will find many publications that match the style of your new sletter.

Next, establish how much time and money you can spend on your new sletter. These factors will help determine how frequently you publish the new sletter and its length. It's recommended that you publish your new sletter at least quarterly so that it's considered a consistent source of information. Your customers or employees will look forw ard to its arrival.

\section{Secondary Story Headline}

This story can fit 75-125 words.

Your headline is an important part of the new sletter and should be considered carefully.

In a few words, it should accurately represent the contents of the story and draw readers into the story. Develop the headline before you w rite the story. This way, the headline will help you keep the story focused.

Examples of possible headlines include Product Wins Industry Award, New Product Can Save You Time!, Membership Drive Exceeds Goals, and New Office Opens Near You.

\section{Special points of inter- est:}

- Briefly highlight your point of interest here.

- Briefly highlight your point of interest here.

- Briefly highlight your point of interest here.

- Briefly highlight your point of interest here. 


\section{Inside Story Headline}

This story can fit 150-200 words.

One benefit of using your new sletter as a promotional tool is that you can reuse content from other marketing materials, such as press releases, market studies, and reports.

While your main goal of distributing a new sletter might be to sell your product or service, the key to a successful new sletter is making it useful to your readers.

A great way to add useful content to your new sletter is to develop and write your ow $n$ articles, or include a calendar of upcoming events or a special offer that promotes a new product.

You can also research articles or find "filler" articles by accessing the World Wide Web. You can write about a variety of topics but try to keep your articles short.

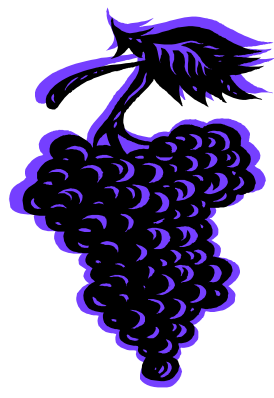

Caption describing picture or graphic.

Much of the content you put in your new sletter can also be used for your Web site. Microsoft Publisher offers a simple way to convert your new sletter to a Web publication. So, when you're finished w riting your new sletter, convert it to a Web site and post it.

\section{Inside Story Headline}

This story can fit 100-150 words.

The subject matter that appears in new sletters is virtually endless. You can include stories that focus on current technologies or innovations in your field.

You may also want to note business or economic trends, or make predictions for your custo mers or clients.

If the new sletter is distributed internally, you might comment upon new procedures or improvements to the business. Sales figures or earnings will show how your business is growing.

"To catch the reader's attention, place an interesting sentence or quote from the story here."

Some new sletters include a column that is updated every issue, for instance, an advice column, a book review, a letter from the president, or an editorial. You can also profile new employees or top customers or vendors.

\section{Inside Story Headline}

This story can fit 75-125 words.

Selecting pictures or graphics is an important part of adding content to your new sletter.

Think about your article and ask yourself if the picture supports or enhances the message you're trying to convey. Avoid selecting images that appear to be out of context.

Microsoft Publisher includes thousands of clip art images from which you can choose and import into your new sletter. There are also several tools you can use to draw shapes and symbols.

Once you have chosen an image, place it close to the article. Be sure to place the caption of the image near the image. 


\section{Inside Story Headline}

This story can fit 150-200 words.

One benefit of using your new sletter as a promotional tool is that you can reuse content from other marketing materials, such as press releases, market studies, and reports.

While your main goal of distributing a new sletter might be to sell your product or service, the key to a successful new sletter is making it useful to your readers.

A great way to add useful content to your new sletter is to develop and w rite your ow $\mathrm{n}$ articles, or include a calendar of upcoming events or a special offer that promotes a new product.

You can also research articles or find "filler" articles by accessing the World Wide Web. You can write about a variety of topics but try to keep your articles short.

Much of the content you put in your new sletter can also be used for your Web site. Microsoft Publisher offers a simple

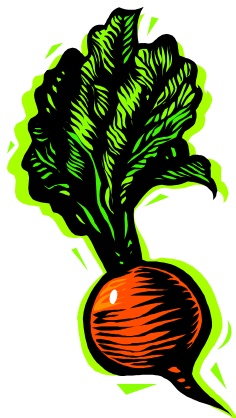

Caption describing picture or graphic. way to convert your new sletter to a Web publication. So, when you're finished w riting your new sletter, convert it to a Web site and post it.

\section{Inside Story Headline}

This story can fit 100-150 words.

The subject matter that appears in new sletters is virtually endless. You can include stories that focus on current technologies or innovations in your field.

You may also want to note business or economic trends, or make predictions for your customers or clients.

If the new sletter is distributed internally, you might comment upon new procedures or improvements to the business. Sales figures or earnings will show how your business is growing.

Some new sletters include a column that is updated every issue, for instance, an advice column, a book review, a letter from the president, or an editorial. You can also profile new employees or top customers or vendors.

\section{Inside Story Headline}

This story can fit 75-125 words.

Selecting pictures or graphics is an important part of adding content to your new sletter.

Think about your article and ask yourself if the picture supports or enhances the message you're trying to convey. Avoid selecting images that appear to be out of context.

Microsoft Publisher includes thousands of clip art images from which you can choose and import into your new sletter. There are also several tools you can use to draw shapes and symbols.

Once you have chosen an image, place it close to the article. Be sure to place the caption of the image near the image.
"To catch the reader's attention, place an interesting sentence or quote from the story here." 
This would be a good place to insert a short paragraph about your organization. It might include the

\section{Organization}

Building 43, Room 250

Cal Poly University

Phone: 555-555-5555

Fax: 555-555-5555

Email: xyz@microsoft.com purpose of the organization, its mission, founding date, and a brief history. You could also include a brief list of the types of products, services, or programs your organization offers, the geographic area covered (for example, western U.S. or European markets), and a profile of the types of customers or members served.

It would also be useful to include a contact name for readers who want more information about the organization.

\section{Your organization tag line here.}

We're on the Web!

example.microsoft.com

\section{Back Page Story Headline}

This story can fit 175-225 words.

If your new sletter is folded and mailed, this story will appear on the back. So, it's a good idea to make it easy to read at a glance.

A question and answer session is a good way to quickly capture the attention of readers. You can either compile questions that you've received since the last edition or you can summarize some generic questions that are frequently asked about your organization.

A listing of names and titles of managers in your organization is a good w ay to give your new sletter a personal touch. If your organization is small, you may want to list the names of all employees.

If you have any prices of standard products or services, you can include a listing of those here. You may want to refer your readers to any other forms of communication that you've

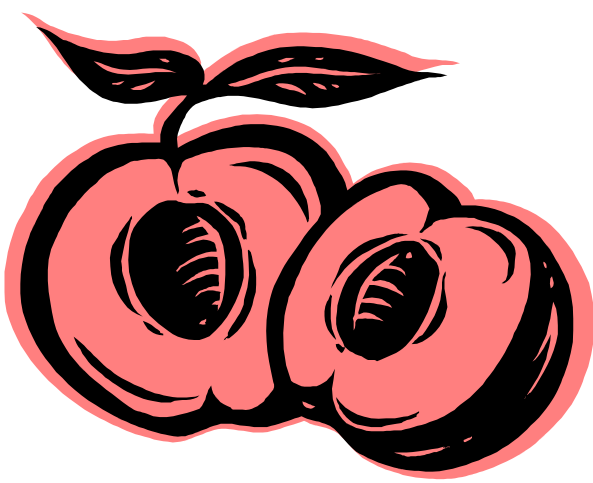

Caption describing picture or graphic. created for your organization.

You can also use this space to remind readers to mark their calendars for a regular event, such as a breakfast meeting for vendors every third Tuesday of the month, or a biannual charity auction.

If space is available, this is a good place to insert a clip art image or some other graphic. 
Appendix E: Food Frequency Checklist 


\begin{tabular}{|c|c|c|c|c|c|}
\hline \multicolumn{6}{|c|}{ Food Frequengy Cheallist } \\
\hline Serving sizes & Food Group & $\frac{7}{8}$ & $\frac{3}{2}$ & $\stackrel{5}{2}$ & $\frac{2}{9}$ \\
\hline \multirow{2}{*}{$\begin{array}{l}1 \text { slice bread } \\
1 \text { c dry cereal } \\
1 / 2 \text { c cooked rice } \\
1 / 2 \text { bun, bagel, or English muffin } \\
1 \text { small rill, biscuit, or muffin }\end{array}$} & $\begin{array}{l}\text { Refined Grains - white } \\
\text { bread, pasta, cereals }\end{array}$ & & & $\square$ & \\
\hline & $\begin{array}{l}\text { Whole Grains - whole } \\
\text { wheat bread, brown rice, } \\
\text { oatmeal, bran cereal }\end{array}$ & & & $\square$ & \\
\hline $\begin{array}{l}1 \mathrm{c} \text { raw leafy vegetable } \\
1 / 2 \mathrm{c} \text { cooked or raw vegetables } \\
6 \mathrm{oz} \text {. vegetable juice }\end{array}$ & Vegetables & & & $\square$ & \\
\hline $\begin{array}{l}6 \text { oz. fruit juice } \\
1 \text { medium fruit } \\
1 / 4 \text { c dried fruit } \\
1 / 2 \text { c fresh, frozen, or canned fruit }\end{array}$ & Fruits & & & $\square$ & \\
\hline \multirow{2}{*}{$\begin{array}{l}8 \text { oz. milk } \\
1 \mathrm{c} \text { yogurt } \\
11 / 2 \text { oz. cheese } \\
2 \text { oz. process cheese }\end{array}$} & $\begin{array}{l}\text { Dairy - low-fat or fat-free } \\
\text { ice cream, milk, cheese, } \\
\text { yogurt, frozen yogurt }\end{array}$ & & & $\square$ & \\
\hline & $\begin{array}{l}\text { Dairy - whole milk, regular } \\
\text { cheese, regular ice cream }\end{array}$ & & & $\square$ & \\
\hline \multirow[t]{2}{*}{$\begin{array}{l}3 \text { oz. cooked meats, poultry, and } \\
\text { fish }\end{array}$} & $\begin{array}{l}\text { Meats, Poultry, and Fish - } \\
\text { lean }\end{array}$ & & & $\square$ & \\
\hline & $\begin{array}{l}\text { Meats, Poultry, and Fish - } \\
\text { high-fat, sausage, cold cuts, } \\
\text { spareribs, hot dogs, eggs, } \\
\text { bacon }\end{array}$ & & & $\square$ & \\
\hline 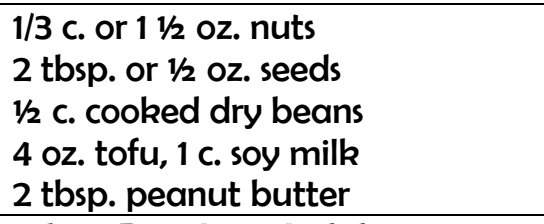 & $\begin{array}{l}\text { Nuts, seeds, and Dry } \\
\text { Beans }\end{array}$ & & & $\square$ & \\
\hline $\begin{array}{l}1 \text { tbsp. Regular salad dressing } \\
2 \text { tbsp. Light salad dressing } \\
1 \text { tsp. Oil } \\
1 \text { tbsp. Low-fat mayonnaise } \\
1 \text { tsp. Margarine, butter }\end{array}$ & Fats and Oils & & & $\square$ & \\
\hline $\begin{array}{l}8 \text { oz. lemonade } \\
11 / 2 \text { oz. candy } \\
8 \mathrm{oz} \text {. soda }\end{array}$ & Sweets & & & $\square$ & \\
\hline $\begin{array}{l}12 \text { oz. beer, } 4 \text { oz. wine } \\
1 \text { shot hard liquor }\end{array}$ & Alcohol & & & $\square$ & \\
\hline
\end{tabular}


Appendix F: Twenty-four Hour Recall 


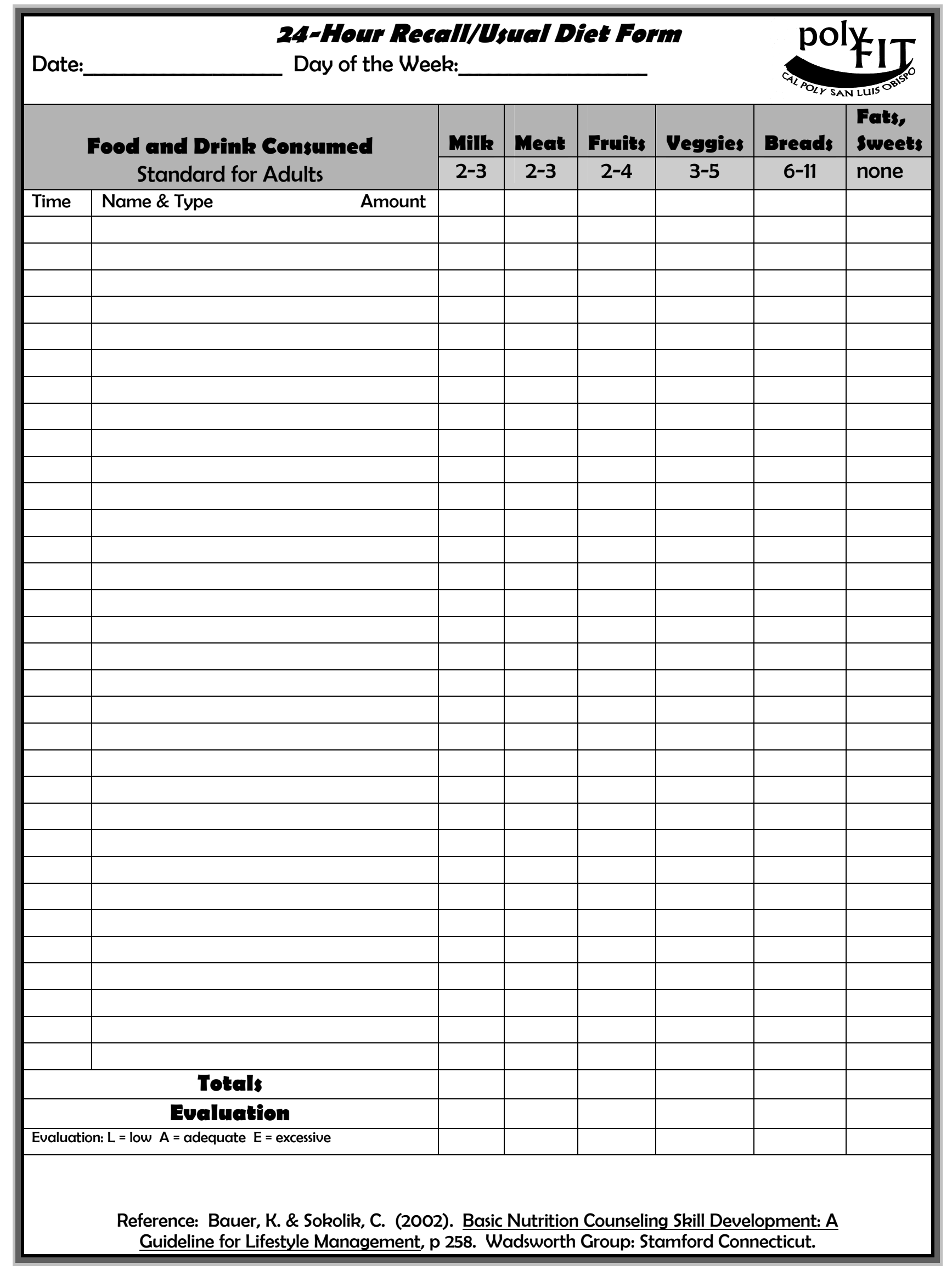


Appendix G: Protocol for Diet Interview 


\section{Protocol for Diet Interview}

Particularly the 24-hour recall/ Usual Diet

\section{Diet I nterview}

The purpose of the diet history is to obtain an account of a person's usual food intake. Structurally it takes the form of a description of meals consumed throughout the day accompanied by a food frequency cross-check. One way to look at the first component of the diet history is as a story with a beginning (usually breakfast) and an end (usually dinner or an evening snack). Use of the narrative approach means that participants are given the opportunity to finish their story before they are asked any questions. In this way, the flow of the participants' information given is not interrupted (but what they say is acknowledged and supported by the interviewer). Additional comments, not necessarily food per se, made during this description may provide the interviewer insights for questions or discussion later. When introducing the diet history, the interviewer refers to the notion of usual, meaning within the past couple of months, and a time sequence for the description, such as duration of the day. Participants are asked to provide a general pattern and then point out variations.

\section{Interview Protocol}

- Explain the purpose of the interview. Advise the participant that you are seeking a description of usual eating patterns and suggest that she or he start with the beginning of the day.

- If the participant begins with the first meal of the day and uses time references or meal sequences of the day to progress with a description, do not interrupt the story; merely indicate that you are listening (nod, write, say "hmm" or "yes").

- If the participant stops at intervals along the way waiting for you to respond, provide narrative support to continue - for example "Was that all for breakfast?" or "Do you have anything after that?"

- If the participant volunteers explanations for why or how he or she consumes certain foods, acknowledge the explanation in a supportive, non-judgmental way, but keep the account on track.

- When the participant has reached the end of the day, look at what you have noted and identify the areas for which you need more detail. Ask specific, strategic questions.

- If the participant responds to a topic with "it depends," be sure to encourage possible variations on that topic (usually a meal description).

- If the participant says "probably" in defining amounts of foods, use visual aids, such as food models or portion representations to assist in the estimation process.

- Summarize the overall pattern of the diet and ask whether there is a great deal of variation in this pattern. Note the variation.

- Proceed with a food frequency checklist.

- Ask the participant if there is anything else she (or he) would like to add to what he or she has told you and if he or she thinks you have a true reflection of his or her eating pattern. 
Appendix H: Decision Tree 


\begin{tabular}{|c|c|c|c|}
\hline \multirow{15}{*}{$\begin{array}{l}\text { General } \\
\text { Goal }\end{array}$} & \multirow{7}{*}{ Disease-Related } & \multirow{2}{*}{$\begin{array}{r}\text { Topic } \\
\text { Heart Disease }\end{array}$} & Education \\
\hline & & & $\begin{array}{l}\text { Nutrition For The Heart - Fat \& Cholesterol (1,2) } \\
\text { Nutrition For The Heart - Ways To Keep The Heart Healthy (2) } \\
\text { Nutrition For The Heart - Cooking For A Healthy Heart (3) } \\
\text { Ways To Decrease Saturated Fat }(1,2,3)\end{array}$ \\
\hline & & High Blood Pressure & $\begin{array}{l}\text { Nutrition \& High Blood Pressure }(1,2) \\
\text { Reducing The Sodium In Your Diet }(1,2,3) \\
\text { Nutrition fact sheet - A Dash of Prevention }\end{array}$ \\
\hline & & Cancer & $\begin{array}{l}\text { Nutrition \& Cancer }(1,2) \\
\text { Fruits \& Veggies - Get More }(1,2,3)\end{array}$ \\
\hline & & Overweight/Obesity & $\begin{array}{l}\text { Nutrition And Your Weight }(1,2,3) \\
\text { Weight Loss And Nutrition Myths }(1,2,3) \\
\text { Overweight \& Obesity - At A Glance (1) careful! } \\
\text { Nutrition fact sheet - Fad Diets: What You May Be Missing }\end{array}$ \\
\hline & & Osteoporosis & $\begin{array}{l}\text { Nutrition \& The Skeleton }(1,2,3) \\
\text { Ways To Increase Calcium }(1,2,3)\end{array}$ \\
\hline & & Diabetes & $\begin{array}{l}\text { Food And Your Glucose - for those with diabetes }(1,2,3) \\
\text { Nutrition fact sheet - Smart Solutions for People With Diabetes } \\
\text { How To Prevent Diabetes - for those at risk, with family history, } \\
\text { concerned }(1,2,3) \\
\text { Nutrition fact sheet - Healthy Habits To Help Manage and Prevent } \\
\text { Type } 2 \text { Diabetes }\end{array}$ \\
\hline & Digestive & & \\
\hline & Disorders & Celiac Disease & Nutrition fact sheet - Celiac Disease \\
\hline & & Diverticulosis \& Diverticulitis & Diverticulosis \& Diverticulitis $(1,2,3)$ \\
\hline & & Heartburn & $\begin{array}{l}\text { Heartburn \& Self-Care }(1,2) \\
\text { Stock The Pantry To Relieve Heartburn }(2,3)\end{array}$ \\
\hline & & Irritable Bowel Syndrome & $\operatorname{IBS}(1,2)$ \\
\hline & & Lactose Intolerance & Lactose Intolerance $(1,2,3)$ \\
\hline & Athletic/Exercise & General Sports Nutrition & Nutrition 101 For Athletes $(1,2,3)$ \\
\hline & Reidited & Hydration & $\begin{array}{l}\text { Hydration - Critical To Athletic Performance }(1,2) \\
\text { Optimizing Hydration (3) }\end{array}$ \\
\hline
\end{tabular}




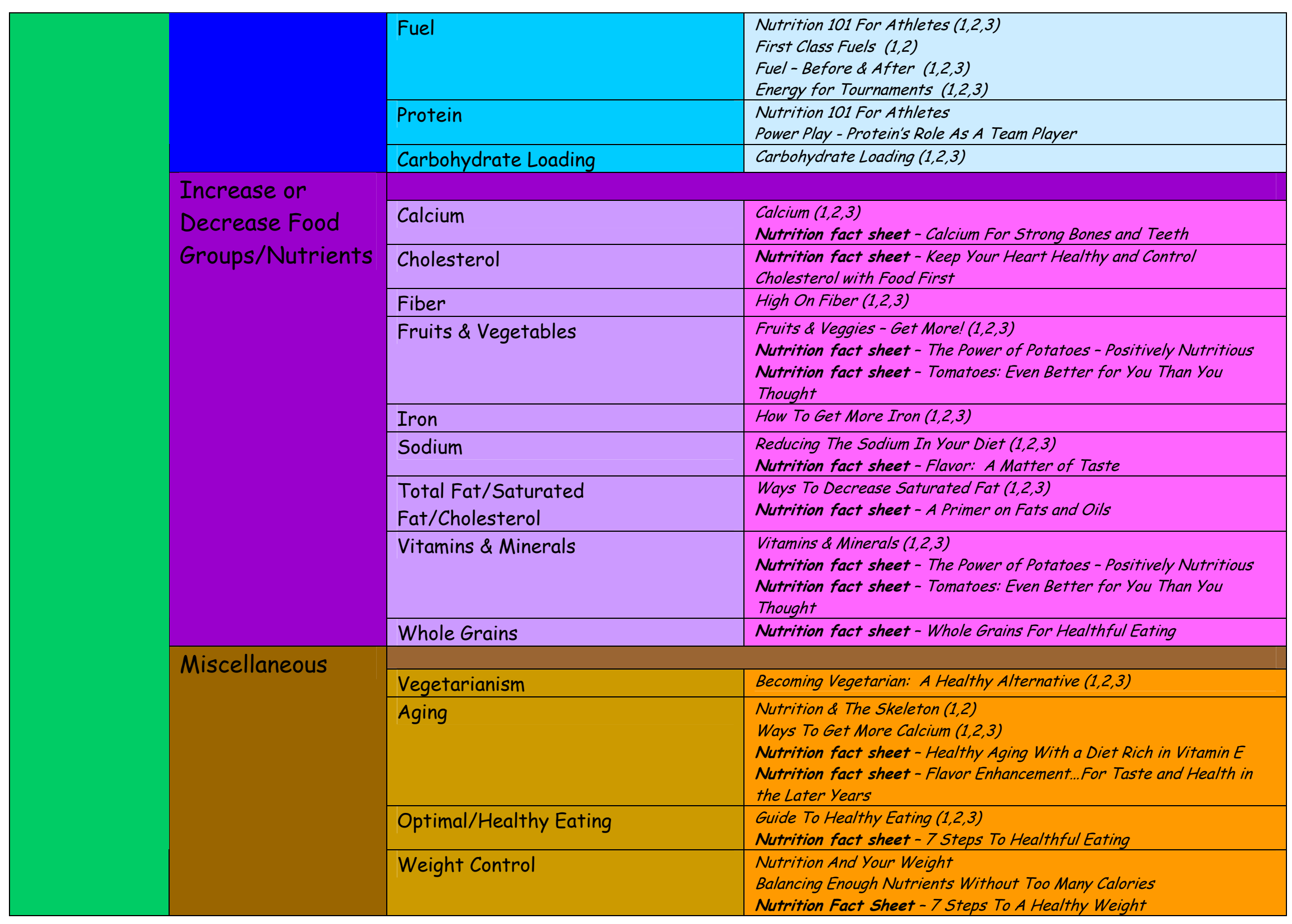




\begin{tabular}{|c|c|c|}
\hline & Fad Diets & $\begin{array}{l}\text { Nutrition fact sheet - Fad Diets: What You May Be Missing } \\
\text { Fad Diets - The Good, the Bad, and the Ugly }(1,2,3)\end{array}$ \\
\hline & Shopping & $\begin{array}{l}\text { Shopping Made Easy! }(1,2,3) \\
\text { Nutrition fact sheet - Shopping Solutions for Healthful Eating }\end{array}$ \\
\hline & Snacking & Snack Attack! $(1,2,3)$ \\
\hline & Child Nutrition & $\begin{array}{l}\text { Nutrition fact sheet - Wanted: More Fruits and Vegetables } \\
\text { Nutrition fact sheet - } 5 \text { A Day For Young Children up to } 2 \text { Years of } \\
\text { Age } \\
\text { Nutrition fact sheet - Healthful Eating For Your Young Child } \\
\text { Nutrition fact sheet - Kid's Breakfast Pyramid }\end{array}$ \\
\hline & Nutrition During Pregnancy & $\begin{array}{l}\text { Nutrition fact sheet - "B" Smart for Your Heart and Pregnancy with } \\
\text { Folic Acid and Vitamins B6 and B12 } \\
\text { Nutrition fact sheet - Breast-feeding Basics - and Beyond }\end{array}$ \\
\hline RED FLAG!!!!! & Eating Disorder & $\begin{array}{l}\text { Eating Disorder Resource } \\
\text { Love Your Body }\end{array}$ \\
\hline \multirow{4}{*}{\multicolumn{2}{|c|}{ Nothing in Particular... }} & $\begin{array}{l}\text { Nutrition fact sheet - } 7 \text { Steps To Home Food Safety } \\
\text { Nutrition fact sheet - Unwrap the gift of home food safety this } \\
\text { holiday season }\end{array}$ \\
\hline & & Nutrition fact sheet - Canned Food: a Timeless Trend! \\
\hline & & $\begin{array}{l}\text { Nutrition fact sheet - Alcohol Beverages: Making Responsible Drinking } \\
\text { Choices }\end{array}$ \\
\hline & & Nutrition fact sheet - 7 Steps To Being More Active \\
\hline
\end{tabular}


Appendix I: Detailed Methods of Consultant Training 


\section{Extension of Training Protocol For Student Volunteers}

\section{Session 1:}

- Purpose for the program

o The purpose of the program was to provide appropriate education about healthy eating behaviors based on dietary analysis, stage of change and client goals. The student volunteers were introduced to the idea and the reason for the development of the program.

- Importance of language

o Because the student volunteers may not have received a formal education or participated in any formal training in nutrition, they were required to disclose this information to the clients. The volunteers were to approach the clients as “coaches” and provide suggestions relative to nutrition. They did not have the authority to counsel or prescribe eating plans or individual diets. Volunteers were to approach all topics in a positive, non-judgmental manner and tell the client that there are no wrong answers.

- Navigation of nutrition file - "Nutri-file”

o The resource for nutrition information was the nutrition file. It was divided into topics that were color coded for easy navigation and access. Information relative to chronic disease, digestive disorders, athletic/exercise, nutrients/food groups, and miscellaneous topics were placed in red, yellow, blue, purple, and brown colored files, respectively. The file consisted of original copies of information that would be photocopied and disseminated to the clients relative to the topic pertaining to specific goals or needs. A decision tree was created for further ease 
of navigation and is provided in appendix $\mathrm{H}$. This was color coded as well, corresponding to the topic files. Depending upon the general goal(s) and/or nutrition needs based on the dietary analysis of the client, student volunteers were instructed to begin at the left of the tree and work their way across using the information gathered from the health screening questionnaire and session one. A guide identifying particular questions to which students were to be especially attentive relative to the health screening was provided and discussed. This guide was to assist the students in session one during the review of the client answers and in gathering education materials for session two.

Volunteers were encouraged to flip through the file several times before their first client to familiarize themselves with the location of materials for quick access using the decision tree for guidance.

- Computer program - Diet Analysis Plus

o Volunteers congregated around the computer with the screen in view as the program coordinator highlighted the important components of the program that would be most frequently used by the students. A short sample analysis was conducted for the students to observe.

- Homework -Students were assigned the task of completing a tutorial offered by the program coordinator with a partner. They were instructed to bring the printout of the tutorial to the following meeting, paying specific attention to the nutrient component and food group analysis, the latter provided relative to the USDA’s Food Guide Pyramid. 
Session 2:

- Review of the previous week

o The program coordinator briefly reviewed the previous session's topics and provided time for questions.

- Review of the tutorial

o The program coordinator asked the students to get with their partner and find another set of partners to discuss the tutorial. If any problems arose and could not be explained or worked through among the students the program coordinator addressed the concerns.

- Client session protocol

o The program coordinator provided the student volunteers with an outline of the steps to be followed for client sessions and between sessions. The protocol was called the "Order of Operations." An explanation of each step was provided in detail with questions answered and clarifications provided along the way. The "Order of Operations" is provided in appendix K.

- Standard Forms Introduction - Health Screening - Nutrition Assessment, Food Frequency Checklist, 24-hour-Recall/Usual Diet Form, Assessment Ruler

o Copies of all of the forms that each client would fill out were given to the volunteers. The purpose of each form was provided along with a description of how to introduce the form to the client. The program coordinator then discussed the components of each form, paying close attention to those the volunteers would use to decide the appropriate education materials to present to the client.

- Conducting a 24-hour Recall 
o Program coordinator conducts 24-hour recall on a volunteer using the interview protocol provided in appendix G

- Homework - Volunteers conducted a 24-hour recall using a friend, family member, etc. and input the information into the program. Volunteers printed it out and took a look at the results. They paid attention to the positive aspects of day and then looked at the "could be better" aspects. Also, they noted anything that is interesting, confusing, exciting, etc. and brought the printout to the following meeting.

Session 3:

- Review of the previous week

o The program coordinator briefly reviewed the previous session's topics and provided time for questions.

- Review of the homework

o Volunteers found a partner and reviewed the printout and shared ways to approach the results of the analyses and how to provide an explanation to the client. The program coordinator spoke with each team to provide any additional help.

- $\quad$ Practice Dietary Interviews

o The program coordinator conducted a dietary interview with a volunteer while the others observed. Volunteers found a partner and conducted interviews for practice. They were encouraged to continue until they felt very comfortable with the process. The program coordinator was available for questions. 
Appendix J: Informed Consent 


\section{Program Director}

Janay Arnold

B.S. Nutrition, California Polytechnic State University

NASM Certified Personal Trainer

BTS, Spinning

jlarnold@calpoly.edu

Department of Kinesiology, California Polytechnic State University, (805) 756 -?

\section{Faculty Advisor}

Susan Puhl, Ph. D.

spuhl@calpoly.edu

Department of Kinesiology, California Polytechnic State University, (805) 756-2087

\section{Purpose}

The purpose of the program is to assess your current dietary status and provide nutrition education relative to your personal goals.

\section{Location}

The polyFIT program is located in the James L. Webb Human Performance Laboratory, Building 43, on the California Polytechnic State University campus. Assessments will be performed at this location, or other locations on the Cal Poly campus as deemed appropriate by the Fitness Specialists.

\section{Your Time Commitment}

The estimated time needed to complete your nutrition consultations will be divided into two 1-hour sessions. These sessions will be completed on different days.

\section{Description of the Assessment}

Your dietary assessment will include the following.

- Determination of how frequently you consume certain foods

- A verbal dialogue between you and the fitness specialist about the last 24 hours with regard to food intake

- Analysis of your current diet

- Determination of individual goals

- Provision of appropriate education materials relative to your goals 


\section{Benefits of Your Participation}

The assessment results will provide you with information regarding your current dietary status. This information can be used to provide appropriate education relative to the goals you have and ultimately increase your awareness about healthy dietary behaviors.

\section{Right to Ask Questions and Have Such Questions Answered}

You have the right to ask any questions that you feel are relevant to your well-being regarding your participation. You have the right to have all such questions answered to your satisfaction.

\section{Right to Refuse to Answer any Questions}

You have the right to refuse to answer any questions, either verbal or in questionnaire form. However, this may limit your participation in some assessments, and/or affect the provision of education.

\section{Confidentiality}

All information gathered from you will be kept confidential. The only individuals who will have access to the information is the Program Director, Faculty Advisor, and Fitness Specialists. At no time will your information be identified by name to anyone else. Any information that is presented in professional reports will be done without identifying you.

\section{Withdrawing From the Program}

You have the right to withdraw your consent and terminate participation without penalty at any time.

\section{Right to Access Information}

You have the right access to your assessment information at any time. For the disclosure of information, contact the Program Director or Faculty Advisor identified on page 1 of this document.

If you have any questions about your participation please contact the Program Director or Faculty Advisor identified on page 1 of this document.

Consent form continues on the next page. 
This is to certify that I hereby agree to participate in a dietary assessment used to determine my dietary status as an authorized part of polyFIT at the California Polytechnic State University, San Luis Obispo, CA 93407.

The assessment and my participation in the assessment have been defined and fully explained to me and I understand the explanations. The procedures of this assessment have been discussed with me.

I have been given an opportunity to ask whatever questions I may have and all such questions and inquiries have been answered to my satisfaction.

I understand that I am free to deny any answer to specific items or questions in interviews or questionnaires. I understand that refusal to answer such questions may disqualify me from participating, or limit my participation in this program.

I understand that any data or answers to questions will remain confidential with regard to my identity.

If I have questions about the protection of human subjects at California Polytechnic State University, I can contact Dr. Steve Davis, Chair of the Human Subjects Committee, Kinesiology Department (office 43-363; phone 805-756-2754) or Dr. Susan Opava, Dean, Research and Graduate Programs (office 38-155; phone 805-756-1508).

To the best of my knowledge and belief I have no physical or mental illness or weakness that would increase the risk associated with participation.

I understand that I am free to withdraw my consent and terminate my participation at any time without penalty.

Name

Signature

Date

I, the undersigned, have fully explained the tests to the above named client.

Name

Signature

Date

Thank you for participating in the polyFIT Nutrition Program. 
Appendix K: Session “Order of Operations” 


\section{"Order of Operations"}

\section{poly/TIT}

Pre-session 1

Obtain completed health screening/nutrition assessment and review, paying close attention to the health screening guide. If necessary, write down questions for the client.

\section{Session 1}

1. Establish rapport

Introduce yourself, shake hands

2. Review what is to come

a. Tell the client what to expect for the next hour

Mention review of health screening and nutrition history, diet analysis forms and process, and goal setting.

b. If you want to take notes, let them know that you are doing so

3. Encourage input

Ask the client why they have come

i. Concerns, confusion, information, etc.

ii. What they want to change, improve, learn, etc.

iii. Topics to explore - concerns about health risks with current behavior, concerns about changing food patterns, past lifestyle change success, past experiences changing food habits, difficulties in the past strategies that worked or did not work, education

4. Review health screening/nutrition assessment

Write down information that will be helpful when gathering materials appropriate for the individual

5. Dietary assessment

\section{a. Food Frequency Checklist}

Ask the client if they need any clarification

b. 24-hour recall

6. Assess stage of change relative to general eating patterns

Give them the assessment ruler and explain ask "On a scale of 1-12, how ready are you to change?"

7. Goals (maximum 2)

a. Guide them in determining one or two goals based on the above information and write them down. They could be one long-term and one short-term goal or two short-term goals. 
b. Goals must be specific, timely, measurable and positive.

Examples: General, then specific

1. Reduce saturated fat intake - Replace meat with fish twice a week.

2. Improve eating habits - Eat 1 more serving of fruit and vegetables daily or Replace 1 serving of cheese with 1 serving of low-fat cheese three times a week

3. Increase calcium - Drink one glass of milk daily

4. Lose weight - Lose five pounds by December 1

8. Closing

a. Tell the client what to expect next session and, briefly, what you will be doing in the meantime

b. Provide Guidelines To Healthy Eating, offering a brief explanation of content

c. Provide a list of nutrition websites, local nutrition related contacts, and 30 Ways to Eat Healthier in the Next 30 Days

\section{Between Session 1 and Session 2}

1) Input 24-hour recall using ESHA/Food Processor

2) Printout nutrient summary and food guide pyramid

3) Analyze results

a. Review established goals - general and specifc

b. Assess diet analysis with these goals in mind

i. From the food component printout, take note of the caloric intake and nutrients that are low (less than $80 \%$ of recommended) and the nutrients that are high (above 105\%).

ii. From the Food Guide Pyramid printout and the Food Frequency checklist, take note of the recommendations of food groups that are not being met.

c. Find the positive aspects of the diet, the "good"

For example - if fiber is at $80 \%$ or above, vitamins/minerals are at $80 \%$ or above, Cholesterol, sodium and/or saturated fat are below $100 \%$, etc.

d. Find the "could be better" aspects of the diet

For example - if protein is below $80 \%$, if saturated fat is above $100 \%$, if calcium is below $80 \%$, etc.

4) Gather materials for client

a. Using the forms below and best judgment to find the appropriate materials in the nutrition file guided by the decision tree

i. Diet analysis results

ii. Food Frequency Checklist 
iii. Client's stage of change and established goals

iv. Health screening/nutrition assessment form

b. Photocopy materials and place them in the order in which you will present them to the client

c. Review materials and prepare for Session 2

\section{Session 2}

1) Reestablish rapport

2) Assess "good" and "could be better" about analysis

a. Show the client the printout of nutrient summary and food guide pyramid

b. Try to keep the assessment specific to the goals established. There may be many things that could be addressed, but there is only a limited amount of time.

3) Present and review materials with client

Handouts based on readiness to change and dietary assessment

Nutrition facts sheets, nutrition education, general guidelines and/or sample meal plan 
Appendix L: Client Survey Questionnaire 


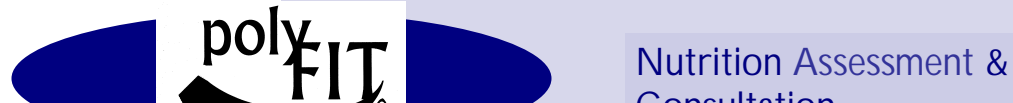

Dear Polyfit Participant,

W e would like to thank you for participating in the Polyfit N utrition Assessment and Consultation program. It was a pleasure working with you.

Because we are in the beginning stages of this program, we are asking you to take a moment to fill out this short evaluation. Your answers are very important to us as they will assist the creators of this program in making it better for future participants. W e thank you for your time and effort.

Please answer to the best of your ability. Circle yes or no, and then please explain if you feel it is necessary.

1. Did you feel comfortable during session 1-discussion of the health screening questionnaire, dietary analysis, and goal setting?

2. Did you feel comfortable during session 2- presentation of dietary analysis results and education materials?

Yes No

3. Did you feel as if the fitness specialist knew what they were doing?

Yes No

4. Did you understand the materials presented to you?

Yes

No

5. Did you find the materials useful?

Yes

No

W hen you have completed this form, please email your answers to jlarnold@ calpoly.edu.

Thank you,

The Polyfit Team 
Appendix M: Fitness Consultant Survey Questionnaire 


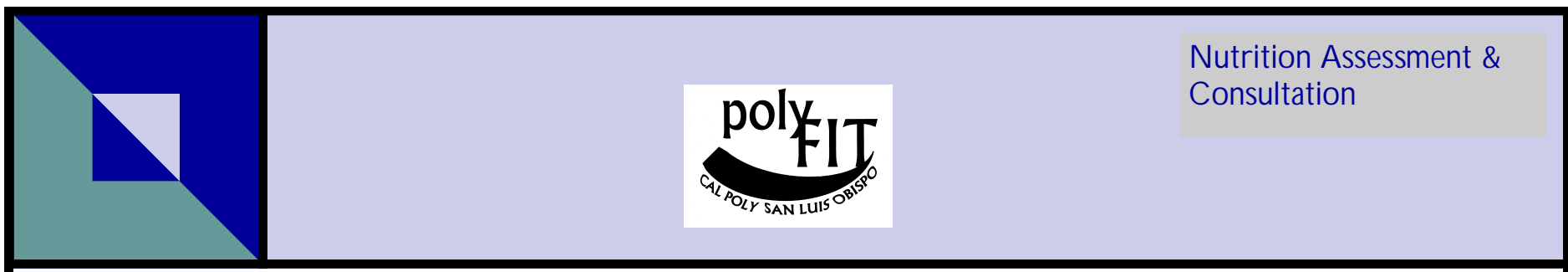

\section{Fitness Consultant Evaluation}

Please complete the following questions. You can answer yes or no and then elaborate if you feel it is warranted. Please be as detailed as you can

1. Did you feel as if the 2 week-training adequately prepared you for client sessions?

2. Did you feel as if the order in which sessions were conducted was logical in acquiring information from clients? Effective?

3. Did you feel as if the time allotted for client sessions was adequate?

4. How would you rate the Diet Analysis Program based on ease of use and why? (Scale of 1-10, 1 being Impossible and 10 being Very easy)

5. Did the Decision Tree assist you in finding proper education based on your clients? needs?

6. Did the Nutrition file contain the all of the education/information that clients requested or needed?

7. Were clients receptive to returning for the 2 nd session to receive their handouts/diet analysis? If not, why?

8. If clients did pick up their handouts/education, did they stay long enough to have you briefly review the information (required for session 2)?

9. Name 2 things that would have made this program better. 